\title{
80. Jahrestagung der Deutschen Gesellschaft für Rechtsmedizin
}

\section{5.-29. September 2001 in Interlaken}

\section{Vorträge}

\section{$\mathrm{V}-1$}

EINFÜHRUNG INS THEMA

Dirnhofer R

Institut für Rechtsmedizin der Universität Bern

\section{V-2}

\author{
ERKENNTNISTHEORIE UND ORGANISATIONSFEHLER \\ Malik F \\ Management-Zentrum St. Gallen
}

\section{V-3}

DER BEWEIS AUS RECHTLICHER SICHT

Weber M

Generalprokuratur des Kantons Bern

\section{V-4}

DER BAYES'SCHE APPROACH - FLUCH ODER SEGEN

IN DER BEWEISWERTUNG

Arnold J

Wissenschaftlicher Dienst, Sektion Physik, Stadtpolizei Zürich

In der allgemeinen Naturwissenschaft und in der Forensik steht man immer wieder vor zwei Problemen:

Dem Problem der Induktion, dem Schliessen von Einzelbeobachtungen (z.B. Indizien, Spuren, Hintergrundwissen....) auf ein allgemein gültiges Gesetz (z.B. der tatsächliche Tatverlauf). Einen Beweis für die Richtigkeit des Schlusses von Einzelbeobachtungen auf ein allgemeines Gesetz gibt es nicht.

Dem Problem der Bewertung: Wie kann man Resultate von Beobachtungen mit vorhergesagten Resultaten verknüpfen (z.B. Theorem von Bayes)?

Selbst in den exakten Naturwissenschaften (Quantenphysik) ist der Schritt aus der Welt von "Wahrscheinlichkeitsvorhersagen" in die Welt von "entweder oder Aussagen" heikel, das Resultat wird in einer nicht zu vernachlässigenden Art und Weise beeinflusst bzw. verändert!

Der "Bayesian Approach" in der Beweiswertung in der Forensik ist eine Methodik, die uns bei der Auflösung eines Falles helfen soll: Beim forensischen Argumentieren - durch bewusstes Benutzen von Indizien und Hintergrundwissen - die verschiedenen Szenarien auf ihren Wahrheitsgehalt zu prüfen und diese nach einem bestimmten System zu werten.

Die zentrale Idee des "Bayesian Approach" ist, dass die zu beantwortenden Fragen und damit auch die resultierenden Antworten immer nach dem folgenden Schema in drei Kategorien bzw. in drei Levels eingeteilt werden können.

Offence Level DIE Tat, DIE Täter (Bezug zur konkreten Tat maximal)

Activity Level Täter-Tätigkeiten (Tatbezug ist vorhanden) Scientific Level reine Laborarbeit (kein direkter Bezug zur Tat) Die Unterschiede der drei Levels liegen im Mass des Tatbezuges. Ein weiterer Begriff des Bayesian Approach ist das Plausibilitätsverhältnis, Likelihood Ratio, das die erhaltenen Resultate bezüglich den Szenarien resp. experimentellen Daten bewertet. In sehr vielen Fällen kann jedoch nicht gerechnet werden, da diese Daten schlicht fehlen. Der "Bayesian Approach" ist eine Methodik, die es ermöglicht, auch unter (Zeit-) Druck systematisch vorzugehen und Entscheide in Bezug auf das Vorgehen bewusst und systematisch zu fällen.

V-5

ERFOLGSRISIKO TATORTARBEIT VERHALTEN UND MASSNAHMEN AM TATORT Pfefferli P

Kriminaltechnische Abteilung, Kantonspolizei Zürich

Was alle wissen, gelernt haben und das sich in den Grundsätzen auf wenige aber entscheidende Grundsätze zurückführen lässt, wird in der täglichen Tatort-Arbeit immer wieder zu Erfolgsrisiko: Das richtige Verhalten und das Ergreifen von notwendigen Massnahmen beim Ersten Angriff. Auch wenn keine zwei Tatorte bezüglich angetroffener Situation sowie Ablauf der Tatortarbeit identisch sind und jede Tatortarbeit ihre eigene Dynamik entwickelt, so lassen sich die immer wiederkehrenden Fehler auf wenige allgemeine Schwachstellen zurückführen.

Schwachstelle ,Führung': Wichtig ist nicht wer führt, sondern dass geführt wird. Je komplexer und unübersichtlicher die angetroffene Lage, je dynamischer und ständig wechselnd die Situation, desto entscheidender ist ein konsequent angewendeter Führungsrhythmus. Schlüsselfaktor ist dabei das Anordnen von Sofortmassnahmen hinsichtlich eingesetzter Mittel, Spurenschutz und Führungsorganisation.

Schwachstelle,Mittel': Der materiellen Mittel wären genügend vorhanden, doch werden sie allzu oft schlecht genutzt. Warum immer mit dem kleinsten Essbesteck arbeiten? Je grösser der Zeitdruck, desto wichtiger ist die Zweckmässigkeit der eingesetzten Mittel. Leider ist 
den am Tatort eingesetzten Spezialisten oft zu wenig bewusst, was in den eigenen Reihen noch vorhanden wäre, um besser und effizienter arbeiten zu können.

Schwachstelle, Verhalten am Tatort': Die taktisch-technischen Grundsätze des forensisch richtigen Verhaltens am Tatort zwecks Spurenschutz sind hinlänglich bekannt; dennoch werden Aspekte wie Absperrung, Bestimmung des Trampelpfades, Festlegung von Warteräumen, Regelung der Zutrittskompetenzen und das Betreiben von aktivem Spurenschutz zu ständig wiederkehrenden Risikofaktoren. Schwachstelle ,Führungsorganisation': Klare Zuweisung von Kompetenzen und Verantwortungen, kompromisslose Unterstellungen und Zuweisungen, verbunden mit einem konsequenten Informationsmanagement schaffen Voraussetzungen, dass die Spezialisten am Tatort ihren Auftrag unter bestmöglichen Bedingungen erfüllen können.

Vielleicht gilt es am Tatort vermehrt Denkpausen einzuschalten, um Verhalten und Massnahmen nicht nur mit Blick auf das Fachspezifische, sondern vermehrt auf das allgemeine Erfolgsrisiko zu beurteilen.

\section{V-6 \\ GÜTERABWÄGUNG: PERSÖNLICHE SICHERHEIT - SPURENSICHERUNG \\ Noth J \\ Regionalpolizei Berner Oberland, Kantonspolizei Bern}

\section{V-7}

FEHLER UND MANIPULATIONSMÖGLICHKEITEN

BEI DER DIGITALEN BILDGEWINNUNG

UND BILDVERARBEITUNG IN DER RECHTSMEDIZIN: STRATEGIEN FÜR EINE BEWEISKRÄFTIGE DOKUMENTATION

Fink T, Dilger M, Rittner C

Institut für Rechtsmedizin, Johannes Gutenberg-Universität,

D-55131 Mainz

Der zunehmende Einsatz der digitalen Befunddokumentation ist sowohl im Bereich der forensischen Pathologie als auch bei der polizeilichen Fundort- bzw. Tatortdokumentation zu beobachten. Die elektronische Bildgewinnung und -verabeitung birgt dabei die Gefahr einer bewussten aber auch unbewussten Bildmanipulation. Diese Gefahr ist jedoch prinzipiell auch bei der konventionellen (analogen) Fotografie gegeben. Als wesentliche Einflussfaktoren kommen dabei Bildoptimierungsalgorithmen der eingesetzten Bildverarbeitungssoftware, verschiedene verlustbehaftete Bildkompressionsverfahren und Veränderungen der Bildinhalte durch das Ausgabemedium in Frage. Eigene Erfahrungen der digitalen Bildverarbeitung in der forensischen Pathologie zeigen, dass der ausschließliche Versuch, durch technische Lösungen Fehlerquellen zu eliminieren, nicht ausreicht. Eine beweiskräftige und authentische Dokumentation erfordert vielmehr die Einhaltung organisatorischer und struktureller Vorgaben, die geeignet sind, einer kritischen Überprüfung im Rahmen eines Qualitätsmanagements standzuhalten. Auch für die digitale Befunddokumentation ist daher die Erarbeitung von standardisierten Arbeitsanweisungen (SOPs) unumgänglich. Die Bandbreite der Fehlermöglichkeiten wird auf der Grundlage umfangreicher eigener Erfahrungen dargestellt. Ein praktikables, standardisiertes Lösungskonzept in Form einer SOP wird präsentiert und kritisch diskutiert.
V-8

FEHLERQUELLEN BEI DER BEURTEILUNG VON „SNUFF VIDEOS“

Seidl S, Hausmann R, Betz P

Institut für Rechtsmedizin

der Friedrich-Alexander-Universität Erlangen-Nürnberg,

Universitätsstraße 22, D-91054 Erlangen

Zuweilen werden von Polizei oder Staatsanwaltschaft im Internet aufgefundene Gewaltvideos („snuff videos“) zur Begutachtung hinsichtlich der „Echtheit“ der dargestellten Gewalttat übergeben. Während amateurhafte Darstellungen aufgrund des Spurenbildes oder auffälliger technischer Manipulationen in der Regel für die Begutachtung keine Probleme bereiten, ist für die Beurteilung professioneller Gewaltvideos die Verwendung eines Videoschnitt-Programmes erforderlich, welches die Ausgabe, Vergrößerung und Betrachtung der Einzelbilder (frames) gestattet.

Insbesondere bei der im Internet gebräuchlichen MPEG-Kompression kann es zu Artefakten kommen, die in Form grober Pixel auf den Einzelbildern erkennbar werden und den Verdacht auf Manipulationen nahe legen.

Im Fall eines Gewaltvideos, welches die Erschießung einer im Rollstuhl sitzenden Frau darstellt, wurde aufgrund grober Pixel im Bereich des Mündungsfeuers und der Schusshand sowie aufgrund des Spurenbildes („Blutung“) der Verdacht geäußert, es handele sich mit hoher Wahrscheinlichkeit um ein gestelltes Tötungsdelikt und somit um kein ,snuff video“.

Zur Absicherung wurde Kontakt mit einem Animationsgraphiker eines lokalen Fernsehsenders aufgenommen, der nach ausgiebiger Analyse der Filmsequenz zu dem gleichen Schluss kam. Allerdings waren für den Fachmann die Kompressionsartefakte kein wesentliches Kriterium, sondern Manipulationszeichen im Bereich der Einschussöffnung an der Stirn sowie im Übergangsbereich zwischen Kopfhaar der Frau und Hintergrund bzw. Schusshand, die auf eine äußerst professionell ausgeführte Kopiertechnik und damit eine Manipulation schließen ließen.

\section{V-9}

FEHLER UND IRRTÜMER AUF DEM GEBIET DER IDENTIFIKATION: BEISPIELE, ANALYSE UND VERMEIDUNGSSTRATEGIEN

Ritz-Timme S

Institut für Rechtsmedizin der Christian-Albrechts-Universität zu Kiel

Auf dem Gebiet der Identifikation wird mit morphologischen, biochemischen und molekularbiologischen Verfahren gearbeitet. Entsprechend breit ist das Spektrum möglicher Fehler und Beinahefehler. Diese müssen im Sinne eines „Riskmanagements“ erfasst und analysiert werden, um in Zukunft vermeidbar zu sein.

Ursache jeden Fehlers ist ein mangelndes Qualitätsmanagement mit unzureichenden Maßnahmen zur Sicherung der Struktur-, Prozessund Ergebnisqualität von Untersuchungen sowie auch der Gutachtenqualität. Sehr charakteristische Fehler und Beinahefehler aus dem eigenen Institut (selbstverständlich mittlerweile abgestellt) können hier als Beispiele dienen: Mangelnde Qualifikation eines Humanmediziners bei einer Identifizierung durch odontologischen Vergleich (Strukturqualitätsmangel), Zerstörung der Möglichkeit einer biochemischen Altersschätzung durch Mazeration (Prozessqualitätsmangel), Verstoß gegen selbst vorgegebene Qualitätssicherungsmaßnahmen bei einer biochemischen Altersschätzung (Ergebnisqualitätsmangel) oder mangelnde Angaben zu Referenzstudien, Fehlerbreiten und Einflussfaktoren bei Altersschätzungen an jungen Straftätern (Gutachtenqualitätsmangel).

Solche Fehler lassen sich durch suffiziente Qualitätssicherungsmaßnahmen vermeiden, deren Umsetzung kontrolliert werden muss. Dazu müssen alle Arbeitsabläufe transparent sein und dokumentiert werden. 
Ein weiteres Instrument zur Fehlervermeidung und zur Qualitätssicherung ist die Formulierung von Empfehlungen oder Leitlinien durch qualifizierte Gremien. Dies ist auf dem Gebiet der Identifikation bereits für zwei Fragestellungen geschehen, nämlich für die Altersschätzung bei jungen Straftätern (Arbeitsgemeinschaft für Forensische Altersdiagnostik der DGRM: „Empfehlungen für die Altersdiagnostik bei Lebenden im Strafverfahren") sowie für die Fotoidentifikation (Arbeitsgruppe für anthropologische Identifikation lebender Personen aufgrund von Bilddokumenten: „Standards für die anthropologische Identifikation lebender Personen auf Grund von Bilddokumenten....").

\section{$\mathrm{V}-10$ \\ FEHLERANALYSE BEI DER ALTERSSCHÄTZUNG - EIN BEITRAG ZUR QUALITÄTSSICHERUNG DER IDENTIFIZIERUNG \\ Benthaus S, Pfeiffer H, Du Chesne A, Teige K, Brinkmann B Institut für Rechtsmedizin des Universitätsklinikums Münster}

Nach Angaben des Bundeskriminalamtes bleiben jährlich 50 bis 70 Leichen in der Bundesrepublik Deutschland unidentifiziert. Häufig fehlen jegliche Anhaltspunkte für eine mögliche Identität, so dass der forensische Gutachter zunächst Primärdaten (Geschlecht, Alter und Körpergröße) bestimmen muss. Während das Geschlecht und das Alter in vielen Fällen genau zu eruieren ist, ist die Altersdiagnose nach wie vor mit Fehlern behaftet.

Die vorliegende Arbeit analysiert drei Kasuistiken, bei denen eine ungenaue Altersschätzung zu Problemen bei der Identifikation führte. Kasuistik 1: $\quad$ Fehler durch Übersehen pathologischer und wachstumsverzögernder Begleiterkrankungen.

Kasuistik 2: $\quad$ Fehler durch Anwendung falscher - nicht populationsspezifischer Referenzstudien.

Kasuistik 3: $\quad$ Fehler durch Überbewertung einer einzelnen Methode zur Altersschätzung.

Schlussfolgerungen:

In der forensischen Praxis ist der Rechtsmediziner in zunehmendem Maße mit der Begutachtung nicht-mitteleuropäischer Populationen beschäftigt, zu denen ihm morphologische Vergleichsdaten häufig fehlen oder nur unzureichend zur Verfügung stehen. Die Anwendung populationsspezifischer Referenzdaten oder Methoden, die mit anderen Kollektiven erhoben wurden, müssen zwangsläufig zu Fehlbeurteilungen führen, die einen Ausschluss bei der Identifikation bedeuten können. Pathologische Veränderungen, die zu einer Wachstumsverzögerung führen können, sollten unbedingt berücksichtigt werden.

\section{V-11 \\ FEHLERMÖGLICHKEITEN BEI DER FORENSISCHEN ALTERSDIAGNOSTIK

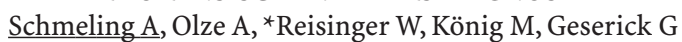 Institut für Rechtsmedizin und \\ *Institut für Radiologie Berlin (Charité)}

Forensische Altersschätzungen bei Lebenden sind in zunehmendem Maße zu einem festen Bestandteil der forensischen Praxis geworden. Seit 1992 wurden im Institut für Rechtsmedizin Berlin (Charité) 246 Altersschätzungen durchgeführt, davon 188 im Rahmen von Strafverfahren (Stand 31.12.2000).

Auf der Grundlage eines richterlichen Beschlusses werden für eine strafrechtliche Altersschätzung eine körperliche Inspektion mit Erfassung der sexuellen Reifezeichen, eine Röntgenuntersuchung der linken Hand sowie eine zahnärztliche Untersuchung mit Erhebung des Zahnstatus und Auswertung eines Orthopantomogramms kombiniert. Bei fraglicher Vollendung des 21. Lebensjahres wird eine zusätzliche Röntgenuntersuchung der Schlüsselbeine durchgeführt. Das wahrscheinlichste Alter der zu untersuchenden Personen wird auf der Grundlage der zusammengefaßten Einzeldiagnosen und der kritischen Diskussion des konkreten Falls ermittelt.

Zur Verifizierung unserer Schätzergebnisse wurden die entsprechenden Gerichtsakten eingesehen. In 45 Fällen konnten Verifizierungsquellen erschlossen werden. Bei den Verifizierungsquellen handelt es sich um Personenfeststellungsverfahren, Geburtsurkunden, Pässe, korrigierte Angaben der untersuchten Personen sowie Telefonüberwachungen.

Die verifizierten Altersangaben werden den Schätzergebnissen gegenübergestellt. Mögliche Ursachen für Abweichungen werden diskutiert. Hierbei wird insbesondere auf Fehlermöglichkeiten des Untersuchers, in der Methodik und in der Befundinterpretation eingegangen.

V-12

LEICHENVERWECHSLUNG - EIN VERMEIDBARER FEHLER?

Verhoff MA, Riße M, Weiler G

Institut für Rechtsmedizin der Justus-Liebig-Universität Gießen

Wie oft kommt es vor, daß auf dem Obduktionstisch oder bei der Krematoriumsleichenschau durch eine Verwechslung ein anderer Leichnam als der erwartete vorliegt? Die Frage nach der Dunkelziffer wird kaum zu beantworten sein.

Es wird ein Fall vorgestellt, bei dem die Leichen bereits vor der polizeilichen Leichenschau durch den Bestatter verwechselt wurden. Eine Anerkennung i.S. $\$ 88$ StPO durch die Polizei vor der Obduktion fand nicht statt. Die im Polizeibericht erwähnten Identitätsmerkmale konnten von den Obduzenten am Leichnam nachvollzogen werden. Ein Fußzettel oder eine Identitätskarte lagen jeweils nicht vor. Dies führte trotz fehlender gesicherter Identität für die Obduzenten zu einer gerichtlichen Obduktion und einer späteren Exhumierung des eigentlich zu obduzierenden Leichnams. Die Verwechslung war erst aufgefallen, als Angehörige nach der Obduktion von dem Verstorbenen Abschied nehmen wollten.

Die Identifikationskette eines Leichnams und deren Lücken und Fehlerquellen insbesondere im menschlichen Bereich durch Personalmangel werden aufgezeigt und diskutiert. Strategien zur Vermeidung von Verwechslungen aus Sicht des Rechtsmediziners werden angesprochen.

\section{V-13}

KRITISCHE PRÜFUNG DER VORAUSSAGE „TODESZEIT“

Henßge $C$

Institut für Rechtsmedizin der Universität Essen

Hufelandstraße 55, D-45147 Essen

Übertragung der Wissenschaftsphilosophie Popper's auf die Wissenschaftsarbeit, insbesondere aber auf die wissenschaftliche Arbeitsweise in der Anwendungspraxis: Die nach Regeln am Leichenfundort erfolgende Eingrenzung der Todeszeit ist eine Art Voraussage. Voraussagen ,sind intellektuell interessant, weil sie uns erlauben, unsere Theorien, die Erklärungsversuche darstellen, an der Wirklichkeit und in der Praxis auf ihren Wahrheitsanspruch hin zu überprüfen" (Karl R. Popper).

Kritische Auswahl der Regeln (Theorien) nach ihrem theoretischen und empirischen Gehalt:

Vergleich von $1^{\circ} \mathrm{C}$ pro Stunde Abkühlregel mit dem Zwei-Exponentialausdruck.

Die meisten rechtsmedizinischen Methoden zur Todeszeiteingrenzung haben mit einem bei Null gelegenen theoretischen Gehalt und einem für die praktische Anwendung im Ermittlungs- und Beweisverfahren von Kapitaldelikten zu geringen empirischen Gehalt ein hohes Irrtumsrisiko. Zur Fehlervermeidung: 


\section{Abstracts}

Kritische Zusammenstellung eines fallorientierten Methodenspektrums

Beispiel einer checklisten- bzw. computergestützten Auswahl-Logistik. Kritische Überprüfung (Falsifikation) der Regeln

Kritische Überprüfung (Falsifikation) des Gültigkeitsbereichs der Regeln

Kritische Überprüfung (Falsifikation) der zur Todeszeiteingrenzung verwendeten Befunde / Primärdaten.

Unkritische Anwendung von Meßgrößen

Fehleinschätzung von Beobachtungsgrößen

Unsichere Befunderhebung /-differenzierung von Beobachtungsgrößen

Entgehen von Befunden, falsch negatives Ergebnis

Vortäuschung von Befunden, falsch positives Prüfergebnis

Kritische Diskussion der Voraussagen zur Todeszeiteingrenzung in Relation zum geringen Wahrheitsgehalt der Regeln (= Falsifikation der Ergebnisinterpretation)

Statistische Maßzahlen der zwischen der aus Leichenbefunden abgeleiteten und der ermittelten Todeszeit

Todeszeit $\neq$ Tatzeit

Qualitätsmanagement

\section{$\mathrm{V}-14$}

ZU FEHLERN BEI DER RECTALTEMPERATURMESSUNG

FUR DIE TODESZEITSCHÄTZUNG

Mall G* ${ }^{*}$, Budjarek B**, Keil W*

* Institut für Rechtsmedizin der Ludwig-Maximilians-Universität, München

** Bayerisches Landeskriminalamt, München

In Einzelfällen haben wir Differenzen zwischen dem Ergebnis der rectalen Temperaturmessung am Leichenfundort und der später im Institut durchgeführten weiteren Rectaltemperaturmessung festgestellt, die durch das zu erwartende Abkühlverhalten der Leiche nicht ohne weiteres erklärbar waren. Bei einem dieser Fälle handelte es sich um einen 60 Jahre alt gewordenen Taxifahrer $(56,7 \mathrm{~kg}, 155 \mathrm{~cm}$, Winterbekleidung), der erschossen in seinem Taxi aufgefunden worden war. Die Umgebungstemperatur betrug $-2,5{ }^{\circ} \mathrm{C}$. Am Fundort wurden um 14.43 Uhr rectal $16,9{ }^{\circ} \mathrm{C}$ gemessen. Um 16.35 Uhr wurde unter Institutsbedingungen (Raumtemperatur $21^{\circ} \mathrm{C}$ ) ein Wert von $19,4^{\circ} \mathrm{C}$ ermittelt. Für das Zustandekommen der Werte waren Übertragungsfehler ausgeschlossen, da am Leichenfundort zwei Messungen in kurzem zeitlichen Abstand erfolgt waren, die miteinander vereinbar waren. Alle Messungen wurden mit demselben geeichten Digitalthermometer durchgeführt. Auch die notwendige Meßdauer soll bei allen Messungen eingehalten worden sein. Die Messungen am Leichenfundort wurden von einem anderen Arzt ausgeführt als die Messung im Institut. Die „Temperaturzunahme“ der Kerntemperatur von $2,5{ }^{\circ} \mathrm{C}$ in 1,5 Stunden wurde zunächst durch eine unterschiedliche Eindringtiefe der Meßsonde in das Rectum erklärt. Da dazu allerdings keinerlei Daten vorlagen, wurden einige Leichenexperimente ausgeführt. Es erfolgten synchrone Temperaturmessungen in jeweils unterschiedlichen Rectumtiefen. Aufgrund dieser Daten können Empfehlungen für die Praxis gegeben werden, um Fälle mit nicht vereinbaren Meßwerten, wie bei uns selbst beobachtet, zu minimieren und somit die Todeszeitschätzung zu präzisieren.

\section{$\mathrm{V}-15$}

FEHLERMÖGLICHKEITEN DER HÄMATOMALTERSBESTIMMUNG

BEIM LEBENDEN MITTELS VIS-SPEKTROMETRIE

$\underline{\text { Arnold }}^{1} \underline{\text { R }}$, Rommei $\aleph^{1}$ S, Klein ${ }^{1}$ A, Fischbacher ${ }^{2}$ C, Jagemann ${ }^{3} \mathrm{KU}$

${ }^{1}$ Institut für Rechtsmedizin der Friedrich-Schiller-Universität Jena, ${ }^{2}$ Analytik Jena AG, ${ }^{3}$ Brooks Automation GmbH Jena

Die rein visuelle Hämatomaltersbestimmung ist naturgemäß mit Fehlern behaftet.

Wie wir bereits an artifiziell erzeugten Hämatomen zeigen konnten, ist die VIS-Spektrometrie in diffuser Reflexion als objektive nichtinvasive Untersuchungsmethode für die Altersbestimmung von Hämatomen bei Lebenden prinzipiell geeignet.

Ausgehend davon wird in einer Studie an einem großen Patientenkollektiv mit Hämatomen unterschiedlicher Entstehungsart, Ausprägung und Intensität mittels bereits bewährten multivariaten Kalibrationsverfahren das Hämatomalter vorhergesagt. Diese Vorhersage wird mit der tatsächlichen Entstehungszeit verglichen, woraus sich die Wiederfindungsrate errechnet.

Die Ergebnisse von bisher 3530 Einzelspektren aus mehrtägigen Verlaufsmessungen von 50 Hämatomen unabhängig von der Intensität des Hämatoms und anderen möglichen Einflußfaktoren zeigen, daß das Auswerteverfahren insbesondere in den ersten 4 Tagen nach Entstehung nicht geeignet ist, zuverlässig das tatsächliche Hämatomalter vorherzusagen. In knapp der Hälfte der Fälle betrug die prozentuale Abweichung vom wahren Hämatomalter weniger als $25 \%$; eine bis $75 \%$ ige Abweichung zeigten $35 \%$ der untersuchten Hämatome. Berücksichtigt man jedoch als eines der Kriterien die Intensität des Hämatoms, so verbessert sich die Wiederfindungsrate signifikant; die prozentuale Abweichung vom wahren Hämatomalter betrug in $64 \%$ der Fälle weniger als $25 \%$. Eine bis $75 \%$ ige Abweichung zeigten nur noch $21 \%$ der Fälle.

Der Einfluß verschiedener Faktoren wie Intensität, Meßort und Ausdehnung des Hämatoms auf die Wiederfindungsrate wird an Beispielen gezeigt.

\section{V-16}

\section{VITALE REAKTION UND POSTMORTALE BIOCHEMIE}

Madea B

Institut für Rechtsmedizin der Universität Bonn, Stiftsplatz 12, D-53111 Bonn,

Als vitale Reaktion bezeichnet man Folgen am Organismus auf eine Traumatisierung, die einen sicheren Rückschluß darauf zulassen, dass das Trauma zu Lebzeiten - vital - eingewirkt hat. Die Validität einer vitalen Reaktion korreliert u.a. mit ihrer Manifestationszeit (Verhältnis der Manifestationszeit zur Agoniedauer einerseits und zur Supravitalphase anderseits) und ist davon abhängig, ob sich die Reaktion auf lokaler Ebene oder in Abhängigkeit von den großen Funktionssystemen Kreislauf und Atmung etabliert. Allgemein gilt, dass lokale Vitalreaktionen, deren Manifestationszeit kürzer ist als die Supravitalphase des entsprechenden Gewebes und die sich unabhängig von Respiration und Zirkulation entwickeln, sich grundsätzlich auch supravital erzeugen lassen. Diese Zusammenhänge werden bei der Ansprache lokaler morphologischer Veränderungen als eindeutig vitale Reaktion zuweilen nicht hinreichend beachtet.

Postmortal chemische Untersuchungen an verschiedenen Flüssigkeits-kompartimenten dienen neben der Todeszeitbestimmung vor allem der Todesursachendiagnostik. Die Möglichkeiten einer postmortalen Diagnostik am vital diagnostisch maßgeblichen intravaskulären Kompartiment werden dabei limitiert durch den raschen postmortalen Zusammenbruch der selektiven Membranpermeabilität mit freiem Konzentrationsausgleich vital ungleich verteilter Stoffe. Daher wird die postmortal chemische Diagnostik überwiegend an Kompartimenten mit gegenüber Blut deutlich verzögerter freier Dif- 
fusion durchgeführt. Methodisch immanente und schwer zu lösende, häufig auch nicht beachtete Probleme sind dabei:

- die Erarbeitung von Referenzwerten in anderen Flüssigkeitskompartimenten im Vergleich zum Serum,

- die Äquilibration von Serumwerten in die anderen Flüssigkeitskompartimente und die Geschwindigkeit, mit der ein Verteilungsgleichgewicht eintritt,

- postmortale Stabilität der Werte in anderen Flüssigkeitskompartimenten,

- Erarbeitung von Diskriminanzwerten zwischen „normal“ und „pathologisch“.

Aufgrund dieser nur schwer zu lösenden Probleme verhält sich die Anzahl methodisch einwandfrei erarbeiteter und unbedenklich zu nutzender postmortal chemischer Meßgrößen (Referenzwerte) für verschiedene Fragestellungen (Diabetesdiagnostik, Störungen des Wasser-Elektrolyt-Haushaltes, alkoholische Ketoazidose usw.) reziprok zum Umfang der Literatur. Sowohl die Erarbeitung sensitiver, spezifischer und valider vitaler Reaktionen als auch postmortal chemischer Referenzwerte setzt neben klarer Begrifflichkeit die mühsame Rekrutierung geeigneter Kollektive voraus.

\section{V-17}

FEHLERHAFTE INTERPRETATION EINER EXTREMEN EXSIKKOSE IM SÄUGLINGSALTER?

Klein $\mathrm{A}^{1}$,Zintl $\mathrm{F}^{2}$

Institut für Rechtsmedizin ${ }^{1}$,

Klinik für Kinder- und Jugendmedizin² ${ }^{2}$ der FSU Jena

Es wird ein Fall vorgestellt, bei dem Irrtümer, Fehler, zu langes Beharren auf voreilig getroffenen Schlußfolgerungen im Fall eines Todes im Säuglingsalter zu einer richterlichen Fehlentscheidung geführt haben dürften.

Der knapp ein Jahr alte Säugling wurde am Morgen reaktionslos und zyanotisch noch atmend aufgefunden. Körpertemperatur $39,1^{\circ} \mathrm{C}$. Am Vorabend unauffällig, normale Nahrungsaufnahme. Bei der Obduktion, die unter Hinzuziehung eines Pädiaters erfolgte, fand sich ein in der Gewichtsentwicklung und im Längenwachstum erheblich retardierter Säugling, der zudem hochgradig ausgetrocknet war. Bis auf kleinflächige „verkrustete“ Hautveränderungen am Hinterkopf und im Gesäßbereich keine Auffälligkeiten. Die nicht von den Obduzenten, sondern vom Pädiater abgegebene erste Stellungnahme bescheinigte einen natürlichen Tod, wobei die Hautveränderung am Hinterkopf als „mögliche Eintrittspforte für Eitererreger mit Auslösung einer akuten bakteriellen Blutvergiftung und Ursache für das sehr hohe Fieber" angesehen wurde. Infolge dessen unterblieben weitere Ermittlungen. Unsere Befundinterpretation:

- Todesursache ist eine Exsikkose.

- Eine natürliche Ursache für diesen Flüssigkeitsverlust konnte nicht gefunden werden. Für die erhöhte Körpertemperatur bestanden keine morphologischen Korrelate.

- Als Ursache für den Flüssigkeitsverlust und den Tod des Kindes verblieb nur eine hochgradig verminderte oder fehlende Flüssigkeitszufuhr. Unter Beachtung der Untermaßigkeit des Säuglings und der Gesamtumstände wurde für uns der Verdacht des von außen induzierten Flüssigkeits- und Nahrungsmangels zwingend. Dringend notwendige Ermittlungen wurden von uns angemahnt.

Im Ergebnis dessen wurde ein Zusatzgutachten von einem bekannten Pädiater eingeholt, das unsere Interpretation in allen Punkten untermauerte. Dennoch kam es zu einem Freispruch der Eltern, wohl deshalb, weil der erst begutachtende Pädiater bei der Diagnose des natürlichen Todes blieb und die Obduzenten sich zu undeutlich davon distanzierten.

\section{V-18}

ALLGEMEINE FEHLER UND IRRTÜMER

IN DEN FORENSISCHEN WISSENSCHAFTEN

Bauer G

Institut für Gerichtliche Medizin der Universität Wien

Die wesentliche Aussage in Popper's Logik der Forschung aus dem Jahr 1935 besteht darin, daß der Erkenntnisfortschritt aus Versuch und Irrtum resultiert. Daraus frei inspiriert könnte man als Aufgabe des forensischen Wissenschaftlers definieren, am Erkenntnisfortschritt mitzuwirken, den aktuellen Wissens- und Erfahrungsstand nicht unberücksichtigt zu lassen, aber - und das ist hier der entscheidende Punkt - das Naturgesetz von Versuch und Irrtum vom forensischen Sachbeweis fernzuhalten.

Nicht alles, was in foro sachverständig vorgetragen wird, fällt bereits unter forensisch-wissenschaftlich, andererseits ist nicht nur die Erarbeitung neuen Wissens und neuer Erkenntnisse, sondern auch deren tägliche Anwendung im Rechtsleben als forensisch-wissenschaftliche Betätigung aufzufassen. Somit meine ich, daß bei Fehlern und Irrtümern in den forensischen Wissenschaften ein auch praktische Seiten beinhaltender und damit weiterer Problemkreis anzusprechen ist, als dies etwa der Fall wäre, wollte man über Fehler und Irrtümer in der Quantenphysik sprechen.

Karl Popper möchte Widersprüche im Bereich der Wirklichkeitswissenschaften über die Falsifikation erkannt sehen. Tatsächlich gehört das Aufzeigen einer falschen Aussage durch forensisch-wissenschaftlichen Gegenbeweis zu unseren Aufgaben. Falsifikation eines im ersten Prozeß geführten Sachbeweises im Wiederaufnahmeverfahren ist hingegen der Alptraum jedes Sachverständigen und Richters. Das Fehlen von Daten und der Mangel an Transparenz zu diesem Thema wurde schon immer beklagt. Statistiken bis zur Rechtskraft des Verfahrens gibt es genug, was auf die Rechtskraft folgt, bleibt im Dämmerlicht. Bahnbrechend waren die Tübinger Untersuchungen von Karl Peters über zahlreiche Wiederaufnahmefälle, in welchen neun Todesurteile und 1.200 Jahre verhängte Freiheitsstrafen enthalten waren, hinsichtlich welcher die Wiederaufnahme bewilligt wurde. Deutlicher läßt sich die Bedeutung des gestellten Themas wohl kaum veranschaulichen.

Bei Indizienprozessen haben die Regel bzw. das Erfahrungswissen, womit der Indizienbeweis geführt wird, geradezu zentrale Bedeutung, da ja aus dieser Erfahrungsgrundlage auf den klärenden Sachverhalt geschlossen wird. Die Anwendung von Beweisregel und Beweismaß sind entscheidende Punkte im Strafprozeß, dessen beherrschendes Prinzip die Ermittlung des wahren Sachverhaltes ist.

Die wesentliche Grundvoraussetzung für eine Betätigung gerade auch in den forensischen Wissenschaften sehe ich daher in der Fähigkeit zur sachgerechten Beobachtung, Beschreibung und logischen Schlußfolgerung - entsprechend der Kategorienlehre des Aristoteles.

\section{V-19}

VERURTEILUNG WEGEN MORDES 20 JAHRE NACH DER TAT FEHLLEISTUNGEN VON POLIZEI UND RECHTSMEDIZIN

Du Chesne A, Bajanowski Th, Fechner G, Brinkmann B, Institut für Rechtsmedizin, Münster

Im November 1979 findet ein vom Ehemann zur Leichenschau gerufener Hausarzt die Leiche einer jungen Frau in der Badewanne. Die Leiche ist bekleidet. Die Atemöffnungen befinden sich unter Wasser. Am Duschschlauch ist ein Strangwerkzeug befestigt, welches um den Hals der Leiche führt. Im Polizeibericht über die Auffindungssituation wird - ohne Konsequenzen - erwähnt, daß sich der Verlauf des Strangwerkzeugs am Hals nicht mit einer dort befindlichen Strangmarke zur Deckung bringen läßt. Die Polizei geht von einem Suizid aus. Der rechtsmedizinische Obduzent verzichtet auf eine Besichtigung des Fundortes. Die fotografisch dokumentierte Auffindungssituation bleibt ihm unbekannt. Bei der Sektion findet er neben Ertrinkungs- 


\section{Abstracts}

befunden Strangulationsmarken. Im Ergebnis wird festgestellt: „Die Befunde in ihrer Gesamtheit sprechen nicht gegen, sondern für eine sogenannte Selbsttötung“.

Im Oktober 1996 erinnern sich die inzwischen erwachsenen Töchter des Ehepaars bei einer Familienfeier, eine tätliche Auseinandersetzung der Eltern in der Nacht vor dem Tod belauscht und am nächsten Morgen einen Fön neben der Leiche der Mutter in der Badewanne gesehen zu haben. Die Familie betreibt über einen Rechtsanwalt die Wiederaufnahme der Ermittlungen.

Im 19 Jahre nach der Tat erstatteten neuen rechtsmedizinischen Gutachten wird festgestellt, daß ein Suizid durch Sektionsbefunde und die Fotos der Auffindungssituation nicht plausibel zu begründen, daher vom Vorliegen eines Tötungsdelikts auszugehen sei.

Der Ehemann gesteht, seine Frau bis zur Bewußtlosigkeit gewürgt und gedrosselt und dann in die Badewanne verbracht zu haben.

Fehler in der Beurteilungsstrategie der Polizei und der Rechtsmedizin werden diskutiert:

- $\quad$ Oberflächliche Beurteilung ohne Kenntnis aller Anknüpfungspunkte

- Voreingenommene Begünstigung einer (meist der harmlosesten) Erklärungsmöglichkeit bei der Prüfung von Hypothesen

- $\quad$ Mangel kritischen gegenseitigen Hinterfragens

\section{$\mathrm{V}-20$}

GEWALT DURCH EIGENE ODER FREMDE HAND?

Peschel O, Eisenmenger W

Institut für Rechtsmedizin

der Ludwig-Maximilians-Universität München

Es werden drei Fälle geschildert, in welchen es aufgrund unterschiedlicher Ursachen zu Fehldiagnosen kam.

Fall 1) Bei der Obduktion einer jüngeren Frau ergaben sich Hinweise für eine Cyanidvergiftung. Seitens der Obduzenten wie auch der anwesenden Toxikologen wurde nach einem positiven Schnelltest von einer oralen Aufnahme ausgegangen. Nachdem durch eingehende weitere Untersuchungen die orale Aufnahme nicht bestätigt werden konnte und weitere kriminalpolizeiliche Ermittlungen den Verdacht auf ein Tötungsdelikt ergaben, wurde eine Exhumierung und Nachobduktion der Leiche durchgeführt. Die weiteren Untersuchungen und Ermittlungen bestätigten den Verdacht auf ein Tötungsdelikt. Die Cyanidaufname war über einen in die Scheide eingeführten Tampon erfolgt.

Fall 2) Ein junges Mädchen wurde in Abwesenheit der Eltern mit einem Halsstich ohne Verletzung von Organen oder Gefäßen und einem Herzstich tot in der Wohnung der Familie aufgefunden. Zur Differenzierung Suicid/Tötungsdelikt wurde eine Obduktion angeordnet. Die zwischenzeitlich durch die Polizei geführten Ermittlungen wiesen auf einen Suicid hin und wurden dem ersten Obduzenten nachdrücklich dargelegt. Nach dem Obduktionsergebnis war ein Suicid zumindest nicht ausgeschlossen, obwohl häufig anzutreffende, Charakteristika für einen Suicid fehlten. Wenige Tage später führte ein Geständnis des Täters zur Klärung des Falles.

Fall 3) Die Obduktion eines Mannes nach Überrollung durch ein Schienenfahrzeug ergab als wesentliche Befunde u.a. Punktblutungen in den Augenbindehäuten und erhebliche Blutungen in den allerdings schwer traumatisch geschädigten Halsweichteilen. Die Verletzungen wurden als Unfallfolge interpretiert, nachdem vom Obduzenten vergleichbare Verletzungen durch Hydraulikschläuche an Triebwagen beobachtet und als Kasuistik veröffentlicht worden waren. Der Fall wurde Jahre später durch das spontane Geständnis eines der Täter geklärt.

Die Ursachen für die Fehlleistungen waren unterschiedlicher Natur; sie sollen zur Diskussion gestellt werden.

\section{V-21}

WO BLIEB DAS MESSER ?

EIN BEITRAG ZUR WUNDMORPHOLOGIE

BEI SCHNITTVERLETZUNGEN DURCH PORZELLANSCHERBEN

Stiller D, Trübner K, Kleiber M

Institut für Rechtsmedizin

der Martin-Luther-Universität Halle-Wittenberg

Ein 37-jähriger Strafgefangener wurde vom Wachpersonal blutüberströmt, leblos im Toilettenraum einer Gemeinschaftszelle, umgeben von Porzellanscherben eines Urinals aufgefunden.

Die Leiche wies eine klaffende $8 \mathrm{~cm}$ lange Wunde an der linken Halsseite auf. Davon ausgehend ein bis zum 5. Halswirbelkörper reichender Stichkanal.

Todesursache war ein Verbluten aus den glattrandig durchtrennten Blutgefäßen am Hals links. Weitere Stich-Schnittverletzungen waren in Gruppen an der Schläfe, an der Oberlippe, an der Schulter und am li. Oberarm angeordnet. Am Sektionstisch sind wir davon ausgegangen, dass die Verletzungen durch ein messer- oder stilettartiges Werkzeug hervorgerufen worden sein müßten. Ein solches Werkzeug wurde trotz intensiver Suche nicht gefunden.

Von den Mitinsassen wurden die tödlichen Verletzungen durch einen Sturz des betrunkenen Häftlings auf das Urinal erklärt.

Im Gutachtenauftrag der Staatsanwaltschaft wurde daraufhin rein hypothetisch eine „messerartige, z.B. aus dem zerstörten aber noch an der Wand fixierten Urinal herausragende Scherbe" als mögliche Verletzungsursache zur Diskussion gestellt. Wir entschlossen uns, die eigene Hypothese -Messer o.ä. Werkzeug- anhand von Versuchen zu überprüfen, da uns das Zustandekommen dieser Verletzungen durch zufällig entstandene Porzellanbruchstücke unwahrscheinlich erschien. Bei den Versuchen mit Tierkörpern stellte sich - auch für erfahrene Rechtsmediziner überraschend - heraus, dass jede Einzelverletzung, insbesondere auch die todesursächliche Halswunde, durch Scherben eines zerbrochenen Urinals hervorgerufen worden sein könnte. Allerdings blieb es bei der Feststellung, dass die Gesamtheit der Verletzungen nicht durch einen einzelnen Sturz entstanden sein konnte. Deshalb wurde Anklage wegen eines Körperverletzungsdeliktes erhoben.

\section{$\mathrm{V}-22$}

RETROPERITONEALE BLUTUNG SPONTANES KRANKHEITSBILD ODER FREMDEINWIRKUNG? Peschel O, Keil W

Institut für Rechtsmedizin

der Ludwig-Maximilians-Universität München

Ein 53jähriger drogenabhängiger Mann wurde in der Haftzelle durch seinen Mithäftling tot aufgefunden. Zum Zeitpunkt der Obduktion war nur bekannt, daß Verletzungen im Gesicht daher rühren sollten, daß der Betroffene im Entzug immer wieder den Kopf auf den Tisch geschlagen habe.

Die Obduktion ergab als Todesursache eine retroperitoneale Blutung im Bereich der linken Colonflexur und Durchbruch in die freie Bauchhöhle ohne eindeutigen Nachweis einer Blutungsquelle. Daneben bestanden eine Aufreißung der Oberlippe, ein unterbluteter Hautdefekt an der linken Augenbraue sowie ein unterbluteter Bruch der Halswirbelsäule, die zunächst als Folge agonaler Stürze interpretiert wurden. Nachdem bei Präparation der rückwärtigen und seitlichen linken Rumpfpartie in korrespondierender Höhe keine Hinweise für ein direktes stumpfes Trauma erkennbar waren, wurde im vorläufigen Gutachten ausgeführt, daß hinsichtlich der Blutungsursache zunächst von einem natürlichen Geschehen auszugehen sei.

Durch die Schwester des Verstorbenen initiierte Nachermittlungen ergaben Unstimmigkeiten in der Aussage des Mithäftlings. Toxikologische Untersuchungen erbrachten Spuren von Morphin, die aufgrund 
der Zeitverhältnisse nur durch einen Konsum während der Haft erklärbar waren. Histologisch fand sich in einem Lymphknoten aus der Region der Blutung eine granulocytäre Infiltration und in der Wand einer benachbarten Arterie eine Invasion von Granulocyten.

In der Literatur finden sich Kasuistiken von retroperitonealen Blutungen, in denen als Blutungsquellen neben makroskopisch auffälligen Veränderungen insbesondere Aneurysmata z.B. von Spinalarterien oder der Aa. suprarenales beschrieben werden, die einer autoptischen Diagnostik nicht ohne weiteres zugänglich sind.

Im vorliegenden Fall hätten jedoch die Verletzungen im Kopf-HalsBereich Anlaß für eine vorläufige Beurteilung als tödliche Fremdeinwirkung sein können, auch wenn die Befunde bis heute kontrovers diskutiert werden.

\section{V-23 \\ KOMPLEXES TUMORLEIDEN MIT TODESFOLGE ALS SPÄTKOMPLIKATION VON HAFTBEDINGUNGEN Bartsch $\mathrm{Ch}^{*}$, Helmchen $\mathrm{B}^{\star}$, Verhoff $\mathrm{MA}^{\star *}$, Krempien B*, Weiler $\mathrm{G}^{\star *}$ * Pathologisches Institut der Universität Heidelberg \\ **Institut für Rechtsmedizin der Universität Giessen}

Vorgestellt wird der Fall eines 59-jährig verstorbenen Mannes, bei dem im Alter von 32 Jahren wegen einer chronisch-progredienten Nephritis eine beidseitige Nephrektomie durchgeführt und 2 Jahre später eine Niere transplantiert wurde. Sechs Monate vor dem Tod entwickelte sich am Ohr ein Merkel-Zell-Carcinom mit ausgedehnter hämatogener Metastasierung. Die Pathogenese des hochmalignen Merkel-Zell-Carcinoms kann durch langjährige Immunsuppression begründet werden, die Ätiologie der anamnestisch bekannten Nephritis ließ sich bei Zustand nach Nephrektomie autoptisch nicht klären. Durch einen Zufall wurden nachträglich weiterführende anamnestische Informationen bekannt. Danach wurde der Verstorbene im Alter von 29 Jahren in der ehemaligen DDR wegen Fluchtversuchs inhaftiert und körperlich und seelisch misshandelt, was zu einer Exazerbation seines chronischen Nierenleidens geführt hatte. Im Laufe der immunsuppressiven Therapie entwickelten sich mehrere, metachron entstandene Tumore.

Der Fall zeigt beispielhaft, dass auch sorgfältig erhobene pathologisch-anatomische Befunde bei der kausalpathogenetischen Klärung eines Tumorleidens unzulänglich sind, wenn wichtige anamnestische Daten nicht zur Verfügung stehen. Im vorliegenden Fall hat nur ein Zufall dazu geführt, dass die kausale Pathogenese des Tumors mit mittelbarem, ursächlichem, haftbedingtem Zusammenhang geklärt wurde und somit ein Rechtsanspruch der Hinterbliebenen gewahrt werden konnte.

\section{V-24}

FALLSTRICKE BEI DER BESCHREIBUNG VON “AUTOUNFÄLLEN”

Walz F

Institut für Biomedizinische Technik, Universität/ETH Zürich

"Nichts wird so fest geglaubt wie das, was wir am wenigsten wissen" (Montaigne). Oder: "Was ist ein schwerer Unfall" ? Der Laie weiss es genau - der Fachmann hat keine Ahnung. Die dem Arzt üblicherweise zugänglichen Grundlagen zu einem "Unfall”, z.B. die Patientenaussage, das Auto sei mit „Schritt-Tempo" oder “mit $50 \mathrm{~km} / \mathrm{h}$ und voller Wucht" angefahren worden, ein Polizeirapport oder die Schadenbilder des Fahrzeuges, sind für den Arzt meist stark fehlleitende "Grundlagen" für die sachgerechte Beurteilung. Nur wenn diese, in ihrer Komplexität oft nicht erkannten, Anknüpfungspunkte durch einen spezialisierten technischen Fachmann gewertet werden, kann abgeschätzt werden, was in der Tat geschehen war. Binsenwahrheit: "Zeitlich, nach" heisst nicht automatisch,wegen ". Durch Presse- und Fernsehberichte bestehen viele falsche Vorstellungen, wie "ein Autounfall" abläuft. In rechtlich relevanten Fällen bei Beschwerden nach "Unfällen" führen solche mit ungenügendem fallbezogenen und fachlichen Hintergrund vorgenommenen Beurteilungen, ob "so ein Ereignis" geeignet sei, die Beschwerden zu verursachen, zu belastenden Verlängerungen der juristischen Auseinandersetzung.

Vier Beispiele aus Arztberichten: 1. "Die Frontalkollision von $42+$ $48 \mathrm{~km} / \mathrm{h}$ ergab eine Wucht von $90 \mathrm{~km} / \mathrm{h}$ " (wusste der Arzt, was er schrieb?). 2. " ... als ein anderer Autofahrer mit $120 \mathrm{~km} / \mathrm{h}$ ins Heck fuhr". Es wurde nicht erwähnt, dass der Betroffene in gleicher Richtung mit $90 \mathrm{~km} / \mathrm{h}$ fuhr, was ein Delta-v von $20 \mathrm{~km} / \mathrm{h}$ ergab. 3. Ein Ereignis lief lange in den medizinischen Gutachten unter "Autounfall mit $100 \mathrm{~km} / \mathrm{h}$ ". Tatsache war, dass ein Motorrad beim Überholen von hinten die Türe gestreift hatte (gemäss Patient "mit möglicherweise ungefähr $100 \mathrm{~km} / \mathrm{h}$ "); es resultierte dadurch nichts ausser einer seitlichen Verschiebung des Autos von maximal $3-4 \mathrm{~km} / \mathrm{h}$. 4 . Aufgrund der Dissimulation des Patienten ("nur ein kleiner Unfall") wurde trotz Heckkollision mit später ermittelten Delta-v von $20 \mathrm{~km} / \mathrm{h}$ kein Röntgenbild gemacht.

"Ein Irrtum ist umso gefährlicher, je mehr Wahrheit er enthält" (Arniel).

\section{V-25}

\section{FEHLER UND IRRTÜMER}

IN DER FORENSISCHEN NEUROTRAUMATOLOGIE

Bratzke $\mathrm{H}$

Zentrum der Rechtsmedizin Frankfurt am Main

Folgenschwere Falschbegutachtungen bei tödlichen Schädel-HirnTraumen sind relativ selten, weil die Befunde meist eindeutig und Irrtümer kaum zu gänzlich falschen Resultaten führen.

Die Ursachen für Fehlinterpretationen liegen vor allem in der Verkennung neurotraumatologischer und -physiologischer Gesetzmäßigkeiten bis hin zum beharrlichen Verweilen auf falsch eingeschlagenem Weg („undiszipliniert autistisches Denken“ nach BLEULER).

Aus der eigenen Sicht werden bisweilen die Folgen einer Gewalteinwirkung gegen den Kopf überbewertet und als todesursächlich angesehen, obwohl das Gehirn keine ausreichende Erklärung für ein traumatogenes Geschehen hergibt oder die Befunde mehrdeutig sind. Oft wird zuwenig bedacht, dass es bei vorgeschädigtem Herz-Kreislaufsystem allein durch die psychische Belastung zur Kreislaufdekompensation kommen, die zur hypoxischen Hirnschädigung und schließlich sekundär zum Tode führen kann („Hirntod“). Sind in solchen Fällen Spuren einer Gewalteinwirkung gegen den Kopf vorhanden, kann fälschlicherweise ein tödliches Schädel-Hirn-Trauma diagnostiziert werden.

Eng damit verbunden sind solche Fälle (vor allem bei fraglichen Kindesmisshandlungen), bei denen aus dem Vorhandensein eines Schädelbruches bei gleichzeitig vorliegender Hirnschwellung auf einen gewaltsamen Tod geschlossen wird. Nicht selten ergibt die feingewebliche Untersuchung des Schädelbruches, dass dieser schon einige Zeit zurückliegt und mangels jeglicher Brückensymptomatik ein Zusammenhang mit dem Tod nicht vorliegen kann bzw. nicht belegbar ist.

Bei zunächst überlebten Schädel-Hirntraumen kann die fehlende Kenntnis des klinischen Verlaufes zu Fehlinterpretationen führen, weil primäre und sekundäre Befunde aus der nachträglichen Sicht nur schwer zu differenzieren sind. Zudem können mit modernen radiologischen Methoden (CT, NMR, PET) Befunde erhoben werden sein, die sich dem späteren morphologischen Nachweis entziehen (z.B. Ödeme).

Zur Vermeidung folgenschwerer Fehlinterpretationen sind „Schnellschüsse" am Sektionstisch zu vermeiden und die Arbeitshypothese durch Nachuntersuchung der Gehirnes zu sichern, auch durch feingewebliche Untersuchungen, ggfs. in Zusammenarbeit mit der Neuropathologie. 


\section{Abstracts}

\section{V-26 \\ STURZ ODER STICH - FORENSISCHE FEHLEINSCHÄTZUNG EINER SCHÄDEL-HIRN-VERLETZUNG AM LEBENDEN \\ Bauer M \\ Institut für Rechtsmedizin der Universität Würzburg}

Der vorgestellte Fall wurde vom Autor im Rahmen des rechtsmedizinischen Bereitschaftsdienstes begutachtet. Ein 6o-jähriger Mann wurde am Tag vor Heiligabend im Rahmen einer tätlichen Auseinandersetzung in einem Treppenhaus durch Stiche im Brustbereich verletzt und vom Autor noch vor bzw. während der operativen Versorgung untersucht. Eine ebenfalls vorliegende Schädel-Hirn-Verletzung wurde zunächst trotz der auffallend scharfrandigen Wundbegrenzungen am ehesten als Folge eines Sturzes auf eine Treppenstufenkante gedeutet. Der Tod trat am folgenden Tag ein. Erst bei der Obduktion konnte eindeutig nachgewiesen werden, dass es sich hier um eine kranielle Stichverletzung handelte, die todesursächlich war. Diese Falldarstellung zeigt exemplarisch, wie eine an den Gutachter aus verschiedenen Gründen herangetragene Erwartungshaltung in Verbindung mit ungenauen und mangelhaften Informationen (klinische CT-Interpretation als Kontusion, Fehlen einer adäquaten Tatwaffe etc.) dazu führen konnte, dass die durchaus vorhandene Wahrnehmung der retrospektiv als richtungsweisend einzuschätzenden Wundbeschaffenheit überlagert wurde mit der Folge, dass die Möglichkeit einer Stichverletzung nicht in die differentialdiagnostischen Überlegungen miteinbezogen worden war. Eine solche, hier folgenlos gebliebene Fehleinschätzung lässt sich wahrscheinlich nicht in jedem Fall vermeiden, sollte jedoch bei auffälliger Diskrepanz zwischen favorisiertem Geschehensablauf und objektiver Befundlage u.a. $\mathrm{zu}$ einer besonders kritischen Bewertung von Fremdinformationen Anlass geben.

\section{$\mathrm{V}-27$ \\ FEHLER UND IRRTÜMER BEI DER DIAGNOSTIK DES ERSTICKUNGSTODES \\ Maxeiner $\mathrm{H}$ \\ Institut für Rechtsmedizin, FB Humanmedizin, \\ Freie Universität Berlin, Deutschland}

Die Beurteilung der Todesursache bei Fällen von gewaltsamem Erstickungstod ist nicht selten schwierig und ähnelt auch manchmal dem Versuch einer Sichtbarmachung des Unsichtbaren. Dies gilt für „eigentliche“ Erstickungen (z.B. Verschluß der Atemöffnungen, Ersticken unter Plastiktüte) besonders, betrifft jedoch auch alle anderen Formen, insbesondere Strangulationen. Die morphologische Zeichen können je nach den Gegebenheiten zwar überaus deutlich sein - eindeutig sind sie aber meist nicht. Selbst bei beträchtlichen Verletzungen - etwa in Form von perioralen Kratzern beim Angriff gegen die Atemöffnungen oder intensiven äußeren und inneren Würgemalen ist der Rückschluß auf eine Todesursächlichkeit nicht unproblematisch. Aus der Literatur und dem eigenen Untersuchungsgut werden Fallbeispiele referiert: z.B. gewaltsames Ersticken bei Obduktion nicht eindeutig erkannt - Aufklärung nach 10 Jahren durch Geständnis; anscheinend Tötung durch Erwürgen - Würgen überlebt, Tod an anderer Ursache. Trotz aller (Selbst-)Kritik muss gesagt werden, dass „Fehler“ der ersten Art angesichts der Geringfügigkeit und Unspezifität der Befunde insbesondere bei bestimmten Opfergruppen (Babies, krankheitsbedingt abwehrgeschwächte oder intoxikierte Personen) kaum sicher vermeidbar sind. Bei der gebotenen zurückhaltenden Begutachtung wird man grundsätzlich damit rechnen müssen, solche Fälle mitunter nicht auf klären zu können. Die zweite Fallkonstellation scheint viel problematischer, da die Gefahr einer fälschlichen Zurechnung der Todesfolge besteht. Dies wirft die Frage nach dem minimalen Untersuchungsstandard auf, der nach hiesiger Einschätzung recht umfangreiche histologische Untersuchungen er- fordert. Bemerkenswerterweise gibt es hierzu in der einschlägigen Literatur aber nur wenige Hinweise, und möglicherweise wird da und dort auch auf eine mikroskopische Vitalitäts- und Altersschätzung von Verletzungen ganz verzichtet.

Während die eine Gewalteinwirkung anzeigenden Lokalbefunde ihrer Art und Interpretation nach in der Literatur zurecht relativ einheitlich gesehen werden, muss der zweite Befundkomplex immer wieder kritisch hinterfragt werden, da aus diesem für die Juristen entscheidende Schlußfolgerungen gezogen werden, nämlich zur Zeitdauer des Angriffes und damit zur wahrscheinlichen Intention des Täters. Relativ einheitlich wird - im Falle eines eingetretenen Todes - von einem über Minuten andauernden „wirksamen“ Angriff ausgegangen, wie er sich im wesentlichen aus tierexperimentellen Ergebnissen und Beobachtungen bei Erhängungsfällen (Hinrichtungen) ergibt - für die anderen Fallgruppen fehlen aber naturgemäß direkte Beobachtungen an Menschen. Nur wenige Autoren (z.B.Henssge 1990, Knight 1991, 1996) setzen sich indes kritisch mit der Wertigkeit solcher allgemeinen Zeitangaben auseinander. Weiter kompliziert wird die Situation dadurch, dass die Befunde, anhand derer überhaupt auf eine tatsächliche Effektivität einer Strangulationssituation geschlossen wird, teilweise (an der Leiche zu beobachtender Blutstau des Kopfes) zumindest nicht nur von der speziellen Strangulationsagonie, sondern von ganz anderen Faktoren abhängen.

Die Diskussion über solche Zusammenhänge sowie über gutachtlich haltbare Zeitangaben sollte intensiviert werden.

\section{$\mathrm{V}-28$}

SERIENTÄTER NICHT ERKANNT

Schröer I, Heinemann A, Püschel K

Institut für Rechtsmedizin,

Universitätsklinikum Hamburg-Eppendorf

Falldarstellung: Eine 33-jährige Frau wurde tot in ihrer Wohnung aufgefunden; sie lag in Bauchlage unbekleidet unter einer Decke im Bett. In der letzten Zeit hatte sie sich nicht wohlgefühlt. Nach Angaben von Angehörigen fehlte Schmuck. Bei der äußeren Besichtigung wurden an der rechten Halsseite strangmarkenähnliche Hautvertrocknungen sowie zahlreiche petechiale Bindehautblutungen festgestellt. - Die Todesursache wurde durch die Sektion nicht eindeutig geklärt. Die Obduzenten diskutierten einen Tod aus innerer Ursache durch Myokarditis, schlossen jedoch eine Strangulation nicht sicher aus. Im abschließenden rechtsmedizinischen Gutachten wurde die Druckmarke am Hals durch das Aufliegen auf einen übersehenen Gegenstand zurückgeführt. Die punktförmigen Blutungen wurden mit dem Herzversagen und der Lage der Sterbenden erklärt. Ein natürlicher Tod infolge Herzversagens wurde als wahrscheinlich angenommen. Retrospektive Analyse: Eine Woche nach Erstattung des abschließenden Gutachtens nahm der Fall eine überraschende Wendung. Ohne $\mathrm{da} ß$ der geringste Verdacht auf ihm lag gestand ein 25 -jähriger psychisch kranker Mann (mit schizophrener Psychose) eine Vergewaltigungsserie und Einbruchtaten sowie in diesem Zusammenhang die Tötung der jungen Frau. Vom Gericht wurde eine Unterbringung im Maßregelvollzug gemäß $\$ 63$ StGB (bei aufgehobener Schuldfähigkeit des Täters) angeordnet. - Schwachstellen bei den polizeilichen Ermittlungen sowie rechtsmedizinischen Untersuchungen werden analysiert. 


\section{V-29}

\section{ER WAR DOCH SO KRANK}

Stiller D, Kleiber M, Trübner K

Institut für Rechtsmedizin

der Martin-Luther-Universität Halle-Wittenberg

Spurenarme Tötungsdelikte, insbesondere Erstickung durch Verschluß der Atemöffnungen, stellen auch für den erfahrenen Obduzenten eine Herausforderung dar.

Ein 70-jähriger Mann wurde vom Pflegedienst leblos in seinem Bett aufgefunden. Die Bettdecke lag über dem Gesicht.

Das Sektionsprotokoll vermerkt zahlreiche vorbestehende Erkrankungen u.a. eine Linksherzhypertrophie (Herzgewicht 570g), eine hochgradig stenosierende Koronararteriensklerose (Restlichtung 20\%), rezidivierende alte zentrale und periphere Lungenembolien mit beginnender Thrombolyse und Infarktpneumonie, cerebrale Apoplexnarbe mit Muskelatrophie der rechten Körperseite. Allerdings wurden auch eine kleine Schürfung am Mund sowie eine Unterblutung der Wangen- und der Lippenschleimhaut beschrieben. Keine Erstickungsblutungen, nur mäßige Lungenblähung (Z.n. Reanimation). Verständlich, dass während der Sektion die Möglichkeit eines natürlichen Todes infolge der vorbestehenden Erkrankungen besprochen wurde. Der unter Zeitdruck stehende Polizeibeamte verließ das Institut vor Beendigung der Sektion und fertigte eine Aktennotiz, wonach von einem natürlichen Tod auszugehen sei.

Nach Abschluß der Obduktion fand die obligatorische Fallbesprechung („Abnahme“) im Kollegenkreis noch am Sektionstisch statt. Im Ergebnis dieses „brain-storming“ entschlossen wir uns, dass trotz der nur schwach ausgeprägten Befunde der Vorbehalt eines „Erstickens unter weicher Bedeckung" deutlich gemacht werden sollte. Der Staatsanwalt war nunmehr gehindert, die Akte zu schließen. Weitere Ermittlungen führten zu zwei Täterinnen. Beim Haftrichter wurde geschildert, dass dem alten Mann Mund und Nase mit einem Kissen und der Bettdecke zugehalten wurden. Während des mehr als 10 Minuten langen Überlebenskampfes kniete eine Täterin auf dem Kissen und die andere hielt den Arm fest.

Eine mittlerweile rechtskräftige Verurteilung erfolgte für die Tötung des alten Mannes.

\section{V-30}

\section{FEHLER BEI „WISSENSCHAFTLICHEN“}

\section{VERKEHRSMEDIZINISCHEN GUTACHTEN}

Mattern R

Institut für Rechts- und Verkehrsmedizin Heidelberg

Das weite Feld verkehrsmedizinischer Begutachtungen umfasst 2 große Gebiete:

1) Traumatologische und traumatomechanische Analysen des Kausalzusammenhangs zwischen Unfall, mechanischer (auch psychischer) Belastung und Folgen

2) Medizinische, psychologische und toxikologische Aussagen zur Fahrtüchtigkeit und Kraftfahreignung.

Der Beitrag befasst sich ausschließlich mit einigen Aspekten des 2. Gebiets:

Eine 1. Fehlerquelle der Begutachtung von Fahrtüchtigkeit und Kraftfahreignung liegt darin, dass diese unbestimmten Rechtsbegriffe eine wissenschaftlich begründbare eindeutige Trennung in tüchtig und untüchtig, geeignet und ungeeignet suggerieren, obwohl sich die zugrundeliegenden Eigenschaften nicht eindeutig quantifizieren lassen. Die Rechtsprechung stützt mit der „normativen“ Festlegung von Grenzwerten oder Ausprägungen von Kriterien diese Vorstellung und trägt dazu bei, dass die Sensibilität für die Grenzen der wissenschaftlichen Beweisbarkeit von Fahruntüchtigkeit und Fahreignung selbst bei manchen Wissenschaftlern als Gutachter in Vergessenheit gerät. Sie tappen dann in die Falle des normativen Nachweises in Verwechslung mit dem wissenschaftlichen Beweis.
Die 2. Fehlerquelle betrifft die Tatsache, dass bei nicht normativ festgesetzten Kriterien keiner der im Begutachtungsverfahren Beteiligten, weder die Betroffenen, noch Richter, Rechts- oder Staatsanwälte, auch nicht die Gutachter, wirklich wissen, ob Fahrtüchtig- oder Untüchtigkeit, Fahreignung oder Nichteignung vorliegt. Der Fehler manifestiert sich, wenn im - insbesondere wissenschaftlichen - Gutachten diese kaum ernsthaft bestrittene Aporie nicht thematisiert wird.

Dies gilt insbesondere für Prognosegutachten über zukünftige Verkehrsbewährung, in denen eine 3. Fehlerquelle droht: Bei der Begründung der Prognose mit wissenschaftlichen Erkenntnissen, weil die wissenschaftliche Nachvollziehbarkeit in Rechtsverordnungen (Hier: Fahrerlaubnisverordnung Anlage $15 \mathrm{zu} \$ \$ 11$ und 66) gefordert wird. Man findet in solchen Gutachten Wahrscheinlichkeitsaussagen, die sich auf frühere, oft Jahrzehnte zurückliegende Untersuchungen stützen, die nicht immer heutigen Ansprüchen an Wissenschaftlichkeit genügen, oft fehlt die kritische Prüfung, ob der zu beurteilende Einzelfall in die Rückfallgruppe oder die Bewährungsgruppe gehört und mit welcher Wahrscheinlichkeit sich dies feststellen lässt. Schließlich ist das gesamte Begutachtungsverfahren wissenschaftlich nicht validiert, solange Negativgutachten mit Versagung der Fahrerlaubnis nicht falsifizierbar sind: Sie wären es, wenn der negativ Begutachtete die Chance bekäme, sich im Verkehr zu bewähren.

\section{V-31}

\section{DIE VERKEHRSMEDIZINISCHE BEGUTACHTUNG} UND DEREN POTENTIELLE FEHLERMÖGLICHKEITEN

Liniger B

Verkehrsmedizinische Abteilung, Institut für Rechtsmedizin St. Gallen

In Anbetracht der von Bundesebene aus geförderten, gesamtschweizerisch angestrebten Vereinheitlichung einerseits der Kriterien zur Anordnung einer verkehrsmedizinischen Untersuchung, andererseits auch der Begutachtungsleitlinien, entstehen in dem in der Schweiz im Vergleich zu Deutschland längst noch nicht so breit gepflegten und abgestützten Fachbereich der Verkehrsmedizin vermehrt neue Herausforderungen. Dabei sind nicht nur die mittlerweile deutlich angestiegenen Fallzahlen und die vergleichsweise noch zu wenig vorhandenen Abklärungsstellen und Gutachter zu nennen. Vielmehr hat vor allem auch die Entwicklung, dass in den Administrativmassnahmen-Verfahren zunehmend mehr Juristen bzw. Rechtsanwälte tätig sind, dazu geführt, dass die Anforderungen an die verkehrsmedizinischen Begutachtungen immer höher werden, und zwar nahezu in jeder Hinsicht. Dies stellt für den motivierten Gutachter natürlich eine überaus interessante Aufgabe dar, birgt aber auch etliche potentielle Fehlermöglichkeiten, auf welche im Rahmen des Vortrags selbstkritisch hingewiesen werden soll.

\section{V-32}

MÖGLICHE FEHLEINSCHÄTZUNG DER INSASSENBELASTUNG BEI PKW- FRONTALKOLLISIONEN MIT NICHT ANGEGURTETEN FONDPASSAGIEREN

Schönpflug M, Schuller E, Eisenmenger W

Institut für Rechtsmedizin der Universität München, Frauenlobstr. 7a, D- 80337 München

Im Rahmen der Begutachtung tödlicher Pkw- Frontalkollisionen ergibt sich häufig folgende Fragestellung:

Haben nicht angegurtete Fondinsassen in erheblichem Maße an der Entstehung der tatsächlichen Verletzungen des Fahrers bzw. Beifahrers Anteil ?

Anhand eines konkreten Unfalls mit einem nicht angegurteten Fahrer und zwei nicht angegurteten Fondinsassen erschien bei Betrachtung der Rückenlehnendeformation des Fahrer- und Beifahrersitzes zunächst die Antwort eindeutig. 


\section{Abstracts}

Insbesondere, da die Rückenlehne des Beifahrersitzes, der zum Unfallzeitpunkt unbesetzt war, im Vergleich zum Fahrersitz weitaus größere Deformationen auf Grund der Wechselwirkung mit dem hinten rechts plazierten Insassen aufwies. Dies ließ zunächst den Schluß zu, daß der Fahrzeuglenker zusätzlich einen Teil der Aufprallenergie des hinter ihm sitzenden Insassen aufnehmen musste.

Die genaue Rekonstruktion des Verkehrsunfalls mit Simulation der Insassenkinematik mit Mehrkörper Systemen (MKS) zeigt die Problematik der zuvor noch eindeutig geglaubten Lösung bei derartigen Unfällen auf.

\section{V-33}

\section{FEHLER UND IRRTÜMER}

IN DEN FORENSISCHEN WISSENSCHAFTEN:

\section{SCHUSSVERLETZUNGEN}

Pollak S

Institut für Rechtsmedizin, Albertstr. 9, D-79104 Freiburg/Br.

Grundsätzlich sind 2 Arten von Falschbeurteilungen zu unterscheiden: Die erste Kategorie umfasst jene Fehlleistungen, die auf mangelndes Wissen/zu geringe Erfahrung/unzureichende Sorgfalt des Untersuchers zurückzuführen sind. Die zweite Gruppe ist dadurch charakterisiert, dass entweder der Befund als solcher untypisch/unspezifisch/mehrdeutig ist oder dass besondere Umstände die richtige Interpretation erschweren. Die Übergänge zwischen den beiden Fallgruppen sind fließend, da in der konkreten Situation auch eine Kombination der genannten Ursachen vorliegen kann.

Als klassische Beispiele für Irrtümer, die vornehmlich in der Person des Untersuchers begründet sind, können gelten: Das Vorliegen einer Schussverletzung bleibt unerkannt (z.B. wegen unterlassener Entkleidung der Leiche oder wegen nicht erfolgter Inspektion der Körperrückseite bzw. der Körperöffnungen); eine morphologisch eindeutige Schusswunde wird fälschlich als andersartige Verletzung (z.B. als Stich-oder Rissquetschwunde) aufgefasst; Ein- und Ausschussöffnung werden verwechselt; Nahschusszeichen werden übersehen oder unrichtig gedeutet; bedeckende Kleidungsstücke werden nicht in die Beurteilung einbezogen.

Unabhängig von etwaigen Insuffizienzen auf Seiten des Untersuchers können die Schussverletzungen als solche mannigfach Anlass zu Fehlbeurteilungen geben. Exemplarisch seien genannt: Abwandlung des Einschussbefundes durch vorausgegangene Interaktion zwischen Geschoss und Zwischenziel, Modifikation des Schussbildes durch die lokalen Gewebseigenschaften, Variation von Nahschusszeichen durch zusätzliche Einflussfaktoren, morphologische Ähnlichkeit von Einund Ausschüssen, Geschosszerlegung und -ablenkung. Die wichtigsten Fehlerquellen werden anhand von Fallbeispielen aus der rechtsmedizinischen Obduktionspraxis aufgezeigt und erläutert.

\section{V-34}

\section{SCHUSS UND IRRTUM}

Kneubuehl BP

Gruppe Rüstung, FA 26, Ballistik- und Detoniklabor, $\mathrm{CH}-3602$ Thun

Die Vorgänge, die sich beim Schuss abspielen, finden unter extremsten physikalischen Bedingungen statt. Beschleunigungen, Kräfte, Temperaturen und insbesondere die Kurzzeitigkeit der Ereignisse übersteigen das menschliche Vorstellungsvermögen bei weitem. Die Modelle, die zum Verständnis des Geschehens aufgestellt wurden, waren deshalb oft von Irrtümern begleitet, die vor allem aus der dem Menschen naheliegenden quasi-statischen Betrachtungsweise entstanden sind.

Im Verlauf der letzten zwanzig Jahre hat das optische Erfassen kurzzeitiger Vorgänge große Fortschritte gemacht. Die Möglichkeit des direkten Betrachtens von Vorgängen, die in Bruchteilen von Millisekunden ablaufen, hat viel zu einer besseren Erkenntnis des Schusses und seinen Auswirkungen beigetragen.

\section{V-35}

ZUR (FEHL-)INTERPRETATION

VON SCHMAUCHANHAFTUNGEN.

$\underline{\text { Peschel }} \underline{\underline{1}} \underline{\mathrm{O}}$, Manthei ${ }^{2} \mathrm{~A}$, Wasserburger ${ }^{2} \mathrm{~L}$

${ }^{1}$ Institut für Rechtsmedizin der Ludwig-Maximilians-Universität München

${ }^{2}$ Bayerisches Landeskriminalamt, SG 27

Nach einem mißlungenen Raubüberfall auf eine Pilsbar wurde ein Passant, der den beiden Tätern gefolgt war, durch 10 Schüsse aus einer vollautomatischen Waffe getötet. Kurze Zeit später wurde als Tatverdächtiger Robert B. ermittelt. Er war am Tattag in einer Münchner Klinik an der Hand operiert worden und wurde, nachdem er von der Nachtschwester aber in den Stunden um den Tatzeitpunkt nicht gesehen worden war, auf der Krankenstation festgenommen. In ersten Vernehmungen gab er an, daß er sich an die Tatnacht nicht erinnern könne, da er am Abend zuvor Flunitrazepam eingenommen habe und dann eingeschlafen sei. Die Untersuchung der kurz nach der Festnahme in den Räumen der Mordkomission abgenommenen Kontaktproben der Hände (Stubs) sowie der Kleidung durch REM und RFA ergab den Nachweis einiger Partikel in einer Zusammensetzung, wie sie dem an den Hülsen $\left(\mathrm{S} \& \mathrm{~B}^{\circledR}\right.$, $)$ vom Tatort nachgewiesenen Schmauch entsprach. B. wurde ferner von einigen Zeugen eindeutig identifiziert. Ein Zeuge, der den Tatverdächtigen entlastete und selbst eine Tatbeteiligung einräumte, wurde wegen uneidlicher Falschaussage verhaftet. Während der Gerichtsverhandlung gab B. an, er könne sich den Schmauch an seinen Händen nur dadurch erklären, daß er mehr als 24 Stunden vor der Tat mit einer Gas-Alarm-Waffe hantiert gehabt habe. Ein waffentechnischer Sachverständiger stellte fest, daß bei der Polizei üblicherweise Munition der Firma Dynamit Nobel (andere Schmauchzusammensetzung) Verwendung finde und eine Kontamination durch Polizeibeamte daher zunächst nicht nachvollziehbar sei. $\mathrm{Da}$ B. aber durch SEK-Kräfte festgenommen und transportiert worden war, wurde auf Antrag der Verteidigung das Einsatzfahrzeug auf Schmauchspuren untersucht. Dabei wurden erhebliche Mengen an Schmauch unterschiedlicher, u.a. der gegenständlichen Zusammensetzung gefunden.

Der Fall zeigt, daß der Schmauchnachweis nicht zwangsläufig unmittelbar mit einer Schußabgabe in Zusammenhang steht.

\section{V-36 \\ EIN KLASSISCHER FEHLER: \\ EINE UNERWARTETE SCHUSSRICHTUNG. \\ Schyma (1) C, Schmidt (2) P, Madea (2) B \\ 1) Institut für Rechtsmedizin der \\ Heinrich-Heine-Universität Düsseldorf \\ 2) Institut für Rechtsmedizin \\ der Friedrich-Wilhelms-Universität Bonn}

Ein 77jähriger Mann wurde an einem Garagentor erhängt aufgefunden. Zu seinen Füßen lag eine Kleinkaliberpistole. Im Scheitelhaar fanden sich Anhaftungen von Hirngewebe. Die Ermittlungsbeamten vermuteten einen zusätzlichen Schuß in den Mund. Bei der Obduktion wurde eine adaptierbare, mehrzackige Rißwunde des Scheitels ohne Stanzmarke und makroskopisch erkennbare Schmauchhöhle festgestellt, als Ausschuß interpretiert. Das Schädeldach zeigte jedoch den typischen trichterförmigen Ausbruch der tabula interna, so daß man von einem Schuß in den Scheitel ausgehen mußte. Auf der tabula externa war eine saumartige, graue Verfärbung um das Schußloch zu 
erkennen. In der Schädelbasis wurde ein deformiertes Bleiprojektil gefunden, der Gaumen war unversehrt. Durch Mikrofokusröntgen (Faxitron M55) der Kopfschwarte konnte eine für das Kaliber .22 long rifle bemerkenswerte Schmauchhöhle dargestellt werden. Die Röntgenfluoreszenzanalyse der Knochenoberfläche bestätigte den absoluten Nahschuß. Erst durch Obduktion und systematische Untersuchung der Asservate war bei atypischer Wundmorphologie eine korrekte Klärung des Falles zu erreichen.

\section{V-37}

ERSCHIESSUNGSSZENEN IM INTERNET: REAL ODER VIRTUELL ?

Schyma (1) C, Mattern (2) R, Bratzke (3) H

1) Institut für Rechtsmedizin

der Heinrich-Heine-Universität Düsseldorf

2) Institut für Rechtsmedizin

der Ruprecht-Karls-Universität Heidelberg

3) Zentrum der Rechtsmedizin

der Johann Wolfgang Goethe-Universität Frankfurt

Seit mehreren Jahren werden Polizeibehörden immer wieder von Internetsurfern auf sogenannte „snuff clips“ aufmerksam gemacht, in denen die Tötung von Menschen zu sehen sei. Zunehmend werden deshalb auch Rechtsmediziner mit der Begutachtung solchen Materials beauftragt. Die wichtigste Frage ist, ob es sich um Realvorgänge oder inszenierte Darstellungen handelt. Bis jetzt sind mehrere Erschießungsszenen bekannt, die auf unterschiedlichen Internetseiten mit schnell wechselnden Adressen angeboten werden. Meist handelt es sich dabei um kurze Videoclips von wenigen Sekunden. Während einige Darstellungen aufgrund offensichtlicher Fehler schnell als Montagen zu entlarven sind, geben einzelne Clips Rätsel auf. Erst die Sammlung mehrerer Clips und ihre vergleichende Analyse ermöglicht eine gutachterliche Einordnung der zweifelhaften Szenen. Als Beurteilungskriterien wurden die Rahmenhandlung, die verwendeten Waffen, die Schmauchspuren, die Entwicklung und Ausbreitung von Blutspuren, die Reaktion der Opfer, die Kameraführung und die technischen Parameter der Aufnahme untersucht. Anhaltspunkte für einen realen Homizid fanden sich bisher nicht, die Irrtumsgefahr für den Sachverständigen bleibt jedoch. Wegen der Komplexität der Problematik ist eine interdisziplinäre Zusammenarbeit unerläßlich.

\section{V-38 EIN SCHUß ZUVIEL. \\ Schyma (1) C, Placidi (2) P, Madea (3) B \\ 1) Institut für Rechtsmedizin \\ der Heinrich-Heine-Universität Düsseldorf \\ 2) Labor für experimentelle Ballistik, Hürth \\ 3) Institut für Rechtsmedizin \\ der Friedrich-Wilhelms-Universität Bonn}

WEIL ... NICHT SEIN KANN, WAS NICHT SEIN DARF:

Ein Amokschütze, der mit zwei Pistolen und einer Maschinenpistole im Kaliber $9 \mathrm{~mm}$ Luger bewaffnet war, wurde von einem Sondereinsatzkommando (SEK) gestellt und mit zwei Schüssen aus etwa $50 \mathrm{~m}$ Distanz außer Gefecht gesetzt. Mit einem Brustkorb- und einem Unterschenkeldurchschuß wurde er in die Klinik verbracht. Je zwei Schußdefekte wurden an der Windjacke und der Jeanshose vom Erkennungsdienst markiert. Die Untersuchung des kreuzförmigen Stoffdefektes im linken Brustbereich ergab eine intensive bleihaltige Beschmauchung. Es handelte sich um einen absoluten Nahschuß, den sich der Täter in suizidaler Absicht beigebracht hatte. Die Unterschenkelverletzung war auf einen Distanzschuß des SEK zurückzuführen. Erst bei der Abschlußinspektion der Asservate wurde ein weiterer, unscheinbarer Einschuß auf der linken Brustseite, $20 \mathrm{~cm}$ unterhalb der ersten Verletzung entdeckt. Der Schußkanal verlief ab- steigend nach links außen und durchsetzte die leere Innentasche, die mit Taschentüchern und Kräuterbonbons gefüllte Außentasche bis in den Saum der Windjacke. Dort wurde ein loses, stark aufgepilztes Quick Defense Projektil (MEN, 9 mm x 19, $\mathrm{E}_{\mathrm{o}} \mathrm{ca} .500$ Joule) gefunden, das aus einer SEK-Waffe abgefeuert worden war. Dieser Schuß hatte zu keiner Verletzung des Täters geführt. Rätselhaft blieb zunächst, warum das Geschoß keinen Durchschuß verursacht hatte und sich sogar verformt hatte, obwohl kein Weichgewebe getroffen worden war. Experimentell konnte nachgewiesen werden, daß das Aufpilzungsverhalten vom Feuchtigkeitsgehalt der Taschentücher und vor allem von den Bonbons beeinflußt wird.

\section{V-39}

QUALITÄTSFÜRSORGE, LAST ODER LUST?

Tóth J

Niederländisches Forensisches Institut (NFI), Rijswijk, Niederlande

Qualitätsfürsorge ist eine zeitraubende und teure Tätigkeit. Der Beschluss in ein solches System zu investieren kann gesetzlich festgelegt sein oder zum Teil durch die Benutzer der Resultate und Gutachten bestimmt werden. Die Resultate und Gutachten müssen zuverlässig sein und eine hohe Qualität haben, weil sie einen unmittelbaren Einfluss auf die Untersuchungsverfahren oder die Beschlussfassung der Gerichte ausüben.

Das DNA-Labor hat, neben der Sicherheit, dass zuverlässige Resultate und Gutachten hergestellt werden, vom eingeführten Qualitätsfürsorgesystem auch andere Vorteile. Die eigene Organisation und die Untersuchungsprozesse werden transparenter. Es ist festgelegt, wer für die verschiedenen Untersuchungsabschnitte die Verantwortung trägt. Durch gute Ausbildung sind die Mitarbeiter kompetent, die notwendigen Analysen und Untersuchungen durchzuführen oder die Gutachten herzustellen. Der ganze Untersuchungsprozess (Ausführung und Resultate) ist dokumentiert und kann, wenn notwendig, überprüft werden.

Das Ausarbeiten eines Qualitätsfürsorgesystems wird durch Internationale Normblätter gesteuert. Für die forensischen Untersuchungen können zum Beispiel die ISO-NEN 17025 und die ILAC Normblätter genannt werden. Die nationale, für die Akkreditierung zuständige Instanz kann weitere Richtlinien geben. Es ist unbedingt notwendig, dass die Instituts- oder Laborleitung bei den Mitarbeitern die Begeisterung für ein solches System weckt und dass das Management vollständig dahinter steht. Die Vor- aber auch Nachteile müssen genannt werden. Im Institut oder im DNA-Labor soll ein Mitarbeiter als Qualitätsmanager tätig sein. Dieser Qualitätsmanager ist hierarchisch dem Direktor oder Labormanager unterstellt. Er ist verantwortlich für alle qualitätsbezogenen Angelegenheiten.

Sicherheitsmassnahmen und Kontrollen sind in der DNA-Analytik in drei Formen allgegenwärtig. Techniker kontrollieren die eigene Arbeit mit Hilfe von Reagenznegativ- und -positivkontrollen sowie Kontrollspuren. Leitende Techniker kontrollieren generell oder mit Hilfe von internen Ringversuchen die Resultate. Wissenschaftliche Mitarbeiter prüfen nochmals die DNA Profile und machen die Evaluation von internen und externen Ringversuchen. Das Überprüfen der Konzeptgutachten ist ebenfalls eine geläufige Methode der Qualitätsüberwachung und Qualitätskontrolle. Systematische Validierung von neuen Untersuchungsmethoden garantiert ebenfalls zuverlässige Resultate mit hoher Qualität.

Neben Qualitätsfürsorge gibt es noch andere Möglichkeiten, die Qualität positiv zu beeinflussen. Die beim Untersuchungsprozess beteiligten Instanzen, Staatsanwaltschaft, Polizei und Labor haben ein gemeinsames Ziel: durch Beweismaterial den mutmasslichen Tatverdächtigen zu überführen oder die Unschuld zu beweisen. Eine reibungslose Zusammenarbeit ist notwendig, um auf schnelle Weise qualitativ hochwertige Resultate zu gewährleisten. Das Managementteam oder die Laborleitung hat die Verantwortung, dem gesamten Untersuchungsprozess Richtung zu geben und optimal auszurüsten. 


\section{Abstracts}

“Total Quality Management”(TQM) Instrumente wie die holländische Variante "INK" können ebenfalls eingesetzt werden.

Teamarbeit ist auch im Labor notwendig. Das Untersuchungsteam hat ebenfalls ein gemeinsames Ziel, nämlich DNA Resultate oder Gutachten fehlerfrei an den Auftraggeber zu überbringen. Der richtige Mitarbeiter auf dem Arbeitsplatz wo dieser am besten funktioniert, wird qualitativ die besten Resultate ergeben. Weil als Team operiert wird, ist die Einführung eines "Change for the Better" Systems realisierbar. Mit dieser Methodik (Deming-Kreis), wobei Beinahfehler, Fehler oder Bemerkungen von Mitarbeitern oder Auftraggebern gebraucht werden, kann man die eigene Organisation, den Untersuchungsprozess und das Qualitätssystem verbessern.

Die Qualitätssicherung bei der Untersuchung von Asservaten zum Auffinden von humanen biologischen Spuren, wird meistens nicht standardmässig durchgeführt. Die Einführung einer Prozedur für eine Zweitüberprüfung von Asservaten, bei denen bei der ersten Untersuchung keine humanen biologischen Spuren angetroffen wurden, liefert überraschenderweise in manchen Fälle doch Material für eine DNA-Analyse.

Das Ausfindigmachen von (Mikro)spuren, die "chain of custody" und die Prävention von Kontamination spielen eine grosse Rolle in Relation mit der jetzigen Empfindlichkeit der gebrauchten Singleplex PCR-Systeme, Multiplex-PCR-Kits oder "Low Copy Number" PCRMethoden. Diese machen es möglich, von Mikrospuren (oder MikroKontamination!) ein DNA-Profil herzustellen. Diese Tatsachen machen unmittelbar deutlich, dass der Kontrolle des Ausfindigmachens von (Mikro)-Spuren mehr Aufmerksamkeit, Zeit und Qualitätsfürsorge gewidmet werden muss.

Die beschriebene Massnahmen zeigen, dass Qualitätsfürsorge mehr Lust als Last ergibt. Sie ist eine sehr geeignete Methode, um zu gewährleisten, dass DNA Resultate und Gutachten zuverlässig sind und dass die Labororganisation transparent und vollständig dokumentiert ist. “Total Quality Management” (TQM) Instrumente können gebraucht werden, um die Zusammenarbeit der beim Strafprozess beteiligten Instanzen und die eigene Organisation zu verbessern.

\section{$\mathrm{V}-40$}

\section{INTERPRETATION VON DNA-SPUREN AUF EINEM KÖRPER}

Banaschak S, Baasner A, Driever F, Madea B

Institut für Rechtsmedizin,

Rheinische Friedrich Wilhelms-Universität Bonn,

Stiftsplatz 12, 53111 Bonn

Eine Frau wurde erstochen in ihrer Wohnung aufgefunden. Vor der Leichenöffnung wurden Körperabriebe mit einem Wattestieltupfer durch die Polizei angefertigt. Bei den Ermittlungen geriet der Freund des Opfers in Verdacht. Er bestritt jede Beteiligung an dem Tötungsdelikt. In den Körperabrieben wurde seine DNA nachgewiesen, was von Seiten der Ermittlungsbehörden als Indiz gewertet wurde, insbesondere da das Tatopfer häufig geduscht haben soll.

Es wurde in einem experimentellen Ansatz untersucht, ob FremdDNA, wie z. B. Speichelspuren, nach längerer Persistenz auf der Haut nach dem Duschen nachweisbar ist.

Dazu wurden 5 Felder von ca. 4 x 4 cm Größe an der Außenseite des Armes eines weiblichen "Opfers" eingezeichnet und diese vom männlichen „Täter“ mit Speichel benetzt. Nach 1, 6, 12 und 24 Stunden (hier vor und nach dem Duschen) wurden mit angefeuchteten Wattestieltupfern Abriebe angefertigt und getrocknet. Diese wurden auf 5 STR-Systeme (vWA, THo1, FGA, F13B, DYS 19) untersucht.

Es standen bislang 3 Probenreihen zur Verfügung. In den vor dem Duschen angefertigten Proben konnte - in unterschiedlichen Mengen - „Täter“-DNA nachgewiesen werden. Nur in zwei Proben fand sich eine Mischspur aus „Täter“- und „Opfer“-Allelen. Dies spricht dafür, dass die Probenabnahme sehr vorsichtig durchgeführt wurde bzw. reichlich „Täter“-DNA vorhanden war. In zwei Fällen konnte auch nach dem Duschen eindeutig „Täter“-DNA nachgewiesen werden.
Die Interpretation des Nachweises von Fremd-DNA aus Körperabrieben - insbesondere wenn keine Auftragungen zu sehen sind und „auf Verdacht“ abgerieben wird, muß sehr zurückhaltend erfolgen. Eine längerfristige Persistenz (hier 24 Stunden und nach Duschen) war problemlos zu reproduzieren. Rückschlüsse auf die aufgetragene DNA-Menge sind nicht möglich.

\section{V-41 \\ KASUISTIK EINER VERSPÄTETEN TÄTERIDENTIFIZIERUNG AUF MT-DNA-BASIS \\ NACH ZUNÄCHST IRRTÜMLICHEM AUSSCHLUß \\ EINER HUMANSPEZIFITÄT VON FAECES \\ Heidorn F, Verhoff MA, Oehmke S, Weiler G \\ Institut für Rechtsmedizin der Justus-Liebig-Universität Gießen}

Acht Tage nach einem Banküberfall wurde im engeren Tatortbereich ein von Schnee bedeckter Kothaufen gefunden. Der Kothaufen wurde mitsamt dem Trägermaterial, einer Waschbetonplatte, in einer Plastiktüte weitere zwölf Tage später zur spurenkundlichen Untersuchung übergeben, da er den einzigen Identitätshinweis auf den Täter darstellte.

Es erfolgte eine Präparation der DNA mit zwei unterschiedlichen Methoden. Eine frische Stuhlprobe fungierte als Positiv-Kontrolle. Bei dem Asservat konnten, im Gegensatz zur Positivkontrolle, keine Amplifikationsprodukte in nucleären PCR-Polymorphismen gewonnen werden, so daß zunächst die Vermutung geäußert wurde, daß es sich wohl nicht um menschliche Kotanhaftungen handele.

Nach einer Literaturrecherche wurde zur Prüfung der Humanspezifität eine Methode etabliert, die auf einer Co-Amplifikation jeweils eines Abschnittes der HV1-Region und des Cytochrom-B-Gens auf der mtDNA basiert. Das nunmehrige Ergebnis sprach eindeutig für eine menschliche Herkunft.

Im Anschluß daran gelang es, die HV1- und die HV2-Region aus der Kotprobe zu sequenzieren. Diese Sequenz ließ sich einem Tatverdächtigen zuordnen.

Die mehrfachen vergeblichen Amplifikationsversuche der nucleären Polymorphismen bei offensichtlich ausreichend gut erhaltenem Spurenmaterial und problemlosen Amplifikationen bei der Positivkontrolle führten zu der Bewertung, daß es sich wohl um tierisches Material handele, wobei die Fundsituation durchaus für Hundekot sprach. Bei der zwölftägigen Liegezeit des Spurenmaterials in einer „feuchten Kammer" wurde anscheinend die nucleäre DNA viel stärker degradiert als erwartet. Nur durch Etablierung einer neuen Methode mit Nachuntersuchung eines abgeschlossenen Falles konnte das Erstergebnis korrigiert und das Ermittlungsverfahren mit Täteridentifizierung erfolgreich abgeschlossen werden. Der Fall spricht dafür, daß DNA- und Spurenmaterial nicht zu früh vernichtet werden dürfen.

\section{V-42 \\ „RICHTLINIENKONFORME FEHLER“ IN KOMPLIZIERTEN ABSTAMMUNGSGUTACHTEN BEI UNKENNTNIS DER LOKALISATION GENETISCHER MARKER Szibor R, Lieske S, Beck N, Plate I, Krause D \\ Institut für Rechtsmedizin \\ der Otto-von-Guericke-Universität Magdeburg}

In Deutschland stehen neue Richtlinien für Abstammungsgutachten vor der Verabschiedung. Danach müssen mindestens 12 Systeme von 10 Chromosomen (Chr) angewandt werden. Das schließt für 10 Marker Kopplung aus. Aber: Zwei bzw. sogar eine praktisch unbegrenzte Zahl von Markern darf man zusätzlich ohne Kenntnis bzw. Beachtung der Lokalisation anwenden. 
Es wird gezeigt, dass ein exzessiver Gebrauch von Markern (z.B. bei isoliertem Ausschluß und in Defizienzgutachten) bei Nichtbeachtung von Kopplung zu „richlinienkonformen Fehlern“ führen kann. In einem „normalen“ Terzettenfall fanden wir einen SE33 Ausschluss, den wir als Mutation ansahen. Wir bezogen alle uns verfügbaren Marker ein und fanden unsere Meinung bestätigt. Während uns natürlich bekannt war, dass ChrY Marker in Putativvater (PV)-Geschwisterfällen keine Auschlusskraft besitzen, waren wir uns der Brisanz einer Verwendung von unzulänglich kartierten Markern nicht ausreichend bewusst. Das Allelsharing zwischen Kind und PV in den Systemen CD4, VWA, und D12S391 betraf gleich zwei seltene Allele und bestärkte uns in der Mutationsvermutung. Aber: VWA, CD4 und D12S391 bilden eine Kopplungsgruppe und somit eine abgeschwächte Analogie zum ChrY. Geschwister haben beim Allelsharing naturgemäß häufig gleich die ganze Kopplungsgruppe gemeinsam bzw. nicht gemeinsam. Deshalb ist die Nutzung gekoppelter Marker nur dann zulässig, wenn man sich der Kopplung bewusst ist und die Ergebnisse sachkundig interpretiert. Das gilt für PV-Verwandtschaftsund Defizienzfälle gleichermaßen. Zu Beginn eines Abstammungsgutachtens ist es aber meist unbekannt, ob ein PV-Verwandtschaftsfall vorliegt. Das Fehlerrisiko von gekoppelten Markern wird zusätzlich am Beispiel eines Defizienzfalles dargestellt. Wir ergänzen unseren Vortrag durch ein Poster über eine Datenbankrecherche zum Markermapping (Lieske et al.).

\author{
V-43 \\ WAS SAGT DER ERSTE EINDRUCK AUS? - \\ FORENSISCHE PHOTOGRAMMETRIE (FPHG) \\ UND DIE AUSWERTUNG VON BISSSPUREN \\ Brüschweiler $\mathrm{W}^{1)}$, Braun $\mathrm{M}^{1)}$, Markwalder $\mathrm{Th}^{2)}$, Thali $\mathrm{MJ}^{2)}$, Yen $\mathrm{K}^{2)}$, \\ Zollinger $\mathrm{U}^{2)}$ \\ 1) Wissenschaftlich-Technischer Dienst Stadtpolizei Zürich, \\ ${ }^{2)}$ Institut für Rechtsmedizin Universität Bern
}

FPHG ist bei Auswertungen von Bissspuren grundsätzlich bei den Overlay-Methoden einzureihen. Das Verfahren hat aber gegenüber allen anderen entsprechenden Methoden einen wesentlichen Vorteil: der Vergleich findet im virtuellen Raum statt mittels $3 \mathrm{D}$-Modellen des Gebisses und der Bissverletzung. Das FPHG-Verfahren erleichtert dem Untersuchenden die Interpretation des Spurenbildes wesentlich. Die Entscheidungsfindung unterliegt aber - wie bei allen andern Vergleichsmethoden - einer gewissen Subjektivität. Darin liegt eine mögliche Fehlerquelle.

Die Form einer Bissverletzung auf dem Rücken eines Opfers liess auf einen dynamischen Ablauf des Beissens schliessen. Dieses Verletzungsbild wurde auf Übereinstimmungen mit dem Gebissabdruck eines Tatverdächtigten verglichen. Wir fanden gute Übereinstimmungen. Vorliegende Abweichungen glaubten wir auf die Dynamik zurückzuführen zu können. Die Möglichkeit einer Spurverursachung durch die fragliche Person bejahten wir daher.

Bei der Überprüfung des Gebissabdruckes eines weiteren Tatverdächtigten stiessen wir aber auf eine fast „lückenlose“ Übereinstimmung. Auffällig war, dass die Übereinstimmung besonders ausgeprägt war im Bereich des ersten Kontaktes der Frontzähne mit der Haut. Somit in einem Bereich, in dem die formliche Ausprägung der Bissspur noch nicht wesentlich beeinflusst wird durch die gesamte Ablaufdynamik des Geschehens.

Anhand der jetzt vorliegenden Erkenntnisse wurde die erste Person vom Tatverdacht entlastet, die nachfolgend überprüfte jedoch sehr stark belastet.

Somit steht fest: Nicht der erste Eindruck, den man bei der vergleichenden Überprüfung einer Bissspur gewinnt, ist der wesentlichste sondern der erste Eindruck, den die Zähne in der Haut hinterlassen.
V-44

DER FEHLERFREIE TOXIKOLOGE

MUSS DIE FEHLER NICHT SELBER MACKEN, ER MUSS SIE NUR ENTDECKEN!

Iten PX

Institut für Rechtsmedizin Universität Zürich

Nur wer nichts tut, macht keine Fehler. Da wir alle etwas tun, sind es die andern, die die Fehler machen, wir natürlich nicht! Wir machen sie nicht, wir entdecken sie!

Nur die andern (z.B.im Spital oder bei der Polizei) schreiben nicht auf das Röhrchen, was die gelbe Flüssigkeit darin wirklich ist und wann sie asserviert wurde. Nur die andern schicken blauen Urin zur Analyse ein und glauben dem Toxikologen nicht, dass der Proband an einer WC-Enten-Vergiftung gestorben ist. Oder lebt er gar noch? War es vielleicht ein Sturz aus dem Fenster mit tödlichen Verletzungen, wie der Pathologe schon vor dem Studium des Toxgutachtens wußte.

Nur die andern finden an einem Knochen Ecstasy, obwohl er ursprünglich keines daran hatte. Kontaminationen sind bei uns doch kein Thema.

Und nur ein einziger Krankenpfleger schaffte es nicht, 50 Gramm Brusthaare für die Kokain-Analysen abzuscheren, weil er Milligramm mit Gramm verwechselte. Deshalb wäre es besser (oder ist es bei Ihnen schon üblich?), nur Zahlen ohne Einheiten zu verwenden.

Selbstverständlich verwenden wir alle moderne Geräte und Methoden und machen damit perfekte Analysen, und wenn ein Giftstoff im Blut nicht gefunden wird, dann ist er nicht drin. Das beweist auch die $\mathrm{Ne}-$ gativ- und Positivkontrolle, die wir alle mitführen. GLP, Zertifizierung und Akkreditierung sind für uns doch keine Fremdwörter. Und was ist, wenn sich der Wirkstoff im Blut oder in der Leiche vollständig zersetzt hat? Und wir (persönlich) haben noch nie etwas von dieser Zersetzung gehört oder die ganze Wissenschaft weiß noch nichts davon?

\section{V-45}

\section{AUSGEWÄHLTE FEHLERQUELLEN}

IN DER FORENSISCHEN TOXIKOLOGIE

Kauert G

Institut für Forensische Toxikologie, Zentrum der Rechtsmedizin, Klinikum der J. W. Goethe-Universität, Frankfurt am Main

„Man soll jedoch von eigenen und fremden Fehlern niemals, am wenigsten öffentlich reden, wenn man nicht dadurch etwas Nützliches zu bewirken denkt." (J.W.Goethe, Dichtung und Wahrheit, II,10)

Für den Forensischen Toxikologen sollte es zwei Albträume geben: 1. Eine Vergiftung zu übersehen, d.h. nicht analysiert zu haben, was tatsächlich vorhanden ist und 2. eine solche nachgewiesen zu haben, obwohl sie gar nicht vorlag.

Während man sich bei der 1. Variante durch entsprechende Gutachtenformulierungen ( z.B.....soweit sie (die Gifte) durch die hier durchgeführten Untersuchungen erfasst werden,....) noch „absichern“ kann, muss man bei der 2. Variante schon überlegen, wie man von einem Befund wieder wegkommt.

Beide Varianten können fatale forensische Auswirkungen haben, daher kommt der kritischen Prüfung eines Ergebnisses und der darauf aufbauenden Bewertung eine besonders wichtige Bedeutung zu.

Als historisches Beispiel, welches gleichsam als Beginn der Forensischen Toxikologie betrachtet werden kann, ist die Erfindung der Marsh'schen Probe zum Nachweis von Arsen und ihre umstrittene Anwendung im Mordprozess gegen Marie Lafarge 1840 zu erwähnen. Doch auch in - und trotz - der modernsten analytischen Toxikologie gibt es Fehler- und Irrtumsmöglichkeiten. An 3 Fällen aus der eigenen Praxis werden Fehlerquellen exemplarisch dargestellt und deren Vermeidbarkeit diskutiert. Sie umfassen als Ursache die Analysentechnik, das Vorliegen konkurrierender Todesursachen sowie Lücken in der „chain of custody“. 


\section{Abstracts}

Die wichtigsten Strategien zur Minimierung von Fehlern und Irrtümern in der Forensischen Medizin / Toxikologie finden sich in den derzeit zu etablierenden Qualitätsmanagment-Handbüchern der Forensischen Institute im Rahmen der Akkreditierung.

Doch bei allem Fortschritt gilt: „ Cuiusvis hominis est errare, nullius nisi insipientis in errore perseverare"

(Jeder Mensch kann irren, Unsinnige nur verharren im Irrtum), Cicero: Philippicae orationes.

\section{$\mathrm{V}-46$ \\ TÖDLICHE INTOXIKATION ODER NATÜRLICHER TOD ? \\ Käferstein H, Pluisch F, Sticht G \\ Institut für Rechtsmedizin der Universität zu Köln, \\ Maleatengürtel 6o, Köln}

Eine 93jährige Patientin einer Pflegestation eines Altenheims wurde wegen Dekubiti mit starken Schmerzen in ein Krankenhaus eingeliefert. Dort verstarb sie $5 \frac{1}{2}$ Tage später. Es wurde ein natürlicher Tod bei Herzinsuffizienz, Koronarsklerose und Infektion bei Dekubitus bescheinigt. Bei der gerichtlichen Leichenöffnung zur Klärung einer unterlassenen Hilfeleistung wurde als Todesursache „Lungenentzündung “festgestellt. Die chemisch-toxikologischen Untersuchungen erbrachten den Nachweis von Tramadol, Methylaminophenazon, Maprotilin und Metoclopramid. Tramadol wurde in den verschiedenen Organen und Körperflüssigkeiten quantifiziert, es ergaben sich folgende Konzentrationen: Herzblut 30,1 mg/L, Femoralvenenblut $18,6 \mathrm{mg} / \mathrm{L}$, Hirn 17,7 mg/kg, Leber 38,6 mg/kg, Niere 86,3 mg/kg, Psoasmuskel 16,9 mg/kg, Brustmuskel 22,9 mg/kg.

Infolge sehr starker Schmerzen hat die Patientin offenbar hochdosiert Tramadol erhalten, ohne daß sich dies aus den Krankenunterlagen allerdings zweifelsfrei nachvollziehen läßt. Die Tramadolkonzentrationen könnten den Todeseintritt infolge einer Intoxikation zwanglos erklären, denn sie liegen weit oberhalb des therapeutischen Bereichs und sind vergleichbar mit einer in der Literatur beschriebenen tödlichen Tramadolvergiftung. Ohne entsprechende Kooperation zwischen Toxikologie und Morphologie könnte daher der Schluß gezogen werden, die Patientin sei vergiftet worden. In der Gesamtschau aller Befunde wird man dagegen von einem protrahiert verlaufenden septischen Schock im Zusammenhang mit einem ausgedehnten Dekubitalulcus und finaler Bronchopneumonie ausgehen müssen.

\section{$\mathrm{V}-47$}

MOLEKULARBIOLOGISCHE UNTERSUCHUNGEN

ZUM PROBLEM DER ETHANOLELIMINATION -

EINGRENZUNG VON IRRTUMERN

IN DER ALKOHOLBEGUTACHTUNG?

Weirich $\mathrm{V}^{1}$, Broese $\mathrm{T}^{2}$, Jaster $\mathrm{R}^{3}$, Koczan $\mathrm{D}^{4}$, Schläfke $\mathrm{D}^{2}$, Schmid $\mathrm{G}^{2}$, Schulz $\mathrm{M}^{2}$, Thiesen $\mathrm{HJ}^{4}$, Titz $\mathrm{K}^{2}$, Wegener $\mathrm{S}^{5}$, Weirich $\mathrm{S}^{2}$, Wegener $\mathrm{R}^{1}$

1 Institut für Rechtsmedizin

2 Klinik und Poliklinik für Psychiatrie und Psychotherapie

3 Institut für Medizinische Biochemie und Molekularbiologie

4 Institut für Immunologie

Medizinische Fakultät, Universität Rostock, Postfach 1008 88,

D-18055 Rostock;

5 DRK-Blutspende-Zentrale Rostock

Die rechtsmedizinische Alkohol-Begutachtung erfolgt in Deutschland nach den Vorgaben des Bundesgerichtshofes. In einschlägigen Trinkversuchen konnte jedoch gezeigt werden, daß in Einzelfällen die Ethanol-Abbauraten deutlich über den vorgegebenen Grenzwerten liegen. Gutachterliche Irrtümer sind daher nicht auszuschließen. Diese Erkenntnisse fanden bereits Eingang in einzelne Gerichtsentschei- dungen, demnach besteht eine gewisse Rechtsunsicherheit in puncto anzusetzender $\beta_{60}$-Werte.

In einer interdisziplinären prospektiven Studie wird - ausgehend von Ergebnissen aus Tierversuchen, die unter chronischer Ethanolexposition eine Aktivitätssteigerung des zentralen MEOS-Enzyms Cytochrom P450-2E1 (CYP2E1) im Lebergewebe ergaben - der Aktivierungszustand von $\mathrm{CYP}_{2} \mathrm{E} 1$ an peripher-venösem menschlichen Blut untersucht. Dazu wurden CYP2E1-spezifische Western blots sowie eine Methode zur Quantifizierung der CYP2E1-mRNA mittels RealTime-PCR auf dem TaqMan 7700 etabliert.

An einer Gruppe Alkoholkranker sowie einer Kontrollgruppe werden vergleichende Untersuchungen zur Expression von $\mathrm{CYP}_{2} \mathrm{E} 1$ in mononukleären Zellen des peripheren Blutes auf mRNA- und ProteinEbene durchgeführt.

Die bisherigen Ergebnisse werden in Hinsicht auf mögliche Ansätze zur Individualisierung der in der Alkoholbegutachtung anzusetzenden Grenzwerte diskutiert.

\section{$\mathrm{V}-48$}

FEHLER IN DER FORENSISCHEN CHEMIE ?

EINE DIE LANDESGRENZEN SPRENGENDE KASUISTIK

Logemann $\mathrm{E}^{1)}$, Wörth J ${ }^{2)}$, Warth $\mathrm{C}^{2)}$, Aebi B ${ }^{3)}$, Regenscheit $\mathrm{P}^{3)}$, Bernhard $\mathrm{W}^{3}$ )

1) Institut für Rechtsmedizin der Universitätsklinik, D-79104 Freiburg/Brsg

2) Chemisches Institut der Universität, D-79104 Freiburg/Brsg

3) Institut für Rechtsmedizin der Universität, $\mathrm{CH}-3012$ Bern

Ein Lederwarengeschäft in Südbaden orderte bei einer italienischen Fabrik 10 Leder-Handtaschen, bekam aber statt der gewünschten Ware nur einen Karton mit ca. 25 Kilogramm granulatähnlichem Verpackungsmaterial geliefert. Der badische Geschäftsinhaber informierte die Polizei, die den Sachverhalt protokollierte und den Karton mit dem Verpackungsmaterial mit aufs Revier nahm. Ein französischer Polizeibeamter, der dort hospitierte, äußerte die Vermutung, dass Rauschgift im Spiel sein könnte. Die auf dem Polizeirevier verfügbaren Drogen-Schnelltests ergaben jedoch ein negatives Resultat. Da der französische Beamte Fragen nach der Beweissicherheit und Qualität dieser Tests stellte, wurde eine kleine Probe dieses Verpackungsmaterials (ca. 2 Gramm kleine, weisse, granulatähnliche Brocken, dem äusseren Aussehen nach zerbrochene Marmorstücke) zur Gerichtsmedizin gebracht mit der Bitte um eilige Schnelltests auf Drogen und dem ausdrücklichen Wunsch, keine Tagebuchnummer anzulegen, keine Analysen mit schwerem Gerät - GC/MS, HPLC etc. - auszuführen und keine Liquidation zu erstellen. Nachdem auch diese Schnelltests auf Betäubungsmittel negativ verlaufen waren, wurde auf weitergehende Analysen von Seiten der Polizei verzichtet, das restliche zur Untersuchung mitgebrachte Probenmaterial (weniger als 2 Gramm) dem Institut grosszügig zur Vernichtung überlassen. Die wissenschaftliche Neugier des Chemikers führte dann zu einem Analysenresultat, das den Polizeibeamten telefonisch mitgeteilt wurde. Daraufhin wurde ein Staatsanwalt vom Sachverhalt informiert und der Karton mit dem restlichen Verpackungsmaterial vom städtischen Polizeirevier zur Kriminalpolizei gebracht. 


\section{V-49}

FEHLER UND IRRTÜMER

IN DEN FORENSISCHEN WISSENSCHAFTEN -

FORENSISCHE HISTOLOGIE

Betz P

Institut für Rechtsmedizin der Universität Erlangen-Nürnberg,

Universitätsstr. 22, 91054 Erlangen

Die Histologie trägt über den Nachweis makroskopisch nicht-faßbarer pathologischer Veränderungen wesentlich zur Absicherung von Verdachtsdiagnosen, die bei der Obduktion formuliert wurden, bei. Mitunter liefert sogar erst die mikroskopische Untersuchung das morphologische Korrelat einer todesursächlichen Schädigung oder aber trägt zumindest über den „Aus-schluß“ relevanter krankhafter Befunde an den inneren Organen zur abschließenden Beurteilung des konkreten Falles bei.

Das Ergebnis der mikroskopischen Untersuchungen wird nicht nur von der Erfahrung des Gutachters bestimmt, sondern von einer Vielzahl weiterer Faktoren beeinflußt. In diesem Zusammenhang ist insbesondere auf die Bedeutung der richtigen Asservierung und Aufarbeitung des Untersuchungsmaterials sowie auf die Auswahl geeigneter Färbemethoden hinzuweisen. Da gerade die immunhistochemische Darstellung bestimmter Antigene die spezifische Erfassung eines Parameters erlaubt und damit häufig anderen Verfahren der Routinehistologie bzw. der Enzymhistochemie überlegen ist, gewinnen diese Methoden auch in der forensischen Begutachtung zu Recht zunehmend an Bedeutung. Je aufwendiger und komplizierter ein Verfahren ist, umso größer wird erfahrungsgemäß aber auch die Anfälligkeit gegenüber Artefakten.

Im Rahmen dieses Vortrages sollen nun prinzipielle Fehlerquellen, die bei der forensisch-histologischen Begutachtung zu berücksichtigen sind, aufgegriffen werden, wobei exemplarisch u.a. Fehlermöglichkeiten bei der Interpretation reaktiv-infiltrativer Veränderungen sowie Artefakte bei immunhistochemischen Färbungen angesprochen werden sollen.

\section{V-50}

ZUR QUALITÄTSSICHERUNG HISTOLOGISCHER DIAGNOSTIK I: HISTOLOGISCHE LUNGENBEFUNDE BEI 3 TODESURSACHEN Ehrlich E, Bockholdt B, Busch K, Maxeiner H

Institut für Rechtsmedizin, FU Berlin, Deutschland

Obwohl histologische Lungenbefunde wiederholt dargestellt und diskutiert wurden, gibt es dennoch wenige vergleichende Untersuchungen. Empfehlungen zur nötigen Anzahl oder zur Auswahl der geeigneten Entnahmestellen fehlen praktisch. Um eine möglichst objektive Basis für den nachfolgenden Untersucher-Test zu erarbeiten, wurden von je 15 Todesfällen durch Erhängen, Ertrinken bzw. primäres kardiales Versagen Präparate von 8 definierten Positionen entnommen und im konventionellen Paraplastpräparat nach H.E.Färbung untersucht. Halbquantitativ beurteilt wurden: Luftgehalt bzw. Blähungszustand, Ödem, Füllung der Alveolarkapillaren. Ausgezählt wurde die Anzahl an Blutgefäßen mit einem vermehrten Vorkommen leukozytärer Zellen oder Mikrothromben.

Beim Lungenödem, Blähungszustand und der Kapillarfüllung lagen die Ergebnisse der Fallgruppen „Herztod“ und „Erhängen“ dicht beieinander, während sich das Ertrinken in allen Parametern signifikant $(\mathrm{p}<0,05)$ von diesen beiden Gruppen unterschied. Bei der Berücksichtigung der Topographie waren bei allen Todesursachen das Ödem sowie der Füllungszustand der Alveolarkapillaren in den dorsalen Anteilen in deutlich mehr Gesichtsfeldern stark ausgeprägt als in den ventralen, während zwischen Ober- und Unterlappen keine nennenswerten Unterschiede bestanden. Das Merkmal „intravasal vermehrt weisse Blut- bzw. Knochenmarkszellen“ war bei $60 \%$ aller Fälle negativ und nur bei etwa $5 \%$ zahlenmässig auffällig. Intravasale Thrombozytenaggregate selbst geringster Ausprägung fanden sich überhaupt nur in knapp 6\% aller Fälle und waren daher für eine Unterscheidung von vorneherein nicht geeignet.

Aufgrund einfacher, routinemäßig zu erhebender Merkmale im konventionellen histologischen Präparat besteht daher anscheinend nur eine geringe Möglichkeit, zwischen Herztod und Erhängen zu unterscheiden.

\section{V-51}

ZUR QUALITÄTSSICHERUNG HISTOLOGISCHER DIAGNOSTIK II: DIE DIAGNOTISCHEN FEHLERQUOTEN BEI UNTERSUCHERN VERSCHIEDENER FORMALER QUALIFIKATION

Bockholdt B, Ehrlich E, Busch K, Maxeiner H

Institut für Rechtsmedizin, FB Humanmedizin, Freie Universität Berlin, Deutschland

Je 8 histologische Präparate aus definierten Entnahmelokalisationen von 15 Todesfällen durch Erhängen, Ertrinken bzw. primäres kardiales Versagen wurden von 4 Untersuchern analysiert (Medizinstudentin, Arzt in Facharztausbildung, Fachärztin für Rechtsmedizin sowie Professor für Rechtsmedizin). Die Untersucher kannten das Todesursachenspektrum, ohne jedoch die zufällig ausgewählten Präparate in ihrer Herkunft identifizieren zu können. Die in der einschlägigen Literatur als für diese Fallgruppen charakteristisch beschriebenen histologischen Merkmale lagen als Merkblatt jedem Präparatetablett bei.Die Auswertung erfolgte nach der jeweiligen Trefferquote (richtige Todesursache erkannt), unter Berücksichtigung der 4 Untersucher, der Lokalisation der Präparate sowie der Todesursache.

Die Todesursachen Herztod, Ertrinken und Erhängen wurden in $72 \%$ (je nach Untersucher zwischen $61 \%$ und $82 \%$ ) bzw. 60\% (50-69\%) bzw. $37 \%$ (30-46\%) der Einzelbewertungen richtig angegeben. Beim Herztod war die Trefferquote in den dorsal gelegenen Präparaten deutlich höher als in den ventralen; beim Ertrinken war dies gegenteilig. Beim Erhängen war ein solcher Unterschied nicht festzustellen. Verwertbare Unterschiede zwischen den Ober- und Unterlappen bestanden nicht. Eine Beziehung zwischen der formalen Qualifikation des Untersuchers und der Anzahl richtiger Diagnosen wurde nicht festgestellt. Dieser Teil der Untersuchung zeigte, dass die meisten histologischen Lungenveränderungen sehr unspezifisch sind und sich für eine Differentialdiagnose selbst so unterschiedlicher Todesursachen kaum eignen. In einem zweiten Test wurden den Untersuchern alle 8 Präparate mit ihrer Lokalisation, jedoch ohne Todesursache übergeben. Das diagnostische Resultat war diesmal weniger enttäuschend. Wenn man also zum Hilfsmittel „Histologie“ greift, so reichen zumindest wenige Lungenpräparate (nicht reproduzierbarer Lokalisation) nicht aus.

\section{V-52}

SIND EIN PAAR SCHNITTE GENUG? -

HISTOLOGISCHE BEFUNDE BEI „CARDIAL GESUNDEN“

Dumser T, Krämer M

Flugmedizinisches Institut der Luftwaffe

Abteilung V - Rechtsmedizin und Flugunfallmedizin, D-82242 Fürstenfeldbruck

Im Hinblick auf den gesetzlich festgelegten Zweck von Flugunfalluntersuchungen, nämlich die umfassende Klärung der Ursache(n) zur Vermeidung weiterer Unfälle wird von uns im Rahmen der flugunfallmedizinischen Untersuchung $u$. a. das Herz bei getöteten Luftfahrzeug-Besatzungsmitgliedern zum sicheren Ausschluß cardialer Ereignisse gründlich untersucht. Routinemäßig erfolgt die Präparation und histologische Aufarbeitung der Coronarien und die Entnahme von zunächst 19 Proben aus allen Abschnitten des Myocards einschließlich des Reizleitungssystems. Abhängig von den Befunden 
an diesem Material erfolgt eine weitere Aufarbeitung, z.B. die vollständige Einbettung des Herzkammerseptums mit dem Reizleitungssystem und Befundung von ca. 2000 Schnitten.

Immer wieder finden wir Befunde, die aus rechtsmedizinischer Sicht Relevanz für das jeweilige Flugunfallgeschehen gehabt haben können. Es werden Beispiele vor dem Hintergrund des Flugunfallablaufes in Verbindung mit ärztlichen Befunden kurz diskutiert.

Relevante Befunde wären uns wahrscheinlich entgangen, wenn wir bei fehlendem „Anfangsverdacht“ - nur einzelne Proben aus dem Herzen untersucht hätten. Wir halten deshalb eine Beschränkung der rechtsmedizinisch-histologischen Untersuchung des Herzens auf einzelne Proben für unzureichend, wenn das Vorliegen cardialer Veränderungen sicher ausgeschlossen werden muß.

Der Untersuchungsumfang lohnt aber auch bei klinischen Sektionen: Bei einer von uns durchgeführten Obduktion konnte durch die in gleicher Weise erfolgte Untersuchung des Herzens eine tuberkulöse Myokarditis bei einer Lungentuberkulose nachgewiesen werden. Dieser nach der Literatur seltene Befund wurde durch den molekularbiologischen Nachweis von Tuberkelgenom im Paraffinschnitt eindrucksvoll untermauert und erklärte den klinisch unklar gebliebenen Krankheitsverlauf mit zunehmendem allgemeinen Verfall trotz Remission der pulmonalen Infiltrate unter Tuberkulostase.

\section{V-53}

DIE GEBURTSASPHYXIE ALS VORLÄUFIGE URSACHE

VON KINDLICHEN HIRNSCHÄDEN?

Schneider $\mathrm{H}$

Frauenklinik, Inselspital Bern

Der Zusammenhang zwischen einem Sauerstoffmangel während der Geburt und der Entstehung von kindlichen Hirnschäden wurde bereits in der 1. Hälfte des 19. Jahrhunderts von dem englischen Orthopäden W.J. Little postuliert. Ende der 6oer- und Anfang der 7oerJahre des vorigen Jahrhunderts wurde durch die Entwicklung von neuen Technologien wie der kontinuierlichen elektronischen Aufzeichnung der Herzfrequenz des Feten sowie der Analyse von Blutproben aus dem fetalen Skalp während der Eröffnungs- und Austreibungsphase der Geburt die Voraussetzung zur Früherkennung der Entstehung einer Hypoxie beim Feten geschaffen. Die Chance, durch die frühzeitige Entbindung im Einzelfall die Entstehung einer Geburtsasphyxie mit ihren Folgen zu vermeiden, führte zu einer raschen Verbreitung der neuen Überwachungstechniken. Während für das Absterben des Feten unter der Geburt ein deutlicher Rückgang gezeigt werden konnte, blieb die Prävalenz kindlicher Hirnschäden einschliesslich der Cerebralparese (CP) konstant. Kindliche Entwicklungsstörungen und die daraus resultierenden Behinderungen galten lange als unvermeidbar und wurden als schicksalhaft von den betroffenen Eltern angenommen. Nach der Einführung der modernen Überwachungsmethoden war eine markante Zunahme von Haftpflichtprozessen gegen Geburtshelfer festzustellen. Immer häufiger, wenn sich die als zunehmend selbstverständlich angenommene Erwartung eines gesunden Kindes nicht erfüllte, wurde die Frage nach Versäumnissen und Fehlern im Zusammenhang mit der Geburtsleitung gestellt. Diese Entwicklung fand ihren Niederschlag in einem Anstieg der Haftpflichtprämien, die im Vergleich zu anderen Fachgebieten der Medizin in der Geburtshilfe astronomische Dimensionen erreichten. Erst durch verschiedene Fall-Kontrollstudien der letzten 2 Jahrzehnte ist zunehmend deutlich geworden, dass unter den verschiedenen Entwicklungsstörungen auf der Basis eines kindlichen Hirnschadens nur die spastisch-motorische Bewegungsstörung im Sinne einer CP-Folge einer Geburtsasphyxie sein können. Als weitere wichtige Erkenntnis ist festzuhalten, dass die CP keineswegs spezifisch für eine Geburtsasphyxie ist, sondern Folge einer Vielzahl unterschiedlicher Störungen, die teilweise lange vor der Geburt im Verlaufe der Schwangerschaft wirksam werden, sein kann. Inzwischen wurden verbindliche Kriterien und Merkmale definiert, anhand derer im Einzelfall festgelegt werden kann, ob eine Geburtsasphyxie als Ursache einer CP angeschuldigt werden kann. 2/3 aller Fälle von CP entwickeln sich nach einer Geburt am Termin und lediglich bei 10-15\% kann eine Geburtsasphyxie für die Entstehung verantwortlich gemacht werden. Diese Zusammenhänge sind von hoher forensischer Relevanz.

\section{V-54}

\section{FEHLER UND FEHLERQUELLEN}

IN DER GERICHTSARZTLICHEN PRAXIS

EIN BEITRAG ZU CASE-MANAGEMENT

UND QUALITATSKONTROLLE

IN DER FORENSISCHEN PATHOLOGIE

Lignitz E

Institut für Rechtsmedizin,

Ernst-Moritz-Arndt Universität Greifswald

Die strukturellen und finanziellen Probleme des Gesundheitswesens im Zeitalter der Globalisierung und Fusionierung sind kaum zu übersehen. Sie werden von den Ausübenden der Heilberufe gemeinhin als Druck von außen empfunden, unter dem weiter fehlerfrei Höchstleistungen erwartet werden. Die gleichzeitigen, vielfach überzogenen Erwartungen der Leistungsempfänger führen dazu, daß jeder Fehler, jeder Irrtum, jede Komplikation und alle Therapieversager sogleich auf den Prüfstand gelangen und häufig auf dem Klageweg verfolgt werden und zwar mit der unverkennbaren Absicht, geldwerten Vorteil aus etwaigen Versäumnissen zu schlagen. So nimmt es nicht Wunder, daß allenthalben Diagnostik- und Therapiestandards ins Kraut schießen und Qualitätskontrollen und Fehleranalysen immanenter Bestandteil aller medizinischen Disziplinen sind. Objektive Prüfungen (Gutachten) wiederum zeigen, daß mancher Anspruch berechtigt ist.

Dem Grundsatz nach gilt das alles auch für die Rechtsmedizin. Indessen sind praktisch nur in den naturwissenschaftlichen Zweigen des Faches Ringversuche und anderweitige Qualitätskontrollen zur Regel geworden.Zertifizierungen und Akkreditierungen beginnen sich erst durchzusetzen, wiewohl auffällt, wie schnell sich Personen und Institutionen als Prüfinstanzen dafür als qualifiziert empfehlen, gewissermaßen die Marktlücke erkennend.

Über Fehler in der Medizin zu reden ist also längst kein Tabuthema mehr. Es ist jedoch noch keineswegs die Regel. Das Generalthema „Fehler in der Rechtsmedizin“ dieser Tagung hat ja auch nicht überall große Freude ausgelöst. Auch die Tatsache, daß die „Primerspeaker“ die Fehlerdiskussion, die ja erst in Gang kommen soll, dadurch kultivieren und unter Kontrolle halten sollen, daß nur aus „eigenen“ Fehlern Schlußfolgerungen gezogen werden dürfen, belegt überdeutlich, daß die Gerichtsmediziner selbst erst am Anfang stehen.

$\mathrm{Daß}$ in der rechtsmedizinischen Routinetätigkeit Fehler vorkommen (können), ist schon dadurch belegt, daß gelegentliche sog. Nachobduktionen Befunde aufdecken, die unbekannt geblieben waren. Zwangsläufig führt das zu anderen Betrachtungen von Todesursachen, der Kausalität bestimmter Ereignisse für den Todeseintritt, über Tatabläufe u.a.m. Schon 1956 hat Moritz die klassischen Fehler in der forensischen Pathologie systematisiert. Verf. stellt an einer Reihe von Fehlern (eigenen und selbst erlebten!) dar, wie sie entstanden, welche Folgen sie hatten und wie sie zu vermeiden sind. Die „alltäglichen“ Fehler scheinen grundsätzlich vermeidbar zu sein. Jedoch sind weitere Fehlerquellen zu antizipieren, die sich aus Ausbildungsmängeln, persönlicher Nicht-Eignung (bei gesicherter Lebenszeitstellung!), Überforderung, Fehleinschätzung der eigenen Sachkunde und Kompetenz speisen werden. Als essentiell störend werden sich immer wieder Charakterzüge erweisen, die sich als Unfehlbarkeit, Kritikunfähigkeit, Überschätzung, mangelhafte Dialogfähigkeit und vorgefaßte Meinung erweisen. 
Die Väter unserer Strafprozeßordnung haben einiges weise vorhergesehen, indem sie 2 Obduzenten für eine gerichtliche Sektion festschrieben und Juristen und Ärzte gleichzeitig bei der gerichtlichen Leichenschau einsetzten. Alles konnten sie nicht ahnen. Insoweit ist jede Überlegung in Richtung Globalisierung und Fusionierung für die Rechtsmedizin als potentielle Fehlerquelle solange abzulehnen, wie sie zu einer Schwächung des Faches führt, d.h. zwangsläufig zu Lasten der Sorgfalt und Qualität dieser wichtigen Arbeit an der Grenze von Medizin und Recht geht.

\section{V-55 \\ PRESSEARBEIT: EIN FEHLER IN DER RECHTSMEDIZIN? FALLBERICHTE AUS DEN MEDIENSTÄDTEN KÖLN UND NEW YORK. \\ Benecke $\mathrm{M}$ \\ International Forensic Research \& Consulting, \\ Postfach 250411, D-50520 Köln}

Darstellungen in foro sind eine ursprüngliche Selbstverständlichkeit der Rechtsmedizin. Im deutschsprachigen Raum wird dies vorwiegend als Verpflichtung zu öffentlichen Stellungnahmen vor Gericht verstanden. Andererseits verstärkt sich in der westlichen Welt das Publikumsbedürfnis, auch in Massenmedien über forensische Arbeitsabläufe informiert zu werden.

Vier aktuelle und zwei weiter zurückliegender Fälle aus den von TVund Radiosendern sehr dicht besiedelten Großstädten Köln und New York (Manhattan) sollen daher schlaglichtartig beleuchten, ob und ggf. wie die Arbeit mit PressevertreterInnen gesteuert und ggf. in eine wünschenswerte Richtung gebracht werden kann: (1) Haar-Analysen im Fall des Fußballtrainers Christoph Daum (Kokaingebrauch, Flucht in die USA, dort angebliche toxikologische Nachuntersuchung, inhaltliche Manipulationen in Massenblättern), (2) der Fall der von der Presse so genannten „Mumie im Horrorhaus“ (Liegezeit 13 Monate (Bestimmung über Insektenhäute), Fragen nach urbaner Nachbarschaft), (3) eine Spiegel-TV-Dokumentation über die Arbeit des Kölner Kriminalkomissariats für Tötungsdelikte (mit kurz darauf folgenden Klagen wegen Hausfriedensbruch, Beleidigung, Amtsanmaßung, Rechtsbeugung und Verunglimpfung des Ansehens Verstorbener), (4) Verdacht auf Kokaingebrauch und sexuelle Handlungen an Minderjährigen durch den ehemaligen Sprecher des Festkomitees des Kölner Karnevals (systematischer Aufbau eines Zeugen durch die lokale Boulevardpresse), (5) Gerüchte um die Entlassung des Direktors des Manhattener Instituts für Rechtsmedizin wegen Auskünften zum Todesfall eines Mitgliedes der Familie Rockefeller (Öffentlichkeitsbeteiligung angeblich politisch unerwünscht) und (6) Serienvergewaltigungen in Manhattan (Vorbeugung des Bekanntwerdens ermittlungswichtiger Tatsachen).

\section{V-56}

VERBLUTEN INFOLGE INTRAOPERATIVER SCHLAGADERVERLETZUNG ODER DEGENERATIVER GEFÄßERKRANKUNG?

Keil W, Mall G, Peschel O, Eisenmenger W

Institut für Rechtsmedizin der Ludwig-Maximilians-Universität, München

Bei einer 35-jährigen augenscheinlich gesunden Erstgebärenden mußte aus kindlicher Indikation eine Not-Sectio durchgeführt werden. Ursache war offenbar eine plötzlich aufgetretene Plazentainsuffizienz. Einen Tag nach der erfolgreichen Sectio war eine Nachoperation der Bauchdecke notwendig, da sich aus einem subfaszialen Redon $700 \mathrm{ml}$ Blut entleert hatten. Nachdem sich der Zustand der Betroffenen in den folgenden Tagen stabilisierte, kam es am Nachmittag des 7. postpartalen Tages zu einer erheblichen Verschlechterung, insbesondere traten zunächst Bauchschmerzen auf. In den Abendstun- den dieses Tages wurde die Patientin schließlich bewußtlos. Bei einer Not-Laparotomie wurde reichlich Blut in der Bauchhöhle festgestellt, eine Blutungsquelle fand sich nicht. Die Patientin verstarb. Bei der Obduktion wurden zwei nicht frische 2,6 cm bzw. 2,9 cm lange scharfrandige Läsionen der rechten A. iliaca interna festgestellt, die im Zentrum einer in die Bauchhöhle durchgewühlten retroperitonealen Blutung lagen. Dieser Befund und die Gesamtumstände des Falles (Ermittlungen betrafen auch etwaigen Alkoholmißbrauch des Operateurs) waren zunächst dafür richtungweisend, daß eine intraoperative Verletzung mit protrahierter Nachblutung als Ursache der Geschehnisse in Betracht gezogen wurde. Erst die histologische Untersuchung zahlreicher Arterien erbrachte, daß bei der Betroffenen eine extrem seltene degenerative Erkrankung der Media im Beckenbereich vorlag, wodurch Spontanrupturen der Gefäße erklärt werden konnten. Demzufolge mußte der Grundtenor des vorläufigen Gutachtens revidiert werden. Die zunächst geäußerte Vermutung, es könne sich um einen ärztlichen Kunstfehler handeln, wurde verworfen. Die Möglichkeit der Spontanruptur von Arterien stand auch mit operationstechnischen Überlegungen im Einklang, die eine Verletzung der A.iliaca interna im Rahmen einer Sectio kaum wahrscheinlich machten.

\section{V-57}

PROBLEME UND FEHLER VON RECHTSMEDIZIN

UND UNTERSUCHUNGSBEHÖRDEN IM KONTAKT

MIT ANGEHÖRIGEN VON VERSTORBENEN

Plattner T, Zollinger U,

Institut für Rechtsmedizin der Universität Bern

In einer laufenden Untersuchung werden brieflich erreichbare Angehörige am Institut für Rechtsmedizin der Universität Bern obduzierten Verstorbenen, nachträglich mittels eines Fragebogens zu ihren Erfahrungen im Umgang mit Untersuchungsbehörden und Rechtsmedizin befragt.

Schwerpunkte der Befragung waren die Akzeptanz der rechtsmedizinischen Obduktion und die Qualität der Information über Untersuchungsresultate.

Bis zum jetzigen Zeitpunkt wurde der Fragebogen von 51 Angehörigen beantwortet. Daraus ergeben sich folgende Zwischenresultate: Rund die Hälfte der befragten Parteien gab an, den Entscheid zur Durchführung einer Obduktion von Anfang an begrüsst zu haben, ein Drittel machte eine indifferente Haltung geltend und nur wenige (15\%) standen einer Obduktion ablehnend gegenüber. Grossmehrheitlich wurden die Angehörigen zufriedenstellend über die Ergebnisse der Obduktion durch die Rechtsmedizin oder die Untersuchungsbehörde orientiert. Lediglich fünf der Befragten gaben an, die Information sei ungenügend bzw. unverständlich gewesen.

Konkrete Kritikpunkte bezogen sich darauf, dass die Information über die Untersuchungsergebnisse nicht ungefragt an die Angehörigen geht. Mehrfach wurde von Angehörigen geltend gemacht, sie hätten den raschen Abtransport vom Leichenfundort ins Institut für Rechtsmedizin als belastend empfunden und hätten sich mehr Zeit zum Abschiednehmen gewünscht. Problematisch erscheint uns, dass acht der befragten Angehörigen vorgängig überhaupt nicht darüber informiert wurden, dass eine Obduktion durchgeführt werden würde. 


\section{V-58}

PROGRAMMFEHLER

BEI DER AUTOMATISCHEN BAK-BERECHNUNG:

HAARSCHARF AN EINER KATASTROPHE VORBEI!

Zollinger U, Dirnhofer R

Institut für Rechtsmedizin der Universität Bern,

$\mathrm{CH}-3012$ Bern/Schweiz

Anlässlich der periodischen externen Qualitätskontrollen der Alkoholanalysen des IRM Bern wurden geringfügige Abweichungen der ausgedruckten Resultate, nicht aber der einzelnen Analysenresultate festgestellt. Die Nachforschung zeigte den Fehler im EDV-Programm. Im Rahmen einer Umstellung zum Jahreswechsel war der Umrechnungsfaktor für Blut von 0,944 „verloren“ gegangen, weshalb die abgegebenen Resultate um 5,9\% zu hoch ausfielen. Bei der Entdeckung des Fehlers waren über einen Zeitraum von 2 Monaten bereits 726 Fälle bearbeitet und versandt worden.

Die neue, korrekte Berechnung zeigte auf, dass 12 Personen der Führerausweis zu unrecht entzogen worden war, weil der gesetzliche Grenzwert von $0,8 \%$ nun nicht mehr erreicht oder überschritten wurde. Zahlreiche weitere Personen waren aber ebenfalls vom Fehler betroffen, weil das Strafmass und die Dauer des Führerausweisentzuges vom Promillewert abhängt. Letzteres ist in den Kantonen unterschiedlich geregelt.

Wir entschlossen uns zu einer sofortigen Korrektur sämtlicher 726 Fälle und zu einer offenen Darlegung des uns unterlaufenen Fehlers gegenüber den Betroffenen, den Untersuchungsbehörden, den Strassenverkehrsämtern und der Öffentlichkeit. Dieses offensive Vorgehen wurde, obwohl mit einem immensen administrativen Aufwand verbunden, durch äusserst positive Reaktionen und einen Vertrauensgewinn ins Institut „entlöhnt“. Die einzige Schadenersatzforderung betraf eine Person, welche sich während der Dauer des ungerechtfertigten Führerausweisentzuges mit dem Taxi zur Arbeit fahren liess.

Es hat sich damit erneut gezeigt, dass eingestandene und sofort korrigierte Fehler keinen Image-Verlust für eine Institution bedeuten müssen.

\section{V-59 \\ AKKREDITIERUNG EINES RECHTSMEDIZINISCHEN INSTITUTES ALS INSTRUMENT ZUR FEHLERMINIMIERUNG IN DER FORENSISCHEN PRAXIS \\ Rittner C \\ Institut für Rechtsmedizin der Johannes Gutenberg-Universität Mainz, Am Pulverturm 3, D-55131 Mainz}

Das hiesige Institut hat das Akkreditierungsverfahren beantragt. Mit Inkrafttreten der ISO 17025 ist ein QM-Handbuch zu erstellen, das auf der Grundlage von Richtlinien auszuarbeiten ist, welche durch die einzelnen Fachgesellschaften ( DGRM, GTFCH u.a.) erstellt wurden. Mit positivem Abschluss des Verfahrens wird in zwei Jahren gerechnet. Mit Unterstützung einer Beratungsfirma werden derzeit SOP's und Verfahrensanweisungen ausgearbeitet. Mehrere Fachgesellschaften (ISFG, EFI u.a.) beabsichtigen, die Akkreditierung des Labors eines Gutachters als Zulassungsvoraussetzung in ihre Richtlinien aufzunehmen. Zuerkennung von Kompetenz an ein Institut/Labor setzt eine wirksame Fehlererkennungs-, korrektur- und -vermeidungsstrategie voraus. Fehler haben die verschiedensten Ursachen. Anhand der Betriebsabläufe sollen wesentliche,,Sollbruchstellen“ und Wege zu ihrer Beseitigung aufgezeigt werden. Aber: Irren ist menschlich!

\section{V-60}

\section{CRITICAL INCIDENTS: IRREN IST MENSCHLICH}

Kehrer B

Ostschweizer Kinderspital St.Gallen

Die moderne Medizin entwickelt sich mit einem Tempo wie nie zuvor und hat einen Stand erreicht, der vor wenigen Jahren kaum vorstellbar war. Möglich wurde dieser Fortschritt durch immer wirksamere und komplexere therapeutische Massnahmen, die zunehmend schwieriger zu überblicken und zu beherrschen sind. Nun birgt aber jede medizinische Handlung die Gefahr in sich, dem Patienten Schaden zuzufügen, beispielsweise durch unerwünschte Nebenwirkungen von Medikamenten, falschen Einsatz von therapeutischen Mitteln, technischen Mängeln an Geräten, Unkenntnis, Fehlleistungen und Fehlbeurteilungen, Verwechslungen etc.

Fehler sind bei uns ein Tabu und werden kaum diskutiert. Gründe dafür sind u.a.

- die Bevölkerung zieht es vor zu glauben, dass Fehler in der Medizin selten sind.

- Ärzte und Pflegepersonal haben Schwierigkeiten, mit Fehlern umzugehen, weil sie an sich selber hohe Ansprüche stellen.

- die Bedrohung durch rechtliche Konsequenzen hat massiv zugenommen.

- in unserer Kultur und Erziehung lernen wir, dass Fehler bestraft werden.

Primäre Massnahme zur Verhütung von Zwischenfällen muss sein, beim Personal Verständnis für die Probleme zu wecken und Voraussetzungen zu schaffen, dass wir über alle Fehlleistungen und Zwischenfälle informiert werden; dies unabhängig davon wie sie ausgegangen sind. Nur so können wir erkennen, wo die eigentlichen Probleme liegen und etwas dagegen unternehmen. Um dieses Ziel zu erreichen ist es entscheidend, dass es gelingt, die in unserer Erziehung und Gesellschaft verankerte "Schuldkultur“ zu überwinden und glaubwürdig eine neue „Kultur“ im Umgang mit Fehlern zu entwickeln.

Systeme, deren Zuverlässigkeit perfektes Funktionieren des Individuums voraussetzen, werden früher oder später versagen, weil niemand fähig ist, immer fehlerfreie Arbeit zu leisten. Wenn wir also Fehler vermeiden wollen, so müssen wir unsere Denkweise und Haltung Fehlern gegenüber grundsätzlich verändern. Die Erkenntnis muss sein: Menschliche Fehler sind häufig und unvermeidbar.

Fehler ergeben sich oft aus Faktoren, die sich unserer bewussten Kontrolle entziehen, aus Mängeln in unserem Arbeitssystem die geradezu dazu „verführen“ Fehler zu machen. Beispiele dafür sind falsch geplante Arbeitsabläufe, schlechte Arbeitsbedingungen oder ungenügende Ausbildung. Solch grundlegende Fehler im System zeigen sich oft erst dann, wenn sich ein den Patienten schädigender Fehler ereignet hat. Solche Fehler, die sich im System verborgen halten und sich erst unter ungünstigem oder zufälligem Zusammentreffen von Ereignissen zeigen, nennt man „latente Fehler“ (latent errors). Es sind primär nicht erkennbare aber schon vorher im System vorhandene Fehler, die gleichsam darauf lauern sich plötzlich durch einen „überraschenden Unfall“"zu manifestieren. Weil sie lange Zeit unerkannt im System vorhanden sein können, sind sie besonders gefährlich. Im Gegensatz zu den „latenten Fehlern“ stehen diejenigen Fehler, die auf einer klaren Fehlhandlung, Fehlleistung oder Fehlbeurteilung beruhen und die unmittelbare Auswirkungen zeitigen (mistakes). Sie sind leichter zu erkennen und auch einfacher zu vermeiden.

Sind systemimmanente Fehlerquellen erkannt, dann stellt sich die Frage was getan werden kann. Entscheidend ist, dass wir uns nicht auf die Fehlleistung konzentrieren, sondern auf die der Fehlleistung zugrunde liegende Ursache. Die Frage ist deshalb nicht „wer ist schuldig“, sondern „wo liegt der Fehler im System“, bezw. wo müssen wir Korrekturen ansetzen, damit der Fehler in Zukunft nicht mehr passieren kann. Mögliche Strategien können sein:

- Ersatz des (schlechten) Kurzzeitgedächnisses durch den viel verlässlicheren Computer 
- Rasche Verfügbarkeit der entscheidenden medizinischen Patientendaten (z.B. online)

- Prozesse so strukturieren, dass Fehler automatisch erkannt oder verunmöglicht werden.

- Standardisierung von Arbeitsabläufen

- Verbesserung der Ausbildung

- Änderungen in der Arbeitsumgebung (Gruppendynamik, Verantwortlichkeiten, Einsatzplanung, Zeitdruck)

- Verbesserung von medizintechnischen Geräten (z.B.bessere Ablesbarkeit, Anordnung der Bedienungselemente)

Eine effektive Fehlerprävention setzt also nicht beim 'schuldigen' Individuum an, sondern am zugrunde liegenden System.

'Change the system not the person!'

oder wie es J.Reason formuliert:"We cannot change the human condition, but we can change the conditions under which humans work“.

\section{V-61}

NEUE ENTWICKLUNGEN IN DER COMPUTERTOMOGRAPHIE FÜR UNTERSUCHUNGEN IN VIVO UND IN VITRO

Kalender WA

Institut für Medizinische Physik, Universität Erlangen

Die Röntgen-Computertomographie (CT) ist in der klinischen Radiologie heute fest etabliert. Sie hat seit ihrer Einführung in den frühen siebziger Jahren mehrere Entwicklungszyklen durchlaufen. Dabei wurden zwei Ziele kontinuierlich und erfolgreich verfolgt: die Erhöhung der Aufnahmegeschwindigkeit und die Verbesserung der Ortsauflösung. Die Einführung der Volumenaufnahmetechnik mit SpiralCT, die 1989 in Bern weltweit zum ersten mal klinisch zum Einsatz kam, stellte hierfür einen Durchbruch dar [1].

In diesem Vortrag werden die neuesten Entwicklungen im Bereich der CT vorgestellt und diskutiert. Hierzu gehören neue Komponenten wie Mehrschicht- und Flächendetektoren und neue Rekonstruktionsverfahren für die Spiral-CT. Diese erlauben inzwischen Aufnahmen ganzer Organe in typischerweise $10-20$ Sekunden bzw. "Ganzkörper"-Aufnahmen in weniger als 1 Minute ohne Nachteile bezüglich der Bildqualität. Hierbei kann auch eine isotrope Ortsauflösung von besser als $1 \mathrm{~mm}$ routinemäßig bereit gestellt werden. Diese Leistungsmerkmale der klinischen CT gelten natürlich auch für Untersuchungen post mortem.

Für die forensische Medizin sind Untersuchungen von Resektaten und Biopsien von zusätzlicher Bedeutung. Hierfür bietet insbesondere die Mikro-CT $(\mu \mathrm{CT})$ neue technische Möglichkeiten. Die Aufnahmeprinzipien und Rekonstruktionsverfahren sind ähnlich wie in der klinischen Anwendung; es können aber Auflösungswerte zwischen 10 $\mu \mathrm{m}$ und $100 \mu \mathrm{m}$ erreicht werden. Diese Technik wird ebenfalls im Detail dargestellt. Eine wesentliche Beschränkung besteht darin, dass extrem hohe Ortsauflösung nur für zunehmend kleine Proben erreicht werden kann. Die Leistungsfähigkeit der CT und der $\mu \mathrm{CT}$ in vivo und in vitro wird an Fallbeispielen demonstriert.

[1] Kalender, W.A.: Computertomographie. Wiley VCH Verlag, Weinheim (2000)

\section{V-62}

\section{MAGNETRESONANZ-TOMOGRAPHIE HEUTE UND MORGEN}

Heid O

Siemens AG, UB Medizintechnik, Erlangen

In den letzten 20 Jahren hat sich die Magnetresonanz-Tomographie (MRT) in der Radiologie ein breites Einsatzfeld errungen und sich in vieler Hinsicht als ideale Ergänzung zur Röntgen-Computertomographie (CT) erwiesen. Dabei erwies es sich als besonderer Glücksfall, daß das für den Magnetresonanzeffekt geeignetste Atom, Wasserstoff, im menschlichen Gewebe in Form von Wasser und Fett sehr häufig vorkommt, und für vielfältigste Bildkontraste sensibilisiert werden kann.
Damit kann mittels MRT eine extrem große Breite von klinischen Fragestellungen, insbesondere betreffend Weichteile und Körperflüssigkeiten nichtinvasiv beantwortet werden. Die Kombination mit der Magnetresonanz-Spektroskopie (MRS) ermöglicht darüber hinaus eine zerstörungsfreie chemische Analyse des abgebildeten Gewebes. Dieser Vortrag soll einerseits eine Einführung in die physikalischen Grundlagen der MRT und einen Überblick über den momentanen Stand und die Zukunftsperspektiven der unverändert raschen technischen Entwicklung geben. Die heute erkennbaren prinzipiellen Grenzen werden aufgezeigt.

Daneben wird anhand von klinischen Beispielen ein Eindruck der Anwendungsbreite der MRT vermittelt. Die MRT steht im Begriff, in Nachbargebiete der Radiologie wie Orthopädie, Angiologie und Kardiologie und möglicherweise auch die Rechtsmedizin einzudringen. Dabei kommt die Vielfalt der verfügbaren MRT-Techniken dem Wunsch entgegen, mittels eines einzigen Untersuchungsverfahrens die gestellten diagnostischen Fragen zu beantworten und damit Zeit und Kosten zu sparen.

\section{V-63}

EINFÜHRUNG IN DIE MAGNETRESONANZ-SPEKTROSKOPIE (MRS)

Boesch C

Departement Klinische Forschung

(Magnetresonanz-Spektroskopie und Methodologie),

MR-Zentrum 1, Universität und Inselspital, 3010 Bern

Unter dem Eindruck der Magnetresonanz-Bildgebung (MRI, KST) wird in der Medizin oft vergessen, dass die hochauflösende NMRSpektroskopie (Nuclear Magnetic Resonance) in Chemie und Pharmazeutik ein ebenso mächtiges wie weitverbreitetes Instrument ist. Die in-vivo Spektroskopie (MRS) ist eigentlich eine Kombination dieser beiden Methoden: analog der Bildgebung, wird ein MR Spektrum nicht-invasiv und aus definierten anatomischen Strukturen gewonnen; wie in der NMR, wird Information über die Chemie des Gewebes erhalten. Die Verwandtschaft mit der hochauflösenden NMR ist für die MRS deshalb wichtig, weil teilweise Methoden übertragen werden können, die in der NMR im Reagenzglas erfolgreich angewendet werden, oder wenigstens erahnen lassen, was in Zukunft möglich sein könnte.

MRI, NMR und MRS beruhen letztlich auf denselben physikalischen Grundlagen. Während die MRI aber hauptsächlich die starken Signale von Wasser und Fett zur Beschreibung von Morphologie und Funktion einsetzt, eröffnet die MRS eine weitere Dimension. Durch die Beobachtung der sogenannten chemischen Verschiebung können eine Vielzahl von Stoffwechsel-Produkten und -Wegen identifiziert und quantifiziert werden. Damit kann die MRS in einem anatomisch definierten Volumen den Metabolismus beschreiben - die MRS macht quasi eine „chemische Biopsie“. Dies kann entweder in einem einzelnen Volumen geschehen oder in Form eines relativ groben Bildes („Chemical Shift Image“). Da die interessierenden Stoffwechselprodukte aber wesentlich weniger konzentriert sind als Wasser oder Fett, bleibt die räumliche Auflösung deutlich unter derjenigen der normalen Bildgebung.

Eine weitere Stärke - und gleichzeitig methodische Schwierigkeit - der MRS liegt in der Tatsache, dass nicht nur Wasserstoffkerne (1-H) beobachtet werden können, sondern auch andere, natürlich vorkommende und stabile Isotope wie z.B. 13-C oder 31-P. Durch diese Aufnahmetechniken wird eine ganze Liste von weiteren Stoffwechselprodukten beobachtbar. Da die spezifische Empfindlichkeit dieser Kerne aber unter derjenigen von Wasserstoffkernen liegt, müssen üblicherweise grössere und damit der Anatomie weniger angepasste Volumina beobachtet werden.

Die Zukunft der MRS ist einerseits durch die technischen Entwicklungen (Stichwort höhere Magnetfeldstärken), anderseits durch die Erfahrung und Ausbildung der Anwender (vor allem in der klinischen Anwendung) bestimmt. 


\section{Abstracts}

V-64

„FORENSIC RADIOLOGY“

Brogdon G

Alabama

\section{V-65}

VON DER AUTOPSIE ZUR VIRTOPSY

Dirnhofer R

Institut für Rechtsmedizin der Universität Bern

Das dreiphasige Forschungsprojekt „Virtopsy“ hat die Entwicklung einer minimal-invasiven untersucherunabhängigen objektiven $\mathrm{Be}$ fundaufnahme im Bereiche der forensischen Pathologie mittels postmortal durchgeführtem MRT und MS-CT Untersuchungen zum Ziel. Bei 41 auf forensisch unterschiedliche Art verstorbenen Personen wurden MS-CT und/oder MR-Untersuchungen durchgeführt. Aus den erhaltenen Datensätzen wurden auch 2D/3D-Rekonstruktionen angefertigt. Anschliessend wurden die radiologischen Befunde durch eine rechtsmedizinische Obduktion validiert.

Die radiologische Diagnostik forensisch relevanter Befunde erfolgte unter dem Gesichtspunkt der alltäglichen rechtsmedizinischen Begutachtung, nämlich unter den Aspekten der Todesursache, der Erfassung traumatologischer Befunde und deren Vitalität sowie den sich daraus ergebenden Rekonstruktionsmöglichkeiten.

Vorgestellt werden die Logistik dieses transdisziplinären Projektes und die ersten Ergebnisse.

\section{V-66}

KLINISCHE CCT-AUFNAHMEN

IN DER FORENSISCHEN BEGUTACHTUNG

VON SCHÄDEL-HIRN-TRAUMEN

Bauer M, Patzelt D

Institut für Rechtsmedizin der Universität Würzburg

Die craniale Computertomographie (CCT) zählt zu den Standardverfahren in der Diagnostik von Schädel-Hirn-Traumen (SHT). Somit existieren zumindest bei jedem Patienten mit SHT, der über eine größere Klinik zur rechtsmedizinischen Begutachtung kommt, entsprechende CCT-Aufnahmen, die in der rechtsmedizinischen Praxis eine vielfältige Bedeutung erlangen können. So kann eine CCTgestützte Befunddokumentation herangezogen werden, wenn es um die Abgrenzung von primären versus sekundären Schädigungen bei längerer Überlebenszeit geht. Auch bei der Beurteilung fraglicher ärztlich Sorgfaltspflichtverletzungen und bei der retrospektiven Abschätzung der Überlebensprognose können CCT-Bilder eine wichtige Rolle spielen ebenso wie natürlich in der Begutachtung lebender Personen mit SHT. In diesem Beitrag sollen auch anhand von Fallbeispielen die verschiedenen Möglichkeiten und Grenzen der Einbeziehung klinischer CCT-Aufnahmen in die forensische Begutachtung aufgezeigt werden. Aus den dabei erworbenen eigenen Erfahrungen u.a. im interdisziplinären Informationsaustausch lässt sich folgern, dass für eine selbstständige rechtsmedizinische Meinungsbildung eigene Grundkenntnisse und Erfahrungen in der CT-Interpretation nützlich sind, da die klinische Befundung sich in der Regel nicht an der forensischen Fragestellung orientiert. In Verbindung mit der fachspezifischen traumato-pathologischen Kompetenz des Rechtsmediziners kann so eine wertvolle Ergänzung Erweiterung der Begutachtungsmöglichkeiten entstehen.
V-67

VERGLEICH RADIOLOGISCHER

UND HISTOLOGISCHER BEFUNDE

ZUR ALTERSBESTIMMUNG KINDLICHER FRAKTUREN

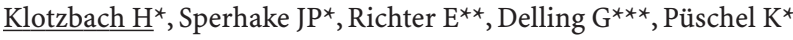

${ }^{\star}$ Institut für Rechtsmedizin;

${ }^{*}$ Abt. f. Kinderradiologie der Kinderklinik;

${ }^{* * *}$ Abt.f. Osteopathologie; Universitätsklinikum Hamburg-Eppendorf

Der Altersbestimmung kindlicher Frakturen kommt in der forensischen Begutachtung eine überragende Bedeutung zu. Unterschiedlich alte Frakturen weisen auf eine wiederholte Mißhandlung des Kindes hin. Einlassungen der Beschuldigten können hinsichtlich der zeitlichen Verhältnisse überprüft werden.

Vorgestellt werden Vergleiche postmortaler radiologischer - einschließlich kontaktradiographischer - Befunde im Vergleich mit den Sektionsergebnissen und anschließender histologisch-osteopathologischer Auswertung dreier kindlicher Todesfälle, die allesamt multiple, unterschiedlich alte Frakturen aufwiesen. Hierbei fanden sich größtenteils Übereinstimmungen in der Einschätzung des Alters der Läsionen. Abweichungen ergaben sich zum Teil in der Einschätzung des Ausmaßes reparativer Vorgänge (z.B. Kallusbildung). Die histologischen Befunde (Markraumfibrose, metaplastische Knorpelinseln, perisotale und endostale Knochenneubildung u.a.) ermöglichten eine etwas engere zeitliche Eingrenzung als die radiologische Darstellung. Fragliche Frakturen wurden durch Kontaktradiographie, Sektionsbefunde sowie die histologische Untersuchung meist verifiziert. Einzelne Frakturen entgingen der radiologischen Befundung und kamen erst autoptisch, zum Teil auch erst histologisch zur Darstellung.

Nach unserer Einschätzung ist zu empfehlen, bei kindlichen Todesfällen vor der Sektion eine Röntgenuntersuchung des gesamten Skelettsystems zur Planung des Ausmaßes der Skelett- und Weichgewebspräparation durchzuführen. Die im Rahmen der Sektion festgestellten knöchernen Verletzungen sind ggf. kontaktradiographisch und anschließend histologisch-osteopathologisch zu begutachten. Umfassende Auswertungen dieser Befunde ermöglichen Erkenntnisgewinne für die klinisch-radiologische Altersschätzung kindlicher Frakturen.

\section{V-68}

PRAKTISCHE ERFAHRUNGEN DER ALTERSDIAGNOSTIK MIT BILD-GEBENDEN VERFAHREN AN DER BERLINER CHARITE Reisinger W, Schmeling A, Olze A, Mühler M, Hermann KG Institut für Radiologie und Institut für Rechtsmedizin des Universitätsklinikums Charité Berlin, Deutschland

Am Institut für Radiologie der Charité wird die Altersdiagnostik mit Hilfe bildgebender Verfahren seit Oktober 1993 durchgeführt. Nach zunächst nur gelegentlichen Vorführungen registrieren wir ab dem Jahre 1996 zunehmende Untersuchungszahlen. Neben stets angefertigten Röntgenaufnahmen des Handskeletts und zunehmend durchgeführten Röntgenuntersuchungen der Sternoklavikulargelenke wurden Skelettuntersuchungen zur Altersdiagnostik mit Hilfe der Magnetresonanztomographie erprobt, die Ergebnisse werden vorgetragen. Unsere Erfahrungen bei der Altersdiagnostik mit bildgebenden Verfahren bestätigen belegbar die Feststellung, daß Methodik und genutzte Referenzsysteme geeignet sind, eine hinreichend sichere Aussage zum Lebensalter erbringen zu können. Die gutachterliche Aussage gewinnt wesentlich an Sicherheit, wenn sie auf einer Kombination der Untersuchungsergebnisse des Radiologen, des Zahnarztes und des Rechtsmediziners beruht. Das Einfließen unserer Aussagen in die Rechtsprechung an Berliner Gerichten läßt eine zunehmende Akzeptanz erkennen. 


\section{V-69}

RADIOLOGISCHE FEHLDIAGNOSEN ALS URSACHE FÜR FEHLEINSCHÄTZUNGEN IM BEGUTACHTUNGSVERFAHREN Rygol K, Kobek M, Chowaniec CZ

Institut für gerichtliche Medizin der Schlesischen Medizinischen Akademie, Katowice, Polen

Es werden drei Kasuistiken vorgestellt, die inkorrekte radiologische Befunderhebungen und ihre rechtlichen Folgen behandeln.

Im ersten Fall wurde ein Fußgänger von einem Pkw angefahren und erlitt eine Knieprellung. Der behandelnde Chirurg diagnostizierte auf einem Röntgenbild eine Fibulaköpfchenfraktur, die ein Radiologe anschließend nicht bestätigte. Eine erneute Röntgenaufnahme neun Monate später ergab einen Zustand nach Fibulaköpfchenfraktur, die sich jedoch bei der Begutachtung durch ein radiologisches Konsilium im Institut für Gerichtliche Medizin nicht bestätigte.

Die Diskrepanz hinsichtlich der Beurteilung der Röntgenbilder war aus der unterschiedlichen Stellung des rechten Kniegelenks während der Aufnahme entstanden.

Im zweiten Fall einer im Institut für gerichtliche Medizin durchgeführten Beurteilung einer CT-Untersuchung des Kopfes eines 19-jährigen Patienten nach einem Verkehrsunfall zeigte sich, daß Veränderungen, die auf eine Blutextravasation im Bereich der rechten Hemisphäre, insbesondere am rechten Temporalpol, hindeuteten, lediglich durch sogenannte Aufhärtungsartefakte auf Grund der asymmetrischen Lagerung des Kopfes entstanden waren. Zusätzlich wurde im linken Temporalpol ein Bereich von geringerer Dichte festgestellt, was einer kleinen Subarachnoidalzyste und nicht einer Hämorrhagie entsprach.

Im dritten Begutachtungsfall von zwei Insassen eines Pkw's nach Verkehrsunfall wurden anhand von im Institut durchgeführten CTund MRT-Untersuchungen frühere Diagnosen einer Densfraktur korrigiert und als Normvarianten klassifiziert.

Die in den drei dargestellten Fällen im Institut für Gerichtliche Medizin durchgeführten Korrekturen in der radiologischen Begutachtung führten schließlich auch zu einer veränderten rechtlichen Bewertung.

\section{V-70}

SOGENANNTES „SCALPING“ BEI KINDESMIßHANDLUNG

$\underline{\text { Seifert }}^{*}$, Püschel $\mathrm{K}^{\star}$, Tholen $\mathrm{P}^{* *}$, Zimmermann $\mathrm{W}^{\star * *}$

* Institut für Rechtsmedizin der Universität, 22529 Hamburg

** Katholisches Kinderkrankenhaus Wilhelmstift,

Abt. für Bildgebende Diagnostik, 22149 Hamburg

$* * *$ Katholisches Kinderkrankenhaus Wilhelmstift,

Kinderchirurgische Abt., 22149 Hamburg

Die Mutter brachte ihren $3^{1 / 2-j a ̈ h r i g e n ~ S o h n ~ i n ~ e i n ~ H a m b u r g e r ~ K i n d e r-~}$ krankenhaus wegen starker Schwellung und Blauverfärbung im Stirnbereich. Gegenüber der diensthabenden Ärztin konnte die Mutter keinerlei Erklärung für dieses Befundmuster geben. Der Junge selbst erklärte später, er sei „gegen einen Schrank gelaufen“. Klinisch fiel bei der Untersuchung auf, daß sowohl im Stirnbereich als auch im Bereich der behaarten Kopfhaut eine deutlich sichtbare wie auch tastbare teigige Schwellung vorhanden war. Nach Stunden trat auch ein massives Brillenhämatom zutage.

Während die Röntgenaufnahmen keinen diagnostischen Zuwachs brachten, ergab die am gleichen Tag durchgeführte sonografische Untersuchung des Schädels ein ausgedehntes subgaleales Hämatom: Das Panoramabildverfahren SieScape ergibt eine sehr informative Dokumentation der Ausdehnung im Stirn- und gesamten Parietalbereich. Dieses Phänomen wird in der Bildgebenden Literatur als "Scalping“ bezeichnet und auf erhebliche stumpfe Gewalteinwirkung (Scherkräfte, z. B. durch Ziehen an den Haaren) zurückgeführt.
V-71

REKONSTRUKTION EINES VERSUCHTEN TÖTUNGSDELIKTES MITTELS PKW DURCH NMR-UNTERSUCHUNG 6 WOCHEN NACH DER TAT

Seifert $\mathrm{D}^{*}$, Püschel $\mathrm{K}^{*}$, Weber $\mathrm{M}^{* *}$

* Institut für Rechtsmedizin der Universität, 22529 Hamburg

** Institut für Unfallanalysen, 22303 Hamburg

Die 40jährige Frau wurde in der Tiefgarage ihres Hauses von mehreren Tätern überfallen und ihres PKWs beraubt. An den Hergang des Geschehens hatte sie nur partielle Erinnerungen, da sie aufgrund von Mißhandlungen eine Commotio cerebri erlitt. Die Erstversorgung im Hinblick auf diverse Kopfverletzungen und Abschürfungen an den Füßen erfolgte in der Chirurgischen Notaufnahme eines Hamburger Krankenhauses. Erhebliche Schmerzen in beiden Oberschenkeln wurden dokumentiert, eine weitergehende klinische Untersuchung erfolgte jedoch nicht. Nachbehandlungen geschahen bei dem langjährigen Hausarzt der Patientin.

Sechs Wochen nach der Tat wurde die Patientin von ihrer Anwältin an die „Rechtsmedizinische Untersuchungsstelle für Gewaltopfer" verwiesen. Nach Erhebung des noch sichtbaren klinischen Befundes unter Berücksichtigung des Geschehensortes wurde eine NMR-Untersuchung durchgeführt - die unsere Verdachtsdiagnose bezüglich eines Anfahrens (am Boden liegend) mit massiver Quetschung beider Oberschenkel bestätigte. Im NMR zeigten sich „langstreckige gekammerte Serome "im subkutanen Fettgewebe beider Oberschenkel. Eine nunmehr angeregte Tatrekonstruktion im Beisein eines technischen Sachverständigen sowie mit einer sorgfältigen Untersuchung der Kleidung der Verletzten (daran eindeutige Profilspuren) brachte die endgültige Klärung des Falles.

\section{V-72}

MÖGLICHKEITEN DES 3-D-SCANNINGS

AM KNÖCHERNEN SCHÄDEL UND BEI LEBENDEN PERSONEN

Jachau K, Häusler G, Wittig H, Krause D

Institut für Rechtsmedizin, Otto-von-Guericke-Universität Magdeburg, Leipziger Straße 44, 39120 Magdeburg, Deutschland

Zur Superimposition unbekannter Schädel in Vergleichsfotos und zur Einscannung lebender Personen zum Abgleich mit vorliegenden Fotografien ist ein schnelles dreidimensionales Scannen notwendig. Durch ein spezielles Lichtschnittverfahren, das mathematisch auf dem Triangulationsprinzip beruht, wird diese Aufgabe in entsprechender Genauigkeit und Schnelligkeit erfüllt. Dadurch entfällt die zeitaufwendige Positionierung des Schädels. Artefakte durch Bewegungen der lebenden Person werden durch die kurze Scanningzeit von wenigen Sekunden weitgehend vermieden. Dieses ist insbesondere geeignet zum Abgleich mit Fahndungsfotos, Bildern einer Geschwindigkeitsmessung o.ä. auch bei wenig kooperativem Verhalten des Beschuldigten. Im Computer liegt nach der Scannung ein dreidimensionales, in allen 3 Ebenen bewegliches Bild des Schädels oder des Kopfes der lebenden Person vor.

\section{V-73}

POSTMORTALE COMPUTERTOMOGRAPHIE

IN DER FORENSISCHEN PATHOLOGIE; MÖGLICHKEITEN, GRENZEN, VISIONEN

Stein $\mathrm{KM}^{\star}$, Zimmer $\mathrm{G}^{\star}$, Schnatterbeck $\mathrm{P}^{\star *}$, Mattern $\mathrm{R}^{\star}$

${ }^{\star}$ Institut für Rechtsmedizin Heidelberg

**Inselspital Bern

1995 führten wir, in Kooperation mit dem DKFZ Heidelberg die ersten eigenen computertomographischen Untersuchungen zunächst an Organteilen (Lungen) später an Leichen durch. Seit Juni 2001 verfügt das 


\section{Abstracts}

Institut für Rechtsmedizin über einen eigenen Siemens Somatom Puls (Bj.1989) so dass nun auch der Einsatz in der Routine möglich ist. Wie schon mehrfach dargestellt, erhält man mit der vor der Obduktion durchgeführten CT einen hervorragenden zusätzlichen Informationsgewinn. So ist die Quantifizierung der extrakardialen Gasembolie, z.B. in Hautgefäßen oder im Gehirn, präparatorisch nicht möglich. Verletzungen, die in präparatorisch schwer zugänglichen Regionen liegen, z.B. Mittelgesichtsfrakturen, sind mittels CT gut zu diagnostizieren und ermöglichen ein gezieltes Vorgehen bei der Obduktion. Letztlich lassen Erkenntnisse aus der postmortalen CT z.B. bei Schussverletzungen, Rückschlüsse auf die ballistische Beurteilung auch bei Lebenden mit Schussverletzungen zu.

Ein Ersatz der indizierten rechtsmedizinischen Leichenöffnung kann die postmortale CT schon wegen der noch unzureichenden Organdiagnostik nicht sein. So sind frische Herzmuskelnekrosen, Gefäßveränderungen ohne dichteanhebende Wandeinlagerungen, Wundalterbestimmungen oder diskrete Einblutungen mit den jetzigen Untersuchungstechniken nicht möglich.

Der routinemäßige Einsatz der CT wird zeigen, ob über die bisherigen Möglichkeiten hinaus durch die Entwicklung leichenspezifischer Protokolle eine differenziertere Betrachtung unklarer Sektionsfälle möglich wird.

Vielleicht kann eine wissenschaftlich validierte postmortale CT in Ländern mit religiös bedingten unzureichenden Obduktionsraten in Einzelfällen zur Rechtssicherheit beitragen.

Ziel der Entwicklung der postmortalen CT ist nicht, die rechtsmedizinische Leichenöffnung zu ersetzen, sondern diese durch eine radiologische Untersuchung qualitativ zu erweitern.

\section{V-74 \\ DIGITALE ORTHOPANTOMOGRAPHIE: MÖGLICHKEITEN UND GRENZEN BEI DER IDENTIFIKATION UNBEKANNTER LEICHEN \\ Benthaus S, Teige K, Du Chesne A, Brinkmann B \\ Institut für Rechtsmedizin des Universitätsklinikums Münster}

Seit Entwicklung und Einführung der postmortalen Orthopantomographie ist die rechtsmedizinische Praxis (Benthaus et al.1997) wurde deren Nutzen bei der Identifikation unbekannter Leichen in zahlreichen Kasuistiken belegt. Da die Orthopantomographie in der klinischen Praxis eine Reihe von Problemen lösen kann, stehen in Identifizierungsfällen dem Rechtsmediziner häufig Vergleichsröntgenbilder zur Verfügung.

Die Hauptaufgabe des Röntgenologen besteht dabei im Konturvergleich prä- und postmortaler Aufnahmen. Fehlbelichtungen, Projektionsfehler, Überlagerung des Filmmaterials oder Mängel bei der chemischen Entwicklung erschweren das Erkennen individualspezifischer Strukturen oder machen es sogar unmöglich.

Der Vorteil prä- und postmortaler OPG-Aufnahmen liegt zum einen in der korrekten Seitenwiedergabe, der guten Reproduzierbarkeit des Strahlenganges im Röntgengerät und der Komplettübersicht beider Kiefer in einer Aufnahme.

Die vorliegende Arbeit zeigt die Möglichkeiten und Grenzen der digitalen Orthopantomographie bei der Identifikation auf. Durch sekundäre Digitalisierung herkömmlicher Röntgenbilder und durch eine digitale Overlay-Technik können auch Nativröntgenbilder geringerer Qualität in ihrer Bildaussagen optimiert und für den Röntgenbildvergleich besser genutzt werden. Die schnelle Verfügbarkeit digitaler Röntgenbilder sowie die Datenfernübertragung mittels Internet werden an einem kasuistischen Beitrag demonstriert.

\section{V-75}

\section{EFFIZIENZ VERSCHIEDENER BILDGEBENDER VERFAHREN}

ZUR ALTERSBESTIMMUNG AN ZÄHNEN

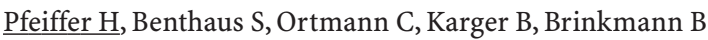

Institut für Rechtsmedizin Münster,

Von Esmarch Str.62, 48149 Münster

Bei der forensischen Beurteilung von unbekannten Skelettfunden stehen Untersuchungen zur Alters-, Geschlechts- und Liegezeitbestimmung im Vordergrund.

Dem Gebiß kommt bei der Identifikation ein besonderer Stellenwert zu: zum einen aufgrund der Stabilität gegenüber extremen Umwelteinflüssen andererseits aufgrund des hohen individuellen Informationsgehaltes.

Nach Abschluß des Wurzelwachstums der dritten Molaren, d.h. ab einem Lebensalter von 19-21 Jahren ist eine Lebensaltersbestimmung am Gebiß nur durch die Beurteilung des Grades von Abnutzungs- und Alterungsprozessen möglich. Biomorphologische Zahnveränderungen im Erwachsenenalter wurden bereits von Gustafson $(1955,1956)$ zusammengefaßt. Eines dieser 6 Kriterien ist die Sekundärdentinablagerung im Pulpencavum. Diese nimmt mit steigendem Lebensalter konstant zu und engt den Pulparaum in Zahnwurzeln- und -Kronen zunehmend ein. Heute ermöglichen moderne bildgebende Verfahren eine Quantifizierung des Grades der Sekundärdentinablagerung. Konventionelle radiologische Methoden der Zahnmedizin (apikale Zahnfilme in Rechtwinkelparalleltechnik, Orthopantomogramm), Computertomographie und die direktradiographische Vergrößerungstechnik mittels Mikrofokus-Röntgenröhren werden bezüglich ihrer Effizienz für die Lebensaltersbestimmung am Gebiß miteinander verglichen.

Die Anwendung der direktradiographischen Vergrößerungstechnik erlaubt im Vergleich zu Zahnfilmaufnahmen eine erhebliche Steigerung des Auflösungsvermögens und besitzt eine überlegene Bildqualität. CT-Untersuchungen gestatten bei ebenfalls hoher Auflösung eine digitale Bildauswertung. Sowohl die CT- Technik als auch die direktradiographische Vergrößerungstechnik sind bei Indikationsstellung am Lebenden durchführbar. Insbesondere bei letztgenannter Technik ist die Strahlenexposition deutlich reduziert.

\section{V-76 \\ HILFE DURCH POST MORTEM CT \\ BEI DER KLÄRUNG DER TODESURSACHE: DARSTELLUNG ANHAND ZWEIER OBDUKTIONSFÄLLE. \\ Schultes A, Schuff A, Graß H, Riepert T, Lackner K \\ Institut für Rechtsmedizin der Universität zu Köln}

Fall 1: Eine 19 Jahre alte Frau verstirbt infolge eines Verkehrsunfalles noch an der Unfallstelle. Bei der gerichtlichen Obduktion wird als Todesursache ein schweres offenes Schädelhirntrauma mit Schädelbruch in Kombination mit Verbluten nach außen diagnostiziert. Anhand der Auswertung des CT des Schädels/Thorax konnte zudem eine massive Luftansammlung im gesamten rechten Herzen sowie in der A. pulmonalis beidseits nachgewiesen werden, so daß davon auszugehen ist, daß eine Luftembolie maßgeblich den Tod der Frau mitbedingte.

Fall 2: Eine 66 Jahre alt gewordene Krebspatientin verstirbt während einer stationär durchgeführten Chemotherapie, nachdem sie kurz zuvor aus dem Krankenbett gestürzt war. Die Obduktion bestätigte das klinisch diagnostizierte Mamma-Carcinom mit ossären und pulmonalen Metastasen. Todesursächlich war eine frische subarachnoidale Blutung mit konsekutiver Kompression des Hirnstamms infolge einer hochgradigen Fibrosklerosierung der leptomenigealen Gefäßen mit hieraus resultierender Blutung. Die Auswertung des CT bestätigte das bereits fortgeschrittene Tumorstadium. Zudem ließ sich computertomographisch ein weit in den rechten Vorhof vorge- 
schobener Katheter darstellen, der, das Grundleiden hinweggedacht, für sich allein gesehen dazu geeignet wäre, insbesondere bei kardial vorgeschädigten Patienten den Tod durch Herzrhythmusstörungen zu bedingen.

$\mathrm{Zu}$ 1. An eine todesursächliche Luftembolie sollte bei offenen Schädelhirntraumata gedacht werden. Zudem kann diese mittels postmortal durchgeführtem CT verifiziert werden.

$\mathrm{Zu}$ 2: $\quad$ Eine genaue Lagebestimmung von eingebrachtem Fremdmaterial, insbesondere von zentral-venösen Kathetern ist anhand des Computertomogramms möglich und kann zur der Findung der Todesursache sinnvoll beitragen. Deshalb sollte zu diagnostischen/ therapeutischen Zwecken eingebrachtes Fremdmaterial unbedingt im Originalzustand an/in dem Leichnam verbleiben.

\section{V-77 \\ DISKREPANZ \\ ZWISCHEN POSTMORTALER COMPUTERTOMOGRAFIE \\ UND SEKTIONS-BEFUND; \\ DARGESTELLT AM BEISPIEL EINES LUNGENDURCHSCHUSSES

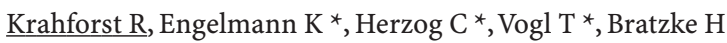 \\ Zentrum der Rechtsmedizin, Johann Wolfgang Goethe-Universität, Frankfurt am Main \\ *Institut für Diagnostische und Interventionelle Radiologie, \\ Johann Wolfgang Goethe-Universität, Frankfurt am Main}

Seit Dezember 2000 werden im Zentrum der Rechtsmedizin Frankfurt/M. in Zusammenarbeit mit dem hiesigen Institut für Diagnostische und Interventionelle Radiologie Leichen vor der Obduktion computertomografisch untersucht. Hierfür wird ein hochauflösendes Multi-detector CT verwendet, welches die Anfertigung von $1 \mathrm{~mm}$ Schichten erlaubt (Somatom Plus 4 Volume Zoom, Siemens, Erlangen). Es wurden vor allem Tötungen, Suizide und Verkehrsunfälle (bisher insgesamt 15 Fälle) untersucht. Einer der ersten Fälle mit postmortaler Computertomografie betraf einen 39 Jahre alten Bauarbeiter, der nach Streitigkeiten vor einer Gaststätte mit einem Brustdurchschuß getötet worden war. Die CT- Aufnahmen ließen einen Schußkanal durch das Lungenparenchym erkennen, der jedoch mit den äußerlich sichtbaren Schußwunden nicht korrespondierte. Bei der Sektion wurde ein in der Körperquerachse von links nach rechts verlaufender Schusskanal festgestellt. Das Projektil hatte den linken Lungenunterlappen nahe des Zwischenlappenspaltes, die Aorta descendens und den rechten Lungenunterlappen durchschlagen. Der beidseitige Pneumo- und Hämatothorax (links $1000 \mathrm{ml}$, rechts $600 \mathrm{ml}$ Blut) hatte zu einer Verlagerung der kollabierten Lungen und damit auch des Schusskanales geführt.

Der Fall zeigt exemplarisch, dass moderne bildgebende Verfahren keine ausreichende Beweisgrundlage bilden. Nur im Zusammenhang mit Obduktionsergebnissen ist eine sichere Aussage möglich.

\section{V-78 \\ ANWENDUNG VON BILDGEBENDEN VERFAHREN \\ BEI DER ANALYSE VON KOPFSCHÜSSEN \\ Meissner ${ }^{1} \underline{\text { C }}$, Gehl $^{2}$ HB, Petersen ${ }^{3}$ D, Höche ${ }^{4}$ W, Gerling ${ }^{1}$ I, König ${ }^{5}$ HG, Oehmichen ${ }^{1} \mathrm{M}$ \\ ${ }^{1}$ Institut für Rechtsmedizin, Universitätsklinikum Lübeck \\ ${ }^{2}$ Institut für Radiologie, Universitätsklinikum Lübeck \\ ${ }^{3}$ Institut für Radiologie, Abteilung für Neuroradiologie, \\ Universitätsklinikum Lübeck \\ ${ }^{4}$ Städtisches Krankenhaus Süd, Lübeck \\ ${ }^{5}$ Institut für Rechtsmedizin, Eberhard-Karls-Universität Tübingen}

Zur Frage, ob bildgebende Verfahren einen zusätzlichen Informationsgewinn bei einer Leichenöffnung liefern können, wurden 17 Gehirne von Personen analysiert, die an den Folgen eines Kopfschusses gestor- ben waren. Es erfolgte ein Vergleich zwischen einer routinemäßig durchgeführten und ausführlich fotografisch dokumentierten neuropathologischen Untersuchung und bildgebenden Verfahren, die sowohl vor der Obduktion als auch am isolierten, formalinfixierten Gehirn durchgeführt wurden. Bei den Waffen handelte es sich ausschließlich um Faust- und Langfeuerwaffen mit niedrigen Mündungsgeschwindigkeiten; überwiegend lagen Kopfdurchschüsse vor. Die bildgebenden Verfahren erlauben bereits vor der Obduktion eine Differenzierung zwischen Ein- und Ausschußlücken, die durch die bei der Sektion erhobenen Befunde bestätigt werden konnte. Mittels Subtraktionsverfahren u.a. konnten innerhalb des Hirnparenchyms straßenförmige Verläufe aus abgesprengten Knochen und Projektilteilen dargestellt und ein Schußkanal im 3 D-Bild, ebenso wie ein Winkel des Schußkanals, rekonstruiert werden.

Am isolierten formalinfixierten Gehirn wurde u.a. der Schußkanal entlang einer Destruktionszone mit Blutungen, Luftblasen oder Ödem nachgewiesen. Unklar blieb eine radiär den Schußkanal umgebene Aufhellung, die der temporären Wundhöhle entsprechen dürfte.

Bildgebende Verfahren ermöglichen einen zusätzlichen Informationsgewinn, der sowohl in der hervorragenden Dokumentation der Verhältnisse in-situ, als auch in der vereinfachten biometrischen Rekonstruktion durch Analyse der Daten zur Erfassung des Schußwinkels und des Schußkanals besteht.

\section{V-79}

VIRTOPSY: SCHUSS

POSTMORTALE MULTISCLICE-CT UND MR-UNTERSUCHUNG

Thali MJ (1,2,3), Yen K (1), Schweitzer W (1), Kneubuehl B (1), Scheurer E (1), Vock P (2), Ozdoba C (3), Schroth G (3),

Sonnenschein M (2), Ith M (4), Boesch C (4), Brügger K $(2,4)$, Spielvogel E (3), Königsdorfer U (1), Dorn R (1), Dirnhofer R (1)

1. Institut für Rechtsmedizin, Universität Bern

2. Institut für Diagnostische Radiologie, Universität Bern, 3010 Bern

3. Abteilung für Neuroradiologie, Universität Bern, 3010 Bern

4. Spektroskopie und Methodologie, Universität Bern, 3010 Bern

Ziel: Evaluation und Validation von postmortalen radiologischen Vollkörper-Untersuchungsmethoden (CT,MR) bei Schuss - Einwirkungen im Vergleich zur klassisch forensischen Autopsie.

Methode: Die postmortalen Untersuchungen erfolgten mit einem MSCT resp. MR der Firma GE. Das Postprocessing (2D / 3D Rekonstruktionen) wurde mit einer GE Workstation durchgeführt.

Resultate: Mittels MSCT-Untersuchung, (incl. 2D / 3D Rekonstruktionen) und MR-Untersuchung konnten schussbedingte Verletzungsmuster visualisiert werden. Es war auch möglich Vitalzeichen $\mathrm{zu}$ dokumentieren, so z.B. die Luftembolie im Herzen und klassische Blutaspirationsherde in der Lunge.

Diskussion: Die radiologische Autopsie mit Multislice-CT (MSCT) eignet sich aufgrund ihrer kurzen Scanzeit ( 1 bis 2 Minuten) für eine schnelle vollumfängliche Dokumentation des Körpervolumens. Die Untersuchungsmethode mit Multislice-Computertomographie eröffnet Dokumentationsmöglichkeiten im Millimeterbereich; aus den axial gewonnenen Datensätzen können aufgrund der isotropen Dokumentation problemlos $2 \mathrm{D}$ sowie $3 \mathrm{D}$ Rekonstruktionen hergestellt werden.

Die MR-Untersuchung ergänzt die CT-Untersuchung in der höheren Weichteilauflösung, was sich bei der Darstellung von Schusskanälen als hilfreich erwies.

Mit der Kombination von MSCT und MR können forensisch-relevante Verletzungsmuster zerstörungsfrei dokumentiert und visualisiert werden. 


\section{V-80}

DREIDIMENSIONALE DARSTELLUNG EINES BECKENS

MIT KÜNSTLICHEM HÜFTGELENK

DURCH SPIRAL-COMPUTERTOMOGRAFIE

UND GEGENSTÄNDLICHE SCHNITTMODELL-HERSTELLUNG

ZUR FORENSISCHEN BEURTEILUNG

EINES IATROGENEN SCHADENS

Kuchheuser W $^{1}$, Fiedler $\mathrm{R}^{2}$, Roßbach JS ${ }^{3}$, Krause $\mathrm{D}^{1}$

Institut für Rechtsmedizin ${ }^{1}$, Klinik für Diagnostische Radiologie ${ }^{2}$, Institut für Fertigungstechnik und Qualitätssicherung ${ }^{3}$

der Otto-v.-Guericke-Universität Magdeburg

Im Rahmen der gutachterlichen Klärung eines iatrogen verursachten Todes (Verbluten infolge Verletzung der V. iliaca externa im Rahmen der operativen Einsetzung eines künstlichen Hüftgelenkes) wurde eine Leichenöffnung vorgenommen. Die Beurteilung des Falles war erschwert durch die klinisch notwendige Einsetzung einer metallenen Hakenschale zur Stabilisierung der neuen künstlichen Hüftgelenkspfanne und durch Einbringen von Zementmaterial. Die wichtige Frage nach der Lokalisation der in den Knochen eingedrehten Schrauben konnte mit Hilfe herkömmlicher Methoden ohne Zerstörung der vorhandenen Strukturen nicht gelöst werden. Daher wurde der relevante Teil des Beckens entnommen und mazeriert.

Die Spiral-Computertomografie erfolgte mittels Siemens Somatom Plus 4, die dreidimensionale Rekonstruktion mittels VG-studiomaxSoftware auf PC-Basis.

Als besonderer Vorteil erwies sich die zerstörungsfreie, praktisch beliebig oft wiederholbare Darstellung in unterschiedlichen Perspektiven und elektronischen Schnittebenen im virtuellen Raum. Die Vorgehensweise ermöglichte eine exakte Lokalisation des implantierten Materials. Durch die Anwendung von Falschfarben gelang zudem eine eindruckvolle, überzeugende Darstellung der anatomischen Situation und der operativ gesetzten Veränderungen.

Auf der Basis der Rechnerdaten wurden ein Modell des Beckenknochens in natürlicher Größe und mehrere Schnittmodelle in Achsrichtung der implantierten, zum Teil in das Beckeninnere ragenden Schrauben angefertigt. Die Modelle sind insbesondere für medizinische Laien aussagekräftig und somit eine wertvolle Bereicherung in foro.

\section{V-81}

AUTOPSIE UND POSTMORTALE COMPUTERTOMOGRAPHIE EIN PROSPEKTIVER VERGLEICH

$\underline{\text { Riepert }} \underline{\underline{1}}$ T, Schultes ${ }^{1} \mathrm{~A}, \mathrm{Graß} \mathrm{H}^{1}$, Schuff A $\mathrm{A}^{1}$, Paperno $\mathrm{S}^{2}, \mathrm{Krug}^{2} \mathrm{~B}$,

Lackner $^{2} \mathrm{~K}$, Staak $^{1} \mathrm{M}$

(1) Institut für Rechtsmedizin der Universität zu Köln, Melatengürtel 60-62,50823 Köln-Ehrenfeld

(2) Klinik und Poliklinik für Radiologie der Universität zu Köln

Die Wertigkeit pathomorphologischer und computertomographischer Befunderhebung wurde in einer prospektiven Untersuchung verglichen. Die Versuchsanordnung wurde so gewählt, dass nach einer äußeren Leichenschau und in Kenntnis der Vorgeschichte ein Computertomogramm von Schädel, Hals, Thorax und Abdomen (Spiral-CT, Standarduntersuchungsprotokoll, Siemens Somatom Plus 4) angefertigt wurde. Anschließend erfolgte die pathomorphologische Befunderhebung durch Autopsie ohne Kenntnis der röntgenmorphologischen Ergebnisse, im Anschluss daran die Auswertung der CTs. Im letzten Schritt wurde eine Entblindung vorgenommen und geprüft, welche Befunde mit beiden Techniken in gleicher Weise zur Darstellung gelangen und welche Befunde radiologisch bzw. morphologisch mit höherem Aussagewert nachgewiesen werden können. Bei bislang 38 vergleichenden Untersuchungen (jeweils 19 natürliche und 19 nicht-natürliche, meist traumatische Todesfälle) zeigte sich die hohe Aussagekraft der postmortalen Computertomographie. Der
Nachweis und die Darstellung von Gasen (Pneumothorax, Luftembolie), Fremdkörpern und Frakturen ebenso wie von topographischen Zusammenhängen war in der Regel bevorzugt radiologisch möglich. Dagegen sind nach unseren Ergebnissen traumatische Veränderungen im Bereich der Weichteile und krankhafte Befunde der inneren Organe, insbesondere im Bereich der Gefäße, meist autoptisch besser darstellbar.

Nach den vorgelegten Untersuchungen stellt die Computertomographie als nicht-invasives bildgebendes Verfahren eine komplementäre Untersuchungstechnik zur Obduktion dar. Sie kommt auch als ein Instrument der Qualitätssicherung in Betracht. Die Computertomographie erscheint insbesondere bei Todesfällen sinnvoll, die komplexe traumatologische Befunde, Fremdkörper oder pathologische Gasansammlungen erwarten lassen.

\section{V-82}

VIRTOPSY: DOKUMENTATION VON HERZBEFUNDEN BEI 35 AUTOPSIEN IM VERGLEICH MIT CT UND MRI

${\text { Schweitzer } W^{\star}}^{(1)}$, Yen K (1), Thali M $(1,2)$, Scheurer E (1), Vock P (2), Bösch C (3), Ith M (3), Sonnenschein M (2), Brügger K (2,3), Spielvogel E (2), Königsdorfer U (1), Dorn R (1), Dirnhofer R (1) (1) Institut für Rechtsmedizin, Universität Bern, Bühlstrasse 20, 3012 Bern, Schweiz

(2) Department für Diagnostische Radiologie, Universität Bern, Inselspital, 3010 Bern, Schweiz

(3) Department für Klinische Forschung, Universität Bern, Inselspital, 3010 Bern, Schweiz

Im Rahmen eines Forschungsprojektes wurden 35 Leichen mit CT und MRI untersucht. Aus Rumpf- und Thoraxscans wie auch aus spezifischen Herzsequenzen lassen sich dabei forensisch wichtige Herzbefunde ableiten.

Preliminäre Messungen ergaben zum Beispiel, dass bei beiden Fällen von plötzlichem Tod bei älterem Herzinfarkt der Signalunterschied -I/R zwischen infarziertem (gemittelt über $\mathrm{n}=1500$ ) und nicht infarziertem (gemittelt über $\mathrm{n}=3100$ ) Myokard in T2-Sequenzen etwa $30 \%$ beträgt. Dieser Messwert entspricht Ergebnissen aus vergleichbaren Sequenzen bei Lebenden.

Ein preliminärer Vergleich der Messwerte zur Wandstärke der linken Kammer ergab, dass die Bildgebung geringfügig höhere Werte als die Autopsie liefert $(18.3 \pm 4.2 \mathrm{~mm}$ auf MRI-Bildern im Vergleich $\mathrm{zu}$ $16.8 \pm 3.5 \mathrm{~mm}$ bei der Autopsie, $n=5$ ). U.a. können Herzen in situ eine im Vergleich zum Sektionstisch kompaktere Form aufweisen.

Die Autopsie hat gegenüber der Bildgebung auch untersuchungstechnische Vorteile. Dazu gehört das mechanische Verändern der Organform. Dies wird durch einen Befund einer Herzverletzung verdeutlicht, der sich in MR und CT nicht, bei der Autopsie durch Aufspannen der betroffenen Herzstrukturen jedoch sehr einfach diagnostizieren liess.

Die Diagnostik wird auch beim Herz gerade in der postmortalen Traumatologie von der Bildqualität mitbestimmt. Dies ist ein wichtiger technischer Annäherungspunkt in der Verbesserung klinischer und forensischer Radiologiemethoden.

(Teil eines Forschungsprojektes, das durch die Gebert-Rüf Stiftung (Schweiz) gefördert wird). 
$\mathrm{V}-83$

VIRTOPSY: SCHARFE GEWALT, STRANGULATION, HITZE, FÄULNIS - POSTMORTALE MULTISCLICE -CT UND MR-UNTERSUCHUNG

Thali M (1,2,3), Yen K (1), Schweitzer W (1), Scheurer E (1), Vock P (2), Ozdoba C (3), Schroth G (3), Sonnenschein M (2), Ith M (4), Boesch C (4), Brügger K (2,4), Spielvogel E (3), Königsdorfer U (1), Dorn R (1), Dirnhofer R (1)

1. Institut für Rechtsmedizin, Universität Bern

2. Institut für Diagnostische Radiologie, Universität Bern, 3010 Bern

3. Abteilung für Neuroradiologie, Universität Bern, 3010 Bern

4. Spektroskopie und Methodologie, Universität Bern, 3010 Bern

Ziel: Evaluation / Validation von postmortalen radiologischen Untersuchungsmethoden bei Einwirkungen von scharfer Gewalt, Strangulation Hitze im Vergleich zur klassischen forensischen Autopsie. Material und Methode: Die postmortalen Untersuchungen erfolgten mit einem MSCT / MR der Firma GE. Das Postprocessing wurde mit einer GE Workstation durchgeführt.

Resultate: Bei Einwirkung scharfer Gewalt konnte die Lokalisation von Stichkanälen dokumentiert werden.

Bei der Strangulation konnten Verletzungen des Kehlkopfskelettes zwei- und dreidimensional visualisiert werden, ebenfalls waren Einblutungen in die Halsweichteile darstellbar. Bei einer Brandleiche konnten hitzespezifische Veränderungen wie Brandhaematom als auch Vitalzeichen radiologisch dokumentiert werden.

Bei Fäulnisleichen konnte die Fäulnisveränderung (Gasbildung in den Weichteilen sowie Organen) dokumentiert werden.

Diskussion: Mit Hilfe der MSCT und der MR-Untersuchung war es möglich, forensisch relevante Verletzungen und Befunde nach scharfer Gewalteinwirkung, Hitze, Strangulation und Fäulnis zu dokumentieren. Im Gegensatz zur klassischen Autopsie erfolgte die Dokumentation zerstörungsfrei, womit der ursprüngliche Befund untersucherunabhängig erhoben werden konnte und einer nachträglichen $\mathrm{Be}$ gutachtung jederzeit offen steht. Die modernen radiologischen Dokumentationsmöglichkeiten eröffnen im weiteren Dokumentations- und Analysemöglichkeiten, die der klassischen Autopsie nur schwer, oder nicht zugänglich sind.

\section{V-84}

VIRTOPSY: DER EINSATZ BILDGEBENDER VERFAHREN

(MR, MS-CT) ZUR POSTMORTALEN DIAGNOSTIK

VON SCHAEDEL-HIRN-VERLETZUNGEN

Yen K (1), Thali M $(1,2,3)$, Schweitzer W (1), Scheurer E (1), Vock P (2), Ozdoba C (3), Schroth G (3), Sonnenschein M (2), Boesch C (4),

Ith M (4), Brügger K (4), Spielvogel E (3), Königsdorfer U (1),

Dorn R (1), Dirnhofer R (1)

(1) Institut für Rechtsmedizin der Universität Bern

(2) Institut für Diagnostische Radiologie Universität Bern

(3) Abteilung für Neuroradiologie, Universität Bern

(4) Abteilung für Klinische Forschung - Magnetresonanzspektroskopie, Universität Bern

Ziel: Anhand von 13 an Schädel-Hirn-Trauma Verstorbenen soll gezeigt werden, dass der postmortale Einsatz bildgebender Verfahren im Hinblick auf rechtsmedizinische Begutachtungsfragen eine geeignete, der klassischen Autopsie in mancher Hinsicht überlegene Methode darstellt.

Material und Methode: Ganzkörper-MR und Multislice-CT-Untersuchung von 13 Leichen mit Schädel-Hirn-Trauma unterschiedlicher Ätiologie, darunter 7 Verkehrsunfälle, 3 x stumpfe Gewalteinwirkung, 1 x Sturz im Alter und 3 x Sturz aus der Höhe. Durchführung einer klassischen Autopsie im Anschluss an die radiologische Untersuchung.

Resultate: Anhand der radiologischen Datensätze und der daraus angefertigten $2 \mathrm{D} / 3 \mathrm{D}$-Rekonstruktionen liessen sich forensisch wich- tige Befunde wie Schädelfraktursysteme, intracranielle Blutungen und direkte bzw. indirekte Hirnverletzungen eindeutig diagnostizieren. Daneben wurden auch sekundäre Traumafolgen wie Hirnödem, Hirndruck und sek. Hirnstammblutungen richtig erkannt.

Diskussion: Rechtsmedizinisch bedeutsame Fragen wie Todesursache, Befunderfassung, Vitalität der Verletzungen und forensische Rekonstruktion können allein aufgrund der radiologischen Untersuchung beantwortet werden. Die zerstörungsfreie „Virtuelle Autopsie“ bietet u.a. die Möglichkeit der Darstellung von Befunden in allen 3 Ebenen und eröffnet somit völlig neue Perspektiven in der Begutachtung von Schädel-Hirn-Traumatisierten .

\author{
$\mathrm{V}-85$ \\ ${ }^{1}$ H-MR-SPEKTROSKOPIE IN DER FORENSISCHEN MEDIZIN I: \\ EINE NEUE METHODE ZUR SCHÄTZUNG \\ DER POSTMORTALEN LIEGEZEIT \\ Ith $\mathrm{M}$, Scheurer $\mathrm{E}^{\star}$, Kreis R, Yen $\mathrm{K}^{\star}$, Thali $\mathrm{M}^{*}$, Schweitzer $\mathrm{W}^{*}$, \\ Dirnhofer R*, Boesch C \\ Departement Klinische Forschung \\ (MR-Spektroskopie und Methodologie) MR-Zentrum 1, \\ Inselheimmatte, 3010 Bern \\ Institut für Rechtsmedizin der Universität Bern, Bühlstrasse 20, \\ 3012 Bern* $^{*}$
}

Die Schätzung der postmortalen Liegezeit ist in der forensischen Medizin von grosser Wichtigkeit. Während in den ersten Tagen bekanntlich Totenflecken, Totenstarre und Körperkerntemperatur zur Todeszeitbestimmung herangezogen werden können, fehlen später verlässliche, objektive Parameter.

Mittels hochauflösender ${ }^{1} \mathrm{H}$-Magnetresonanz-Spektroskopie (MRS) von Gehirnextrakten wurde gezeigt, dass Änderungen der Metabolitenkonzentrationen gemessen und so der postmortale Stoffwechsel beobachtet werden kann (Michaelis T, et al., NMR Biomed 1996; 9: 121124). Im Gegensatz zu diesen „sterilen“ in vitro Versuchen kann im Gehirn, in situ, das gleichzeitige Ablaufen von Autolyse und bakterieller Zersetzung das metabolische Profil grundsätzlich verändern und die Qualität der Spektren mindern. Die ${ }^{1} \mathrm{H}$-MRS mit klinischen Ganzkörpergeräten ist gegenwärtig in der Lage, die chemische Zusammensetzung von Hirngewebe zu messen und Metabolitenkonzentrationen von minimal ca. $1 \mathrm{mMol}$ zu quantifizieren. Dank der Nicht-Invasivität der Methode ist es möglich, ein und dieselbe Region des Gehirns in situ mit wiederholten Messungen über einen längeren Zeitraum zu beobachten und so metabolische Veränderungen festzuhalten.

In diesem Vortrag soll anhand eines Schafmodells und ausgewählten menschlichen Leichen gezeigt werden, wie die Methode der ${ }^{1} \mathrm{H}-\mathrm{MRS}$ angewandt wurde, um die postmortalen Veränderungen im Hirngewebe zu dokumentieren. Es stellte sich heraus, dass die zeitlichen Verläufe der gemessenen Metaboliten-Konzentrationen dazu beitragen können, die Schätzung der Todeszeit für Liegezeiten $>3$ Tage zu verbessern und zu objektivieren. 


\section{Abstracts}

\section{V-86}

${ }^{1} \mathrm{H}-\mathrm{MR}$-SPEKTROSKOPIE IN DER FORENSISCHEN MEDIZIN II: EINE PILOTSTUDIE ZUR TODESZEITSCHÄTZUNG AM GEHIRN VON SCHAFEN UND MENSCHEN

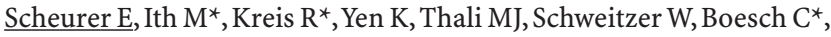
Dirnhofer R

Institut für Rechtsmedizin der Universität Bern, Bühlstrasse 20, 3012 Bern

Departement Klinische Forschung

(MR-Spektroskopie und Methodologie) MR-Zentrum 1, Inselheimmatte, 3010 Bern*

Die Methode der Magnetresonanz-Spektroskopie (MRS) ist geeignet, die chemische Zusammensetzung von Gewebe in situ zu bestimmen. Im Rahmen einer Pilotstudie wurde an einem Tiermodell mittels ${ }^{1}$ H-MRS der zeitliche Ablauf des postmortalen Stoffwechsels von Hirngewebe in situ über einen Zeitraum von max. 18 Tagen untersucht. Diese Studie hatte folgende Ziele: (i) Beurteilung der Machbarkeit mittels Beobachtung des zeitlichen Verlaufs der MRS Signale im sich zersetzenden Hirn, (ii) Validierung des Schafmodells mittels Vergleich der ${ }^{1}$ H-MRS von Schafshirn mit menschlichem Gehirn, (iii) Identifizierung von Substanzen des postmortalen Stoffumbaus, welche dank der zeitlichen Veränderung ihrer Konzentration für die Todeszeitbestimmung in Frage kommen.

Die ${ }^{1}$ H-MRS wurden mit einem klinischen 1.5T Ganzkörper-System durchgeführt. Übliche Volumina von ca. $2 \mathrm{~cm}^{3}$ wurden in der parietooccipitalen und der frontalen Region des Gehirns platziert. Schafe: Die Schafsköpfe wurden unmittelbar nach ihrem Tod im Schlachthof geholt und in einem Plastikcontainer bei Raumtemperatur gelagert. Spektroskopische Untersuchungen fanden jeweils im Abstand von $24 \mathrm{~h}$ während bis zu 18 Tagen statt. Menschen: 4 menschliche Leichen mit unterschiedlichen postmortalen Liegezeiten wurden untersucht. Deren Untersuchungsergebnisse wurden mit den Resultaten der Schafe verglichen.

Die Ergebnisse der Spektroskopie im Tiermodell und die Resultate der ersten Messungen an Leichen werden vorgestellt. Dabei wird hauptsächlich der Vergleich mit dem Tiermodell, sowie dessen Probleme und mögliche Lösungsansätze diskutiert.

\section{$\mathrm{V}-87$}

IN DER TIEFE LIEGT DIE ANTWORT -

FORENSISCHE PHOTOGRAMMETRIE (FPHG)

UND RADIOLOGISCHES SCANNEN

ANHAND EINES PRAKTISCHEN FALLES

Brüschweiler $\mathrm{W}^{1)}$, Braun $\mathrm{M}^{1)}$, Thali $\mathrm{MJ}^{2)}$, Taubenreuther $\mathrm{U}^{3)}$,

Scholz N ${ }^{3}$, Kalender W ${ }^{3)}$, Dirnhofer $\mathrm{R}^{2)}$

1) Wissenschaftlich-Technischer Dienst Stadtpolizei Zürich,

2) Institut der Rechtsmedizin Universität Bern,

3) Institut für medizinische Physik Universität Erlangen

FPHG ist eine Weiterentwicklung der u.a.in der Unfallauswertung altbewährten Photogrammetrie. Damit lassen sich in einem 3D/CADProgramm originalgetreu erstellte 3D-Modelle von geformten Verletzungen mit entsprechenden $3 \mathrm{D}$-Modellen von tatverdächtigen Werkzeugen auf gleiche Winkel, Masse und Formen überprüfen. Die Erfassung der Objekte erfolgt mittels Mehrfach-Fotographie oder bei einfachen Formen durch direkte Konstruktion im 3D/CAD-Verfahren. Zur Auswertung gelangt die Oberfläche der Modelle und nicht deren Tiefe. Um auch diese einbeziehen zu können, wird Radiologisches Scannen (Micro-TC) angewandt.

Das Opfer bei einem Tötungsdelikt wurde u.a. ins Gesäss gestochen. Für die Täteridentifizierung war bedeutend, ob der Stich mittels eines bestimmten Küchenmessers oder eines Stiletts erfolgte. Der Einstich war an der Knochenoberfläche wesentlich länger als je die breiteste Stelle an den beiden Klingen. Zudem war die Verletzung durch ein
Knochenbrücklein unterbrochen. Die Stichtiefe liess sich nicht bestimmen.

Das Ergebnis der am herauspräparierten Knochenstück ausgeführten Micro-TC ergab diesbezüglich aber eine genaue Angabe. Vergleichsversuche an Knochen mittels Küchenmessern und Stiletten der vorgegeben Art zeigten, bei welcher Art der Führung der Stichinstrumente das Knochenbrücklein entstand. Die kombinierten Untersuchungsergebnisse des FPGH-Verfahrens, der Micro-TC-Anwendung und der Stichversuche liessen das Küchenmesser als Tatwerkzeug ausscheiden. Das fragliche Stilett oder ein Instrument mit entsprechender Form, stand somit im Mittelpunkt der daraufhin weitergeführten polizeilichen Täterermittlung.

\section{V-88}

KÖNNEN PASSSPUREN FALSCH SEIN? -

FORENSISCHE PHOTOGRAMMETRIE (FPHG)

UND DIE AUSWERTUNG VON GEFORMTEN VERLETZUNGEN

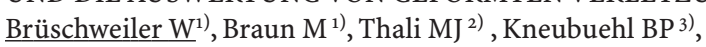

Dirnhofer $\mathrm{R}^{2)}$

1) Wissenschaftlich-Technischer Dienst Stadtpolizei Zürich,

2) Institut der Rechtsmedizin Universität Bern,

3) Bundesamt für Waffensysteme und Munition Thun

FPHG ist eine Weiterentwicklung der u.a. in der Unfallauswertung altbewährten Photogrammetrie. Eine Schlagverletzung lässt sich damit auf die Verursachung hin überprüfen. Die Verletzung und die Schlagfläche eines fraglichen Werkzeuges werden mittels Photogrammetrieund $3 \mathrm{D} / \mathrm{CAD}$-Verfahren im virtuellen Raum als $3 \mathrm{D}$-Objekte dargestellt und gegeneinander auf übereinstimmende Winkel, Mass und Formen überprüft. Die Erfassung der Objekte erfolgt mittels Mehrfach-Fotographie; liegen beim Werkzeug einfache Formen vor, kann dies auch direkt durch Rekonstruktion im 3D/CAD-Programm erfolgen.

Vergleichbar ist das FPHG-Verfahren mit direkten Einpassversuchen. FPGH widerläuft dabei aber nicht der Grundregel der Spurenauswertung - d.h. die Originalspur wird bei der Erfassung wie bei der Auswertung in keiner Art und Weise verändert. Zudem ist das FPHG-Verfahren zeitunabhängig - d.h. ist die Originalspur einmal fotografisch erfasst, kann der Vergleich mit einem tatverdächtigten Instrument später noch jederzeit ausgeführt werden.

FPHG nutzt im virtuellen Raum alle Vorteile eines 3D/CAD-Programmes, wie beliebiges Drehen der Modelle bis hin zur seitenverkehrten Darstellung. Eine solche Bild-Dokumentation erlaubt jedermann selber ein Urteil bezüglich des erzielten Ergebnisses abzugeben. Wir stellen einen Fall vor, bei dem nach unserer Beurteilung eine passgenaue Übereinstimmung zwischen der Schlagfläche des in die Untersuchung einbezogenen Werkzeuges und einer Schlagverletzung am Schädel eines Opfers vorliegt. Wir untermauern unseren Befund mit übereinstimmenden Ergebnissen, die wir mit Schlagversuchen mittels eines Fallapparates ausführten. Als Schädelersatz kam ein bewährtes Kunststoffmodell zum Einsatz.

\section{V-89}

DARSTELLUNG CAPILLÄRER GEFÄßSTRUKTUREN

MIT DER CONFOKALEN LASER-SCANNING-3D- MIKROSKOPIE

Lasczkowski ${ }^{1}$, Risse M1, Bohle RM ${ }^{2}$, Gamerdinger $\mathrm{U}^{2}$, Weiler $\mathrm{G}^{1}$

${ }^{1}$ Institut für Rechtsmedizin der Justus-Liebig-Universität,

Frankfurter Str. 58, 35392 Gießen

${ }^{2}$ Institut für Pathologie der Justus-Liebig-Universität,

Langhansstr. 10, 35392 Gießen

Die Confokale Laser Scanning Mikroskopie (CLSM) stellt ein Verfahren dar, welches sich die Erkenntnisse aus verschiedenen Feldern, 
wie Mikroskopie, Optik, Laser-, Video- und Computertechnik zunutze macht. Sie erlaubt die optische Darstellung definierter Schnittebenen in verschiedenen Tiefen eines Präparates, da Licht aus nur dieser einen, vorher bestimmten Ebene detektiert wird. Die so erzielten Informationen werden digitalisiert und dem Computer übermittelt. Im Rahmen eines Scann-Vorganges können verschiedene Schichten des Präparates aufgenommen und abgebildet werden. Bilder verschiedener Schnittebenen können vom Rechner übereinander projiziert und mit der 3 D Funktion räumliche Eindrücke vermittelt werden. Exemplarisch werden Darstellungen capillärer Gefäße im Bereich von Eryrthrocyten-Extravasaten präsentiert. Die Detektion erfolgte mit dem Confokalen Laser Scanning Mikroskop „Leica TCS SP“.

Nach den ersten Erfahrungen ist die CLSM als bildgebendes Verfahren geeignet, forensischen Fragestellungen nachzugehen, wobei die letztendlich nicht ausreichend geklärte Genese von conjunktivalen Stauungsblutungen mit dem exemplarisch dargestellten Verfahren geprüft werden soll.

\section{V-90}

IST DIE FORENSISCHE PSYCHIATRIE EINE WISSENSCHAFT?

Mitterauer B

Universität Salzburg, Institut für Forensische Neurospychiatrie, Ignaz-Harrer-Str. 79, A-5020 Salzburg

Es wird davon ausgegangen, dass die Forensische Psychiatrie die wissenschaftlichen Kriterien einer Naturwissenschaft nicht erfüllen kann. Die auf der Willensfreiheit beruhende Beurteilung der Schuldfähigkeit sowie Gefährlichkeitsprognosen sind naturwissenschaftlich nicht begründbare Fragen und daher eigentlich unentscheidbar. Da der Sachverständige aber diese Entscheidungen treffen muss, kann er zunächst auf eine Wahlfreiheit seiner Argumentation zurückgreifen. Dieser Entscheidungsprozeß sollte möglichst gut begründet sein, was eine laufende Verbesserung der psychobiologischen Begutachtungsmethodik erfordert. Dasselbe gilt für die psychiatrische Diagnostik, welche ebenfalls auf naturwissenschaftlich nicht begründbaren Konzepten beruht. Wir diagnostizieren psychobiologische Störungen, deren Ätiologie bzw. Pathogenese nach wie vor im Dunkeln liegt.

Der psychiatrische Sachverständige sollte dieses grundlegende Nichtwissen nicht nur selbst reflektieren, sondern sich auch in foro dazu bekennen. Gerichte gehen häufig davon aus, dass ein psychiatrisches Gutachten einer naturwissenschaftlichen Expertise vergleichbar ist. Dieser Irrtum sollte von vornherein aufgeklärt werden.

\section{V-91 \\ FEHLER DER AUFTRAGGEBER \\ Brunner A \\ Staatsanwaltschaft des Kantons Zürich}

Fehler (oder Irrtümer) können unter anderem in folgenden Bereichen liegen: Dass überhaupt ein Gutachten in Auftrag gegeben wird, dass der Auftrag an den „falschen“ Gutachter erteilt wird, dass der Auftrag zum falschen Zeitpunkt und ohne Berücksichtigung der zeitlichen Verhältnisse erteilt wird, dass die falschen Fragen gestellt werden, dass das Gutachten vom Auftraggeber ungelesen oder unverarbeitet zu den Akten genommen wird, dass der Gutachter nicht aufgefordert wird, sein Gutachten zu vervollständigen oder zu verbessern, dass zu viele Zweitgutachten oder Obergutachten bestellt werden. Bei so viel Fehlerquellen ist es aber gleichwohl sehr erfreulich, dass viele Gutachten auch wirklich gut sind.
$\mathrm{V}-92$

SIND FEHLER IN FORENSISCH-PSYCHIATRISCHEN GUTACHTEN VERMEIDBAR?

Mielke U

Integrierter Forensisch-Psychiatrischer Dienst, IRM, Universität Bern

Psychiatrische Gutachten helfen bei der Urteilsfindung und tragen zu Rechtssicherheit und Rechtsgleichheit bei. Sie müssen daher wissenschaftlich begründet und nachvollziehbar sein.

Falsche Schlussfolgerungen sind unvermeidbar, wenn Gutachter von unzutreffenden Voraussetzungen ausgehen. Psychiatrische Fehldiagnosen, die sich aus den Besonderheiten von Forschungsgegenstand und psychopathologischer Methodik ergeben, sind empirisch gut untersucht. Sie sind bei, ,harten “ Diagnosen wie hirnorganischen Störungen oder voll ausgebildeten Psychosen seltener, bei Persönlichkeitsund Anpassungsstörungen häufiger. Irrtümer sind dagegen vermeidbar, wenn sie auf fehlerhafter oder missverständlicher Anwendung von Methoden beruhen: Experten müssen die Reliabilität der angewandten Methode kennen und das diagnostische Referenzsystem nennen. Unzureichende Anknüpfungstatsachen bergen Fehlerquellen für prospektive und retrospektive Einschätzungen menschlichen Verhaltens. Ungenügende Würdigung individueller Befunde und mangelhafte Berücksichtigung empirischer Daten (z.B.Basisraten) können zu Fehleinschätzungen führen. Die operationale Diagnostik nach ICD10 oder DSM-4 hat zwar zu einer grösseren Validität psychiatrischer Diagnosen beigetragen. Sie ist jedoch typologisch ausgerichtet und löst die gutachtliche Aufgabe einer Aussage über Fähigkeitsprofile nicht. Die strukturale Psychologie und Psychopathologie bietet dagegen eine diagnostisch übergreifende Handlungstheorie. Sie ist systematisch, da sie sich auf grundlegende psychische Funktions- und Entwicklungsprinzipien (Kognition und Affektivität) bezieht. Rollenkonflikte gutachtender Therapeuten bedeuten Befangenheit. Irrtümer resultieren aber auch, wenn Wissenschaftler den Kompetenzbereich ihres Wissens überschreiten. Kompetenzentrennung bedeutet, dass das Gericht die Schuld beurteilt und der Experte lediglich die psychopathologischen Voraussetzungen der Schuldfähigkeit. Sie beginnt mit der begrifflichen Unterscheidung zwischen der allgemeinen Fähigkeit und deren motivabhängigen speziellen Gebrauch. Diese ist notwendig, da die Psychiatrie nur für die Beantwortung der Frage nach der allgemeinen, psychologisch-psychopathologisch erfassbaren Fähigkeit wissenschaftlich kompetent ist, für die Beurteilung des speziellen Fähigkeitsgebrauchs aber nicht.

Irrtümer infolge terminologischer Missverständnisse sind vermeidbar. Gutachtliche Schlussfolgerungen müssen verständlich formuliert, Fachbegriffe erklärt werden, andererseits müssen Beweisfragen eindeutig formuliert und die Anknüpfungstatsachen, auf die sie sich beziehen, benannt werden.

Wird der Aussagebereich forensisch-psychiatrischer Begutachtung kritisch reflektiert, terminologische Zweideutigkeit vermieden und die sachlich gebotene Kompetenzentrennung beachtet, sollte methodisch unvermeidbare Unsicherheit in Diagnose und Expertise nicht zu vermeidbaren Irrtümern im rechtlichen Ermessen führen.

\section{V-93}

FEHLER

IN DER FORENSISCH-PSYCHOLOGISCHEN BEGUTACHTUNG Pülschen D

Integrierter Forensisch-Psychiatrischer Dienst, IRM, Universität Bern

Betrifft die Rechtspsychologie jeden Schnittpunkt zwischen Jurisprudenz und Psychologie, so tangiert die Forensische Psychologie vornehmlich den der Rechtspflege mit einem ausgewiesen klinisch / diagnostischem Schwerpunkt. Forensische Psychologen sind in dabei als Sachverständige in den verschiedenen Rechtsgebieten, wie dem Straf-, Jugend-, Familien-, Verwaltungs- sowie zivilrechtlichem Gebiet zu finden. 
Angesichts der Komplexität der Materie, mit der es die Forensische Psychologie zu tun hat, betreffen Fehlerquellen der forensischen Aussagepsychologie vornehmlich deren Methodik sowie die weitergehende Interpretation der Befundlage zum Zweck der Erstellung psychologischer Glaubwürdigkeitsgutachten. Der Beitrag geht auf die (fallspezifischen) situativen und kognitiven Determinanten der Aussagegenauigkeit vs. Glaubhaftigkeit ein und beleuchtet den theoriegeleiteten Prozeß der forensischen Aussageanalyse mit Fokus auf die drei Bausteine ein: Analyse der Aussagetüchtigkeit (1), der Motivanalyse (2) und der abschließenden Inhaltsanalyse (3).

Im Rahmen der Beurteilung zur Zurechnungsfähigkeit (Art. 10, 11) ist innerhalb des diagnostischen Prozesses bspw. zu entscheiden, welche kognitiven, verbalen etc. Fertigkeiten als dynamische Persönlichkeitsanteile Untersuchungsgegenstand zurechnungsfähigkeitsrelevant sind, was wiederum die Frage nach einer Auswahl geeigneter psychologischer Testinstrumente aufwirft, die geeignet ist, eine etwaige krankheitsbedingte Herabsetzung der Einsichts- und / oder Steuerungsfähigkeit zu detektieren und damit Eingang in die gutachterliche Untersuchung finden soll, die ihrerseits welchen Qualitätsstandards $\mathrm{zu}$ genügen hat und wie zu strukturieren ist.

Auch hier betreffen die Fehlerquellen also vornehmlich methodische und Interpretationsfehlschlüsse, wenn mit Krankheitsbegriffen gearbeitet werden soll, die den juristischen kongruent sind.

\section{V-94}

GERICHTSMEDIZIN (RECHTSMEDIZIN) IM ALPINEN UMFELD

Rabl W

GMI Tirol, Innsbruck

„Zu Risiken und Nebenwirkungen fragen sie ihren Alpenverein oder Bergführer."

Das alpine Umfeld birgt neben wunderschönen Gipfeln, herrlicher Natur, interessanten Sport- und Freizeitmöglichkeiten auch einige spezifisch-alpine, oft unterschätzte Gefahren und physiologische Besonderheiten. Daraus ergeben sich indirekt spezielle Anforderungen an Erste Hilfe, Bergrettung, Alpingendarmerie und letztlich auch an die Gerichtsmedizin. Mitunter ist dies eine besonders günstige Gelegenheit, Beruf und Freizeit miteinander zu verknüpfen, wenn es gilt, einen unklaren Berg- oder Schiunfall vor Ort zu rekonstruieren oder etwa menschliche Knochen aus unwegsamem Gelände zu bergen. Daß einem dabei im Ötztal eine uralte Gletschermumie unterkommen kann, muß nicht extra erwähnt werden.

Ausgehend von markanten Fällen werden die besonderen fachlichen Anforderungen bei der Klärung von alpinen Todesfällen im Zusammenhang mit Wandern, Klettern, Schifahren, Snowboarden, Mountainbiking, Gletscherspalten, Lawinen, Blitzschlag etc. dargestellt.

\section{V-95}

TODESFÄLLE UND VERLETZUNGSMUSTER

IN DER SÄCHSISCHEN SCHWEIZ

Dreßler J, Arnold H, Arnold T

Institut für Rechtsmedizin, Medizinische Fakultät Carl Gustav Carus der Technischen Universität Dresden, Fetscherstraße 74, 01307 Dresden

Die Möglichkeiten der Diagnostik nach Sturz aus der Höhe sind insbesondere für den Leichenschauarzt begrenzt. Im Elbsandsteingebirge treten daher gehäuft Fälle mit primär unklarer Todesursache und -art auf. Im Untersuchungszeitraum von 1970-2000 wurden die obduzierten Todesfälle, Verletzungsmuster nach Sturz beim Klettern, die mögliche Alkoholisierung und die Autolyse-/Fäulnisresistenz morphologischer Befunde analysiert. In diesem Zeitraum gab es grundlegende Veränderungen in der Sicherungstechnik: Anfänglich wurde nur eine sog. Brusteinbinde durchgeführt, diese wurde durch den Brustgurt (größere Auflagefläche) abgelöst. Später erfolgte die Sicherung durch kombinierte Brust- und Beckengurte, während heute fast ausnahmslos Sitzgurte verschiedener Hersteller zum Einsatz kommen. Das Tragen eines Schutzhelmes ist im Elbsandsteingebirge wegen fast auszuschließender Steinschlaggefahr wenig verbreitet. Aufgrund der genannten Sicherungstechniken resultieren charakteristische Verletzungen, z.B. traten bei der Brustsicherung signifikant häufiger Herzkontusionen und bei isolierter Verwendung des Sitzgurtes Beckenverletzungen mit Rupturen des Hilus renalis im Vergleich zu kombinierten Sicherungssystemen auf.Ein Drittel aller Todesfälle des Untersuchungsgebietes waren als natürlicher und zwei Drittel als nichtnatürlicher Tod zu klassifizieren. Unter den nichtnatürlichen Todesfällen waren $45 \%$ alkoholisch beeinflusst. Zwei Drittel dieser Fälle wiesen eine BAK von $2 \%$ auf. Histologisch wurden trotz fortgeschrittener Leichenveränderungen in $54 \%$ Schockäquivalente festgestellt. Besondere Autolyse- /Fäulnisresistenz besitzt dabei die Mikrothrombosierung und Fettembolie der Lunge. Nur die Obduktion kann in Verbindung mit kriminalpolizeilichen Ermittlungen, so. z.B. zu Einzelheiten am Fundort oder Zeugenangaben, Aufschluss in der Unterscheidung Unfall, Suizid oder Homizid geben.

\section{V-96}

BEFUNDMUSTER BEIM LAWINENTOD

Eberl N, Paetzold V, Keil W

Institut für Rechtsmedizin der Ludwig-Maximilians-Universität, München

Im Zeitraum von 1990 bis 2001 wurden im bayerischen Alpenraum 46 Menschen von Schneelawinen erfaßt, dabei kamen 23 ums Leben. Im Institut für Rechtsmedizin der Universität München wurden im selben Zeitraum lediglich drei Opfer obduziert. Die geringe Obduktionsquote beim Lawinentod und die nur sporadische Bearbeitung dieser Thematik in der Literatur waren Anlaß, die von uns bearbeiteten Fälle näher zu analysieren.

Bei den Toten handelte es sich um zwei Frauen im Alter von 43 und 57 Jahren und einen 41-jährigen Mann. Bei den Leichen der Frauen dominierten Erstickungszeichen - besonders punktförmige Blutaustritte in der Augenregion bzw. subpleural, die allerdings nur dezent ausgebildet waren. Ferner wurden erhebliche Hirndruckveränderungen beobachtet. Deshalb wurde als Todesursache in beiden Fällen Ersticken durch Kompression des Brustkorbes bzw. durch Verlegung der Atemwege mit Schnee festgestellt. Bei der Obduktion der Leiche des Mannes zeigten sich Zeichen stumpfer Traumatisierung besonders des Brustkorbes (Rippenserienfrakturen, Lungenrupturen, Hämatopneumothorax) und Befunde wie bei allgemeiner Unterkühlung (Kälteerythem, hämorrhagische Magenschleimhauterosionen). Die Kombination von beidem wurde als ursächlich für den Tod angesehen. Die Obduktionsbefunde werden unter Berücksichtigung der Auffindungssituationen diskutiert, wobei insbesondere das Vorhandensein etwaiger Atemhöhlen im Schnee beachtet wurde. Da die Obduktionsrate bei Lawinentodesfällen verhältnismäßig niedrig ist, kann die Todesursache häufig nicht mit letzter Sicherheit geklärt werden. Ihre Kenntnis wäre aber eine wesentliche Voraussetzung, um die Todeseintrittsmechanismen bei Lawinenopfern besser zu verstehen, weitere Therapierichtlinien für die erstversorgenden Ärzte abzuleiten und die Überlebenschance Verschütteter zu erhöhen. 
V-97

EIN DOKUMENTIERTER FALL

EINES TÖDLICHEN SNOWBOARDUNFALLES

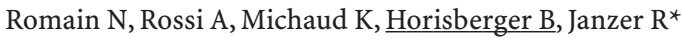

und Mangin $\mathrm{P}$

Institut für Rechtsmedizin der Universität Lausanne,

Rue du Bugnon 21, CH-1005 Lausanne

*Institut für Pathologie, Rue du Bugnon 25, CH-1005 Lausanne

Wir berichten über den ersten im Lauf eines Weltcupwettkampfes tödlich ausgegangenen Snowboardunfall, für welchen uns eine Videoaufnahme zur Verfügung steht. Auch wenn es relativ zahlreiche Studien über Snowboardunfälle gibt, haben wir nur 8 in der Literatur abgehandelte Fälle von tödlichen Unfällen gefunden.

Während des Parallel-Riesenslaloms prallte ein 25 jähriger Profisnowboarder gegen das Zieltor und verstarb auf der Stelle. Seine Aufprallgeschwindigkeit wurde auf $60-70 \mathrm{~km} / \mathrm{h}$ geschätzt.

Außer einer linken palpebralen Ekchymose hat die Leichenschau dieses athletischen Opfers keine Verletzungen aufgezeigt. Die Obduktion hat thorakale und zervikale Läsionen traumatischen Ursprunges aufgedeckt. Wir haben einen Doppeldurchbruch des Aortenbogens mit beidseitigem $1300 \mathrm{ml}$ fassenden Hämothorax festgestellt, sowie mehrere beidseitige kostale Frakturen und Lungenprellungsherde. Die zervikale Wirbelsäule hat eine Dens Axis Fraktur mit Rückenmarkdruck gezeigt. Des weiteren ist neuropathologisch ein Hirnstammabriß auf pontobulbärer Höhe dargestellt worden. Die toxikologisch-chemischen Untersuchungen waren negativ.

Diese thorakalen und zervikalen traumatischen Läsionen sind mit jenen bei Verkehrsunfällen vergleichbar. In diesem Zusammenhang hat eine neue Studie bewiesen, dass bei der Kollision eines PKW's mit einem Fußgänger Durchbrüche oder Riße der thorakalen Aorta entstehen, sobald Aufprallgeschwindigkeiten von $63 \mathrm{~km} / \mathrm{h}$ erreicht werden. Traumatische Wirbelsäulenfrakturen, die in 50\% der Fälle die Zervikalsäule betreffen, sind ab $45 \mathrm{~km} / \mathrm{h}$ üblich.

Nach Beendigung seiner Nachforschungen hat der zuständige Untersuchungsrichter, der die Obduktion angeordnet hatte, die Einstellung des Verfahrens ausgesprochen.

\section{V-98 \\ STEINSCHLAG ODER SCHLÄGE MIT STEINEN? \\ Zollinger $\mathrm{U}^{1}$, Brüschweiler $\mathrm{W}^{2}$ \\ ${ }^{1}$ Institut für Rechtsmedizin der Universität Bern \\ ${ }^{2}$ Wissenschaftlicher Dienst der Stadtpolizei Zürich}

Im August 1985 verstarb eine 47-jährige Frau anlässlich einer Bergwanderung mit ihrem Ehemann. Dieser gab an, sie seien bei der Begehung eines lichten Wäldchens unterhalb einer Felswand plötzlich von einem Steinschlag überrascht worden. Während der Ehemann mit Ausnahme einiger Schürfungen an den Beinen unverletzt blieb, erlitt die Frau ein schwerstes stumpfes Schädelhirn- und Nackentrauma. Aufgrund der Verteilung und Morphologie der Weichteilquetschungen, der Hautwunden und der Schädelfrakturen war von einer mehrfachen stumpfen Einwirkung auf die Hinterkopf- und Nackenregion auszugehen.

Am Ereignisort wurden zahlreiche Blutspuren und mehrere, zum Teil doppelseitig mit Blut und Haaren behaftete schwere Steine gefunden, welche bemoost waren und keine frischen Abbruchspuren eines Steinschlages zeigten. Einer dieser Steine passte in eine frische Erdvertiefung. Nur ein Baumstamm unterhalb des Tatortes wies eine Beschädigung der Rinde auf.

Wir beurteilten den Fall als Fremdtötung durch mehrmalige massive Schläge mit Steinen auf das bäuchlings am Boden liegende Opfer. Der Ehemann, welcher die Tat stets vehement bestritt, wurde erstinstanzlich wegen vorsätzlicher Tötung verurteilt. Nach Appellation seines Verteidigers erfolgte zweitinstanzlich ein Freispruch mangels Beweisen. Dazu beigetragen hatten ein nicht erkennbares Tatmotiv und nicht zuletzt Aussagen eines Psychiaters und ein geologisches Gutachten.

Die rechtsmedizinischen Befunde und die spurenkundlichen Untersuchungsresultate dieses Falles werden vorgestellt.

\section{V-99}

DER ABSTURZ IM GEBIRGE -

VITAL, AGONAL ODER POSTMORTAL ?

Patscheider ${ }^{1} \mathrm{H}, \underline{\text { Dirnhofer }} \underline{2} \underline{\mathrm{R}}$, Thali $^{2} \mathrm{M}$

${ }^{1}$ St. Gallen

${ }^{2}$ Institut für Rechtsmedizin der Universität Bern, Bühlstr. 20, $\mathrm{CH}-3012$ Bern

Der Sturz aus der Höhe und damit auch der Absturz im Gebirge zählt hinsichtlich der forensisch-rekonstruktiven Aufgaben zu den grossen Herausforderungen unseres Faches. Dies vor allem deshalb, weil die unterschiedliche Geländebeschaffenheit wie Schnee, Eis, Fels, Geröll etc. zu unterschiedlichem Verletzungsmuster führt. Anhand kasuistischer Beobachtungen wird ein charakteristisches Befundmuster vorgestellt, das eine Beantwortung der im Vortragstitel gestellten Frage zulässt.

\section{V-100 \\ ZUR WERTIGKEIT DES KEILBEINHOHLENZEICHENS \\ FÜR DIE ERTRINKUNGSDIAGNOSTIK \\ Bohnert M, Ropohl D, Pollak S \\ Institut für Rechtsmedizin, Universitätsklinikum Freiburg, \\ Albertstr. 9, D-79104 Freiburg}

Als ein Zeichen des typischen Ertrinkens wird neben dem Vorliegen eines Schaumpilzes, eines Emphysema acquosum, Paltauf'scher Flecken oder einer vermehrten Hämolyse des Blutes in der linken Herzkammer auch wässriger Inhalt in den Nasennebenhöhlen angesehen. Besonders die Keilbeinhöhle ist autoptisch leicht zugänglich; ihr Inhalt kann von der Schädelbasis aus mit einer Kanüle aspiriert werden. Die Wertigkeit dieses sogenannten Keilbeinhöhlenzeichens wurde konsekutiv bei 60 Todesfällen durch Ertrinken sowie bei 180 anderen Todesfällen untersucht. Es zeigte sich, dass in über $90 \%$ der Ertrinkungsfälle zwischen $1 \mathrm{ml}$ und $4 \mathrm{ml}$ Flüssigkeit in den Kammern des Sinus sphenoidalis gefunden werden konnte. Aber auch in $60 \%$ der übrigen Obduktionsfälle verlief die Probe positiv, wobei das Aspirat in der Kontrollgruppe ein durchschnittlich geringeres Volumen hatte als in der Gruppe der Ertrunkenen. Das Keilbeinhöhlenzeichen sollte daher kritisch und nur im Zusammenhang mit anderen morphologischen Veränderungen für die Diagnose eines Ertrinkungstodes herangezogen werden.

\section{V-101}

MORPHOMETRISCHE UNTERSUCHUNG

ÜBER DAS EMPHYSEMA AQUOSUM IM SENIUM

Kohlhase C, Maxeiner $\mathrm{H}$

Rechtsmedizin der FU Berlin

Bei der Untersuchung ertrunkener alter Personen stellte sich uns wiederholt die Frage, inwieweit senile emphysematische Veränderungen den Nachweis des akuten Ertrinkungsemphysems erschweren. Wir verglichen das Alveolarparenchym von 6 ertrunkenen morphometrisch mit dem von 6 nicht ertrunkenen, akut aus innerer Ursache verstorbenen Personen der Altersgruppe über 70 Jahre. Ausschlußkriterien: Fäulnis, gravierende pathologische Lungenveränderungen (von einem substantiellen Emphysem abgesehen), versuchte Reanimation. 


\section{Abstracts}

Immersionsfixation der rechten, In-situ-Perfusionsfixation der linken Lungen (Formalin). Entnahme von je 3 Proben aus definierten Entnahmestellen der großen Lungenlappen, Paraplasteinbettung, H.E.Färbung. Pro Präparat Mikroaufnahmen von 50 Gesichtsfeldern in mittlerer Vergrößerung als Digitalbilder - pro Fall 600 Bilder - und Messung mittels computergestützter Bildanalyse. Messung von: alveolärem Ödem, Gewebe als Ganzes, Septen bzw. nicht-septale Strukturen getrennt. Anwendung einfacher und komplexer Meßparameter.

Wurde nur immersionsfixiert, so war einzig die minimale Septenbreite der Ertrinkungslungen hochsignifikant geringer als die der Kontrollen, weitere signifikante Unterschiede traten erst nach In-situFixierung hervor. Die Ertrinkungslungen zeigten schon in den einfachen Parametern weniger Ödem sowie mehr Luft/weniger Gewebe pro Raumeinheit als die Kontrollen, insbesondere war der Anteil septaler Strukturen am Gewebsgerüst deutlich erhöht. Komplexere Parameter boten keine verwertbaren Unterschiede zwischen beiden Gruppen. Die Befunde machten generell das Vorliegen hypo- und orthostatischer Einflüsse wahrscheinlich

Trotz signifikanter Unterschiede zwischen Ertrunkenen und NichtErtrunkenen gab es keinen Befund, der beide Gruppen überschneidungsfrei trennte.

\section{V-102}

\section{ALTERSABHÄNGIGE EXPRESSION}

VON 8-HYDROXY-2-DEOXYGUANOSINE

IN MENSCHLICHEN HYPOPHYSEN

Kondo T, Ohshima T, Ohshima K, Ishida Y, Mori R

Institut für Rechtsmedizin der Universität Kanazawa, Kanazawa, Japan

\section{Einleitung:}

In der vorliegenden Studie untersuchten wir die Expression der nuklearen 8-OHdG, ein Marker für oxidative Belastung, in menschlichen Hypophysen.

Materialien und Methoden:

Insgesamt wurden im Rahmen forensischer Autopsien in unserer Abteilung 65 menschliche Hypophysen (37 von männlichen und 28 von weiblichen Kadavern) gesammelt. Das Alter der Leichen variierte zwischen 19 und 88 Jahre (durchschnittliches Alter: 47,4 Jahre) und das Postmortem Intervall war in allen Fällen weniger als 3 Tage.

Die Proben wurden mit einer phosphatgepufferten $4 \%$ igen Formaldehyd Kochsalzlöung fixiert und anschließend $6 \mu \mathrm{m}$ dicke Schnitte der in Paraffin eingelegten Proben angefertigt. Nach der Deparaffinierung wurden diese mit monoklonalen Maus Anti-8-OHdG Antikörpern reagiert. Daraufhin wurde der Prozentsatz der positiv reagierenden Zellen im Verhältnis zur Gesamtzahl der Parenchymzellen für jedes einzelne mikroskopische Feld berechnet. Der Durchschnittswert von 10 ausgewählten mikroskopischen Feldern wurde dann für jede Probe bewertet.

Die Beziehung zwischen Alter und dem Verhältnis 8-OHdG positiv reagierender Zellen wurde mit Hilfe der linearen Regressionsanalyse untersucht.

Ergebnisse und Diskussion:

Immunhistochemisch wurden positive Signale von 8-OHdG im Kern parenchymaler Zellen im Vorderlappen der Hypophyse nachgewiesen. In jeder Altersgruppe nach das Verhältnis 8-OHdG positiv reagierender Zellen allmählich zu. In allen Fällen zeigte die einfache Regressionsanalyse eine signifikante Beziehung zwischen Alter und dem Verhältnis 8-OHdG positiv reagierender Zellen $(\mathrm{r}=0,757, \mathrm{p}<0,01)$. Die Regressionsgleichung lautete $\mathrm{y}=0,957 \mathrm{x}-1,736(\mathrm{x}=$ Verhältnis $8-\mathrm{OHdG}$ positiv reagierender Zellen, $y=$ Alter in Jahren). Pathophysiologisch deuten diese Ergebnisse auf eine Beziehung zwischen dem Altersprozess und oxidativer DNA Schädigungen des endokrinen Systems hin. Daher wird 8-OHdG als ein hilfreicher Marker zur Altersbestimmung von Leichen angesehen.

\section{V-103}

LIPOPOLYSACCHARID-BINDENDES PROTEIN (LBP),

LÖSLICHER INTERLEUKIN-2 REZEPTOR (SIL-2R)

UND INTERLEUKIN-1B (IL-1 $\beta)$ :

BIOCHEMISCHE PARAMETER

FÜR DIE POSTMORTALE DIAGNOSE EINER SEPSIS

Reichelt U, Tsokos M

Institut für Rechtsmedizin, Butenfeld 34, D-22529 Hamburg

Prospektiv wurden die Entzündungsmediatoren LBP, sIL-2R und IL-1 $\beta$ auf ihre mögliche postmortale Anwendbarkeit hin untersucht. In die Sepsisgruppe gingen 8 intensivpflichtige Patienten ein. Die klinische Diagnose wurde durch Autopsie und Histologie verifiziert. Die Kontrollgruppe bildeten 16 Verstorbene ohne Hinweise auf ein infektiöses Geschehen vor dem Tode, was autoptisch bestätigt wurde. In der Sepsisgruppe wurde eine venöse Blutprobe zwischen 54 min und 3,4 h vor dem Tode entnommen, postmortal fanden in beiden Gruppen in einem Zeitraum von 20 min bis 139 h 3 bis 5 venöse Blutentnahmen statt. In der Sepsisgruppe fanden sich antemortal, sowie im gesamten postmortalen Intervall signifikant erhöhte LBP- und sIL-2R-Serumwerte $(\mathrm{p}<0,01)$. Mittels eines linearen Regressionsmodels kann der Wert der Entzündungsparameter zum Zeitpunkt $\mathrm{t}=\mathrm{o}$ (Todeszeitpunkt) errechnet werden. Antemortaler und errechneter postmortaler Wert zum Zeitpunkt $\mathrm{t}=\mathrm{o}$ korrelierten hierbei gut. Bei einem Referenzwert von $<5 \mu \mathrm{g} / \mathrm{ml}$ bei lebenden gesunden Probanden zeigten die LBP-Werte eine Variationsbreite von $112 \mu \mathrm{g} / \mathrm{ml}(1,2 \mathrm{~h}$ p.m.) bis $12,9 \mu \mathrm{g} / \mathrm{ml}$ (139 h p.m.) in der Sepsisgruppe, während sie in der Kontrollgruppe bei 94\% der Patienten zu allen Zeitpunkten unter $10 \mu \mathrm{g} / \mathrm{ml}$ lagen. Zu keinem Zeitpunkt fanden sich in der Sepsisgruppe sIL-2RSerumwerte unter dem Referenzlimit von $<1000 \mathrm{U} / \mathrm{ml}$; in der Kontrollgruppe stiegen die Werte in einem Fall auf $1044 \mathrm{U} / \mathrm{ml}$ (48 h p.m.) an. Im Gegensatz dazu stieg IL-1 $\beta$ in der Sepsisgruppe und in der Kontrollgruppe kontinuierlich an, beginnend im frühen postmortalen Intervall bei Werten, die im Referenzbereich von $<5 \mathrm{pg} / \mathrm{ml}$ liegen. Sowohl LBP, als auch sIL-2R erscheinen bis zu einem Zeitpunkt von 140 Stunden geeignete biochemische Marker für die postmortale Sepsisdiagnostik darzustellen.

\section{$\mathrm{V}-104$}

ZUM ZEREBRALEN AMINOSÄUREMUSTER

BEI NIERENERKRANKUNGEN -

EINE POSTMORTAL BIOCHEMISCHE UNTERSUCHUNG

$\underline{\text { Schmidt P }} \stackrel{1}{ }$, Musshoff $\mathrm{F}^{1}$, Madea $\mathrm{B}^{1}$, Khoury $\mathrm{C}^{1}$, Bürig $\mathrm{KF}^{3}$ Jacob $\mathrm{B}^{2}$, Bonte $\mathrm{W}^{2}(\dagger)$, Daldrup $\mathrm{T}^{2}$

${ }^{1}$ Institut für Rechtsmedizin der Universität Bonn,

Institute für ${ }^{2}$ Rechtsmedizin und

3Pathologie der Universität Düsseldorf

Pathobiochemisch wurden bei Patienten mit Niereninsuffizienz charakteristische Veränderungen der Aminosäurekonzentrationen im Blut gefunden. In einer Studie an autoptisch gewonnenem Hirngewebe (Cortexarea 4 nach Brodmann) wird überprüft, ob sich vergleichbare Veränderungen auch postmortal nachweisen lassen und die morphologische Diagnostik ergänzen können. Das Untersuchungsgut bestand aus 12 niereninsuffizienten Patienten $(m=5, w=7$, Alter 27-85 J, Todesursache: 4 x Herzkreislauferkrankung, 4 x Malignom, $2 \mathrm{x}$ Pneumonie, $3 \mathrm{x}$ andere, Nierenerkrankung: $8 \mathrm{x}$ Schrumpfnieren, $6 \mathrm{x}$ vaskuläre Nierenerkrankungen, $9 \mathrm{x}$ andere, Harnstoff 1,9 $6,9 \mathrm{mg} / \mathrm{dl}$, postmortales Intervall (PMI) $<72 \mathrm{Std}$.). Die Kontrollgruppe umfaßte 26 Patienten $(\mathrm{m}=14, \mathrm{w}=12$, Alter $44-91 \mathrm{~J}$., PMI $<72$ Std. $)$ mit todesursächlichen Herz-Kreislauferkrankungen, die keine Leber- oder Nierenerkrankung und keine Stoffwechselstörung aufwiesen. Ausgewertet wurden Krankenunterlagen, pathologisch anatomische Diagnose und histologische Befunde. Die Konzentrationen der freien Aminosäuren (AS) im Gehirn wurde mit einem Aminosäure- 
analysator bestimmt. Mit Bezug auf Alter, Geschlecht und postmortales Intervall zeigten sich keine signifikanten Konzentrationsunterschiede. Der maßgebliche Unterschied bestand in der signifikanten Erhöhung der zerebralen Harnstoffkonzentration (Median 3,36 vs. 1,42). Ferner waren die Konzentrationen an Glutamin, Glutamat, Cystein und Phenylalanin erhöht. Zusammenfassend deuten diese Befunde darauf hin, dass mit der postmortalen Aminosäureanalytik Veränderungen der zerebralen AS-Konzentrationen erfasst werden, mit deren Hilfe dem morphologischen Bild der schweren Nierenerkrankung das pathophysiologische Korrelat der Niereninsuffizienz zugeordnet werden kann.

\section{V-105}

\section{UNERWARTETER TOD DURCH MAGENRUPTUR}

Miyaishi S, Ishikawa T, Inagaki S, Yoshitome K, Yamamoto Y, Ishizu H Institut für Rechtsmedizin der Universität Okayama, Okayama, Japan

Falldarstellung: Die nicht-traumatische Magenruptur ist ein sehr seltenes Geschehen. - Ein 49-jähriger Mann, der einige Stunden zuvor über Bauchschmerzen geklagt hatte, wurde in einer Toilette tot aufgefunden. Es befanden sich keine Exkremente im Toilettenbecken sowie keine Spuren von Erbrochenem um den Leichnam herum.

Obduktionsbefunde: Bei der Sektion zeigten sich in der Bauchhöhle ca. $3000 \mathrm{ml}$ teils flüssiger Mageninhalt (überwiegend angedaute, gekochte Reiskörner). Der Magen war hochgradig dilatiert. Zwei Rupturen (14 cm und $6 \mathrm{~cm}$ lang) lagen auf der Seite der großen Kurvatur im Bereich des Corpus ventriculi; keine Nekrose am Rand der Rupturstellen. Weiterhin bestanden drei Ulcera in der Magenschleimhaut, wovon ein ca. $3,5 \mathrm{~cm}$ x 3,0 cm großes der kleinen Kurvatur ins Pankreas penetrierte (ohne Gefäßarrosion am Ulcusgrund). Mundhöhle, Ösophagus sowie der gesamte Dünndarm waren leer. Keine Verletzungen und keine sonstigen relevanten inneren Erkrankungen. Todesursache war die Magenruptur.

Diskussion: In den meisten bisher berichteten Fällen mit Magenruptur (überwiegend Frauen) bestand zumeist nur eine kurze Ruptur auf der Seite der kleinen Kurvatur. In unserem Fall fanden sich zwei lange Rupturen an der großen Kurvatur. Pathogenetisch war im hier berichteten Fall an eine sehr hochgradige Magendilatation wegen $\mathrm{Bu}-$ limie des Toten zu denken. Wir haben keine klinische Erklärung dafür, warum der Innendruck des Magens sich sonst erhöhte. Die abnehmende Beweglichkeit und Dehnbarkeit der Magenwand an der Seite der kleinen Kurvatur wegen des ins Pankreas penetrierenden großen Geschwürs lassen auch an die Möglichkeit denken, dass dies eine Störung der Motilität des ganzen Magens sowie eine überschüssige Extension der großen Kurvatur des Magens hervorrief.

\section{V-106}

\section{ZUR FORENSISCHEN QUANTIFIZIERUNG} DER VERLETZUNGSSCHWERE

\section{MITTELS INJURY SEVERITY SCORE}

Schmidt P, Orlopp K, Madea B

Institut für Rechtsmedizin der Universität Bonn

An einem Sektionsgut von 45 Tötungsdelikten (25 Frauen, 20 Männer, Alter 11 bis 91 Jahre, M.W. 42 Jahre) wird retrospektiv analysiert, ob ein in der Unfallchirurgie entwickeltes mathematisches System zur quantitativen Skalierung der Traumaschwere (ISS) geeignet ist, die Verletzungsschwere auch unter forensischen Fragestellungen objektiv und reproduzierbar zu bewerten. Todesursächlich waren $26 \mathrm{x}$ Verletzungen durch scharfe Gewalt, 20 x durch stumpfe Gewalt, 14 x Halskompression und $4 \mathrm{x}$ Schuss. Lokalisiert waren die maßgeblichen Verletzungen $23 \mathrm{x}$ am Schädel, $20 \mathrm{x}$ am Thorax und $3 \mathrm{x}$ im Abdomen. Signifikant hohe Traumascores finden sich bei Opfern aus den jüngeren Altersklassen (<6o Jahre) (ISS von 45 vs. 27). Todesursächliche Verletzun- gen durch scharfe Gewalt und Schuß erreichten signifikant höhere Skalierungen als solche durch stumpfe Gewalt (ISS von 52 bzw. 50 vs. 23). Bei Lokalisation der gravierendsten Verletzung in der Thoraxregion waren die ISS-Werte deutlich höher als bei Schädel- und Bauchverletzungen (ISS von 53 vs. 32 und 28). Probleme ergaben sich bei der angemessenen Bewertung einer tödlichen Halskompression, der quantitativen Berücksichtigung hochgradiger Blutverluste und der Lokalisation mehrerer relevanter Verletzungen in ein- und derselben Körperregion. Systematische Unterbewertungen im Vergleich mit der klinischen Anwendung resultieren daraus, dass die Beeinträchtigung der Vitalfunktionen autoptisch naturgemäß nicht quantitativ abgestuft einbezogen werden kann. Möglichkeiten einer Objektivierung der Begutachtung sind bei Anwendung des ISS z.B. bei der Abwägung einzelner Tatbeiträge in Tötungsdelikten mit mehreren Tätern zu erwarten.

\section{V-107}

WACHSTUMSVERHALTEN NEKROPHAGER INSEKTEN

IN ABHÄNGIGKEIT VON DER UMGEBUNGSTEMPERATUR

Wolf I, Schröder H, Klotzbach H, Püschel K

Institut für Rechtsmedizin,

Universitätsklinikum Hamburg-Eppendorf

Die Entwicklungsgeschwindigkeit nekrophager Insekten ist stark abhängig von äußeren Faktoren, wie vor allem der Umgebungstemperatur, ferner auch den Lichtverhältnissen sowie der Luftfeuchtigkeit. Diese Faktoren müssen bei der Berechnung der Leichenliegezeit berücksichtigt werden. Systematische Untersuchungen an relevanten nekrophagen Insekten des mitteleuropäischen Raumes hinsichtlich des Einflusses der Umgebungstemperatur auf deren Wachstumsgeschwindigkeit finden sich mit Ausnahme von zwei Schmeißfliegenarten (Calliphora vicinia, Phormia regina) in der verfügbaren Literatur nicht.

Ziel der vorliegenden Arbeit war die Dokumentation der Wachstumsgeschwindigkeit von drei nekrophagen Fliegenarten (Calliphora vicina, Calliphora vomitoria, Lucilia sericata) in Abhängigkeit von der Umgebungstemperatur. Hierzu wurden Larven der drei genannten Arten bei verschiedenen Umgebungstemperaturen unter konstanter Luftfeuchtigkeit und Temperatur gezüchtet. Die einzelnen Entwicklungsstadien wurden in engen zeitlichen Abständen kontrolliert und verglichen. Hierbei zeigte sich für alle untersuchten Fliegenarten mit zunehmender Temperatur eine Verkürzung der Entwicklungszeit um einige Tage. Ferner konnte festgestellt werden, dass sich die Toleranzgrenzen gegenüber niedrigen Temperaturen bei den einzelnen Arten stark unterscheiden. Lucilia sericata reagiert besonders sensibel auf niedrige Temperaturen. Bereits bei $12^{\circ} \mathrm{C}$ sind die Larven nicht mehr in der Lage aus dem Ei zu schlüpfen, während Calliphora vicina noch bei $7^{\circ} \mathrm{C}$ zur Entwicklung kommt.

Die vorliegende Arbeit verdeutlicht den erheblichen Einfluss der Umgebungstemperatur auf die Entwicklungsstadien nekrophager Insekten.

\section{V-108}

DNA-ANALYSE ZUR DIFFERENZIERUNG

FORENSISCH RELEVANTER SCHMEIßFLIEGENARTEN

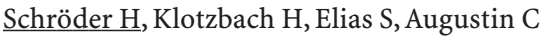

Institut für Rechtsmedizin,

Universitätsklinikum Hamburg-Eppendorf

Anhand des Alters der Entwicklungsstadien von Fliegen, die an einem Verstorbenen gefunden werden, kann der Todeszeitpunkt zurückgerechnet werden. Zu diesem Zweck muß die Artzugehörigkeit der aufgefundenen Fliegenlarven geklärt werden. Innerhalb der forensisch relevanten Familie der Schmeißfliegen (Calliphoridae) und zur 


\section{Abstracts}

nahe verwandten Familie der Fleischfliegen (Sarcophagidae) ist die Unterscheidung mit klassisch-morphologischen Merkmalen nicht immer eindeutig realisierbar.

Ziel der Studie war die Entwicklung eines schnellen und präzisen Tests zur Unterscheidung möglichst vieler heimischer, forensisch relevanter Fliegenarten. Mittels DNA-Analyse - und zwar über die Erstellung von PCR-RFLPs - wird diese Unterscheidung ermöglicht. Es handelt sich hierbei um die Kombination aus PCR-Technik, mit deren Hilfe spezifische Fragmente der mitochondrialen DNA amplifiziert werden und dem Schneiden dieser Fragmente mit Restriktionsenzymen. Es werden Ergebnisse zu zwei verschiedenen Fragmenten vorgestellt: Mit einem 348 bp großen Fragment des COI-Gens werden durch Schneiden mit vier verschiedenen Restriktionsenzymen unterschiedliche Bandenmuster für die wichtigsten Arten erzielt. Mit einem 1305 bp großen Fragment, das im Bereich des COI und COII Gens amplifiziert wird, konnte die Methode bereits optimiert werden. Für dieses Fragment genügt das Schneiden mit nur einem Restriktionsenzym, um die Differenzierung der verschiedenen Arten zu erreichen.

\section{V-109}

ORGANENTNAHME ZU WISSENSCHAFTLICHEN ZWECKEN BEI FÖTEN.

Berzlanovich A, Muhm M, Denk W, Bauer G

Institut für Gerichtliche Medizin, Universität Wien,

Sensengasse 2, A - 1090 Wien

Bei der Leibesfrucht einer 31-jährigen Frau wurde in der 27./28. SSW bei einer Ultraschalluntersuchung ein Bickers-Adams-Syndrom diagnostiziert. Aufgrund der äußerst ungünstigen Prognose und der Tatsache, daß die Frau bereits ein schwer behindertes Kind mit Hydrozephalus geboren hatte, wurde dem Wunsch der Patientin nach einer Schwangerschaftsbeendigung entsprochen.

Nach erfolgtem Fruchtabgang wurde im Rahmen einer wissenschaftlichen Studie die Entnahme beider Bulbi durchgeführt.

Der männliche Fötus gelangte mit der Fragestellung \$190 StGB (Störung der Totenruhe) zur gerichtlichen Obduktion.

Wohl gehört unter den Begriff „menschlicher Leichnam“ auch ein totgeborenes Kind, jedoch mit der Einschränkung, daß nach gängiger Rechtsprechung dem Begriff nur der Körper eines tatsächlich lebensfähig gewesenen menschlichen Wesen entsprechen kann. Nach wissenschaftlichen Erkenntnissen wird eine menschliche Leibesfrucht erst nach Ablauf der 24. SSW als lebensfähig angesehen.

Strafbar ist nach $\$ 190$ StGB auch, wer „einen Leichnam mißhandelt“. Wie Platzgummer am Beispiel der Leichenoperationen nachgewiesen hat, fällt unter Mißhandlung der Leiche nicht jeder körperliche Eingriff am Toten, sondern nur eine „üble, unangemessene Behandlung“" die eine Geringschätzung gegenüber dem Toten zum Ausdruck bringt und das Pietätsempfinden der Allgemeinheit verletzt.

Ob die Organentnahme zu wissenschaftlichen Zwecken bei Föten diese Tatbestände erfüllt wird diskutiert.

\section{$\mathrm{V}-110$ \\ EINSATZ ANIMIERTER GRAFIKEN UND VIDEOSEQUENZEN IN DER RECHTSMEDIZINISCHEN LEHRE: TECHNISCHE UND DIDAKTISCHE ASPEKTE \\ Dilger M, Fink T \\ Institut für Rechtsmedizin, Johannes Gutenberg-Universität, D-55131 Mainz}

Zur Darstellung morphologischer Befunde stehen verschiedene Medien zur Verfügung. Schwieriger ist die didaktische Aufbereitung komplexer dynamischer Vorgänge (Beispiel: Atmungsphysiologie beim Ersticken) und die Präsentation von Sachverhalten, die in der
Lehre nur im bewegten Bild befriedigend dargestellt werden können. Über die Möglichkeiten und praktischen Erfahrungen des Einsatzes geeigneter Hard- und Software zur Herstellung animierter Lernmodule wird berichtet. Animierte GIF-Grafiken können relativ einfach mit GIF-Animationsprogrammen (z.B. dem GIF-Animator, Hersteller: Ulead) erzeugt werden. Die animierten Sequenzen können anschließend z.B. in MS Powerpoint-Präsentationen oder HTML-basierten Intranetsystemen eingebunden werden. Zur Darstellung spezifischer Leichenschau- und Obduktionsbefunde (z.B. Brechen der Leichenstarre, Wegdrückbarkeit von Leichenflecken) lassen sich gute Ergebnisse mit einer digitalen Videoaufzeichnung und digitaler Videonachbearbeitung im PC erzielen. Digitale Videodaten können dabei verlustfrei mittels Firewire-Schnittstelle (IEE 1394) auf den Rechner übertragen werden. So gewonnene Videosequenzen können anschließend im AVI- oder MPEG-Format weiterverarbeitet werden. Auf diese Weise erzeugte Animationen können entweder mittels Beamer im Hörsaal bzw. Seminarraum präsentiert oder auch für das Selbststudium auf CD-ROM bereitgestellt werden. Die vorgestellten didaktischen Möglichkeiten dürften mit dem Ausbau des problemorientierten Kleingruppenunterrichtes an verschiedenen Universitäten zunehmend an Bedeutung gewinnen.

\section{V-111}

DER WEG ZUM GIPFEL - KRIMINALISTISCHE HINTERGRÜNDE Fuhrer R

\section{Poster}

\section{P-1} DER EINSATZ PARASITISCHER INSEKTEN

IN DER FORENSISCHEN ENTOMOLOGIE

Amendt $\mathrm{I}^{1}$, Krettek $\mathrm{R}^{2}$, Niess $\mathrm{C}^{1}$,Zehner $\mathrm{R}^{1}$

${ }^{1}$ Institut für forensische Medizin, D-60596 Frankfurt am Main

${ }^{2}$ Gesamthochschule Kassel, D-34109 Kassel

Die Bestimmung der Leichenliegezeit ist eine der wichtigsten Einsatzgebiete der Forensischen Entomologie. Die genauesten Ergebnisse werden in den ersten zwei bis drei Wochen nach Todeseintritt erreicht, da hier die Entwicklungsdauer der Erstbesiedler herangezogen werden kann. Sind längere Zeiträume zu berechnen, muss oftmals auf ungenauere Methoden wie z.B. die Berücksichtigung des an der Leiche vorgefundenen Sukzessionsstadiums zurückgegriffen werden. Eine bislang kaum beachtete Insektengruppe hat das Potenzial, exakte Berechnungen auch bei längeren Liegezeiten zu ermöglichen: Parasitoide.

Parasitoide töten ihren Wirt im Gegensatz zu echten Parasiten regelmäßig. Die weitaus meisten Parasitoidenarten gehören zu den Hymenopteren (Bienen und Wespen) und Dipteren (Fliegen und Mücken), daneben sind auch Coleoptera (Käfer) von Bedeutung. Parasitiert werden Eier, Larven oder Puppen der Wirtsorganismen, die Entwicklung erfolgt endo- oder ektoparasitisch. Besonders Puppenparasitoide von Schmeissfliegen können in der forensischen Entomologie eine wichtige Rolle spielen, wenn eine Leichenliegezeit von mehreren Wochen ermittelt werden soll. Der Zeitpunkt der Parasitierung ist in der Regel auf ein kleines, definiertes Zeitfenster zu Beginn der Puppenruhe eingrenzbar. Ist die Artidentifizierung des Wirtes und des Parasitoiden möglich, kann durch Addition ihrer Entwicklungszeiten eine exakte Berechnung der Leichenliegezeit auch dann noch erfolgen, wenn die Erstbesiedler ihre Entwicklung bereits abgeschlossen haben.

Das Poster stellt die verschiedenen Parasitoidengilden vor. Eine Fallstudie sowie Labor- und Freilandversuche illustrieren deren potenzielle forensische Relevanz. Neben den positiven Möglichkeiten werden auch die sich aus der Parasitierung ergebenden Probleme bei der Berechnung der Leichenliegezeit diskutiert. 


\section{P-2}

\section{TYPISCHE MESSFEHLER}

BEI POSTMORTALEN KÖRPERKERNTEMPERATURMESSUNGEN

Buromskiy IW, Kildüschov EM, Plaksin WO, Kildüschova EA

Lehrstuhl für Rechtsmedizin,

Russische Staatliche Medizinische Universität

Moskau, Russland

Die exakte Feststellung des Zeitpunktes des Todeseintrittes hat oft eine unmittelbare Auswirkung auf den späteren Ermittlungserfolg. Im Rahmen einer in der Rechtsmedizin in Russland auch heute üblichen Qualitätskontrolle des Gutachtenwesens wurden stichprobenartig 2721 Obduktions- und Fundortprotokolle aus 44 Regionen ausgewertet.

Es war festzustellen, dass der Zeitpunkt des Todeseintrittes oft aufgrund der Analyse der Leichenerscheinungen eingeschätzt wird. Oft wird auch die Rektaltemperatur gemessen. Solche Messungen sind in entsprechenden „Empfehlungen“ des Gesundheitsministeriums, die in Russland bindend sind, beschrieben. Diese enthalten aber keine konkreten Angaben über die Art sowie die Genauigkeit der Thermometer. Unsere Überprüfung zeigte, dass viele verschiedene Modelle von elektronischen und/oder „klassischen“ Quecksilber- oder Alkoholthermometern mit verschiedenen Auflösungen von $0,01-2,0^{\circ} \mathrm{C}$ verwendet werden. Die Messungen werden nicht selten am Fundort und im Sektionssaal von verschiedenen Untersuchern und nicht mit gleichen Instrumenten durchgeführt. Die Messspitzen werden offensichtlich unterschiedlich tief in den Körper eingeführt. Unsere Überprüfung zeigte, dass ein Tiefenunterschied von $13 \mathrm{~cm}$ zu einer Temperaturveränderung von $2-3^{\circ} \mathrm{C}$, maximal sogar bis $6^{\circ} \mathrm{C}$ führen kann. Selten wird die Temperatur zweimal gemessen. Bei Neugeborenen wird das „Erwachsenenmodell“ angewandt.

Unsere Untersuchung lässt folgende Empfehlungen zu:

Am besten eignen sich geeichte Thermometer mit einer Auflösung von $0,1^{\circ} \mathrm{C}$.

Die Messsonde bzw. der Messteil des Thermometers darf nicht kürzer als $13 \mathrm{~cm}$ sein.

Die Einführtiefe der Messsonde soll bei Erwachsenen 10-13 $\mathrm{cm}$ und bei Neugeborenen 4-5 $\mathrm{cm}$ betragen.

Die Körperkerntemperaturmessung soll mindestens zweimal durchgeführt werden.

Bei Berechnungen im Falle eines Neugeborenen darf nur ein speziell für solche Zwecke entwickeltes mathematisches Modell angewendet werden.

\section{P-3}

\section{TEMPERATURGESTÜTZTE BESTIMMUNG DER TODESZEIT}

MIT HILFE DER METHODE DER FINITEN ELEMENTE: I METHODIK UND MODELL

Mall G, Eisenmenger W

Institut für Rechtsmedizin der Ludwig-Maximilians-Universität München

Die Bestimmung der Todeszeit in der frühen postmortalen Phase ist von großer Bedeutung in der rechtsmedizinischen Praxis, denn gerade bei Tötungsdelikten entspricht der Todeszeitpunkt dem mutmaßlichen Tatzeitpunkt. Die genaueste Abschätzung gelingt noch über den zeitlichen Verlauf der Leichenabkühlung. Mit den bisher verfügbaren temperaturbasierten Verfahren war die Beurteilung jedoch auf solche Fälle beschränkt, in denen die Leiche bis zum Zeitpunkt der Rektaltemperaturmessung unter möglichst gleichbleibenden Umgebungsbedingungen gelagert war, insbesondere bei relativ konstanter Umgebungstemperatur. Auch war eine Schätzung der Todeszeit in Situationen mit einer in der Nähe der Leiche befindlichen Strahlungsquelle (Heizkörper, Heizstrahler) nicht möglich. Bei der Finite-ElementeMethode (FEM) handelt es sich um ein numerisches Verfahren zur Lösung partieller Differentialgleichungen, wie der Wärmeleitungs- gleichung, unter komplexen Rand- und Anfangsbedingungen. Es wurde ein dreidimensionales FE-Modell des menschlichen Körpers entwickelt, das nach Länge und Masse skaliert werden kann. Das Anfangstemperaturfeld wurde inhomogen mit einem Temperaturgradienten vom Körperkern zur Körperschale vorgegeben. Das Modell enthält verschiedene Gewebskompartimente (Haut, Fettgewebe, Muskulatur, Knochen, innere Organe), denen unterschiedliche thermische Materialeigenschaften zugewiesen wurden. Als Randbedingungen wurden ein Wärmeverlust durch Konvektion sowie durch Abtrahlung berücksichtigt, außerdem eine Wärmeproduktion im Körper durch supravitale Prozesse in der Phase des intermediären Lebens.

\section{P-4}

TEMPERATURGESTÜTZTE BESTIMMUNG DER TODESZEIT

MIT HILFE DER METHODE DER FINITEN ELEMENTE:

II. VALIDIERUNG UND BERECHNUNGSBEISPIELE

Mall G, Eisenmenger W

Institut für Rechtsmedizin der Ludwig-Maximilians-Universität München

Das entwickelte thermodynamische Finite-Elemente-Modell des menschlichen Körpers wurde unter Standardbedingungen an dem in umfangreichen Versuchsserien verifizierten Modell von Marshall und Hoare (1962) validiert. Dabei wurde auf die Parameterwertbestimmung nach Marshall und Hoare zurückgegriffen mit zwei von einander unabhängigen Parametern ( $Z$ und $p)$, von denen der eine $(Z)$ eine Abhängigkeit von der Körperkonstitution aufweist. Da zum Verlauf der supravitalen Wärmeproduktion nur Abschätzungen, aber keine Daten vorliegen, wurde plausibel ein exponentieller Abfall angenommen und die Abfallrate - als einziger freier Parameter des Modells kalibriert. Alle übrigen Modellparameter waren der Literatur zu entnehmen und gemessen oder es handelte sich um physikalische Konstanten. Die Validierung erfolgte unter Verwendung des kalibrierten Parameterwertes unter von der Kalibrierungssituation abweichenden Umgebungsbedingungen, d.h. bei unterschiedlichen Umgebungstemperaturen und unterschiedlichen Körperkonstitutionen, mit sehr gutem Ergebnis. Beispielhaft wurden Nicht-StandardAbkühlungssituationen berechnet, z.B. eine Abkühlung bei einer abrupten Änderung der Umgebungstemperatur und eine Abkühlung unter externer Einstrahlung durch einen Heizstrahler. Das Verfahren konnte bereits erfolgreich, d.h. mit plausiblem Ergebnis in realen Fällen der Todeszeitbegutachtung eingesetzt werden.

\section{P-5}

HISTOLOGISCHER NACHWEIS EINER KUTANEN STROMMARKE NACH EINWIRKUNG EINES SOGENANNTEN ELEKTROSCHOCKERS Anders S, Junge M, Schulz F, Püschel K

Institut für Rechtsmedizin, Universität Hamburg

Bezug nehmend auf den Vortrag „Kein experimenteller Nachweis kutaner Veränderungen bei Anwendung sog. Elektroschocker" von S. Banaschak und Mitarbeitern auf der 79. Jahrestagung der Deutschen Gesellschaft für Rechtsmedizin in Essen sowie auf die sich daran anschließende Diskussion stellen wir einen in unserem Institut beobachteten Fall dar.

Ein 61-jähriger schwer vorerkrankter Mann wurde in seiner Wohnung das Opfer eines Raubüberfalls. Durch den Täter wurde er, um eine Herausgabe von Geld zu erreichen, in eine Abstellkammer gesperrt und schwer mißhandelt. Hierbei kam, unter anderem, ein sogenannter Elektroschocker zur Anwendung. Im Rahmen der Mißhandlungen erlag der Mann seinen schweren Erkrankungen, welche dem Täter auf Grund einer längeren bekanntschaftsmäßigen Beziehung zu dem Opfer bekannt waren. 
Bei der Sektion fanden sich bereits makroskopisch strommarkenverdächtige Hautveränderungen im Bereich der linken Brustregion. Eine sorgfältige histologische Untersuchung erbrachte hier den Nachweis von Hautveränderungen im Sinne von Strommarken.

Die histologischen Befunde sowie die rechtliche Würdigung des Falles werden vorgestellt.

\author{
P-6 \\ TÖTUNGSVERSUCH DURCH STROMEINWIRKUNG: \\ DISKRETE MORPHOLOGISCHE BEFUNDE \\ UND TECHNISCHE VORFALLSREKONSTRUKTION \\ Fink ${ }^{1} \mathrm{~T}$, Carstens ${ }^{2} \mathrm{~W}$, Dilger ${ }^{1} \mathrm{M}$, Rittner ${ }^{1} \mathrm{C}$ \\ ${ }^{1}$ Institut für Rechtsmedizin, Johannes Gutenberg-Universität, \\ D-55131 Mainz \\ ${ }^{2}$ Landeskriminalamt Rheinland-Pfalz, Dezernat 33
}

Eine 23 Jahre alte Frau erlitt beim Kontakt mit der Metallspüle und dem Wasserhahn in ihrer Küche einen Stromschlag. Nach eigenen Angaben führte offensichtlich erst der Umstand eines Bewusstseinsverlustes mit anschließendem Sturz zur Lösung von den umfassten stromführenden Metallteilen. Die technische Überprüfung der Spüle und der Elektroinstallationen in der Küche deckte eine vorsätzliche Manipulation der Einrichtungen auf, so dass die Spüle in Bezug zum Erdpotential volle Netzspannung führte. Obwohl davon auszugehen ist, dass die Betroffene einen nicht nur kurzfristigen und vital bedrohlichen Kontakt mit den spannungsführenden Metallteilen hatte, waren bei der rechtsmedizinischen Untersuchung nur diskrete Hautbefunde am Opfer zu erheben. Typische Strommarken waren nicht festzustellen, es zeigten sich vielmehr zahlreiche punktförmige bis kleinfleckige, ekzemähnliche Hauteffloreszenzen im Kontaktbereich. Bei der klinisch-laborchemischen Untersuchung konnte lediglich eine leichte Erhöhung der Kreatinkinase (CK) auf 210 U/l bei negativem Troponin I festgestellt werden. Pathologische EKG-Veränderungen bestanden nicht. Ausschließlich die Tatsache, dass der Vorfall von der Betroffenen überlebt wurde und es dem Täter nicht gelingen konnte, eventuell nachträglich die Spuren der abgelaufenen technischen Manipulation zu beseitigen, führte zur Aufklärung des Vorfalls. Bei kritischer Würdigung wäre im Falle eines letalen Ausganges ein Nachweis der Stromeinwirkung weder durch Leichenschau und Obduktion noch durch sonstige Zusatzuntersuchungen objektivierbar gewesen. Die diskreten morphologischen Befunde und die technische Rekonstruktion des Vorfalles werden demonstriert und diskutiert.

\section{P-7}

\section{NACHWEIS ENTEROVIRALER RNA}

\section{AUS PARAFFIN EINGEBETTETEM HERZGEWEBE}

Baasner A, Dettmeyer R, Madea B

Institut für Rechtmedizin, Universität Bonn

Trotz der klinischen Bedeutung der Enteroviren (EV) als häufige Erreger der viralen Myokarditis ist der Nachweis der EV-Infektion des Herzens oft problematisch. Zur Darstellung von EV-Infektionen an Paraffin-eingebettetem Herzgewebe stellt die Polymerasekettenreaktion (PCR) eine schnelle und sensitive Nachweismethode dar.

Enteroviren gehören zur Familie der Picornaviridae. Das Genom besteht aus einem Einzel-+-Strang RNA Molekül.In der vorliegenden Studie wurde eine Methode etabliert, die die Extraktion von RNA aus Paraffin-eingebettetem Herzmuskelgewebe ermöglicht. Die isolierte RNA muß anschließend zunächst durch reverse Transkription in cDNA umgeschrieben werden. Die erfolgreiche Extraktion von RNA aus Paraffinschnitten konnte durch den Nachweis des HousekeepingGens Cyclophilin gezeigt werden. Für den PCR Nachweis enterovi- raler RNA wurden Primerpaare aus dem hochkonservierten Bereich der 5'nichttranslatierten Region von EV ausgewählt und eine seminested PCR durchgeführt. Entscheidend für die Erhaltung der Nukleinsäure ist die Fixierung mit neutral-gepufferten Formalin ( $\mathrm{pH} 7.4$ ) bzw. dem alternativen Fixativ Notox ${ }^{\circledR}$, für max. 48 Stunden.

Unsere Untersuchung zeigt, daß zum Nachweis viraler Infektionen des Herzens Nukleinsäuren aus formalinfixiertem und paraffineingebetteten Gewebeschnitten aus autoptischem Material extrahiert werden können. Die Amplifikation viraler RNA gelingt erfolgreich aus dem Herzen von Personen mit Verdacht auf Myokarditis.

\section{P-8}

EFFECT OF MODE OF DEATH

ON CELLULAR AND SUBCELLULAR STRUCTURE OF RAT BRAIN: LIGHT AND SCANNING

AND TRANSMISSION ELECTRON MICROSCOPIC STUDY

$\underline{\text { Abdelaziz } \mathrm{MH}^{*}}$, El Shennawy I*, Gergis RS ${ }^{* *}$, Abdel Salam HF *, M.A.Hassan $M^{*}$, M.F Elsawy $S^{* * *}$

* Department of forensic medicine \& toxicology,

Faculty of medicine Alexandria University, Egypt

** Medical research institute,

Faculty of medicine Alexandria University, Egypt

*** Department of Histology,

Faculty of medicine Alexandria University, Egypt

The brain of patient who had died as a result of severe diffuse hypoxic damage may appear entirely normal macroscopically although subsequent histological examination shows severe and extreme neuronal affection.

The aim of the study was to explore the characteristic histological and ultrastructural changes of the brain tissue in a designed experimental model representing different modes of deaths. The study was carried out on 80 adult main albino rats $(150-200 \mathrm{gm})$. The rats were divided into five main groups: control group; obstructive asphyxial group (further subdivides) into strangulation, hanging and chocking subgroups; drowning group (freshwater and seawater subgroups); bleeding group; and $\mathrm{CO}$-inhalation group. Specimens were taken from the cerebrum and cerebellum of each animal properly fixed and subjected to : histological examination ( $\mathrm{H} \& \mathrm{E}$ stain), transmission electron microscopic study and scanning electron microscopic study.

Except for the bleeding group, the present study revealed characteristic damage in all groups involving cellular membranes (cell nuclear, and organellar membranes) which were detected by transmission and scanning electromicroscopic and attributed to ischaemia. Also the different types of glial cells showed variable degrees of degeneration in all studied groups.

\section{P-9}

MÖGLICHKEITEN DER DIFFERENTIALDIAGNOSTIK BEI TRAUMATISCHEN UND HYPOXISCHEN ZNS-VERÄNDERUNGEN

Toupalik P, Bouska I, Chadova L

Institut für Rechtsmedizin, Prag, Tschechische Republik

Bei einer Reihe der immunhistochemischen Befunde wird die Anwendungsmöglichkeit des immunhistochemischen Nachweises der neuron-spezifischen Enolase (NSE) und des $\beta$-Amyloid-PräkursorProteins ( $\beta$-APP) zur Diagnostik der Frühstadien traumatischer ZNSVeränderungen vorgelegt, wobei auch der Hypoxie-Einfluß auf die Untersuchung beobachtet wird. Die neuron-spezifische Enolase wird durch die Nervenzellen hergestellt und ist ein geeigneter Marker von Beschädigungen sowohl der Neuronen als auch der Axonen. Während die nicht beschädigten Nervenzellen eine intensive Immunreaktion 
mit dem Anti-NSE-Antikörper aufweisen, konnte eine erhebliche Senkung dieser Eiweißsubstanz in den beschädigten Neuronen schon innerhalb 1 - 2 Stunden nach dem Trauma beobachtet werden, und zwar nicht nur beim mechanischen Trauma, sondern auch im Fall der verzögerten Hypoxie. In den posttraumatisch veränderten Axonen war die NSE schon in kurzer Zeit nach dem Trauma beobachtet, während die Hypoxie des Gehirns ohne mechanisches Trauma keine oder nur geringe Axonreaktion bei der Untersuchung mit Anti-NSE zeigte. Das $\beta$-Amyloid-Präkursor-Protein ist ein niedermolekulares Eiweiß, dessen Normalwerte durch die histochemischen Standarduntersuchungen nicht nachgewiesen werden können. In den posttraumatisch veränderten Axonen sowie in einigen Fällen auch bei der Hypoxie des Gehirns konnte das Vorkommen dieses Eiweißstoffs häufiger beobachtet werden.

\section{P-10}

\section{OPTIMIERUNG DER RT-PCR}

ZUM NACHWEIS SPERMASPEZIFISCHER MESSENGER-RNA

Bauer M, Patzelt D

Institut für Rechtsmedizin der Universität Würzburg

Der Nachweis zell- bzw. organspezifischer messenger-RNA (mRNA) stellt, wie die Autoren kürzlich zeigen konnten (z. B. Rechtsmedizin, Suppl. 1 zu Band 10, V-12), eine geeignete molekularbiologische Methode zur Identifizierung der Spurenart dar. So lässt sich z.B. das Vorhandensein von Spermien in einer Spur durch die Detektion der für die spermaspezifischen basischen Nukleoproteine Protamin-1 und Protamin -2 kodierenden mRNA belegen. Um diese Methode zu optimieren und die Empfindlichkeit zu steigern, wurden Modifikationen in allen Reaktionsschritten (RNA-Isolierung, reverse Transkription, PCR, Visualisierung der Amplifikationsprodukte) untersucht. Dabei konnte u.a. durch die Minimierung der Reaktionsansätze, den Einsatz von Ribonuclease-Inhibitoren und modifizierten Enzymen in der reversen Transkription und durch Analyse der Fluoreszenzfarbstoffmarkierten PCR-Fragmente mittels Kapillarelektrophorese eine deutliche Steigerung der Sensitivität ohne Verlust an Spezifität erzielt werden. Somit erscheint ein Einsatz des Verfahrens auch bei Mikrospuren erfolgversprechend.

\section{P-11}

STATT LEICHENTEIL EIN FADENPILZ

Ehrlich E, Wrobel G, Schneider V

Institut für Rechtsmedizin der Freien Universität Berlin

Alarmierung der Polizei durch einen promovierten Allgemeinmediziner, der angab Teile einer zerstückelten Leiche gefunden zu haben. Beim Abpumpen des Abwassers wegen einer Rohrverstopfung in seinem Wohnhaus kam darin ein ca. $40 \mathrm{~cm}$ langes Darmstück zum Vorschein, der von ihm sicher als menschlicher Darm identifiziert wurde. Die zum Einsatzort herbeigeeilten Polizeikräfte konnten den "grausigen Fund“ bestätigen. Die makroskopische Untersuchung durch uns ergab ein in mehrere Fragmente zerrissenes schlauchförmiges Gebilde von ca. $4 \mathrm{~cm}$ Durchmesser und einer Wandstärke von ca. 1-2 mm, das zwischen den Fingern zerfiel und stark fäulnisverändert war. Übereinstimmend mit anderen Kollegen, die gerade im Sektionssaal mit Obduktionen beschäftigt waren, wurde die Eingangsdiagnose „tierisches oder menschliches Darmfragment“ gestellt. Bei einer anschließenden DNA-Untersuchung konnte keine typische humane DNS nachgewiesen werden, so dass zunächst eine „Entwarnung" gegenüber der Kriminalpolizei gegeben werden konnte.

Zur weiteren Identifizierung des Fundes wurden Abstriche und histologische Schnitte gefertigt. Diese ergaben ein membranartiges Gebilde aus einem Fadenpilz-Myzel mit zahlreichen Bakterien. In einigen Sehfeldern waren auch kleine Nematoden zu finden. Das gefun- dene „Darmfragment“ stellte sich daher als eine membranartige Auskleidung eines kleinen Abflussrohres dar, die durch eine Symbiose „Pilz-Bakterie und Wurm“ entstanden war. Eine genaue Identifizierung des Pilzes, der zu einer großen heterogenen Gruppe „Umweltpilze“ zuzurechnen ist, könnte nur beim Anzüchten erfolgen, so dass jetzt nach der Fixierung diese Möglichkeit nicht mehr gegeben war. Der Fall stellte sich zwar aus kriminalistischer Sicht als unproblematisch dar, hinterließ aber ein ungemütliches Gefühl eigener nicht genügender Kompetenz.

Fazit: man lernt immer wieder etwas Neues in unserem Fach dazu.

\section{P-12}

ZUORDNUNG EINER URINPROBE

ÜBER mt-DNA-SEQUENZIERUNG

Lunge A, Steevens M, Madea B

Institut für Rechtsmedizin, Universität Bonn,

Stiftsplatz 12, D-53111 Bonn

Untersuchungen zur Individualisierung von Urinproben wurden Anfang der 9oer Jahre von verschiedenen Arbeitsgruppen durchgeführt, da im Rahmen positiv verlaufender Dopinganalysen häufig die Frage einer Manipulation von Urinproben aufgeworfen wird.

Nach einer positiv verlaufenen Dopinganalyse wurden wir um individualisierende Untersuchungen an Resturin im Vergleich zu Blut/ Speichel eines Sportlers gebeten. Die Urinprobe war zum Zeitpunkt der Untersuchung knapp $1 \mathrm{Jahr}$ alt, wurde zwischenzeitlich bei $4^{\circ} \mathrm{C}$ gelagert und war bei der Ankunft in unserem Institut leicht trübe. Die Extraktion erfolgte mit $15 \mathrm{ml}$ Urin und entsprechend dem Protokoll des All-tissue DNA-Kit (GEN-IAL). Die Untersuchung von 6 STR-Systemen ergab kein Ergebnis, im Amelogenin-System jedoch XY. Aufgrund der unbefriedigenden Ergebnisse wurden die nicht-kodierenden Bereiche der humanen mitochondrialen DNA HVRI und HVRII untersucht. Beide hypervariablen Regionen konnten erfolgreich amplifiziert und sequenziert werden. Die Sequenzierergebnisse wurden mit denen der Vergleichsprobe sowie der Referenzsequenz verglichen. Die Sequenzen der Urinprobe und der Vergleichsprobe stimmten in dem sequenzierten Bereich vollständig und eindeutig überein und wiesen in HVRI in 3 und in HVRII in 4 Positionen Abweichungen zur Referenzsequenz auf. Aufgrund der identischen Sequenzen von Urin und Vergleichsprobe konnten diese einem Verursacher bzw. einer Person aus der gleichen maternalen Linie zugeordnet werden. Die statistische Auswertung ergab, dass die gefundene Sequenz in einer aus 1914 unverwandten Personen umfassenden Datenbank nicht auftrat. Mit Hilfe der mt-DNA-Analytik war es somit möglich, eine Urinprobe einem Verursacher zuzuordnen, bei nicht mehr möglicher Amplifikation genomischer DNA.

\section{P-13}

ERGEBNISSE EINER DATENBANKRECHERCHE

ZUR LOKALISATION FORENSISCH GENUTZTER

GENETISCHER MARKER

Lieske S, Krause D, Szibor R

Institut für Rechtsmedizin der Otto-von-Guericke-Universität Magdeburg

Die DNA-Technologie hat uns eine praktisch unbegrenzte Anzahl von genetischen Markern beschert. Diese lassen sich verschiedenen Kategorien zuordnen: Klassische Systeme, HLA-Systeme, SLS, AmpFLPs, STRs, SNPs und neuerdings SIDPs (Short Insertion Deletion Polymorphisms). In Deutschland wird vielfach dafür plädiert, für Abstammungsfragen Marker aus verschiedenen Systemkategorien einzusetzen. Die Zuordnung ist aber weitgehend willkürlich und vielfach nur methodisch bedingt. Für forensische Belange sollten ausschließlich Fragen der analytischen Sicherheit sowie biologische Pa- 
rameter wie z. B. Mutabilität, Informativität und die gesicherte Lokalisation als Auswahlkriterien dienen. Die Bedeutung der genauen Kartierung für die Richtigkeit einer Aussage wird u. E. nicht selten unterschätzt. Man kann beobachten, dass in komplizierten Abstammungsgutachten Marker kombiniert werden, deren Lokalisation nicht bzw. nur ungenau bekannt ist. Datebankrecherchen zur Lokalisierung sind aufwendig und bleiben oft ohne Resultat. Unser Poster zeigt die Ideogramme der 22 Autosomen und soweit auffindbar, die Lokalisation der im forensischen Schriftgut genannten Marker. Es berücksichtigt alle Marker, die ab 1990 in den Abstracts von drei führenden forensischen Journalen und in den Proceedings der ISFH Kongresse genannt sind. Die Daten wurden hauptsächlich folgenden Datenbanken entnommen: Genome Data Base, National Center of Biotechnology Information, Center for Medical Genetics. Diese integrieren wiederum Daten verschiedener Institute (Genethon, Sanger Centre, Whitehead, Stanford usw.). Von 135 autosomalen Markern lag z.Z. der Erstellung dieses Abstracts nur in 42 Fällen eine wirklich detaillierte Lokalisationsbeschreibung vor. Die Datenlage entwickelt sich allerdings sehr dynamisch.

\section{P-14}

VALIDIERUNG DES PHOSPHATESMO-KM- UND PSA-TESTS

Rixen S, Rauch E, Anslinger K, Eisenmenger W

Institut für Rechtsmedizin der Universität München,

Frauenlobstr. 7a, D-80337 München

Bei der Untersuchung von Spurenmaterial aus Sexualdelikten werden zum Spermanachweis neben der Histologie häufig auch Tests auf die in der Samenflüssigkeit vorhandene saure Prostataphosphatase oder das prostata-spezifische Antigen eingesetzt.

In dieser Studie sollen Spezifität und Nachweisgrenze des Phosphatesmo-KM-Tests (Machery-Nagel) und des PSA-Tests (Nobis) im Vergleich zur Histologie überprüft werden.

Entsprechend eines standardisierten Protokolls wurden dazu bei 5 Paaren über einen ganzen ovulatorischen Zyklus täglich, bis 6 Tage p.c. Vaginalabstriche genommen. Diese Tupfer wurden auf Objektträger ausgestrichen und histologisch beurteilt. Danach wurden an den Tupfern ein Phosphatesmo-KM-Test und ein PSA-Test durchgeführt. Die Ergebnisse wurden tabellarisch dargestellt und verglichen. Während der Phosphatesmo-KM-Test in allen Fällen einen positiven Reaktionsausgang erbrachte, unterlagen die Ergebnisse des PSA-Tests starken Schwankungen. Ausgehend von diesen Ergebnissen sollen nun beide Testsysteme auf mögliche Störfaktoren, die zum Auftreten von falsch positiven oder falsch negativen Reaktionen führen können, untersucht werden.

\section{P-15}

QUANTIFIZIERUNG DER mRNA DES $\mu$-OPIATREZEPTORS ( $\mu \mathrm{OR})$ IN DEFINIERTEN AREALEN DES GEHIRNS VON DROGENTOTEN VALIDIERUNG DER QUANTITATIVEN PCR - ERSTE ERGEBNISSE Becker J, Schmidt P, Fitzenreiter M, Musshoff F, Madea B Institut für Rechtsmedizin,

Rheinische Friedrich-Wilhelms-Universität Bonn

Die Regulation des $\mu$ OR bei chronischem Opiatkonsum wurde bislang bevorzugt am Tiermodell auf Proteinebene analysiert, kann jedoch seit der Klonierung des Gens (1993) auch auf mRNA-Ebene untersucht werden.

In dieser Studie wurde eine Methode etabliert, welche die quantitative Analyse der $\mu$ OR-mRNA in menschlichem Gehirnmaterial post mortem erlaubt. Es wurde Gesamt-RNA aus 9 verschiedenen Gehirnregionen (Thalamus, Hypothalamus, Nucleus Caudatus, Ventrales Tegmentum, Nucleus Accumbens, Frontalcortex, Hippocampus, Corpus
Amygdala, Putamen) isoliert und durch reverse Transkription (RT) in cDNA umgeschrieben. Die spezifische $\mu$ OR-mRNA konnte nachfolgend mittels LightCycler-Analyse relativ zu dem housekeeping Gen $\beta$ 2-Microglobulin quantifiziert werden.

Erste Ergebnisse zeigen, daß die RNA auch dann erfolgreich isoliert werden kann, wenn Liegezeiten $>72$ Stunden angenommen werden mußten. In einer Validierung konnte in parallel durchgeführten RTAnsätzen und wiederholten LightCyclerläufen reproduzierbare Ergebnisse mit den verwendeten post mortem Materialien erzielt werden. Die Analyse eines Kollektivs bestehend aus 10 Drogentoten und 10 Kontrollen, bei der alle o.g. 9 Gehirnregionen berücksichtigt wurden, ergab bei 2 Drogentoten im Thalamus eine um den Faktor 10.000 gesteigerten mRNA-Level im Vergleich zu den ermittelten „Normalwerten“.Durch Erweiterung des Untersuchungskollektivs soll zukünftig geklärt werden, in wieweit diese auffälligen Befunde statistisch signifikant sind.

Die synthetisierte cDNA eröffnet die Option, neuronale Adaptationen unter chronischer Opiatexposition an menschlichem Hirngewebsmaterial auch in anderen Rezeptorsystemen und auf weiteren Stufen der intrazellulären Signaltransduktionskaskade zu untersuchen.

\section{P-16}

IMMUNOHISTOCHEMICAL DETECTION

OF THE AMPHETAMINE DERIVATIVES

3,4-METHYLENEDIOXYMETHAMPHETAMINE (MDMA)

AND 3,4-METHYLENE-DIOXYAMPHETAMINE (MDA)

IN HUMAN POST-MORTEM BRAIN TISSUES.

De Letter EA ${ }_{2}^{1}$ Espeel $^{2} \mathrm{M}$, Craeymeersch $^{1} \mathrm{M}$, Lambert $^{3} \mathrm{~W}$,

Clauwaert ${ }^{4} \mathrm{~K}$, Piette ${ }^{1} \mathrm{M}$

Ghent University, Belgium

${ }^{1}$ Forensic Medicine Department, J. Kluyskensstraat 29, 9000 Ghent

${ }^{2}$ Anatomy and Embryology Department

${ }^{3}$ Toxicology Department

${ }^{4}$ Medical Biochemistry and Clinical Analysis Department

\section{Objective}

To test a method for the immunohistochemical detection of MDMA and MDA and to examine their distribution in human tissues.

Methods

In a fatal MDMA overdose (proven by HPLC), immunodetection of MDMA and MDA with mouse monoclonal antibodies in 14 brain regions was performed. The method is based on the Catalysed Signal Amplification System $\left(\mathrm{DAKO}^{\circledR}\right)$ using diaminobenzidine-peroxidase (HRP) as chromogen. Specific antibodies were kindly provided by Microgenics Corp, CA.

Analogue samples - taken from a non drug-related case - were included as control. In order to test the specificity of the antibodies, these were saturated with MDMA to induce a negative immunoreaction. For negative control, sections were incubated with IgG fraction from normal mouse serum.

$\underline{\text { Results }}$

MDMA immunoreactivity presented mainly as a diffuse brownish cytoplasmic staining of the neurons in all brain regions except for the corpus callosum. Addition of pure MDMA to the antibody totally abolished the staining reaction. In the lower MDMA concentration range of saturation tests, a gradient of the staining intensity was observed, proving the specificity of the antibodies. Immunoreactivity could not be detected in the control tissue. Incubations with mouse IgG fraction were negative.

Conclusion

A reliable method for the specific immunohistochemical detection of MDA and MDMA in human brain tissues is demonstrated. This method might be used for further study of the topographic distribution of these amphetamine analogues in other human tissues. 


\section{P-17}

\section{OBDACHLOSE DROGENABHÄNGIGE}

Graß H, Behnsen ${ }^{1}$ S, Kimont ${ }^{1}$ HG, Staak M

Institut für Rechtsmedizin der Universität zu Köln

${ }^{1}$ Gesundheitsamt der Stadt Köln

Die medizinische Versorgung von Randgruppen der Gesellschaft hat sich insbesondere in Form von niederschwelliger medizinischer Hilfen zunehmend ausgeweitet. Um den Kenntnisstand zu Lebensumständen, Erkrankungen, Todesumständen und Todesursachen in einem solchen Klientel zu verbessern, wurden für die Jahre 1989 bis 2000 systematisch Todesfälle im Drogen- und Obdachlosenmilieu in Köln untersucht; 1999 und 2000 konnten umfangreiche Untersuchungen durchgeführt werden (Köln Fortune Projekt Nr. 172/98 \& Nr.75/99). Insgesamt wurden 599 Drogentote registriert, 510 chemischtoxikologische Untersuchungen und 170 Obduktionsbefunde wurden ausgewertet. Im Untersuchungsgut fiel ein deutliches Klientel an zusätzlich obdachlosen Personen ( $8=23 \%$ ) auf, die chronologische Entwicklung zeigt eine leicht steigende Tendenz auf $37 \%$ im Jahr 2000. Der Altersgipfel der obdachlosen Frauen lag zwischen dem 20. und 30. Lebensjahr, bei Männer zwischen 30 und 40 Jahren. Fernerhin fiel auf, dass in der Gruppe der obdachlosen Drogenabhängigen häufiger Kontakt zum niederschwelligen medizinischen Hilfssystem bestand ( $36 \%$ versus $14 \%$ ). Eine Betrachtung der Konsummuster zeigte eine zunehmende Aufnahme von Alkohol in der Gruppe der verstorbenen Obdachlosen aber auch generell bei den Drogentoten $(34 \% \geq 0.5 \%$ o BAK). Auf die u.U. lebensgefährliche Interaktion zwischen Drogen und Alkohol (und auch Medikamente) wurde in der Literatur bereits hingewiesen. Diese und weitere Untersuchungsergebnisse werden mit den Verantwortlichen aus den Hilfesystemen erörtert, um auf einer breiten und differenzierten Erkenntnislage die Ressourcen zur Betreuung und Behandlung von sozialen Randgruppen möglichst optimal zu nutzen. Das in Köln praktizierte Netzwerk zwischen der Rechtsmedizin und dem Mobilen Medizinischen Dienst des Gesundheitsamts hat sich als vorteilhaft erwiesen.

\section{P-18}

UNTERSUCHUNG DER AKUTWIRKUNG

VON PSYCHOSTIMULANTIEN BEI DISKOTHEKENBESUCHERN

Hecker R, Röhrich J, Neis P, Rittner C

Institut für Rechtsmedizin, Johannes Gutenberg-Universität Mainz

Am Pulverturm 3, D-55131 Mainz, Germany

Ein Kollektiv jugendlicher Besucher zweier Technodiskotheken im Rhein-Main-Gebiet ( $\mathrm{n}=92)$ wurde auf akute Beeinflussungen durch Amphetaminderivate („Speed/Pep“, „Ecstasy“) untersucht. Es handelte sich um Probanden, die sich nach gezielter Ansprache freiwillig zur anonymen Teilnahme an der Untersuchung bereit erklärt hatten. Neben einer allgemeinen Erhebung zum Körperstatus und zur Person, wurden vegetative Funktionen (z.B.Pupillenreaktion), das emotionale Zustandsbild und insbesondere die psychophysische Leistungsfähigkeit wie z.B. Konzentration, Aufmerksamkeit, Wahrnehmung und Reaktionsvermögen getestet. Zur Ermittelung der aktuellen Wirkstoffspiegel wurde den Probanden eine Blutprobe entnommen. Die Untersuchung erfolgte mittels GC/MS selektiv auf Amphetamin, Methamphetamin, MDA, MDMA, MDE, MBDB, Cocain, Methylecgonin, Benzoylecgonin, 6-MAM, Morphin, Codein, Dihydrocodein, Methadon sowie THC, THC-OH und THC-COOH, außerdem mit HPLC auf LSD. Parallel wurde in allen Proben die Blutalkoholkonzentration bestimmt und eine mögliche Einnahme von Psychopharmaka immunchemisch überprüft. Praktisch alle Teilnehmer hatten Amphetaminderivate konsumiert $(n=87$, entsprechend ca. $95 \%)$ und davon 8o Personen „Ecstasy“, wobei die MDMA-Blutkonzentrationen von 3 bis $2451 \mathrm{ng} / \mathrm{mL}$ variierten (Mittelwert: $478 \mathrm{ng} / \mathrm{mL}$ ). 47 Personen (51 \%) standen zusätzlich akut unter Cannabiseinfluss. 6 Probanden hatten auch Cocain konsumiert und weitere 5 Personen LSD. Alkohol fand sich ähnlich sporadisch, so zeigten lediglich 9 Teilnehmer (10 \%) relevante Alkoholisierungen im Bereich zwischen 0,33 und 1,24\%o (Durchschnitt: ca. 0,8\%o). Erwartungsgemäß fanden sich im gesamten Kollektiv keine Opiate, aber auch Psychopharmaka wie insbesondere Benzodiazepine waren in keiner Probe feststellbar. Nahezu alle Probanden zeigten sich im Verhalten freundlich und kooperativ und arbeiteten bei den durchgeführten Tests bereitwillig mit.

\section{P-19}

KLINISCH-TOXIKOLOGISCHE UNTERSUCHUNG

DER DROGENKONSUMENTEN IN UNGARN

Molnár A ${ }^{*}$, Jeszenszky E ${ }^{* *}$, Hideg $Z^{* * *}$, Kerner Á ${ }^{* * *}$, Varga $T^{* *}$

* Polizeipräsidium Komitat Csongrád, Szeged

** Institut für Rechtsmedizin Szegediner Wissenschaftliche Universität, Szeged

$* * \star$ Nationales Forensisch-toxikologisches Institut, Budapest

\section{Einleitung:}

Die Zahl der Betäubungsmittelkonsumenten in Ungarn ist vom Anfang der neunziger Jahre bis heute etwa auf das 10-fache angestiegen. Die Ersatzmittel und Medikamente wurden in der letzten Zeit durch leichtere oder härtere Drogen ersetzt. Das geltende Gesetz stellt sowohl das Fahren unter dem Einfluss von Alkohol als auch von berauschenden Mitteln unter Strafe.

Material und Methode:

Die einer Straftat Verdächtigen unter dem Einfluß von Rauschmitteln wurden klinisch untersucht und ihre Symptome wurden in einem in Ungarn kürzlich eingeführten Untersuchungsprotokoll festgehalten. Der Urin wurde mit Schnelltesten auf Drogen und Benzodiazepine untersucht und es erfolgten jeweils qualitative und quantitative Bestätigungsanalysen.

Ergebnisse:

Bei den 100 untersuchten Personen $(84 \mathrm{~m}, 16 \mathrm{w})$ waren die Sensitivität und Spezifität der Symptome sehr unterschiedlich. Am häufigsten wurde THC detektiert, gefolgt von Amphetaminen, Opiaten und Benzodiazepinen. Die negativen und falsch-positiven Ergebnisse in Bezug auf alle Wirkstoffgruppen betrugen weniger als 3\%. Die Sensitivität der von uns angewendeten Schnellteste war hinsichtlich des Amphetamins am niedrigsten, die der Opiate betrug $100 \%$.

Schlussfolgerungen

Die Registrierung der klinischen Teste und Symptome, die es zur Zeit in Ungarn in den eingeführten Protokollen gibt, ist zur Erkennung der Symptome der Drogenbeeinflussung nicht ausreichend. Die Spezifität und Sensibilität der Vorteste schien befriedigend zu sein, den Verdacht der Drogenapplikation zu begründen. Die Erkennung der Drogenwirkung ist auch für Fachleute nicht einfach. Deshalb ist die Weiterbildung für die Polizisten und die in die Untersuchungen einbezogenen Ärzte unverzichtbar. Die Zeitdauer zwischen dem Vorfall und der Probeentnahme beträgt zur Zeit mindestens 1 Stunde und sollte kürzer werden.

\section{P-20}

\section{PONTINE AXONSCHÄDEN BEI DROGENKONSUMENTEN}

Niess C, Müllerklein T, Bratzke $\mathrm{H}$

Zentrum der Rechtsmedizin,

Klinikum der Johann Wolfgang Goethe-Universität, Kennedyallee 104, D-60596 Frankfurt am Main

Die immunhistochemisch ( $\beta$-APP) nachgewiesenen Axonveränderungen werden nach wie vor in erster Linie unter dem Begriff „diffuse axonal injury“ (DAI) als Folge einer traumatischen Hirnschädigung betrachtet, obwohl sich Hinweise dafür ergeben, dass auch andere (nicht-traumatische) Mechanismen dafür ursächlich sein können.Vor allem bei Drogenkonsumenten sind in einem hohen Prozentsatz Ax- 
onveränderungen nachweisbar. In Fortsetzung der eigenen Untersuchungen (Niess 2000, 79. Jahrestagung DGRM) wird nunmehr über 63 Fälle verstorbener Drogenabhängiger berichtet. Dabei wurde die rostrale Pons mit dem immunhistochemischen Marker $\beta$-Amyloid Precursor Protein ( $\beta$-APP) gefärbt und mikroskopisch ausgewertet. In diesem Kollektiv von 52 Männern und 31 Frauen fanden sich in 31 Fällen (49\%) Axonschäden in der Pons. Die toxikologischen Untersuchungen zeigten bei den positiven Fällen für alle untersuchten Substanzen (Heroin, Kokain, Methadon, Benzodiazepine, Alkohol) deutlich niedrigere Blutwerte als bei den Fällen ohne pontine Axonschäden. Die negativen Fälle wiesen auch häufiger Monointoxikationen (69\%) auf als die $\beta$-APP positiven (32\%). Die Auswertung des Hirngewichtes ergab für die positiven Fälle im Vergleich höhere Werte als für die negativen.

Die Ergebnisse sprechen dafür, dass sich die Axonschäden während einer protrahierten agonalen Phase ausbilden und damit eine Folge der akuten Drogenaufnahme und -wirkung darstellen. Sie unterstützen die These, dass es sich bei den Veränderungen um sekundäre Phänomene als Folge eines generalisierten hypoxischen Zustandes handelt.

\section{P-21}

\section{ZUR MORTALITAT VON OPIATKONSUMENTEN}

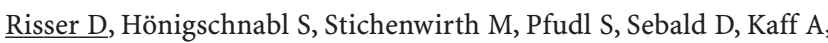
Bauer G.

Institut für Gerichtliche Medizin, Universität Wien, Österreich

Kohortenstudien zur Mortalität von Opiatkonsumenten beschränken sich meistens auf Substitutionspatienten. Ziel dieser Studie war es, die Mortalitätsraten zweier unterschiedlicher Kohorten von Opiatkonsumenten zu ermitteln und miteinander zu vergleichen.

$\mathrm{Zu}$ diesem Zweck wurden standardisierte Mortalitätsraten (SMR) für eine Kohorte von Opiatkonsumenten, die zwischen 1995 und 1997 in Wien in Substitutionstherapie standen und von Personen, die im gleichen Zeitraum von Rettungsdiensten aufgrund einer Opiatintoxikation behandelt wurden und die niemals in Substitutionstherapie standen, ermittelt. Als Standardpopulation wurde die altersgleiche Wiener Bevölkerung in diesem Zeitraum herangezogen.

Im Beobachtungszeitraum standen insgesamt 1.729 Personen in Wien in Substitutionstherapie. 26 dieser Personen verstarben bis zum 31. Dezember 1997 in einem mittleren Sterbealter von 33,6 Jahren. 65,4 \% dieser Todesfälle waren auf eine Suchtmittelintoxikation zurückzuführen. Innerhalb einer Wiener Normalbevölkerung gleichen Alters wären in diesem Zeitraum 1,52 Todesfälle zu erwarten gewesen. Daher ergab sich eine SMR von 12,1.

Im gleichen Zeitraum wurden 2.108 Einsätze wegen einer Opiatüberdosierung von den Wiener Rettungsdiensten registriert, für die insgesamt 1.039 Personen verantwortlich waren. 69 Personen aus dieser Kohorte waren bis zum 31. Dezember 2001 verstorben. Das mittlere Sterbealter betrug 30,9 Jahre. 88,4 \% dieser Personen verstarben aufgrund einer Suchtmittelintoxikation. Für eine gleichaltrige Wiener Normalbevölkerung wären im Untersuchungszeitraum 1,4 Todesfälle zu erwarten gewesen. Daher betrug die SMR 48,8.

Für Substitutionspatienten ergab sich also eine 12-fach höhere Sterberate wie sie für eine altersgleiche Normalbevölkerung zu erwarten gewesen wäre. Allerdings waren die Sterberaten der Kohorte der Opiatkonsumenten die nie in Substitutionstherapie standen um das Vierfache höher.

\section{P-22}

IMMUNHISTOCHEMISCHER NACHWEIS

VON BENZOYLECGONIN IM MENSCHLICHEN GEHIRN

Wehner F, Wehner HD, Subke J

Institut für Gerichtliche Medizin der Universität Tübingen, Nägelestr. 5, D-72074 Tübingen

Immunhistochemische Untersuchungsmethoden haben in den letzten Jahren die Aussagemöglichkeiten in der klinischen und forensischen Pathologie erweitert. Neben der morphologischen Blutgruppenbestimmung und der Wundaltersbestimmung ist der histochemische Nachweis von Medikamenten ein Verfahren, welches seinen Einsatz in der Rechtsmedizin findet. In Fortführung der bereits möglichen Methoden, Medikamente und Drogen nachzuweisen wurde ein Verfahren entwickelt, den Hauptmetaboliten von Kokain, Benzoylecgonin im menschlichen Gehirn immunhistochemisch anzufärben. Zur Untersuchung gelangte Gehirngewebe von Toten welche Blutkokainkonzentrationen zwischen $50 \mathrm{ng} / \mathrm{ml}$ und $8900 \mathrm{ng} / \mathrm{ml} \mathrm{bzw}$. Blutbenzoylecgoninkonzentrationen zwischen $10 \mathrm{ng} / \mathrm{ml}$ und $9900 \mathrm{ng} / \mathrm{ml}$ aufwiesen. Die Auswahl der Gehirnareale erfolgte anhand aus Untersuchungen bekannten Regionen in welchen Benzoylecgonin mittels GC/MS nachweisbar war und umfaßte Großhirnrinde, Kleinhirn, Stammknoten, Hirnstamm, Pons und Hippocampus. Für die immunhistochemische Färbung wurde ein ursprünglich für immunchemische Zwecke benutzter Anti-Benzoylecgonin Antikörper aus dem Kaninchen eingesetzt. Im Vergleich zu Kontrollschnitten von plötzlichen Todesfällen ohne Kokainexposition kann für die Gewebeproben von Kokaintoten eine selektive Darstellbarkeit von Nervenzellen nachgewiesen werden. Somit kann neben Metamphetamin, Phenobarbital, Insulin, Morphin und Methadon nunmehr auch Benzoylecgonin immunhistochemisch nachgewiesen und somit die Einnahme dieses Betäubungsmittels morphologisch belegt werden.

\section{P-23}

DIE ENTWICKLUNG DER DROGENPROBLEMATIK

IN INDONESIEN UND DEUTSCHLAND

AM BEISPIEL DER BTM-BEFUNDE DER FORENSISCHEN INSTITUTE IN DENPASAR UND GÖTTINGEN.

MÖGLICHKEITEN UND GRENZEN DER BEFUNDINTERPRETATION.

Wirasuta $I^{1}$, Thoben $\mathrm{M}^{2}$, Duchstein $\mathrm{HJ}^{3}$, Saternus KS ${ }^{1}$, Kijewski ${ }^{1}{ }^{1}$

('IFR Göttingen, Windausweg 2, D-37073 Göttingen,

${ }^{2}$ IFR Bremen, ZKH Sankt-Jürgen-Strasse, D-28205 Bremen,

Inst. Pharmazie Hamburg, Bundestrasse 45, D-20146 Hamburg)

Den Anlaß für die bestehende Kooperation gab die sich stark entwickelnde Drogenproblematik in Indonesien.

Es wird ein kurzer Überblick über die historische und aktuelle Situation in Indonesien gegeben und mit der Entwicklung in Deutschland und insbesondere mit der Situation am IFR Göttingen verglichen. Dazu wurden u.a. die Drogenbefunde am IFR Göttingen im Zeitraum von Januar 1997 bis Dezember 2000 erfaßt und nach statistischen Methoden ausgewertet. Sowohl in Indonesien als auch im Material des IFR Göttingen fand sich eine starke Zunahme der Anzahl und Untersuchungsaufträge auf Rauschdrogen.

Diese Befunde werden graphisch dargestellt. In Denpasar fand sich die stärkste Zunahme bei den Amphetaminen; in Göttingen bei den Cannabinoiden.

Die Zahl der Todesfälle nach Opiatkonsum war im genannten Zeitraum leicht ansteigend; die Zahl der Todesfälle nach Methadonkonsum war seit 1998 stark ansteigend.

Bemerkenswert erscheint auch eine Verschiebung bei den Opiattodesfällen zu einem höheren Lebensalter. Es ergaben sich Hinweise auf einen Zusammenhang zwischen Alkohol- sowie Opiat-Konsum und Urinmenge, der dargestellt wird. 
Die Opiatbefunde wurden im Detail mit statistischen Methoden und mathematisch-pharmakokinetischen Modellen ausgewertet. Besondere Berücksichtigung fanden dabei ungewöhnliche Befundkonstellationen. Ziel dieser Untersuchung ist es, einen Beitrag zur besseren Interpretation der Opiatbefunde zu liefern.

\section{P-24}

SELBSTSPRENGUNG MITTELS EINER ROHRBOMBE

Bellmann D, Grellner W, Wilske J

Institut für Rechtsmedizin der Universität des Saarlandes, Gebäude 42, 66421 Homburg/Saar

Bombenanschläge mit der Intention der Verletzung bekannter oder fremder Personen zur Durchsetzung eigener Interessen sind aus der Tagespresse geläufig. Der Bau einer beliebigen Bombe erfordert im Zeitalter des Internets keineswegs Spezialkenntnisse, sondern kann mit Hilfe leicht verfügbarer detailgenauer Anleitungen einfach selbst durchgeführt werden. Der nachfolgende Fall soll wegen der ungewöhnlichen Wahl der Suizidmethode mittels Selbstsprengung durch eine Rohrbombe vorgestellt werden.

Von Spaziergängern wurde im Wald die Leiche eines seit 9 Tagen vermissten, 18-jährigen Mannes aufgefunden, welche massive Verletzungen aufwies, die einer Sprengstoffexplosion zuzuordnen waren.

Bei der Obduktion stieß man in der rechten vorderen Schädelgrube, in der linken und rechten Brusthöhle, im Unterhautfettgewebe über der 9. Rippe links sowie an der kleinen Magenkurvatur auf insgesamt 5 Rohrteilstücke, welche durch die Explosion abgesprengt eine geschossähnliche Wirkung erzielt und zu den todesursächlichen Verletzungen, einem schwersten Polytrauma mit u.a. Schädelzerberstung und ausgeprägtem Thoraxtrauma, beigetragen hatten.

Bei der toxikologischen Untersuchung ergaben sich im Urin und im Blut aus dem Brustraum positive Werte für THC-Carbonsäure.

Der junge Mann war als Cannabiskonsument bekannt und befand sich wegen einer psychischen Erkrankung in Behandlung. Schon einige Wochen vor dem Suizid war er durch Suiziddrohungen sowie selbstund fremdgefährdende Aktionen aufgefallen.

Bei der Rekonstruktion des Ereignisses standen die oben angeführten Sektionsbefunde, die Auffindeumstände am Vorfallsort sowie die bekannte Vorgeschichte im Sinne eines suizidalen Geschehens miteinander in Einklang. Die Intention einer Fremdgefährdung hatte nicht vorgelegen. Die Tatmotivation war im persönlichen Bereich zu suchen, wobei eine cannabisinduzierte Psychose in Betracht gezogen werden musste.

\section{P-25}

VERLETZUNGSMUSTER DES NEUROCRANIUMS

DURCH SCHUSSWAFFEN - KLINISCHE ASPEKTE

Giese $\mathrm{A}^{\star}$, Lohmann $\mathrm{F}^{\star}$, Koops E ${ }^{* *}$, Püschel $\mathrm{K}^{\star *}$

${ }^{*}$ Neurochirurgische Klinik, Universitätsklinikum Hamburg-Eppendorf

** Institut für Rechtsmedizin,

Universitätsklinikum Hamburg-Eppendorf

Fälle und Untersuchungsziel: Über einen Zeitraum von 11 Jahren (1990-2000) wurden klinische Fälle penetrierender und perforierender Schussverletzungen des Neurocraniums ( $=31 ; 28$ Männer, 3 Frauen; Altersspanne 16 bis 87 Jahre) retrospektiv ausgewertet. Voraussetzung war, dass sie nach initialer hämodynamischer und pulmonaler Stabilisierung in der Unfallaufnahme des Universitätsklinikums Hamburg-Eppendorf weiterführender bildgebender Diagnostik und neurochirurgischer Therapie zugeführt werden konnten. - Die in der initialen CCT-Diagnostik dargestellten Verletzungsmuster werden dem initialen neurologischen Status und der Prognose gegenübergestellt.
Ergebnisse: In Abhängigkeit von Schusswaffe / Kaliber (überwiegend Handfeuerwaffen, vereinzelt Langwaffe, Schreckschusswaffe, Tiertötungsapparat, Armbrust) sowie Einschusslokalisation und Schusskanal resultierten sehr unterschiedliche Morbidität und Letalität (13 Todesfälle, davon 7 Frühtodesfälle innerhalb der ersten 48 h). Das CCT erlaubt eine rasche Einschätzung der knöchernen Verletzungen, Parenchymläsionen und Blutungen im Bereich der Hirnhäute und im Ventrikelsystem; es ist auch für die spätere rechtsmedizinische Beurteilung zur Art der Verletzung und Schussrichtung hervorragend geeignet. Prognostische Relevanz hat insbesondere der Glasgow Coma Scale; von 11 Fällen mit GLS < 5 überlebten nur 2. Eine schlechte Prognose haben erwartungsgemäß perforierende intraparenchymatöse Schusskanäle durch zentrale Großhirnstrukturen oder den Hirnstamm.

\section{P-26}

TÖDLICHE UND ÜBERLEBTE VERLETZUNGEN

NACH ARMBRUSTEINWIRKUNG

Grellner $^{1} \underline{\text { W, Buhmann }}{ }^{1}$ D, Giese ${ }^{2}$ A, Gehrke ${ }^{3}$ G, Koops ${ }^{4}$ E, Püschel ${ }^{4}$ K, Wilske $^{1}$ J

Institut für Rechtsmedizin der Universität des Saarlandes ${ }^{1}$, Gebäude 42, 66421 Homburg/Saar,

Klinik für Neurochirurgie der Universität Hamburg²,

Klinik für MKG-Chirurgie des Henriettenstiftes Hannover ${ }^{3}$, Institut für Rechtsmedizin der Universität Hamburg ${ }^{4}$

Traumatische Einwirkungen durch eine Armbrust zählen in moderner Zeit zu den Ausnahmebeobachtungen. Nachfolgend sollen aus interdisziplinärer Sicht vier Todesfälle (zwei Tötungen, zwei Suizide) und drei überlebte Verletzungsbefunde (gefährliche Körperverletzung, Suizidversuch, Sportunfall) durch diese Waffe vorgestellt werden. Bei den Betroffenen handelte es sich um Männer zwischen 31 und 54 Jahren. Zum Einsatz kamen überwiegend leistungsstarke Präzisionsarmbrüste mit Zielfernrohr und Jagdpfeile. Betroffene Körperareale waren viermal die Gesichts-/Kopfregion und dreimal der Thorax. Mit einer Ausnahme entstanden tiefreichende bis vollständig penetrierende Verletzungen von Schädel und Brustkorb mit in 4 von 7 Fällen noch steckendem Pfeil. Die überlebten Armbrustverletzungen verliefen trotz teils ausgedehnter Einbeziehung des Schädelinnenraumes (einmal Schädel-Hirn-Penetration) vergleichsweise blande (geringere Paresen). In diesen Fällen fiel - nach initialer Bewusstlosigkeit - auch eine weitgehend unbeeinträchtigte Handlungsfähigkeit auf (eigenständige Pfeilentfernung). Die drei Suizidenten bevorzugten die von Schussverletzungen bekannten Regionen (Mund, rechte Schläfe, Herzgegend). Armbrustverletzungen sind hinsichtlich ihrer ätiologischen Einordnung bei noch steckendem Pfeil eher unproblematisch, nach Entfernung des Pfeiles kann die äußere Morphologie jedoch an eine scharfe Gewalteinwirkung oder eine klassische Schusswunde denken lassen. Die durch die klinischen Daten gestützte Möglichkeit einer längeren Handlungsfähigkeit bzw. Überlebenszeit selbst bei Hirnpenetration sollte rechtsmedizinisch bei der Beurteilung von Todesfällen berücksichtigt werden.

\section{P-27}

HOCHGESCHWINDIGKEITSAUFNAHMEN EXPERIMENTELLER SCHUSSVERLETZUNGEN

DER FEMUR-DIAPHYSEN MIT AK-43 UND AK-74 (MASCHINENPISTOLE KALASCHNIKOW).

Popov V, Tjurin $\mathrm{M}$

Regional Office of Forensic Medicine Examination, 36/40 Shkapina st. S.Petersburg, Russia

Zur Untersuchung der Dynamik von schussbedingten Knochenverletzungen der langen Röhrenknochen wurden Femur-Diaphysen von 
Erwachsenen, die die vierte Lebensdekade erreicht haben, mit erhaltenem Periost untersucht. Diese wurden in die Mitte zylindrischer Gelatineblöcke mit einem Durchmesser von $23 \mathrm{~cm}$ gegossen. Geschossen wurde aus zwei Typen der Maschinenpistole Kalaschnikow AK-43 (Kal. 7,63 mm, Anfangsgeschwindigkeit des Geschosses Vo=710 m/s) und AK-74 (Kal.5,45 mm Vo=900 m/s). Für die Aufnahmen wurde eine Hochgeschwindigkeitskamera mit 13.500 Aufnahmen/Sekunde sowie ein Impuls-Röntgengerät (drei Röhren, Exposition 0,3 ms für AK-74 und $0,25 \mathrm{~ms}$ für AK-43) benutzt.

Die gewonnenen Aufnahmen zeigten eine Ausbreitung der Knochensplitter sowohl zur Ausschuss- wie zur Einschusslücke. Dabei wurden größere Fragmente in Flugrichtung und ein Teil der kleineren Knochensplitter gegen die Flugrichtung getrieben. Es wurde besonders auf das Verhältnis der Knochensplitter zum Rand der temporären Wundhöhle (TWH) geachtet. Die großen Knochenfragmente befanden sich nach der Ausformung der TWH an den Rändern und in der Mitte der entstandenen Sphäre. Bei „Zusammenklappen“ der TWH konzentrierten sich die im Block bleibende Knochensplitter im Schusskanal. Nach Ablauf der Pulsation bildeten sich zwei SplitterStrassen von der Diaphyse beginnend zur Ein- und Ausschusslucke, die im Röntgenbild den Schusskanal markierten.

\section{P-28}

\section{aDNA-ANALYSEN AN MENSCHLICHEN SKELETTEN} AUS EINEM RÖMISCHEN BRUNNEN AUS FRANKFURT/MAIN

Bender $\underline{1} \underline{\text { K }}$, Alt $^{2} \mathrm{KW}$, Balogh $^{2}$ MK, Hampel ${ }^{3}$ A, Rittner ${ }^{1}$ C, Schneider ${ }^{1}$ PM 1 Institut für Rechtsmedizin,

2 Institut für Anthropologie, Johannes Gutenberg Universität, Mainz 3 Denkmalamt der Stadt Frankfurt/Main

Im Jahre 1993 wurden bei der Ausgrabung eines römischen Brunnenschachtes in Heddernheim mehrere menschliche Skelette aus dem 3.Jh.n.Chr. geborgen. Die außergewöhnliche Fundstelle, aber auch die Spuren von Gewalteinwirkungen an Schädel und einzelnen Knochen des postcranialen Skelettes gaben Hinweise auf den gewaltsamen Tod dieser Personen. Eine anthropologische Begutachtung gab Aufschluß über die Mindestindividuenzahl, das Individualalter und das $\mathrm{Ge}-$ schlecht. Nach den vorgenommenen morphologischen Untersuchungen handelt es sich um die Skelettreste von zwei frühadulten (2030 Jahre) Personen (Mann und Frau) sowie von einem etwa 2,5 bis 3 Jahre alten Kind.

Für eine familiäre Beziehung der drei Personen zueinander im Sinne einer morphologischen Ähnlichkeit fanden sich an den Knochen keinerlei Hinweise. Die Hypothese einer möglichen „Kleinfamilie“ sollte durch eine molekulargenetische Analyse überprüft werden. Durch Vergleich der mitochondrialen DNA Sequenzen kann eine Aussage getroffen werden, ob zwei Personen mütterlicherseits verwandt sind. Hierzu wurden aus dem Knochenmaterial bzw. aus Zähnen DNAProben extrahiert und die mtDNA (HV I+II) mittels PCR amplifiziert und sequenziert. Zusätzlich wurde eine STR-Analyse für das geschlechtsspezifische Amelogenin- sowie für 9 autosomale Systeme durchgeführt. Aus den mtDNA-Daten geht hervor, daß die Frau und das Kind in mütterlicher Linie verwandt sein müssen. Aufgrund der Gleichzeitigkeit der „Bestattung“ und des niedrigen Lebensalters der Frau kann davon ausgegangen werden, daß es sich bei dem Kind um ihr eigenes handelt. Aus den STR-Daten konnte das Geschlecht für das Kind als weiblich bestimmt werden, eine Aussage über die Elternschaft konnte wegen der bisher unvollständigen Typisierung des Kindes noch nicht gemacht werden.

\section{P-29}

ZUR SKELETTALTERBESTIMMUNG NACH DER ATLASMETHODE

VON GREULICH UND PYLE

$\underline{\text { Daum S}}{ }^{1}$, Niess $\mathrm{C}^{1}$, Weinandi $\mathrm{T}^{1}$, Schmidt $\mathrm{H}^{2}$, Bratzke $\mathrm{H}^{1}$

${ }^{1}$ Zentrum der Rechtsmedizin

${ }^{2}$ Pädiatrische Radiologie

Universitätsklinikum Frankfurt am Main

Die Bestimmung des Skelettalters findet auch in der Forensik ihre Anwendung. Bei Straffälligkeit nicht registrierter Jugendlicher stellt sich die Frage nach Strafmündigkeit bzw. Anwendbarkeit eines Strafrechtes. Zur Eingrenzung des Alters der Betroffenen werden drei unabhängige Untersuchungsmethoden empfohlen, die in Zusammenschau ein Gesamtgutachten ergeben. Dabei handelt es sich um eine körperliche Untersuchung, eine odontologische Untersuchung und eine Röntgendiagnostik der Hand. Bei der Skelettalterbestimmung mit der Atlasmethode nach Greulich und Pyle werden die Handröntgenbilder mit Referenzbildern verglichen und in Altersgruppen eingeordnet. Entsprechend altersabhängiger Standardabweichungen wird eine Altersspanne angegeben. Die Daten basieren allerdings auf Studien aus den 4oer Jahre. Aufgrund fortschreitender Wachstums- und Pubertätsakzeleration stellt sich die Frage, ob der Einsatz noch vertretbar ist.Zur Überprüfung wurden Röntgenbilder von 307 Personen aus dem Röntgenarchiv der Kinderradiologie von 3 unabhängigen Ärzten befundet. Die vorläufige Auswertung ergab, dass die Untersucher in ihrer Einschätzung nur geringgradig von einander abweichen. Männliche Probanden von 12 - 17 Jahren wurden eher zu jung, weibliche bis $15 \mathrm{~J}$. zu alt, ab $17 \mathrm{~J}$. zu jung eingeschätzt. In den juristisch relevanten Altersstufen wurden folgende Einschätzungen getroffen: 14 Jahre m: $39 \%$ zu jung, 14 Jahre w: $41 \%$ zu alt; 16 Jahre m: $63 \%$ zu jung, 16 Jahre w: $38 \%$ zu jung; $41 \%$ zu alt, 18 Jahre m: $50 \%$ zu alt; 18 Jahre w: $62,5 \%$ zu jung.

Eine Angabe von generellen Standardabweichungen für die einzelnen Altersstufen und Geschlechter kann auf Grund noch zu geringer Fallzahlen nicht getroffen werden. Die bisherigen Untersuchungen deuten jedoch darauf hin, dass trotz Akzeleration der Bevölkerung der Atlas von Greulich und Pyle weiterhin Verwendung finden kann.

\section{P-30}

DIE GRUFT DER FAMILIE REHNSKIOLD IN GRIEBENOW (VORPOMMERN) - MOLEKULARGENETISCHE UNTERSUCHUNG DER GEFUNDENEN MUMIEN

Lignitz $E^{*}$, Preuß $J^{*}$, Härling $M$, Buske $N^{+}$, Poetsch $M^{*}$

${ }^{*}$ Institut für Rechtsmedizin, Universität Greifswald, Deutschland

${ }^{+}$Arbeitsgemeinschaft für Pommersche Kirchengeschichte, Deutschland

Die Familiengruft der Rehnskiölds in der Kirche zu Griebenow in Vorpommern wurde letztmalig 1986 im Zuge der grundlegenden Sanierung der Kirche geöffnet. Damals fanden sich 7 Särge. Davon waren vier Erwachsenenbestattungen (2 Frauen, 2 Männer) und drei Kinderbestattungen. Nach Auswertung der historischen Quellen kann nicht eindeutig belegt werden, um welche Familienmitglieder es sich dabei handelt.

Erbauer der Kirche und der Gruft war der 1610 geborene Gerd Anton v. Keffenbrink. Seine Familie stammte ursprünglich aus Rheine in Westfalen und wanderte 1567 nach Schweden aus. Gerd Anton v. Keffenbrink erhielt 1639 den schwedischen Adelstitel Rehnskiöld. Er war Kammerpräsident von Pommern und Kurator der Universität Greifswald. 1648 erhielt er das Schloß Griebenow bei Greifswald. 1648 bis 1654 ließ er die Kirche und die Gruft für seine Familie in Griebenow erbauen. Die einzig historisch sicher nachweisbare Bestattung in der Gruft erfolgte 1655 .

An das Institut für Rechtsmedizin wurde als Frage herangetragen, ob sich mit neueren molekulargenetischen Methoden die Verwand- 
schaftsverhältnisse der einzelnen Mumien bestimmen lassen. Die Ergebnisse der Untersuchung werden dargestellt.

\section{P-31 \\ SEQUENZPOLYMORPHISMEN \\ INNERHALB DER HUMANEN MITOCHONDRIALEN GENE \\ ATPase 6, ATPase 8 UND ND4 \\ Lutz S, Schmidt U, Schmitt T \\ Institut für Rechtsmedizin, Albert-Ludwigs-Universität, \\ Albertstr. 9, D-79104 Freiburg}

Aufgrund ihrer hohen Kopienzahl und Mutationsrate stellt die Analyse der mitochondrialen DNA in jenen Fällen ein probates Mittel der Identifikation dar, in denen das biologische Material stark degradiert oder der Gehalt an nukleärer DNA für eine STR-Analyse zu gering ist. Dabei eignet sich die Kontrollregion innerhalb der mtDNA (d-loop) zur Typisierung in der Forensik besonders gut, da diese als nichtkodierende Region hochpolymorph ist.

Mittels Sequenzierung der beiden hypervariablen (HV) Bereiche HVI und HVII innerhalb der mitochondrialen d-loop Region läßt sich die Mehrheit humaner DNA-Proben voneinander unterscheiden. Weitere $20 \%$ der Proben, die in HVI und HVII identische Sequenzmuster zeigen, konnten mit Hilfe der hypervariablen Region III voneinander abgegrenzt werden.

Neben der nicht-kodierenden d-loop Region besitzt das menschliche mitochondriale Genom auch Gene für 13 Proteine, 2 rRNAs und 22 tRNAs. Durch Sequenzierung der mitochondrialen Gene ATPase 6, ATPase 8 und $\mathrm{ND}_{4}$ bei ca. 100 Probanden wurde der Frage nachgegangen, ob sich Basenaustausche, die keinen Aminosäureaustausch zur Folge haben (z.B. Änderungen in der dritten Position eines Basentripletts), zur weiteren Differenzierung eignen.

\section{P-32}

UNTERSUCHUNG VON „ANCIENT“DNA

AUS 5000-6000 JAHRE ALTEM SKELETT-MATERIAL -

METHODEN UND PROBLEME

Michael M, Bruchhaus $\mathrm{H}^{\dagger}$, Sanft J, Schmidt S, Klein A, Claussen $\mathrm{U}^{\dagger}$

Institut für Rechtsmedizin,

Institut für Humangenetik und Anthropologie ${ }^{\dagger}$

der Friedrich-Schiller-Universität Jena

Mit dem Ziel aus sehr altem Knochenmaterial mtDNA zu sequenzieren, wurden Knochenproben von insgesamt 66 Individuen der Kulturen der Schnurkeramik, Linienbandkeramik und Aunjetitz mit einer Liegezeit von bis zu etwa 6000 Jahren untersucht.

Ermutigt durch vorangegangene, erfolgreiche Untersuchungen an bis zu 7000 Jahre alten Knochen diente als Kriterium, sich tatsächlich auf der Ebene der aDNA zu befinden, die Geschlechtsbestimmung (Amelogenin) in Form eines Doppelblindversuches. Nach Abgleichen der Ergebnisse mit dem archäologisch-morphologischen Geschlecht wurde die mitochondriale HV I sequenziert.

Die DNA-Extraktion erfolgte zunächst nach dem von Pääbo \& Höss (1993) publizierten Verfahren. Auf Grund des nur geringen Amplifikationserfolges ( $38 \%$ positiv) wurden weitere Extraktionsmethoden eingesetzt (Hagelberg \& Klegg und Kalmar et al.). Damit ließen sich $62 \%$ bzw. $85 \%$ der Proben erfolgreich amplifizieren.

Unabhängig vom Extraktionsverfahren waren die Ergebnisse der Geschlechtsbestimmung widersprüchlich. Lediglich in 34\% der Fälle stimmten genetisch und morphologisch ermitteltes Geschlecht überein. In den übrigen Fällen war eine eindeutige Typisierung nicht möglich; selbst bei Neuamplifikationen des gleichen Extrakts kam es zu differenten Ergebnissen.

Die Sequenzierung der HV I gelang lediglich in $34 \%$ der untersuchten Proben.
Anhand der Ergebnisse erfolgt ein Methodenvergleich der eingesetzten Extraktionsverfahren; die aufgetretenen Probleme werden diskutiert.

P-33

A STUDY OF THE RELATION BETWEEN THE SKELETAL AGE DETERMINED BY THE CERVICAL SPINES AND THE CHRONOLOGICAL AGE IN EGYPTIAN ADOLESCENTS Nour-El-Din M, Foad H ${ }^{*}$, Saleh SA \#, Bedeir SM **

Departments of Anatomy, Forencsc Medicine * and Radiology*, Faculty of Medicine, University of Alexandria Egypt, and Orthodontics\#, El-Azhar University.

Lateral cephalometric examination was done for 405 adolescents of Egyptian ancestry (200 males and 205 females, aged between 11 and 19 years). The third and fourth cervical vertebrae were traced and vertical as well as anteroposterior measurements for the body were taken. The data from 295 radiograghs were used to construct equations for age determination. The resultant equations has a pericability power as $91 \%$ for males and $87 \%$ for females. Data from the remaining 110 radiograghs ( 55 males and 55 females) were used, with age hidden from the investigator to test these equations.

\section{P-34}

STR-ANALYSEN ZUR FORENSISCHEN IDENTIFIZIERUNG

VON HUNDE-DNA - TYPISIERUNG EINES DNA-MOSAIKS

Pádár $\mathrm{Z}^{1}$, Egyed $\mathrm{B}_{2}^{1}{ }_{2}$ Kontadakis $\mathrm{K}^{2}$, Füredi $\mathrm{S}^{1}$, Woller $\mathrm{J}^{1}$, Zöldág $\mathrm{L}^{2}$, Fekete $\mathrm{S}^{2}$

${ }^{1}$ Abteilung für Hämogenetik, Institut für Forensische Wissenschaften, Budapest, Ungarn

${ }^{2}$ Szent István Universität, Fakultät der Veterinärmedizin, Budapest, Ungarn

Während der Ermittlungen im Rahmen des Todesfalles eines 7- jährigen Jungen war die Möglichkeit einer Hundeattacke in Betracht zu ziehen. Die parallel laufenden forensischen Untersuchungen konzentrierten sich auf die Verletzungsmorphologie der Leiche und die Analyse biologischer Spuren. DNA-Untersuchungen wurden aus Haar-, Speichel- und Blutspuren durchgeführt.Zehn hundespezifische STR-Systeme wurden mit fluoreszensmarkierter multiplex PCR typisiert. Die Untersuchung des Hundehaares zeigte eine mögliche somatische Mutation im System PEZ-20. PCR-Produkte aus der Hundehaarspur und vergleichend dazu aus der ungarischen Hundepopulation wurden sequenziert und aufgrund der Repeatanzahl mit bisher gefundenen PEZ-2o Allelvarianten abgeglichen. Die Häufigkeiten der DNA-Profile wurden basierend auf Allelhäufigkeitskalkulationen unter Verwendung der Daten einer gemischten ungarischen Hundepopulation ( 242 Hunde) bzw. einer reinrassigen Rottweiler- und Schäferhundpopulation berechnet. Die STR-Analysen bestätigten, daß die zwei verdächtigen Hunde den Jungen tödlich verletzt hatten. 


\section{Abstracts}

\section{P-35}

DER PLANTARE UND DORSALE CALCANEUSSPORN

ALS HINWEIS AUF HÖHERES LEBENSALTER

UND HÖHEREN BODY MASS INDEX

$\underline{\text { Riepert T }}{ }^{1}$, Baltz $\mathrm{M}^{2}$, Nafe B ${ }^{3}$, Schweden $\mathrm{F}^{4}$, Rittner $\mathrm{C}^{2}$

(1) Institut für Rechtsmedizin der Universität zu Köln, Melatengürtel 60-62, 50823 Köln-Ehrenfeld

(2) Institut für Rechtsmedizin der Universität Mainz

(3) Merowingerring 38a, 65428 Rüsselsheim

(4) Klinik und Poliklinik für Radiologie der Universität Mainz

Der plantare und dorsale Fersensporn sind als Fibroostosen auf degenerativer Basis am Ansatz der Achillessehne bzw. der Plantaraponeurose am Tuber calcanei aufzufassen, sofern nicht in seltenen Fällen eine entzündliche Genese vorliegt. Gehäuft werden beim Vorliegen von Fersenspornen ferner eine Pronationsstellung des Fußes und arthrotische Veränderungen festgestellt.

In eigenen Untersuchungen an Röntgenaufnahmen des oberen Sprunggelenkes von 1.027 mitteleuropäischen Patienten (RöFo 162: 552-9) konnte gezeigt werden, dass Calcaneussporne - im Gegensatz zu Angaben in der Literatur - zwar einen deutlichen Hinweis auf höheres Lebensalter, aber nicht generell auf weibliches Geschlecht darstellen. In der hier vorgestellten Studie wurden die Körpergröße, das Körpergewicht und der body mass index (BMI) bei 283 der o. g. Patienten ermittelt und mit dem Röntgenbefund in Beziehung gesetzt. Hierbei zeigte sich zunächst kein Zusammenhang zwischen hohem BMI und dem Auftreten von Calcaneusspornen. Unter zusätzlicher Berücksichtigung des erreichten Lebensalters konnte jedoch nachgewiesen werden, dass plantarer und dorsaler Calcaneussporn bei hohem BMI gehäuft auftreten und somit einen Hinweis auf den Körperbau darstellen.

\section{P-36}

DIE IDENTIFIZIERUNG

DES LETZTEN UNGARISCHEN „KRIEGSGEFANGENEN“

Sótonyi $\mathrm{P}^{12}$, Bujdosó $\mathrm{G}^{12}$, Lászik A $\stackrel{1}{\text {, }}$, Baur MP ${ }^{3}$

${ }^{1}$ Institut für Rechtsmedizin, Semmelweis Universität Budapest,

Ungarn

${ }^{2}$ Wissenschaftliche Aussenabteilung der Ungarischen Akademie der Wissenschaften, Ungarn

Institut für Medizinische Biometrie, Informatik und Epidemiologie, Medizinische Einrichtungen der Universität Bonn

In einer russischen Psychiatrie wurde ein junger Arzt darauf aufmerksam, dass ein seit 1947 behandelter Patient ein Ungar sein könnte. Nachdem ein ungarischer Konsul ihn besucht hatte, wurde er nach Ungarn verlegt. Nach den Angaben des Mannes konnte man seine mutmasslichen Halbgeschwister ausfindig machen. Zur Identifizierung führten die Autoren in ihrem Institut detaillierte serologische, anthropologische, chromosomale und DNA Untersuchungen durch. Durch diese Untersuchungen war es möglich, diesen Mann mit an Sicherheit grenzende Wahrscheinlichkeit ( 99. $9999 \%$ ) zu identifizieren. Die Untersuchungsergebnisse werden im Rahmen dieses Posters dargestellt.

Der letzte ungarische Kriegsgefangene hat heimgefunden.
P-37

ZUSAMMENHANG ZWISCHEN PIGMENTIERUNG

DER MEDULLÄREN ARACHNOIDEA

UND DEM ALLGEMEINEN PIGMENTSTATUS -

EIN BEITRAG ZUR IDENTIFIKATION

Weinandi ${ }^{1} \underline{T}$, Wicht ${ }^{2} \mathrm{H}$, Niess $^{1} \mathrm{C}$, Bratzke $^{1} \mathrm{H}$

${ }^{1}$ Zentrum der Rechtsmedizin

der Johann-Wolfgang-Goethe-Universität Frankfurt a.M.

${ }^{2}$ Zentrum der Morphologie (Dr. Senckenbergische Anatomie)

der Johann-Wolfgang-Goethe-Universität Frankfurt a.M

Haar- und Augenfarbe gehören zu den wichtigsten individuellen Merkmalen eines Menschen. Ihre Kenntnis kann in Fällen starker Leichenzerstörung, z.B. bei Verkohlung, eine Hilfe bei der Identifikation unbekannter Leichen darstellen.

Bei 60 Autopsien wurde der makroskopische Pigmentierungsgrad der weichen Hirnhaut über der Medulla oblongata mit der Haar- und Augenfarbe verglichen. Zusätzlich wurden histologische und morphometrische Untersuchungen in 20 Fällen durchgeführt.

Die Untersuchungen ergaben einen Zusammenhang zwischen einer stärkeren Pigmentierung der Arachnoidea und einer dunkleren Haarfarbe. Ein Zusammenhang mit der Augenfarbe war nicht festzustellen. Bei fehlender Pigmentierung zeigten sich keine klaren Zuordnungen.

\section{P-38}

STERBEN ÜBER 100-JÄHRIGE GESUND?

Berzlanovich A, Sim E, Fasching P, Muhm M

Institut für Gerichtliche Medizin, Universität Wien,

Sensengasse 2, A - 1090 Wien

Obwohl langlebige Menschen, besonders Hundertjährige, von jeher besonderes Interesse erweckt haben und nun auch einen zunehmenden Anteil an der Gesamtpopulation stellen, sind verläßliche pathologisch-anatomische Daten nur spärlich verfügbar. Nach wie vor dominieren Kasuistiken mit klinisch erhobenen Daten - Autopsieergebnisse wurden als Referenz und „Goldstandard“ für Diagnose und Therapie noch kaum zur Erforschung der oberen Grenze des menschlichen Lebens herangezogen. Von 1989 bis 2000 wurden im Wiener Institut für Gerichtliche Medizin 28312 Obduktionen durchgeführt, darunter fanden sich 20 Todesfälle aus natürlicher Ursache bei über 100-jährigen. In dieser Gruppe analysierten wir die Sektionsprotokolle, die Krankengeschichten und katamnestische Angaben.

Unter den obduzierten 20 über Hundertjährigen (range: 100 - 108 a) fanden sich 12 Frauen und 8 Männer. Alle Todesfälle ereigneten sich ausschließlich bei nicht bettlägerigen Patienten im eigenen Heim. An Vorerkrankungen waren bei 6 Patienten Herzbeschwerden, bei 3 Diabetes mellitus und bei 4 Hypertonie bekannt; immerhin galten 12/20 der über Hundertjährigen zum Zeitpunkt ihres Todes als gesund bzw. beschwerdefrei.

Als pathologisch-anatomisch nachgewiesene Todesursache dominierte die koronare Herzkrankheit (13/20). Die bei allen Leichen atherosklerotisch veränderte Aorta hatte bei $4 / 20$ eine aneurysmatische Aussackung, die in 2/4 durch Ruptur/Dissektion zum Tod führte. Respiratorisch bedingte Todesfälle fanden sich $4 \mathrm{mal}$, nur in einem Fall führte eine gastrointestinale Erkrankung zum Tod.

Zusätzlich zur klinischen Untersuchung erweitern die Autopsien unsere Kenntnisse zur Epidemiologie von Erkrankungen bei über Hundertjährigen. Auch bei hochbetagten Patienten ist eine hohe Sektionsfrequenz zur Qualitätskontrolle unerläßlich. 


\section{P-39}

\section{AUSSERGEWÖHNLICHER FALL EINES MORDES \\ MIT ANSCHLIESSENDEM SUIZID \\ Bungardt N, Ogbuihi S, Rittner C \\ Institut für Rechtsmedizin, Johannes Gutenberg-Universität, \\ D-55131 Mainz}

Ein 89jähriger Mann wurde in seinem Anwesen von der Tochter tot aufgefunden. Er befand sich in sitzender Position gegen einen Heizkörper gelehnt. Um seinen Hals war ein Antennenkabel geschlungen, dieses war an einem Fenstergriff befestigt. Im Schlafzimmer lag seine 79jährige Ehefrau tot im Bett. In Höhe des Brustbeins steckte ein Messer im Brustkorb. Von diesem Messer war nur der schwarze hölzerne Griff erkennbar. In der Kehle steckte parallel zu den Schultern ein Hirschfänger (Jagdmesser). Dieser war von links nach rechts eingeführt worden und auf der rechten Seite nicht mehr ausgetreten, weil sich die Haut gedehnt hatte. Im rechten Gesichtsbereich waren Einschussöffnungen und Schmauchspuren zu erkennen. Auf der Kommode wurde eine Pistole gefunden, deren Verschluss halb geöffnet war. Im Patronenlager war eine Patrone sichtbar.

Die Obduktion ergab bei der Frau eine Mehrfachschussverletzung des Schädels (zwei Einschussöffnungen und drei Projektile intracraniell) mit zusätzlichen Messerstichen in die Brusthöhle und seitlich durch die gesamte Halsregion. Der Ehemann hatte sich in atypischer Weise erhängt. Die polizeilichen Ermittlungen und die Obduktionsbefunde sprechen für einen sog. erweiterten Suizid. Als Motiv kommen Wahnvorstellungen in Frage. Seit einiger Zeit soll der alte Mann unter der übertriebenen Angst gelitten haben, wegen einer banalen Reparatur in einer vermieteten Wohnung zu verarmen. Diese Befürchtungen entbehren aber jeder Grundlage, da der Verstorbene sehr vermögend gewesen sein soll.

Der Fall und die Obduktionsbefunde werden demonstriert.

\section{P-40 \\ A LETHAL CASE OF GASTRIC RUPTURE \\ DUE TO GASTRIC AIR INFLATION \\ Egelund R, Behrendt N \\ Dept. of Forensic Pathology, Inst. of Forensic Medicine, \\ University of Copenhagen. \\ DK-210o Copenhagen OE, Denmark.}

We present a case of gastric rupture at the lesser curvature, pneumoperitoneum, pneumomediastinum, tension pneumothorax and subcutaneous emphysema following accidental air inflation in a nasogastric catheter, causing death in an 85-year old woman.

The woman, who complained of abdominal pains, was transferred from one hospital to another. Before departure she was given intravenous isotonic saline and nasal oxygen $(2 \mathrm{~L} / \mathrm{min})$. Soon after departure the woman complained of abdominal pain, nausea and difficulty in breathing. The nasal air was increased. The paramedic assisting her noticed the patient seemed to grow in body and facial appearance. 5-7 minutes later the patient exhaled. Resuscitation effort were effortless. Postmortem the patient continued to increase in size, until the nasal air was disconnected. Further examination revealed massive amounts of subcutaneous air.

The medico-legal autopsy showed subcutaneous emphysema on the extremities and the thorax.

In the upper left-sided peritoneum $150 \mathrm{ml}$ gastric contents from a $3 \mathrm{~cm}$ large perforation on the lesser curvature in the stomach. There were no gastric ulcers or tumours. There was right-sided pneumothorax and partly atelectasis of the right lung. The cause of death was considered cardiac- and lung failure following massive air inflation of the peritoneum and pleurae due to a misplaced nasopharyngeal catheter to the stomach which perforated.

Over a period of 15-20 minutes approx. 60 liters of 100 percent oxygen was inflated by mistake in the nasogastric catheter of the woman. First, the stomach was mistakenly inflated by oxygen at high pressure causing gastric rupture and pneumoperitoneum. Secondly, by another mistake, the air inflation was increased at this point causing progression of pneumopathology, ultimately resulting in death.

\section{P-41}

TÖDLICHES ÜBERROLLEN ODER ÜBERROLLEN

NACH TÖDLICHEM STURZ?

Draheim N, Maxeiner $\mathrm{H}$

Institut für Rechtsmedizin, FU Berlin, Deutschland

Verkehrsunfall mit Todesfolge, bei dem die Todesursächlichkeit einer unstrittigen Überrollung des Kopfes zur Diskussion stand.34-jähriger Mann, alkoholisiert $(2,4 \% \mathrm{o})$, kurz zuvor noch schwankend sein Fahrrad schiebend gesehen worden; an Unfallstelle Zusammensinken oder Sturz. Wurde mit dem Kopf am Fahrbahnrand liegend überrollt. Unmittelbar danach nicht ansprechbar mit schwallartiger Blutung aus Mund und Ohr vorgefunden; alsbald verstorben.

Autopsie: Kopfüberrollung mit markantem Profilmuster über die ganze rechte Gesichtsseite. Links parieto-temporal oberflächliche Abschürfungen, kleine Hauteinreissungen und bis $15 \mathrm{~cm}$ große unterminierte Wundtasche der Kopfschwarte, unter der ein fast bis nach rechts hinüber quer durch mittlere Schädelbasis verlaufender Schädelbruch begann. Todesursache waren Blutverlust und Blutaspiration, offenbar aus einer Carotisverletzung im Bereich der klaffenden Schädelbasisfraktur. Das linksseitige Kopftrauma wurde primär auf einen der Überrollung vorangegangenen, lebensbedrohlichen Sturz bezogen. Die Plausibilität dieser Interpretation wurde seitens Verfahrensbeteiligter in Frage gestellt.

Ausgangsmaterial einer retrospektiven Analyse waren 102 tödliche Schädeltraumen mit Schädelbruch infolge von Stürzen zu ebener Erde. 56-mal bestanden äußerlich Schürfungen/Blutunterlaufungen und 23-mal offene Wunden. In 23 Fällen fehlten markante Weichteilverletzungen bzw. waren infolge Überlebenszeit/Fäulnis nicht mehr beurteilbar. Ein Decollement wurde in keinem Fall beobachtet. In 26 Fällen war die Schädelbasis gebrochen, davon nur 6-mal quer. Eine Verletzung einer A. carotis interna wurde nicht gesehen. Die Zweitbegutachtung kam zu dem Resultat, dass das Gesamtbild der Kopfhaut- und Schädelverletzungen allein auf den Überrollungsvorgang zurückging und es sich bei den linksseitigen Weichteilverletzungen um Widerlagerverletzungen handelte, wie sie bei einem „einfachen“ Hinstürzen praktisch nicht entstehen können.

\section{P-42}

HYPOTHERMIC DEATH

AND SMALL VACUOLE-CONTAINING CELLS

IN THE ANTERIOR PITUITARY

Ishikawa T, Miyaishi S, Yamamoto Y, Yoshitome K, Inagaki S, Naka T, Tachibana $\mathrm{T}^{\star}$, Ishizu $\mathrm{H}$

Department of Legal Medicine, Okayama University Graduate School of Medicine and Dentistry, Okayama, Japan

${ }^{*}$ Department of Anatomy, Jikei University School of Medicine, Tokyo, Japan

We found the fact that the small vacuole-containing cells appeared in the anterior pituitary in hypothermic death. We report the result of observation in this paper.

Materials and Methods: Pituitary glands were collected at autopsy from 31 cases of hypothermia, 24 cases of traumatic death and 103 cases of natural death. Each ten serial frontal sections of the anterior, middle and posterior one-thirds of pars distalis were made from routinely paraffin-embedded blocks. They were used for H-E or immunohistochemical staining for the hormones of anterior pituitary. Small vacuole-containing cells were calculated by an image analysis device (Olympus Co. Ltd. Japan) . 


\section{Abstracts}

Results: In the anterior pituitary stained by H-E, 33.7-41.0\% of the cells had small vacuoles in the death of hypothermia. Whereas in the other cases, their appearance rate ranged from 0.3 to $0.6 \%$. By the immunohistochemical staining of the hormone producing cells in the cases of hypothermic death, ACTH cells had vacuoles at 57.6-69.3\%, GTH cells (gonadotrope) at $37.6-48.3 \%$, PRL cells at $26.8-35.3 \%, \mathrm{GH}$ cells at $28.2-35.2 \%$, and TSH cells at $12.4-18.5 \%$.

Discussion: The frequency of the small vacuole-containing cells in cases of hypothermia is obviously higher than in those of traumatic or natural death, especially among ACTH cells compared with other hormone producing cells. They were morphologically different from signet-ring cells often seen in GHT cells. Under the electron microscope the small vacuoles only appear in the cytoplasm and are unlikely to be putrefied bubbles. We concluded that the small vacuole-containing cell in the anterior pituitary could be an indicator of diagnosis for hypothermic death.

\section{P-43 \\ HÄUFIGKEIT DER ZUNGENBEINVERLETZUNGEN: IRRTÜMER UND WIRKLICHKEIT. \\ Khokhlov VD \\ Bureau for medico-legal expertise, St.-Petersburg, Russia}

Nach Literaturangaben wird das Zungenbein (ZB) relativ selten verletzt und wenn überhaupt, so überwiegend bei Strangulation (z.B. beim Erhängen nicht öfter als in $25-27 \%$ aller Fälle). Im Alter steigt die Wahrscheinlichkeit der ZB-Verletzungen wegen der Osteoporose und der Synostose der ZB-Gelenke.

Es wurden $440 \mathrm{ZB}$ von Leichen beider Geschlechter im Alter von 10 bis 90 Jahren (m. 311; w. 129) bei Verdacht oder bestätigten Halstraumata präpariert. Dabei wurde bei 137 Fällen die Effektivität verschiedener Untersuchungsmethoden (Palpation, Präparation, in 20 Fällen Röntgen) verglichen und statistisch ausgewertet.

Unsere Untersuchung zeigte, dass die ZB-Verletzungen viel häufiger als allgemein bekannt sind. Mit Hilfe der Präparation konnten wir beim Erhängen $(\mathrm{N}=137)$ in $42 \%$, beim Erdrosseln $(\mathrm{N}=30)$ in $57 \%$ und beim Erwürgen $(\mathrm{N}=12)$ in $92 \%$ solche nachweisen.

Die Effektivität der weit verbreiteten einfachen Diagnostikmethoden ist sehr niedrig. So wurden palpatorisch $45 \%$ und röntgenologisch nur $33 \%$ der vorhandenen ZB-Verletzungen erkannt. Diese beide Methoden erlaubten die Feststellung überwiegend von vollständigen Frakturen oder unvollständigen Frakturen mit Abbiegung des ZB-Hornes. Gleichzeitig wurden falsch positive Befunde registriert. So wurden in 3,2\% aller untersuchten Fälle alte abgeheilte Frakturen sowie anatomische Abnormitäten feststellbar, die leicht für eine frische Fraktur gehalten werden könnten.

Mit dem Alter steigt die Häufigkeit der ZB-Verletzungen. In der Gruppe der Erhängten waren solche bei 10 bis 30-jährigen in 33,3\%, bei 31-50-jährigen in 40,7\% und in der ältesten Fallgruppe in $49,1 \% \mathrm{zu}$ beobachten. Verknöcherung der ZB-Gelenke wird bei Männern durchschnittlich zum 50. Lebensjahr $((=14,5)$ und bei Frauen zum 68. Lebensjahr $((=11)$ abgeschlossen. Von 154 beweglichen großen ZBHörner wurden bei Erhängten $53(34,4 \%)$ und von 120 nicht beweglichen großen ZB-Hörner $25(20,8 \%$, p < o, 01) verletzt. Somit sollte man zwischen der altersbedingten Verknöcherung der ZB-Gelenke und Osteoporose trennen.

\section{P-44}

MODERNE VARIANTE DES ERHÄNGENS -

EINSATZ EINER ZEITPROGRAMMIERTEN SEILWINDE

Krill A, Grellner W, Wilske J

Institut für Rechtsmedizin, Universität des Saarlandes, Geb. 42,

D-66421 Homburg/Saar

Erhängen ist eine der häufigsten Suizidarten. Akzidentielles Erhängen kommt hingegen sehr selten vor, nur in vereinzelten Fällen wurden Tötungsdelikte beschrieben. Fesselungen in Zusammenhang mit Strangulationen können die Abgrenzung eines Suizids von einem Tötungsdelikt unter Umständen erschweren. Sie werden darüber hinaus gehäuft bei autoerotischen Unfällen gefunden. Beschreibungen über den Einsatz bestimmter Strangulationsvorrichtungen sind in der Literatur immer wieder anzutreffen. Dieses Schrifttum soll um eine ungewöhnliche Variante ergänzt werden.

Im vorliegenden Fall handelt es sich um den Suizid eines 41-jährigen Elektrikers, der sich mittels einer elektrischen Seilwinde in nahezu freier Suspension erhängte. Die am Holzgebälk des Dachbodens befestigte Seilwinde war dabei über eine elektrische Zeitschaltuhr programmiert, der Kipphebel der Fernbedienung mittels Pflasterstreifen in Ein-Stellung fixiert. Zum Schutz vor Selbstrettung hatte sich der Mann mit Handschellen auf dem Rücken gefesselt. Die Schlinge war offensichtlich in der Vorstellung einer Schmerzminderung teilweise mit einem Fahrradschlauch abgepolstert. Ein Fremdverschulden konnte aufgrund der Auffindesituation und dem Ergebnis der Obduktion verneint werden.

Der Fall demonstriert, dass nicht nur Schlingenknotungen oder die verwendete Strangart mit verschiedenen Berufsgruppen assoziiert sein können, sondern unter Umständen auch die Wahl der Strangulationsvorrichtung dem beruflichen Umfeld entstammen kann. Die vorgestellte Kasuistik kann dabei als moderne Variante des Erhängens die bekannte Literatur zu teils historischen Fällen mit dem Einsatz von Flaschenzügen und ähnlichen Konstruktionen ergänzen.

\section{P-45 \\ BEOBACHTUNG EINER TRAUMATISCHEN AORTENRUPTUR \\ UNTER LANGZEIT-EKG-KONTROLLE \\ Maxeiner H, Scholz T \\ Institut für Rechtsmedizin, FB Humanmedizin, \\ Freie Universität Berlin, Deutschland}

Ein 77-jähriger Mann kam als Fahrer eines DB 124 ungebremst nach links von der Fahrbahn ab und prallte gegen einen Straßenbaum. Die Mitte der Fahrzeugfront wurde ca. $30 \mathrm{~cm}$ tief eingedrückt, die Lenksäule war etwas nach unten verzogen. Unmittelbar nach der Kollision wurde der bewußtlose Verletzte aus dem Fahrzeug geborgen. Beginn von Laien-Reanimation. Minuten später traf die Feuerwehr ein. Deren halbautomatisches Defibrillationsgerät zeigte einen ventrikulären Ersatzrhythmus von etwa 20/min. Maskenbeatmung, Herzdruckmassage. Etwa 15 Minuten nach dem Unfall traf die Notärztin ein. Pulsloser Patient, im Monitor-EKG breite Kammerkomplexe. Intubation, weiter Herzmassage, Abbruch der Maßnahmen etwa 10 Minuten später.

Der Mann war seit mehreren Jahren behandlungspflichtig herzkrank. Vor etwa einem halben Jahr soll er bereits einen Verkehrsunfall infolge einer Synkope erlitten haben. Er war jetzt auf dem Wege zur Praxis seines Internisten (T.S.), wo das am Vortage angelegte Langzeit-EKG wieder abgenommen und ausgewertet werden sollte.

In den 23 Stunden bis unmittelbar vor dem Unfall Sinusrhythmus, $51-100 / \mathrm{min}$. Der Unfall markiert sich im EKG an einer kurzen Phase irregulärer hoher Ausschläge. Über weitere etwa 6-7 Minuten bleibt das EKG unverändert bei einer Frequenz um 6o/min. Dann kommt es zunächst zunehmend zu Extrasystolen, gefolgt von komplexeren Rhythmusstörungen und Asystolien. Etwa 20 Minuten nach dem Unfall praktisch keine Kammerkomplexe mehr, vollständiges Erlöschen der elektrischen Aktivität nach etwa 40 Minuten. 
Obduktion: äußerlich praktisch unverletzter Patient; Thoraxtrauma mit beidseitigen mehrfachen Rippenserien- sowie Sternumfrakturen. Abriss der Aorta thoracica an typischer Stelle; linksseitiger Hämatothorax $(1,2 \mathrm{l})$. Ferner eine offenbar abstützbedingte Radiusfraktur am rechten Handgelenk sowie ein starkes Kehlkopftrauma mit instabilem Larynx (dieses war der Dokumentation nach offensichtlich ganz ohne Auswirkungen auf die Herzaktivität geblieben).

\section{P-46 \\ VERLETZUNGEN AM HALS: \\ DRITTEINWIRKUNG ODER REANIMATIONS ARTEFACT? \\ Michaud K, Horisberger B, Romain N, Mangin P \\ Institut universitaire de médecine légale, Rue du Bugnon 21, $\mathrm{CH}-1005$ Lausanne}

Ein 62-jähriger Mann wurde auf der Straße, neben einer Telefonkabine tot gefunden. Etwa drei Viertel Stunde vorher hatte er die Polizei angerufen und gesagt, daß er von 4 Unbekannten angegriffen worden sei. Zu diesem Zeitpunkt waren die Umstände unklar. Am nächsten Tag wurden wir informiert, dass das Opfer eine Stunde lang reanimiert worden sei.

Als Obduktionsbefunde stellten wir die Verletzungen an den Weichteilen am Hals vorne (mehrere frische Hämatome in der Halsmuskulatur), am Brustkorb (Hautblutungen, Brüche einiger Rippen und des Brustbeins mit deutlichen Unterblutungen in der Muskulatur, Einblutungen im Mediastinum) und unauffällige Unterblutungen am Kehlkopf mit intaktem Zungenbein und Kehlkopfskelett fest. Histologisch zeigten die Einblutungen keine Entzündungsreaktion. Eine morphologisch eindeutige Todesursache konnte nicht eruiert werden. Das Herz war allerdings dilatiert und hypertrophisch (490 g für ein Körpergewicht von $83 \mathrm{~kg}$ ). Die chemisch-toxikologischen Untersuchungen wiesen nur Lidocain auf.

Verletzungen an Halsweichteilen, Kehlkopf und Brustkorb liessen am Anfang einen Angriff gegen den Hals vermuten. Erst nachdem uns die Informationen über eine einstündige Reanimation im Detail erklärt wurden, konnten die festgestellten Verletzungen an der Halsgegend den Reanimationsmassnahmen zugeordnet werden. Somit können Reanimationsverletzungen zu möglichen Fehlinterpretationen führen. Informationsfluss zwischen kriminaltechnischer Tatortgruppe und forensischer Medizin ist für die Interpretation einer Gewalteineinwirkung von erheblicher Bedeutung.

\section{P-47 \\ INFORMATIONSMANAGEMENT IN DER RECHTSMEDIZIN \\ Neis P, Kaufmann T, Rittner C \\ Institut für Rechtsmedizin Mainz}

Die Bearbeitung rechtsmedizinischer Fälle führt zu einem Anfall verschiedenster Daten. Diese werden bisher häufig auf Arbeitsplatzrechnern des Sachbearbeiters verwaltet. Die gedruckten Gutachten und Fotografien werden meist zentral im Institut z.B. in einer Registratur aufbewahrt. Um die Informationen unserer Fälle sinnvoll zu nutzen wurde ein Datenbanksystem als zentraler Bestandteil des Informationssystems erstellt.

Im Modul Informationsmanagement werden alle bisher angefallenen Daten, egal ob Textdateien, Datenbankeinträge oder Lichtbilder in übersichtlicher Form angezeigt. Die Textdateien liegen bereits in elektronischer Form vor und werden nach Abschluss der Bearbeitung automatisch auf den zentralen Informationsserver kopiert. Die Lichtbilder, also z.B. die Dokumentation von Fundorten und Sektionen, werden vollständig eingescannt und stehen in einer Art „elektronischem Fotoalbum“, z.B.zur Integration in eine Powerpoint-Datei oder zum Ausdrucken, zur Verfügung.

Die zentralen Daten, also Personendaten, Auftraggeber, Sachbearbeiter usw. werden automatisch in zu erstellende Gutachten und
Dokumentationen übernommen. Dies verhindert Übertragungsfehler und die Notwendigkeit der Mehrfacheingabe von Daten.

Schließlich gewährleistet das System eine lückenlose Dokumentation des Werdegangs von Dokumenten innerhalb des Institutes, vom Gutachteneingang, bis zur Versendung der Unterlagen und erleichtert damit das Aufspüren von Fehlerquellen und Verzögerungen. Die lückenlose Dokumentation gibt Hilfestellung bei der anstehenden Zertifizierung bzw. Akkreditierung des Institutes.

\section{P-48 \\ DAS HAMBURGER SEKTIONSGESETZ VOM 9. FEBRUAR 2000 - ENTWICKLUNG DER SEKTIONSZAHLEN IN HAMBURGS PROSEKTUREN \\ Sperhake JP, Püschel K \\ Institut für Rechtsmedizin, Hamburg}

Der Rückgang der Sektionsfrequenz in Instituten für Pathologie und z.T. auch in Instituten für Rechtsmedizin wird zunehmend beklagt. Ein Grund für eine zurückhaltende Obduktionstätigkeit soll unter anderem in der Rechtsunsicherheit bezüglich der Zulässigkeit sog. klinischer oder wissenschaftlicher Sektionen gelegen haben. Während es für verschiedene Sektionsformen (z.B.Legalsektion, Sektion nach dem Bundesseuchengesetz) schon seit längerer Zeit gesetzliche Grundlagen gab, standen diese für den Bereich klinischer Sektionen bisher aus. Seit wenig mehr als einem Jahr gibt es nun in Hamburg, wie schon zuvor in Berlin und Bremen ein verbindliches Gesetz zur Regelung wissenschaftlicher Sektionen. Das Hamburger Sektionsgesetz unterscheidet zwischen klinischen, (nicht staatsanwaltschaftlich angeordneten) rechtsmedizinischen und anatomischen Sektionen. Es regelt Aspekte der Zulässigkeit, Einwilligung, Anordnung und Durchführung der Sektion.

Eine aktuelle Umfrage unter Hamburgs Prosekturen und niedergelassenen Pathologen, die Obduktionen durchführen, verdeutlicht den Rückgang der Sektionszahlen im Laufe der letzten Jahrzehnte bis heute. Den Kollegen wurde auch die Möglichkeit gegeben, zu Ursachen der rückläufigen Sektionsfrequenz und zu ihren Erfahrungen mit dem neuen Sektionsgesetz Stellung zu nehmen. Die Ergebnisse werden vorgestellt.

\section{P-49 \\ VERLETZUNGSMUSTER BEI TÖTUNGSDELIKTEN VON BESONDERER BRUTALITÄT \\ Trnka J, Maksymowicz K \\ Lehrstuhl und Institut für Gerichtliche Medizin \\ der Medizinischen Akademie Wroclaw, Polen}

Die Verfasser analysieren Tötungsdelikte mit jeweils mehrfachen, schweren, voneinander unabhängig potentiell todesursächlichen Verletzungen sowohl nach Wundaspekt und -topografie als auch nach dem mutmaßlichen Tatablauf. Sämtliche Täter waren vorbestraft wegen schwerer Körperverletzung oder Tötungsdelikten.

Der Begriff „besondere Brutalität“ wird gewöhnlich mit der Beibringung zahlreicher und ausgedehnter Verletzungen bei zusätzlicher Wehrlosigkeit des Opfers assoziiert. Die polnische Gesetzgebung sieht für derartige Taten ein höheres Strafmaß vor als für andere Tötungsdelikte und hat dies auch mit einem neuen Passus im Strafgesetzbuch seit 1997 sanktioniert. Die juristische Qualifizierung als „Taten mit besonderer Brutalität" erfolgt nicht anhand der traumatischen Veränderungen, d.h. der Handlungsfolgen, sondern vielmehr nach der Motivation des Täters, dem Opfer besonders schwere Leiden zuzufügen. Dieses juristische Procedere erschwert die gerichtsmedizinische Beweisführung. 


\section{Abstracts}

\section{P-50}

RECHTSMEDIZINISCHE FEHLER

BEI DER UNTERSUCHUNG VON BRANDLEICHEN

Volksone V, Berzinsch U, Grauss G

Staatszentrum für Rechtsmedizin Lettlands, Riga, Lettland

Zu den kompliziertesten Aufgaben der rechtsmedizinischen Begutachtung gehört die Untersuchung von stark verbrannten Leichen. Die Unerfahrenheit von Obduzenten kann zu schwerwiegenden Fehleinschätzungen führen, wie nachfolgender Fall belegt. Binnen zweier Monate brannten zwei ländliche Anwesen bis auf die Grundmauern nieder, an beiden Brandstätten wurde eine männliche Brandleiche aufgefunden. Bei den Obduktionen wurden ausschließlich Brandeinwirkungen diagnostiziert.

Nach dem Mord eines Taxifahrers drei Jahre später in derselben Gegend gestanden die Täter auch die Tötung der Männer in den beiden Brandfällen ein. An den exhumierten Brandleichen konnten noch Stichverletzungen und Schrotschußverletzungen festgestellt werden. Die Fälle belegen die Notwendigkeit der besonders sorgfältigen und kompetenten Obduktion von Brandleichen, da mit Brandlegung zur Vernichtung und Vertuschung von Spuren nach vorausgegangenen Gewaltdelikten gerechnet werden muß.

\section{P-51}

PROBLEME IN DER BEGUTACHTUNG EINES TODESFALLES NACH TRANSLUMINALER ENDARTERIEKTOMIE

Bockholdt B, Maxeiner H

Institut für Rechtsmedizin, FB Humanmedizin,

Freie Universität Berlin, Deutschland

Die Grenze zwischen unvermeidbarer Komplikation und vermeidbarem Behandlungsfehler ist bei komplexen Zusammenhängen oft äußerst schwierig oder auch retrospektiv nicht zu ziehen. Allein ein bei dem Eingriff anwesender erfahrener Beobachter könnte dies beurteilen - als eine Informationsquelle für strafrechtliche Belange kommen ggf. teilnehmende andere Ärzte aber realistischerweise und aus vielfältigen Gründen nicht in Betracht. Die Beweisanforderungen für den Kausalzusammenhang stellen oft eine weitere, kaum überwindbare Hürde dar.

Im Rahmen der jetzigen stationären Diagnostik wurde bei einer 67 Jahre alt gewordenen Frau u.a. neben einem fast vollständigen Verschluß der linken A. carotis comm. (Z. nach alter Angioplastie) eine hochgradige Stenose auch der rechten festgestellt. Empfehlung zu einer transluminalen Thrombendarteriektomie. Perakuter thrombotischer Verschluß des operierten Gefäßes; Tod 3 Tage nach der Operation.

Die aufwendige morphologische Untersuchung des Operationsgebietes zeigte eine unregelmäßige Ebene der Gefäßausschälung mit Stufenbildungen, teilweise bis knapp an die Adventitia. An der Vernähung des Übergangsbereiches von der Endarteriektomie zum belassenen Gefäß selbst fanden sich weiterhin Teile der distalen inneren Gefäßwand nicht von der Naht erfaßt, so dass sie dissektionsähnlich in die Lichtung flottierten und offenbar die Thrombenentstehung mit begünstigt hatten. Beide morphologischen Besonderheiten werden in der einschlägigen Literatur als Komplikationsursache beschrieben; die Notwendigkeit eines sie vermeidenden operativen Vorgehens wird betont.

Obwohl somit morphologische Hinweise für ein nicht einwandfreies technisches Vorgehen vorlagen, wurde dem nicht intensiv weiter nachgegangen. Bei einer praxisnahen Abwägung mußte in Betracht gezogen werden, dass selbst für den Fall eines nachgewiesenen Fehlers in der gegebenen Situation der Beweis des Kausalzusammenhanges kaum gelungen wäre.

\section{P-52}

TODESURSÄCHLICHE ARTERIENVERLETZUNGEN

BEI EINER HÜFTGELENKENDOPROTHESE

Ehrlich,E, Maxeiner H

Institut für Rechtsmedizin, FB Humanmedizin,

Freie Universität Berlin, Deutschland

Wegen einer Coxarthrose wurde einer 73-jährigen Patientin eine zementierte Totalendoprothese des linken Hüftgelenkes eingesetzt, den Beschreibungen nach anscheinend komplikationsfrei. Am Operationsende kam es zu einer zunehmenden Kreislaufinstabilität sowie starken Blutungen aus den bereits eingelegten Drainagen; kurz nach Übernahme auf die Intensivstation Entstehung eines hämorrhagischen Schockes, Ausbildung der Zeichen eines akuten Abdomens, mehrfache notfallmässige Laparotomien sowie lokale Nachoperation. Obwohl mehrere Gefäßverletzungen versorgt wurden, ließ sich die Blutung nicht beherrschen (Massentransfusionen $>50$ Konserven); finaler Kreislaufzusammenbruch knapp 20 Stunden nach dem Ersteingriff.

Autoptisch war eine riesige Wundhöhle von der linken Hüftregion bis weit in den Retroperitonealraum mit ausgedehnter Freilegung der Beckenarterien und teilweise der Aorta festzustellen. Sowohl die Arteria als auch die Vena femoralis waren aufgerissen und wieder vernäht worden. Weitere vernähte Verletzungen fanden sich an der entsprechenden V. iliaca externa.

Das Ausmaß der innerlichen, operationsbedingten Verletzungen war für uns nicht erklärlich bzw. nicht mit einem technisch einwandfreien operativen Vorgehen zu vereinbaren. $\mathrm{Zu}$ einer Fortsetzung des Strafverfahrens nach erforderlicher klinischer Begutachtung kam es jedoch bemerkenswerterweise nicht.

\section{P-53}

GIBT ES EIN „SUDDEN INFANT DEATH SYNDROM“?

Böhme B, Rauch E, Büttner A, Penning R

Institut für Rechtsmedizin der Universität München,

Frauenlobstr. 7a, 80337 München

Im Rahmen der multizentrischen BMBF-Studie „Plötzlicher Säuglingstod“ wurden im Jahr 1999 am Institut für Rechtsmedizin der Universität München 37 Säuglinge obduziert. 34 davon wurden wegen V.a. SIDS untersucht, bei 3 weiteren Kindern war eine nicht natürliche Todesart von vornherein bekannt (Ersticken an einer Erdnuß, Tötung, Kohlenmonoxidvergiftung).

9 der Kinder hatten laut Angaben der Eltern direkt vor dem Ableben Anzeichen einer leichten Erkältung. Bei den meisten Kindern war jedoch eine Erkrankung nicht beobachtet worden.

Nach Durchführung einer mikrobiologischen und histologischen Untersuchung zeigte sich, daß ungewöhnlich viele der Kinder an Atemwegsinfektionen litten.

Aus diesem Grund wurde für das Jahr 1999 eine Gegenüberstellung aller drei Kriterien (Obduktionsbefunde, Mikrobiologie und Histologie) durchgeführt und entsprechend einer von der Studienzentrale festgesetzten Kategorisierung der pathologischen Befunde eingeteilt. Dabei wurde festgestellt, daß lediglich 2 der 37 Kinder in keiner der Untersuchungen krankhafte Veränderungen erkennen ließen. 23 Kinder wiesen Anzeichen einer leichten Erkrankung auf und 4 Kinder bereits schwerwiegendere pathologische Veränderungen. 5 der Kinder verstarben an einem nicht natürlichen Tod.

Anhand dieser Ergebnisse stellt sich für uns die Frage, ob die Diagnose „plötzlicher Säuglingtod“ neu definiert werden müßte oder aber die Zahl der mutmaßlich hieran verstorbenen Kinder geringer ist als bisher angenommen. 


\section{P-54}

NACHWEIS VON METALLPROTEINASEN

IM LUNGENGEWEBE PLÖTZLICH VERSTORBENER SÄUGLINGE.

Bouška I, Toupalík P

Institut für Rechtsmedizin, Prag, Tschechische Republik

Die Matrix-Metallproteinasen gehören zu einer Enzymgruppe, die eine ganze Reihe von Prozessen im menschlichen Organismus regeln. Eine erhöhte Enzymaktivität wurde z.B. bei Entzündungen oder auch bei protrahierter Hypoxie beobachtet. Metallproteinasen werden von mesenchymalen Zellen gebildet und kommen auch in Alveolarmakrophagen vor.

Hier wurde das Vorkommen von MMP-1, MMP-3 und MMP-9 in Alveolarmakrophagen bei Fällen von plötzlichem Säuglingstod (SID) untersucht. Als Kontrollgruppe wurden Todesfälle durch Hypoxie unterschiedlicher Dauer und traumatisch bedingte Todesfälle einbezogen. In der SID-Gruppe, wo reichlich Alveolarmakrophagen beobachtet wurden, konnte ebenso wie bei den Todesfällen nach Hypoxie eine höhere Aktivität der Metallproteinasen festgestellt werden als bei den traumatischen Todesfällen.

Im Zusammenhang mit diesem Befund ist der Einfluß von Stickoxiden $\left(\mathrm{NO}, \mathrm{NO}_{2}\right)$ und Peroxynitriten im Zigarettenrauch auf die Aktivierung der kollagenolytischen Enzyme bei plötzlichem Kindstod zu diskutieren.

\section{P-55 \\ HAT DIE HÄUFIGKEIT EPIDEMIOLOGISCHER MERKMALE BEIM UST UND BEIM ERKLÄRBAREN UST

Nach dem Bericht über „The epidemic of SIDS in Norway 1967-93“: changing effects of risk factors" ist das relative Risiko, ein Kind durch SIDS zu verlieren für unter 20-jährige Mütter gegenüber 25-29-jährigen von 2.5 (1967-71) auf 7.0 (1990-93) gestiegen. Das SIDS-Risiko hat sich für Viertgeborene gegenüber Erstgeborenen von 3.2 auf $14.4 \mathrm{er}-$ höht.

Nach der Studie aus Grossbritannien (1993-96) ist der Wintergipfel zurückgegangen, der Anteil an erklärbarem UST gestiegen und die Nikotinexposition beim UST höher.

Aus den Obduktionsbefunden von 445 unerwartet gestorbenen Säuglingen war der Tod bei 120 (27\%) nicht erklärbar (Gruppe 1), bei 221 (50\%) nicht hinreichend (Gruppe 2 ) und bei 104 (23\%) hinreichend erklärbar (Gruppe 3).

An epidemiologischen Daten wurden erfasst: Geschlecht, Mehrlinge, Gestationsalter, Reifegrad, Geburtsgewicht, Saison bei Geburt und Tod, erreichtes Lebensalter, Wochentag des Todes, Nikotinexposition, Stillzeit und Schlafposition. Mütterliche Daten waren Alter, Parität, Zivilstand und ethnische Zugehörigkeit. Die Referenzgruppe (RG) zum Durchschnitt in der Bevölkerung bestand aus 9886 Lebendgeborenen der Jahrgänge 1983, 1993 und 1999 der Stadt Zürich.

Der Zeitraum 1969-2000 (32 Jahre) wurde unterteilt in die je 10.5 Jahre umfassende Periode I (1969- Juni 79) und II (Juli 79- 1989) und die 11 Jahre zählende Periode III (1990-2000).

Die Auswertung für jede UST-gruppe in jeder Periode ergibt: Zurückgegangen ist der Anteil der Gruppe 1 (ca.50\%), der Erstgeborenen von $42 \%$ (P I) auf $29 \%$ (P II). Angestiegen im Vergleich zur RG sind Drittgeborene (22\% vs $10 \%$ ) und Mehrlinge (6.8\% vs $1.4 \%$ ). Das mittlere Lebensalter der Kinder in Gruppe 1 und 3 ist in P III höher als in P I. Der Sterbegipfel liegt nahezu unverändert in allen 3 Gruppen und Perioden zwischen dem 2. und 4. Lebensmonat.

\section{P-56}

EIN TODESFALL - SIDS, HITZSCHLAG, ALKOHOL -

ODER LIDOCAININTOXIKATION ?

Werner R, Ahrens B, Demme U, Giebe W, Klein A, Giebe B

Institut für Rechtsmedizin der FSU Jena

Ein knapp 6 Monate alter Säugling wurde am 25. 01. 2001 gegen 22.00 Uhr mit Mütze, Jacke, Pullover, Strampler, Strumpfhose und Strümpfen bekleidet im Kinderwagen liegend, in einem beheizten Raum zum Schlafen gelegt. Gegen 10.00 Uhr des Folgetages wurde er durch die Mutter - stark überhitzt und verschwitzt - leblos aufgefunden. Ein sofort herbeigerufener Notarzt konnte nach erfolglosen Reanimationsbemühungen (Intubation, extrathorakale Herzmassage, Legen eines Magenschlauches) nur noch den Tod attestieren.

Autoptisch waren neben deutlich halonierten Augen Verfestigungen und Blutungen im Lungengewebe nachweisbar. Letztere boten histologisch das Bild einer interstitiellen hämorrhagischen Pneumonie. Die toxikologisch-chemische Untersuchung des einbehaltenen Organmaterials erbrachte neben einer BAK von 0,7 \%o den Nachweis von $500 \mu \mathrm{g}$ Lidocain pro ml Blut; die Konzentrationen des Lidocain in Leber und Niere lagen bei $50 \mu \mathrm{g} / \mathrm{g}$.

In asservierten Nahrungsbehältnissen wurde ein Alkoholgehalt von $0,55 \mathrm{Vol} \%$ und $1,35 \mathrm{Vol} \%$ nachgewiesen.

Diskussion:

Die erhobenen Befunde, ihre Plausibilität und ihre Genese werden diskutiert und hinsichtlich ihrer Bedeutung für die Todesursache bewertet. Hierbei wird besonderer Schwerpunkt auf die Beachtung iatrogener Applikationsmöglichkeiten während der Reanimation oder der Sektion und auf die Einbeziehung polizeilicher Ermittlungsergebnisse gelegt.

\section{P-57}

NEVER SAY NEVER AGAIN -

DIE UNGLAUBLICHE AUSSAGE DES ANGESCHULDIGTEN ODER DER EINES BESSEREN BELEHRTE SACHVERSTÄNDIGE

Brüschweiler W, Vogler M, Rauch P

Wissenschaftlicher Dienst Stadtpolizei Zürich

Nirgends mehr als auf die Polizeiarbeit trifft zu, dass es „nichts gibt, was es nicht gibt“. Trotzdem oder gerade deshalb sind wir sehr misstrauisch gegenüber Aussagen von Angeschuldigten. Wir wittern schnell einmal hinter jedem und allem eine Irreführung oder schlicht weg eine Lüge.

Im Laufe einer Auseinandersetzung zwischen einer Frau und einem Mann erlitt sie einen Messerstich im Kniebereich. Das Opfer gab an, mit vom Kontrahenten abgewendetem Blick auf einem Stuhl gesessen zu haben, als sie den Stich erlitt. Der Mann will das Messer im Zorn auf den mit einem Teppich belegten Boden geschmettert haben. Die Waffe sei am Boden abgelenkt worden und habe die Frau rein zufällig getroffen.

Eine Untersuchungsrichterin gab eine Expertise über das fragliche Geschehen in Auftrag. Musste das sein? Nach welchem physikalischen Gesetz sollte denn ein auf einen dickeren Teppich aufprallendes Messer wieder ca. $60 \mathrm{~cm}$ ansteigen und dazu noch mit der Spitze voraus das Knie des Opfers treffen? Wieder einmal mehr eine Schutzbehauptung!

Der Untersuchungsrichterin musste der Auftrag ausgeredet werden! Dies am einfachsten mit einem Versuch, mittels dessen Ergebnis man klar aufzeigen kann, dass das Messer nach dem Aufschlagen am Boden, flach in irgend eine Ecke weiterschlingert.

In kurzer Improvisation wurde in einer Zimmerecke ein dickeres Stück Teppich auf den Boden gelegt, das Messer an dem Griff erfasst und über den Kopf hinweg auf den Teppich geschleudert. Und siehe da: das Messer steckte ca. $60 \mathrm{~cm}$ ab Boden fest in der Wand! Im Nachhinein ist man immer gescheiter. Das Messer schlug mit dem Griffende auf dem Teppich auf, drehte sich und federte in relativ stei- 
lem Winkel wieder nach oben. Dort blieb es in der Wand stecken. Den Versuch ja nicht wiederholen. Denn das Glück (für den Angeschuldigten) des Zufalls darf man nicht ein zweites mal herausfordern!

\section{P-58 \\ KAMPFMITTELRÄUMDIENST IM OBDUKTIONSSAAL: PERSONENGEFÄHRDUNG

In einer Grünanlage in Düsseldorf wurde die Leiche eines 79 Jahre alt gewordenen Rentners aufgefunden. Der vollständig bekleidete Leichnam wies an der rechten Schläfe einen $2,5 \mathrm{~cm}$ großen, stark beschmauchten Defekt auf, in der rechten Hand befand sich eine Signalpistole „Diana“, Kaliber 4. Bei dem Leichnam fand sich eine Tüte, die eine Zigarrenkiste mit Signalpatronen Comet, Kaliber 4, enthielt.

Bei der gerichtlichen Obduktion zeigte sich am Hirnschädel ein ausgedehnter, schräg von rechts vorn nach links hinten verlaufender Defektkanal. Das umgebende Großhirngewebe war in einem Durchmesser von etwa $4-5 \mathrm{~cm}$ völlig zerstört. Direkt vor dem Schädelknochen an der linken Seite wurde in der Schädelhöhle eine Metallkartusche mit Kork- und Gummischeiben vorgefunden. Ein zufällig bei der Obduktion anwesender Militärpolizist machte die Obduzenten darauf aufmerksam, dass offensichtlich nicht die gesamte Signalpatrone bei der Schussabgabe gezündet hatte. Der sofort alarmierte Kampfmittelräumdienst stellte das Munitionsteil unter höchsten Vorsichtsmaßnahmen im Obduktionssaal sicher. Da ein Transport den Fachleuten zu gefährlich erschien, wurde das Munitionsteil im Erdreich hinter dem Institut vergraben und mittels Sprengkapseln zur Explosion gebracht.

Durch die Munitionsexperten wurde festgestellt, dass bei der Schussabgabe nur der Treibsatz der Signalpatrone gezündet worden war. Der Leuchtsatz hingegen hatte nicht gezündet. Die Zündung des Leuchtsatzes war offensichtlich durch die Fixierung der die Treibsätze trennenden Kork- und Gummischeiben im weichen Hirngewebe verhindert worden.

Der berichtete Fall zeigt wie wichtig der vorsichtige Umgang mit Fremdkörpern sein kann, die im Rahmen von Obduktionen in Leichen vorgefunden werden.

\section{P-59 \\ RECHTSMEDIZINISCHE AUFGABEN IM KAMPF \\ GEGEN DIE ORGANISIERTE KRIMINALITÄT \\ IN DER GRENZREGION ZWISCHEN POLEN, TSCHECHIEN \\ UND DEUTSCHLAND \\ Maksymowicz K, Swiatek B \\ Lehrstuhl für Gerichtsmedizin der Medizinischen Akademie, Wroclaw, Polen}

Die besondere geografische Lage der Sudeten im Dreieck zwischen Polen, Tschechien und Deutschland am Verkehrsknoten zwischen Warschau, Berlin und Prag hat diese Region zu einem Tummelplatz international operierender Verbrecherorganisationen werden lassen. Zigaretten-, Alkohol-, Drogen- und Menschenschmuggel sind ebenso wie bewaffnete Überfälle und Erpressung an der Tagesordnung. Nicht seltenen werden auch völlig unbeteiligte Personen als Opfer schwer verletzt oder kommen sogar zu Tode.

Bislang unbekannt ist die neue Dimension der Brutalität in diesem Umfeld, nicht selten in Verbindung mit Folterung. $\mathrm{Zu}$ den neuen rechtsmedizinischen Aufgaben gehören die Befundung und Dokumentation von Verletzungen unter Einbeziehung rechnergestützter
Verfahren, ballistische Analysen sowie Sicherung und Auswertung biologischer Spuren.

P-60

TÖDLICHE VERGIFTUNG EINES 14 MONATE ALTEN JUNGEN

NACH VERSCHLUCKEN VON MÖBELPOLITUR

Chadova L

Institut für Rechtsmedizin, Karlsuniversität, Prag

Es wird über einen Todesfall eines 14 Monate alten Jungen berichtet, der Möbelpolitur getrunken hatte. Obgleich er umgehend auf die Intensivstation eingeliefert wurde, verstarb das Kind 12 Tage später unter den Zeichen eines ARDS, der Sepsis, der intravasalen Gerinnung und des Multiorganversagens. Bei der Sektion fanden sich Zeichen einer Lebernekrose, disperser Kardiomyozytennekrosen, einer Nierenschädigung, einer hypoxischen Hirnschädigung und ausgeprägte hyaline Membranen der Lunge.

Die Möbelpolitur bestand im wesentlichen aus aromatischen und vor allem aus kurzkettigen Kohlenwasserstoffen. Der Verlauf entspricht ganz den in Deutschland bekannt gewordenen Vergiftungen mit sogenannten Lampenölen, bei denen es auch ohne direkte Aspiration zum ARDS kommt.

\section{P-61}

AUSWIRKUNGEN

BERGBAULICH BEDINGTER BODENBELASTUNGEN

AUF DIE SCHWERMETALLGEHALTE IN KNOCHEN

UND HAAREN DER FLEDERMÄUSE

UND DEREN BEDEUTUNG FÜR DIE BEURTEILUNG

ANTHROPOGENER SCHWERMETALLBELASTUNGEN

Hartmann $\mathrm{R}^{*}$, Kijewski H**

${ }^{*}$ Ges. f. angewandte Biologie und Geologie mbH, Postfach 2108,

D-37011 Göttingen

**Inst. f. Rechtsmedizin der Universität Göttingen, Windausweg 2,

D-37073 Göttingen

Das Harzgebiet zählt zu den am stärksten schwermetallbelasteten Regionen in Deutschland. Seit mehr als 1000 Jahren wurden hier Erze abgebaut und verhüttet. Seit 1992 sind alle Bergwerke im Harz geschlossen.Von den Abraumhalden geht eine bis heute andauernde Belastung der Umwelt aus, wie zahlreiche Messungen von Staubniederschlägen und Sedimenten belegen. Aus rechtsmedizinischem Interesse wurden hier erstmalig systematische Messungen der Schwermetallbelastung des Menschen durch Untersuchung von Körpermaterialien durchgeführt.

Da wir bei Fledermäusen einen noch engeren Zusammenhang von Umweltbelastung und Schwermetallen in den Körpergeweben als beim Menschen vermuteten, haben wir die Schwermetallgehalte in Haaren, Knochen und Organen von Fledermäusen bestimmt. Dabei wurden u.a. 111 Zwergfledermäuse (Pipistrellus pipistrellus) hinsichtlich der Schwermetallgehalte im Haar ( $\mathrm{Pb}, \mathrm{Cd}, \mathrm{Cr}, \mathrm{Cu}, \mathrm{Ni}, \mathrm{Zn})$, Knochen $(\mathrm{Pb})$ wurde zudem der Gehalt an Platin analysiert. Es handelte sich bei dem Tiermaterial um Totfunde aus den Jahren 1987-1999.

Die Untersuchungsergebnisse werden dargestellt und im Hinblick auf die Bodenbelastung diskutiert.

Die mittlere Knochenbleibelastung der Tiere aus den nicht schwermetallbelasteten Regionen in Niedersachsen nahm im Untersuchungszeitraum um rund $50 \%$ ab. Keine signifikante Verringerung der Knochenbleigehalte konnte bei Tieren aus der Region des Harzes nachgewiesen werden. 
P-62

TÖDLICHE VERGIFTUNG EINES 5 - JÄHRIGEN KINDES

DURCH CARDIAMID; WÄHREND DER RETTUNGSAKTION

ALS VERGIFTUNG DURCH DIGOXIN DIAGNOSTIZIERT

Kulikowska I, Sybirska H

Institut für Gerichtliche Medizin, Katowice, Polen

Die Autoren stellen anhand einer fälschlich als Digoxinintoxikation diagnostizierten Vergiftung eines 5-jährigen Kindes den Wert der gesammelten Informationen über die Umstände des Falls, den Verlauf der Vergiftung und auch über die Therapie während der Rettungsaktion, dar.

Es wird die Bedeutung dieser Informationen für die gezielte Durchführung der toxikologischen Untersuchung und die richtige Interpretation der Analysenergebnisse für die gerichtsärztliche Begutachtung dargestellt.

\section{P-63}

POSTMORTALE VERÄNDERUNG DES MYOGLOBIN-GEHALTES IN BLUT UND URIN

Miyaishi S, Naka T, Kitao T, Ishikawa T, Takata T, Ishizu H, Püschel K* Institut für Rechtsmedizin der Universität Okayama, Okayama, Japan ${ }^{*}$ Institut für Rechtsmedizin der Universität Hamburg

Fragestellung

Es ist gut bekannt, daß der Myoglobin-Gehalt im Leichenblut mit der Dauer des postmortalen Intervalls deutlich zunimmt. Eine systematische Überprüfung dieses Phänomens im Tierversuch fehlte bisher und das Ausmaß der Veränderung der Myoglobinkonzentration speziell im frühpostmortalen Intervall ist noch nicht bekannt. Wir untersuchten die postmortale Veränderung des Myoglobin-Spiegels im Blut und Urin bei Kaninchen.

Methodik

Ca.3,o kg schwere männliche, anästhesierte Kaninchen wurden durch Kohlendioxid getötet und dann bei 5 Grad Celsius gelagert. Blutproben aus beiden Herzkammern und Urinproben wurden nach definierter Leichenliegezeit durch Punktion oder Katheter entnommen. Der Myoglobin-Gehalt wurde mittels eines selbst entwickelten ELISA gemessen. Myoglobin des Kaninchens sowie KaninchenmyoglobinAntikörper der Ziege wurden hierzu in einem eigenen Verfahren selbst gereinigt und hergestellt.

Ergebnisse und Diskussion

Der Myoglobin-Gehalt im Blut lebender Kaninchen betrug durchschnittlich nur ca. $30 \mathrm{ng}$; im Urin lag er bei $10 \mathrm{ng} / \mathrm{ml}$. Im Leichenblut war die Konzentration ca. 10mal höher schon in einer Viertelstunde, ca. 10omal höher nach einer Stunde, und 10oomal innerhalb von drei Stunden. Nach längerer Leichenliegezeit stieg die Konzentration dann sogar noch weiter an. Es zeigte sich, daß man das postmortale Intervall genau kennen muß, wenn man anhand der Myoglobinkonzentration im Leichenblut eine spezielle rechtsmedizinische Fragestellung zu beurteilen hat (z.B. Muskelschädigung durch Gewalteinwirkung, Stromeinwirkung, Reanimation, usw.). Der Myoglobin-Gehalt im Urin stieg postmortal allmählich bis zu $200 \mathrm{ng} / \mathrm{ml} 24$ Stunden nach dem Tod. Experimentell ließ sich zeigen, daß man die Stärke der antemortalen Muskelschädigung und die Überlebenszeit danach einschätzen kann; die Urinprobe darf nicht durch Blut kontaminiert sein.

\section{P-64}

POSTMORTALE VERTEILUNG VON SERTRALIN

UND DESMETHYLSERTRALIN

BEI EINER PSYCHIATRISCHEN PATIENTIN

Mußhoff F, Banaschak S, Madea B

Institut für Rechtsmedizin

der Rheinischen Friedrich-Wilhelms-Universität,

Stiftsplatz 12, D-53111 Bonn

Serotonin zählt zu den selektiven Serotonin-Reuptake-Inhibitoren (SSRI) und gilt bei der Behandlung von Patienten mit Angstzuständen und Depression als relativ sicheres Medikament. Vornehmlich durch Interaktionen mit zusätzlich aufgenommenen serotonergen Substanzen kann es zur Ausbildung eines Serotonin-Syndroms kommen. Bei alleiniger Aufnahme von Sertralin wurde bisher keine todesursächliche Intoxikation mitgeteilt, eine Ausnahme bildet ein Fall mit einer asthmatischen Vorerkrankung.

Eine 29 Jahre alt gewordene Frau wurde tot im Badezimmer aufgefunden, 50 Minuten zuvor war sie vom Ehemann noch lebend gesehen worden. Bei der Sektion fanden sich die Zeichen des akuten Todes (Hirn- und Lungenödem, flüssiges Leichenblut), eine finale Einatmung von Speisebrei sowie nach ca. $3 / 4$ stündiger Reanimation rötlich scheckige Veränderungen der Hinterwand der linken Herzkammer. Zeichen einer groben äußeren Gewalteinwirkung im Zusammenhang mit dem Todeseintritt konnten nicht nachgewiesen werden. Die histologische Untersuchung der inneren Organe ergab keine todesursächlichen Befunde. Als einzig auffälliger Befund konnte eine perivaskuläre Fibrose der Herzmuskulatur wie bei einem Zustand nach Myokarditis nachgewiesen werden. Die chemisch-toxikologische Untersuchung erbrachte neben sonst unauffälligen Befunden folgende Sertralin- und Desmethylsertralinkonzentrationen: Herzblut 0.20 / $0.30 \mathrm{mg} / \mathrm{l}$, Femoralblut 0.15 / $0.20 \mathrm{mg} / \mathrm{l}$, Galle 1.30 / $3.27 \mathrm{mg} / \mathrm{l}$, Niere 0.74 / $1.02 \mathrm{mg} / \mathrm{kg}$, Leber 1.14 / 1.88 mg/kg, Gehirn 1.59 / 1.83 mg/kg, Mageninhalt negativ.

Die Befunde werden hinsichtlich ihrer todesursächlichen Wertigkeit diskutiert.

\section{P-65}

AUTOMATISCHE HEADSPACE SOLID-PHASE

DYNAMIC EXTRACTION (HS-SPDE) -

EINE NEUE METHODE ZUR BESTIMMUNG VON AMPHETAMIN UND SYNTHETISCHEN DESIGNERDROGEN

Mußhoff F, Lachenmeier D, Kröner L, Madea B

Institut für Rechtsmedizin

der Rheinischen Friedrich-Wilhelms-Universität,

Stiftsplatz 12, D-53111 Bonn

In der klinischen und forensischen Toxikologie hat sich die Festphasen-Microextraktion (solid-phase microextraction, SPME) als Analysentechnik für verschiedenste Anwendungen bewährt. Mit der dynamischen Festphasen-Microextraktion (solid-phase dynamic extraction, SPDE) wird eine Weiterentwicklung des Verfahrens am Beispiel der Analytik von Amphetamin und synthetischen Designerdrogen vorgestellt. Es handelt sich um eine neue Methode zur Adsorption und lösungsmittelfreien Extraktion mit angeschlossener GC/MS-Analytik. Die Adsorption erfolgt in einer innen mit Polydimethylsiloxan belegten Kapillare. Zur Anreicherung der Analyten in der stationären Phase wird die Probe aktiv durch die Kapillare gespült (dynamische Extraktion). Die Desorption erfolgt durch Einführung der Spritzennadel in den heißen Injektor des GC-Systems.

Die ersten Erfahrungen mit dieser neuen Technik werden vorgestellt und mit der traditionellen SPME verglichen. Für die Bestimmung von Amphetamin, Methamphetamin, MDMA, MDA, MDE, BDB and MBDB aus Haaren liegen erste Daten einer Validierung vor. Bei dotierten Haarproben wurden absolute Wiederfindungen zwischen 


\section{Abstracts}

1,5 und $17,5 \%$ gefunden. Die Überprüfung der Linearität von 0,1$50 \mathrm{ng} / \mathrm{mg}$ erbringt Korrelationskoeffizienten zwischen 0,991 und 0,999. Genauigkeit und Präzision bei 2 verschiedenen Konzentrationen betragen 2.2 bis $13.5 \%$ (Präzision) und 1.8-17.6 \% (Genauigkeit). Die Nachweisgrenzen liegen zwischen 0,05 und 0,2 ng/mg. Die Ergebnisse zeigen, daß sich die SPDE für eine schnelle, einfache und sensitive Bestimmung der getesteten Analyte eignet. Im Vergleich mit der SPME sind höhere Extraktionsraten und verkürzte Analysenzeiten zu verzeichnen. Weitere Anwendungsmöglichkeiten werden ausgetestet.

\section{P-66}

IRRTÜMER UND FEHLER IN DER BENZODIAZEPINANALYTIK

Ondra $\mathrm{P}$, Lemr $\mathrm{K}^{\star}$, Zedníková $\mathrm{K}$, Jasková A

Institut für Gerichtsmedizin und medizinisches Recht,

Fakultätsklinik, Hnivotínská 3, 77509 Olomouc,

Tschechische Republik

(Institut für analytische Chemie, Naturwissenschaftliche Fakultät

der Palacky Universität, T. Svobody 8,

772 oo Olomouc, Tschechische Republik

Der vorgelegte Beitrag weist auf mögliche Fehler hin, die bei forensischen Routineanalysen von Benzodiazepinen, aber auch in der klinisch-toxikologischen Praxis auftreten können.

Die Verwendung von immunochemischen Methoden für die Screeninguntersuchung auf Benzodiazepine im Urin bringt neben unbestrittenen Vorteilen auch gewisse Einschränkungen mit sich, deren Nichtbeachtung bedeutende Fehler bei der Interpretation der Ergebnisse und eine Fehlinterpretation der gesamten toxikologischen Analyse zur Folge haben können.

Benzodiazepine bilden eine Gruppe von toxikologisch relevanten Substanzen, bei denen im Vergleich zu anderen Substanzgruppen, bei der Anwendung von immunochemischen Methoden im Rahmen von Screeninguntersuchungen in größerem Ausmaß sogenannte Falschpositivität, aber vor allem Falschnegativität auftreten kann.

Ein typisches Beispiel ist die Falschnegativität bei der Verwendung des ADx Systems der Firma Abbott bei Flunitrazepamintoxikationen, wobei Flunitrazepam vom toxikologischen Gesichtspunkt eines der bedeutsamsten Benzodiazepine ist.

Ein weiteres Problem, das Fehler eines Labors verursachen kann, ist ein negativer Benzodiazepinbefund im Rahmen der Screeninguntersuchung von Urin und Mageninhalt in Fällen, wo die folgende Blutanalyse positiv ist.

Letztendlich stellt die schwierige Interpretation von Benzodiazepinbefunden, die mit Hilfe einer dünnschichtchromatographischen Analyse sauer hydrolysierter Urinproben erzielt wurden, ein weiteres Problem dar.

\section{P-67}

„LEARNING BY DOING?“ - ZUR ARZNEIMITTELSICHERHEIT IN DER PÄDIATRIE AN EINEM FALLBEISPIEL MIT PROPOFOL Schuff A, Fries ${ }^{1}$ JWU, Graß H

Institut für Rechtsmedizin der Universität zu Köln

${ }^{1}$ Institut für Pathologie der Universität zu Köln

Die Kinderheilkunde ist in gleicher Weise auf potente Arzneistoffe angewiesen wie die Behandlung von Erwachsenen. In Deutschland dürfen grundsätzlich nur solche Arzneimittel bei Menschen zur Anwendung kommen, die für den entsprechenden Indikationsbereich nach den Richtlinien des Arzneimittelgesetzes zugelassen sind. Die dafür notwendigen Untersuchungen werden in der Regel mit erwachsenen und einwilligungsfähigen Probanden durchgeführt. Berufsethisch haben aber auch Kinder ein Recht auf eine optimale Pharmakotherapie. An einem Beispiel soll die Problematik der für den pä- diatrischen Einsatz nicht zugelassenen Medikamentenanwendung erörtert werden:

Nach einer Bolusaspiration wurde ein 3 jähriges Kind intubationspflichtig, die Sedierung erfolgte mittels intravenöser Propofol-Applikation. Im weiteren Verlauf traten u.a. bradykarde Herzrhythmusstörungen auf. Das Kind verstarb unter dem Bild eines Multiorganversagens. Aus den Unterlagen liess sich für Propofol eine 5-fach höhere Dosierung ableiten als sie für die Sedierung von Erwachsenen empfohlen ist. Die histologischen Untersuchungen zeigten ein "medikamentös-toxisches" Schädigungsmuster wie es - in Kombination mit der klinischen Symptomatik - als „Propofol-Infusionssyndrom" beschrieben wird.

Da das Medikament Propofol in Deutschland zur Sedierung von Personen unter 16 Jahren nicht zugelassen ist, war die Frage einer korrekten ärztlichen Behandlung zu diskutieren. Unter Dosiskontrolle und intensiver Überwachung durch in der Anwendung von Propofol erfahrene Ärzte bestehen hiergegen keine grundsätzlichen Bedenken. Auf der anderen Seite bleibt die Unsicherheit im Umgang mit nicht oder nicht hinreichend bei Kindern untersuchten Arzneimitteln. Nicht zuletzt die Tatsache, dass in der Pädiatrie bis zu $67 \%$ der verabreichten Medikamente für die entsprechende Indikation nicht zugelassenen sind, verleiht dem Problem der Arzneimittelsicherheit in der Kinderheilkunde aufgrund der hierfür fehlenden Untersuchungen eine besondere Bedeutung.

\section{P-68}

\section{ÜBER POSTMORTALE HAUTVERÄNDERUNGEN}

NACH BENZINEXPOSITION

$\underline{\text { Stengel P }}$, Schnabel A*, Bratzke H

Zentrum der Rechtsmedizin des Klinikums

der Johann Wolfgang Goethe-Universität, Frankfurt/Main

Institut für Rechtsmedizin der Julius-Maximilians-Universität, Würzburg *

Ziel dieser Arbeit war es zu beschreiben, wie sich postmortal entstandene Hautveränderungen nach unterschiedlich langer Benzinexposition makroskopisch und mikroskopisch darstellen.

Hierzu wurden aus dem Sektionsgut des Rechtsmedizinischen Institutes Frankfurt am Main in 18 Fällen zeitabhängig Hautstanzbiopsien am Oberschenkel entnommen, zwei verschiedenen Färbungen unterzogen und beurteilt. Es handelte sich um Verstorbene aller Altersklassen, die keinerlei Hauterkrankungen aufwiesen.

In 15 von 18 Fällen kam es zu charakteristischen Hautveränderungen in der Stachelzellschicht. Diese stellten sich in Form von Lücken- und Lochbildungen dar. Dieses Phänomen wird in der Dermatologie Akantholyse genannt und charakterisiert zahlreiche Hauterkrankungen. Weder Geschlecht noch Lebensalter noch Leichenliegezeit oder Umgebungstemperatur hatten Auswirkungen auf die Versuchsergebnisse.

Wir führen die durch Benzin verursachte Akantholyse auf einen direkten Angriff von Benzin oder einem seiner zahlreichen Bestandteile auf die interzellulären Verbindungen der Stachelzellen zurück. Die Versuche beweisen, dass sich die Hautveränderungen nach Benzinexposition postmortal erzeugen lassen und somit nicht als vitales Zeichen zu werten sind. Dies kann forensisch in Hinblick auf Verkehrsunfallopfer und Tötungsdelikte Anwendung finden. Tendenziell kann dabei nach frühestens einer Stunde (mikroskopisch) beziehungsweise zwei Stunden (makroskopisch) und meist nach 24 Stunden Einwirkdauer mit charakteristischen Hautveränderungen gerechnet werden. 


\section{P-69}

\section{PLÖTZLICHER TOD DURCH VORHOFTHROMBUS}

Dermengiu D, Dermengiu S, Buda O, Trübner $\mathrm{K}^{\star}$

Institute of Legal Medicine „Mina Minovici“,sos. Vitan Birzesti 9, 75669 Bukarest, Rumänien;

*Institut für Rechtsmedizin,

Martin-Luther-Universität Halle-Wittenberg, Deutschland

Eine 21-jährige Frau wurde wegen unklarem Unwohlseins, Blässe, Dyspnoe und erniedrigtem Blutdruck stationär eingeliefert. Die dortige Untersuchung ergab eine Mitralinsuffizenz und eine ektope Schwangerschaft. Bei der daraufhin durchgeführten Laparatomie stellte sich eine leicht blutende rupturierte Ovarialzyste dar. Während des chirurgischen Eingriffes traten schwere arrhythmische Störungen auf: zunächst eine supraventrikuläre Tachykardie, dann ein kompletter AV-Block mit Blutdruckabfall. Trotz Einführung eines intrakardialen Schrittmachers verstarb die Patientin an einer progredienten Herzinsuffizienz. Die Obduktion ergab einen $5 \times 3,5 \times 3 \mathrm{~cm}$ großen gestielten soliden Tumor im linken Vorhof mit kompletten Obstruktion der Mitralklappe, so daß zunächst an einen Herztumor gedacht wurde. Bei der Aufarbeitung des Tumors ergab sich eine zentrale Höhlenbildung mit einer mehrschichtigen fibrotischen Wand. Die mikroskopische Untersuchung zeigte eine endokardiale Fibrohyalinose - der Tumor selbst bestand aus einer mehrschichtigen fibrohyalinotischen Masse mit Gefäßneubildung und einzelnen lymphomonocytären Infiltraten. Diese Befunde wiesen auf einen älteren organisierten Thrombus hin und kleinere Herde einer chronischen Myokarditis wurden als Residuen eines stattgehabten rheumatischen Fiebers interpretiert.

\section{P-70}

\section{PLÖTZLICHER TOD DURCH VIRUSMYOKARDITIS}

BEI AKUTER HEPATITIS C

${ }^{1}$ Dermengiu D, ${ }^{1}$ Dermengiu S, ${ }^{1}$ Buda $O,{ }^{2}$ Zarma L, ${ }^{3}$ Calistru $\mathrm{P}$

${ }^{1}$ Institute of Legal Medicine „Mina Minovici“, sos. Vitan Birzesti 9, 75669 Bukarest, Rumänien

${ }^{2}$ Institute of Cardiovascular Diseases „Prof.Dr.C.C.Iliescu“, Fundeni Hospital, Sos. Fundeni 258, Sector 2 Bukarest, Rumänien

${ }^{3}$ Hospital for infectious and tropical diseases „Professor Victor Babes“, Bukarest, Rumänien

Ein 24jähriger Fußballspieler verstarb plötzlich während eines Fußballspiels. Bei der Obduktion fanden sich ausgedehnte subseröse petechiale Blutungen, ein moderates Hirnödem, eine Blutstauung der inneren Organe, multiple Herde einer chronischen interstitiellen Myokarditis und eine histologisch nachgewiesene aktive Hepatitis C. Immunologische und virologische Untersuchungen ergaben eine hohe Virusreplikationsrate mit einer Viruslast von $883.000 \mathrm{UI} / \mathrm{ml}$. Die toxikologischen Untersuchungen auf stimulierende, narkotische und anabolische Stoffe waren negativ.

Auch wenn wir eine extrem seltene Koinzidenz nicht ausschließen können, sind folgende Befunde unsererseits beweisbar für eine $\mathrm{He}$ patitis C- Ätiologie der Myocarditis: der histologische Nachweis einer aktiven Hepatitis, die Präsenz von HCV-Antikörpern in Serum sowie die hohe Konzentration von viralen Antigenen im Serum. Besonders brisant war die Tatsache, daß der Mann zweimal kurz vor seinem Tod (12 Tage und 3 Tage zuvor) kardiologisch untersucht wurde. Dabei wurden im EKG gehäufte ventrikuläre Extrasystolen festgestellt, die auf einen ischämischen oder entzündlichen Myokardprozeß hindeuteten, wobei die ischämische Genese auf Grund des jugendlichen Alters unwahrscheinlich war.

Drei Tage vor dem Tod betrug der Duke Score +14 - dies entspricht einem sehr geringen Risiko, dass in den nächsten 5 Jahren eine gravierende kardiale Erkrankung (inklusive plötzlicher Herztod) auftreten würde.

\section{P-71}

IMMUNHISTOCHEMISCHE DIAGNOSTIK

VIRALER MYOKARDITIDEN BEI PLÖTZLICHEN TODESFÄLLEN IM KINDESALTER

Detttmeyer R, Baasner A, Winkelmann S, Graebe M, Madea B

Institut für Rechtsmedizin

der Rheinischen Friedrich-Wilhems-Universität Bonn

Einführung: Die Diagnostik viraler Myokarditiden hat mit neuen Methoden eine Verbesserung erfahren. Neben der Qualifizierung und Quantifizierung von Leukozyten, T-Lymphozyten und Makrophagen sowie dem Einsatz nicht-zellulärer Entzündungsmarker läßt sich immunhistochemisch nunmehr auch das VP1-Kapsid-Protein von Enteroviren darstellen. Um Aussagen zur Inzidenz von Myokarditiden machen zu können, wurden in 60 plötzlichen Todesfällen von Kindern Myokardproben untersucht, bei denen nach herkömmlicher Diagnostik lediglich in einem Fall eine Myokarditis diagnostiziert werden konnte. Die Mehrzahl der Fälle war dem Phänomen des plötzlichen Kindstodes zugeordnet worden.

Methode: Es wurden jeweils 8 Myokardproben immunhistochemisch mit Antikörpern gegen HLA-DR, Leucoyte common Antigen (LCA), dem Makrophagenmarker CD68 (PGM1), dem T-Lymphozytenmarker $\mathrm{CD}_{3}$ sowie in ausgewählten Fällen mit $\mathrm{C}_{5}$ b9 untersucht. Zusätzlich kam ein monoklonaler Antikörper gegen das VP1-KapsidProtein von Enteroviren zum Einsatz. Molekularpathologisch erfolgte die Untersuchung auf Enteroviren mittels RT-PCR bzw. auf Parvovirus B19 mittels PCR.

Ergebnisse: Die Untersuchungen bestätigen, daß mit immunhistochemischen Techniken aus dem Kollektiv von plötzlichen Todesfällen im Kindesalter, insbesondere aber auch von SIDS-Fällen jene herausgefiltert werden können, bei denen der begründete Verdacht auf eine Myokarditis gegeben ist. In einem Teil der Fälle konnte neben erhöhten Zellzahlen und einer verstärkten HLA-Expression VP1-KapsidProtein nachgewiesen werden. Der zusätzliche Nachweis enteroviralen Genoms mittels RT-PCR gelang ebenfalls, ebenso in Einzelfällen der Nachweis von PVB19.

Schlussfolgerung: Die Zuordnung eines Todesfalles zum Phänomen des plötzlichen Kindstodes (SIDS) sollte erst erfolgen, wenn immunhistochemisch-molekularpathologisch eine Myokarditis ausgeschlossen wurde.

\section{P-72}

SELTENE URSACHE EINES PLÖTZLICHEN TODES -

ZWEI FÄLLE EINER ECHINOKOKKOSE DES HERZENS

Gatternig R, Darok M, Mannweiler S*, Leinzinger EP

Institut für Gerichtliche Medizin der Karl-Franzens-Universität Graz

*Institut für Pathologie der Karl-Franzens-Universität Graz

Die Echinokokkose stellt einen seltenen (Neben-) Befund dar, der Mensch ist dabei Fehl-Zwischenwirt. Beim Menschen tritt diese parasitäre Erkrankung endemisch in den östlichen und südlichen Ländern Europas sowie in Asien und Nordafrika auf.

Nach der peroralen Aufnahme entwickeln sich die Larven in der Leber, aber auch in der Lunge zu Finnen, seltener im Gehirn, den Nieren oder den Knochen. Der Befall des Herzens ist sehr selten.

Wir berichten von 2 Fällen einer derartigen Echinokokkose des Herzens. Im ersten Fall handelt es sich um eine 75 Jahre alte Frau aus Ostösterreich, die bei einem Verkehrsunfall verletzt wurde. 3 Wochen nach dem Unfall kam es zu einer wesentlichen Verschlechterung des Allgemeinzustandes mit Atemnot, Zyanose und EKG-Veränderungen im Sinne eines Innenschichtschadens. Am 73. Tag nach dem Unfall verstarb die Frau unter den Zeichen eines Vorhofflimmerns.

Bei der Obduktion waren in der Herzmuskulatur kalkharte rundliche, scharf umschriebene Bezirke zu sehen, in denen Finnen des E. multilocularis nachgewiesen werden konnten. Ein Befall von Leber oder Lungen bestand nicht. 


\section{Abstracts}

Beim zweiten Fall handelt es sich um einen 48 Jahre alten gebürtigen Türken, der seit mindestens 10 Jahren in Österreich lebte. Er rief noch einen Arbeitskollegen an und klagte über Übelkeit. Bei dessen Eintreffen lag er auf dem Boden, griff sich auf den Bauch, krümmte sich vor Schmerzen. Er konnte dann zur Toilette gehen und versperrte die Tür von innen. In weiterer Folge zeigte er keine Reaktion mehr auf Klopfen und Rufen, so daß der Kollege die Rettung verständigte. Die Reanimationsversuche verliefen erfolglos.

Autoptisch zeigten sich in der Kammerscheidewand und in der linken Kammer Hohlraumbildungen. Die linke Herzhälfte zeigte eine Innenschichtabblassung. Der rechte Leberlappen war mit kugelförmigen Hohlraumbildungen durchsetzt, in denen Protoscolices von E. granulosus nachgewiesen wurden.

Die Fälle werden ausführlich vorgestellt und diskutiert.

\section{P-73 \\ ROTA-VIRUS-INFEKTION ALS URSACHE EINES PLÖTZLICHEN TODES IM KLEINKINDALTER \\ Heide S, Romanowski U, Kleiber M \\ Institut für Rechtsmedizin der Martin-Luther-Universität Halle, Franzosenweg 1, 06112 Halle/S.}

Rota-Virus-Infektionen sind im Säuglings- und Kleinkindalter weit verbreitet. Die manifeste Erkrankung geht mit Erbrechen, Durchfall und Fieber einher und verläuft, sofern einer möglichen Dehydratation entgegengewirkt wird, in aller Regel komplikationslos. Wir berichten über ein 19 Monate alt gewordenes Kleinkind, das 24 Stunden vor seinem Tod mit Durchfall aber ohne weitere gravierende Krankheitssymptome in einer Kinderambulanz vorgestellt wurde. Der weitere Verlauf war zunächst unauffällig . Plötzlich bemerkte die Mutter eine „pumpende“Atmung. 30 Minuten später konnte im Krankenhaus nur noch der Todeseintritt festgestellt werden. Die Obduktion erbrachte eine Hyperplasie des lymphatischen Apparates des Dünndarms sowie histologisch eine hämorrhagisch eitrige Pneumonie. Virologisch wurden im Dünndarminhalt und im Stuhl Rotaviren nachgewiesen.

\section{P-74}

ATYPISCH VERLAUFENDE NEURODEGENERATIVE ERKRANKUNG BEI EINER 6O JAHRE ALT GEWORDENEN FRAU

Matschke ${ }^{1,2}$, Lamszus $\mathrm{K}^{2}$, Laas $\mathrm{R}^{2}$

${ }^{1}$ Institut für Rechtsmedizin und

${ }^{2}$ Abteilung für Neuropathologie

des Universitätsklinikums Hamburg-Eppendorf

Die Erkrankung bei der 60 Jahre alt gewordenen Frau begann 9 Jahre vor dem Tod mit unspezifischen Verhaltens- und Hirnleistungsstörungen. Innerhalb weniger Jahre entwickelte sich eine spastische Tetraparese mit Pseudobulbärparalyse und pathologischen Fremdreflexen sowie eine Harn- und Stuhlinkontinenz. Im weiteren zeigte sich eine relativ geringe Progredienz der Veränderungen. Bildgebend stellte sich eine langsam zunehmende Großhirnatrophie dar. Klinisch wurde das Leiden zunächst als präsenile Demenz vom Alzheimer-Typ aufgefaßt; wegen des ungewöhnlichen Verlaufs erwog man auch eine Thromangiitis obliterans und ein apallisches Syndrom, das in Zusammenhang mit einer 1990 durchgemachten gynäkologischen Operation gebracht wurde.

Bei der Sektion fanden sich die Zeichen eines septischen Herz-Kreislauf-Versagens bei schwerer eitriger Pyelonephritis. Neuropathologisch wurde eine hochgradige, im Großhirn betonte Atrophie bestätigt, die nicht nur in einer ausgeprägten neuronalen Verödung besonders im Großhirnkortex und im rostralen Hirnstamm bestand, sondern auch in einer hochgradigen Rarefizierung des Marklagers.
Diagnostisch wegweisend waren diffuse, subpial und subependymär akzentuierte Ablagerungen meist kugeliger, im Schnitt $10-20 \mu \mathrm{m}$ durchmessender Strukturen, bei denen es sich nach konventionellen (PAS-Positivität, Diastase-Resistenz) und immunhistochemischen (Ubiquitin-Positivität) Färbungen sowie ultrastrukturell um Polyglukosankörper handelte.

Nach klinischem Verlauf und Ausprägung der neuropathologischen Befunde wurde die Diagnose einer Adulten Polyglukosankörper Krankheit mit überwiegendem Befall des zentralen und peripheren Nervensystems gestellt. Neben der Differentialdiagnose dieser sehr seltenen, meist sporadisch im höheren Lebensalter auftretenden Erkrankung werden insbesondere auch (genetische) Beziehungen zur Glykogenose IV (branching enzyme/Amylo-1, 4-1, 6-transglukosidase-Mangel) diskutiert.

\section{P-75}

QUALITÄTSSICHERUNG DURCH AUTOMATION

BEI DER BLUTALKOHOLBESTIMMUG

Ebenhöh L* ${ }^{*}$ Schuricht $\mathrm{J}^{\star}$, Kilchör $\mathrm{T}^{\star *}$, Iten $\mathrm{PX}^{\star * *}$

* INTEG Labordatensysteme GmbH, D-75196 Remchingen

** Institut für Rechtsmedizin, Universität Bern, $\mathrm{CH}-2012$ Bern

$\star * *$ Institut für Rechtsmedizin, Universität Zürich-Irchel, $\mathrm{CH}-8057$ Zürich

Die Blutalkoholbestimmung in der Schweiz erfordert vier unabhängige Einzelanalysen auf zwei unterschiedlichen Systemen. Die Alkoholkonzentration im Vollblut wird in $\mathrm{g} / \mathrm{kg}$ verlangt, was eine Einwaage der Probe voraussetzt. In dem hier vorgestellten System werden zwei Headspace-Autosampler (Gerstel) und zwei GCs mit der Software ChemStation und der Datenbank ChemStore verwendet (alles Agilent Technologies). Einwaagen werden über $\mathrm{D}_{3} \mathrm{C}$-Boxen und das Modul AlkSeq (beides INTEG) gesteuert. Die Wägeserie wird über Maskendateien erstellt. Hier wird die Abfolge von Proben und Standards vorgegeben. Die Probenidentifikation erfolgt über Barcodescanner. Einwaagen von Sonderproben sind möglich. Es können nur vom Haussystem zur Analyse freigegebene Proben eingewogen werden. Die Solleinwaage wird an der $\mathrm{D}_{3} \mathrm{C}$-Box vorgegeben. Wägeergebnisse werden von der $\mathrm{D}_{3} \mathrm{C}$-Box in die Auswertedatenbank eingetragen. ChemStation-Sequenzen werden automatisch erzeugt. Analysenergebnisse werden von der ChemStation in die ChemStore Datenbank transferiert. Nach beendeter Analyse werden die Ergebnisse durch das Auswerteprogramm AlkValid (INTEG) aus der ChemStore Datenbank extrahiert. In der Sequenz mitgemessene Standards ermöglichen eine Kalibration der Peakfläche pro Konzentration unter Berücksichtigung der Einwaagen. Anhand der Kalibrationsergebnisse werden die Blutproben ausgewertet und validiert. Validierte Ergebnisse werden dem Haussystem bereitgestellt und von diesem abgerufen. Für ungültige Proben kann eine Wiederholungsmessung angestoßen werden. Alle Vorgänge werden in der Auswertedatenbank gespeichert, damit eine lückenlose Historie der Vorgänge für jede Probe nachvollzogen werden kann. Manuelle Interaktionen müssen durch elektronische Unterschrift bestätigt werden.

\section{P-76}

AKUTE LETALE ALKOHOLINTOXIKATION

NACH STURZTRUNK HOCHPROZENTIGEN ALKOHOLS: MORPHOLOGISCHE BEFUNDE

UND AUSGEPRÄGTE POSTMORTALE ALKOHOLDIFFUSION

Fink T, Kaufmann T, Rittner C

Institut für Rechtsmedizin, Johannes Gutenberg-Universität, D-55131 Mainz

Eine 59 Jahre alte Frau mit bekannter depressiver Grunderkrankung wurde von ihrem Ehemann komatös im Keller des gemeinsam be- 
wohnten Hauses aufgefunden. Trotz unmittelbarer notärztlicher Erstversorgung trat der Tod noch vor Ort durch therapierefraktäre Herzrhythmusstörungen ein. Am Fundort wurden mehrere Flaschen hochprozentiger alkoholischer Getränke, darunter auch Strohrum, sichergestellt. Ein Suizidversuch wurde im ebenfalls vorgefundenen Abschiedsbrief angekündigt. Aufgrund der Auffindesituation und der rekonstruierten zeitlichen Abläufe war von einem umfangreichen Sturztrunk vorwiegend sehr hochprozentiger alkoholischer Getränke auszugehen. Bei der Obduktion 4 Tage nach Todeseintritt stellte sich die Schleimhaut des oberen Gastrointestinaltraktes auffällig gut erhalten und praktisch nicht autolytisch verändert dar. Makroskopisch und mikroskopisch bot sich das Bild einer quasi intravitalen Alkoholfixation der Mukosa des Magens sowie der oberen Dünndarmabschnitte. Die postmortale BAK-Bestimmung im Oberschenkelvenenblut ergab eine Konzentration von 4,02 Promille bei der ansonsten nicht alkoholgewohnten Frau. Die Analyse der Körperflüssigkeiten verschiedener Kompartimente zeigte eine ausgeprägte postmortale Alkoholdiffusion. So wurde bei völlig intaktem Zwerchfell und unverletztem Herzbeutel in der Perikardflüssigkeit eine Alkoholkonzentration von 3,2 Prozent festgestellt, wobei von einer Diffusion entlang eines Konzentrationsgradienten aus dem Magen (hier: Alkoholkonzentration 15,3 Prozent) auszugehen ist. Auch die hohe BAK von 8,11 Promille im rechten Ventrikel und 7,10 Promille im linken Ventrikel des morphologisch intakten Herzens ist, vor dem Hintergrund der BAK im peripheren Oberschenkelvenenblut, zweifelsfrei als Diffusionseffekt zu interpretieren. Die makroskopischen und histologischen Befunde werden demonstriert und die Befunde der postmortalen Alkoholdiffusion diskutiert.

\section{P-77}

ALKOHOLBEDINGTE STRAßENVERKEHRSDELIKTE

VON ÜBER 6O-JÄHRIGEN PERSONEN:

VERGLEICH SAARLAND - HANSESTADT HAMBURG

Grellner $\mathrm{W}^{1}$, Heinemann $\mathrm{A}^{2}$, Kratochwil M ${ }^{1}$, Cordes $\mathrm{O}^{2}$, Georg T ${ }^{3}$, Püschel $\mathrm{K}^{2}$, Wilske J ${ }^{1}$

Institut für Rechtsmedizin der Universität des Saarlandes ${ }^{1}$, Gebäude 42, 66421 Homburg/Saar,

Institut für Rechtsmedizin der Universität Hamburg ${ }^{2}$

und Institut für Medizinische Biometrie der Universität des Saarlandes ${ }^{3}$

Der Anteil von über 60-jährigen Menschen an der Bevölkerung und deren Mobilität nehmen bekanntermaßen zu. In einem vergleichenden Ansatz sollte für zwei strukturell unterschiedliche Bundesländer die alkoholbedingte Straßenverkehrsdelinquenz dieser Altersgruppe evaluiert werden. Die Alkoholdatenbanken der rechtsmedizinischen Institute des Saarlandes (Saar) und von Hamburg (HH) wurden für den 10-Jahreszeitraum von 1991-2000 ausgewertet. Einbezogen wurden 1828 (von 40.573: 4,5\%, Saar) und 1638 (von 55.642: 2,9 \%, HH) untersuchte Blutproben von Personen über 6o Jahre. Der Frauenanteil belief sich dabei auf 6,0 \% (Saar) bzw. 9,3\% (HH). Im 10-Jahres-Trend stellte sich ein deutlicher Anstieg des Seniorenanteils dar (von $3 \%$ auf $6,5 \%$ im Saarland bzw. von $1,8 \%$ auf $5 \%$ in $\mathrm{HH}$ ). In zeitlicher Hinsicht dominierten die Senioren an den Werktagen. Trunkenheitsfahrten von Älteren wurden vorwiegend von 12-24 Uhr entdeckt. Bei BAK-Werten über $2 \%$ o waren die Senioren weniger repräsentiert. Bei der ärztlichen Bewertung wurden sie - auch bei gleichen BAK-Werten - eher als stärker beeinträchtigt eingestuft. Ursächlich könnte der erwartungsgemäß höhere Anteil mit Vorerkrankungen und Medikamenteneinnahme sein. Senioren über 60 Jahre waren gegenüber den jüngeren Altersgruppen häufiger vertreten bei Nachtrunkangaben, Unfällen mit Sach- und Personenschaden, Unfallflucht und Unfällen mit Getöteten. Zusammenfassend unterstreicht die Untersuchung die wachsende Bedeutung von älteren Kraftfahrern bei Verkehrsdelikten unter einer alkoholischen Beeinflussung. Die wesentlichen Trends scheinen sich dabei auch in unterschiedlich strukturierten Regionen ähnlich zu entwickeln.

\section{P-78} VERKEHRSMEDIZINISCH RELEVANTES LEISTUNGSPROFIL BEI CHRONISCHER PSYCHOPHARMAKA-EINNAHME Grellner $^{1} \underline{W}$, Zimmer ${ }^{1}$ AK, Kühn-Becker ${ }^{2} \mathrm{H}$, Gerber $^{2}$ HG., Georg ${ }^{3} \mathrm{~T}$, Wilske ${ }^{1}$

Institut für Rechtsmedizin der Universität des Saarlandes ${ }^{1}$, Gebäude 42, 66421 Homburg/Saar,

Abteilung für Psychiatrie und Psychotherapie

der Saarland Klinik Neunkirchen/Saar ${ }^{2}$

und Institut für Medizinische Biometrie der Universität des Saarlandes ${ }^{3}$

Bei einer dauerhaften Einnahme von zentralnervös wirksamen Psychopharmaka kann sich die Frage nach einer Einschränkung der Fahreignung stellen. In die vorliegende Studie wurden 15 überwiegend ambulante Patienten mit Psychosen und depressiven Störungen einbezogen ( 8 Frauen, 7 Männer, Durchschnittsalter: $45 \pm 12$ Jahre). Sie erhielten als Dauertherapie Neuroleptika $(n=9)$ oder Antidepressiva $(n=6)$. Die Probanden durchliefen eine PC-gesteuerte, verkehrspsychologische Testbatterie, die von einem zweifach durchgeführten pupillographischen Schläfrigkeitstest (PST) umrahmt wurde. Die Psychopharmakapatienten schnitten gegenüber den Normstichproben bei folgenden Testparametern signifikant $(\mathrm{p}<0,05)$ unterdurchschnittlich ab: richtige und ausgelassene Reaktionen im Determinationstest, Zahl richtiger Antworten im Linienverfolgungstest, Treffer beim Cognitrone, Reaktionszeit und motorische Zeit bei komplexeren Reaktionstests. Die im PST erfassten Schläfrigkeits-Parameter PUI (Pupillenunruheindex) und Amplitudenspektrum lagen im Durchschnitt im (guten) Normbereich und zeigten bei der Zweituntersuchung eine tendenzielle Verschlechterung. Im Vergleich zu den an Psychosen leidenden Neuroleptika-Patienten waren die Leistungsdefizite unter einer Antidepressiva-Behandlung im Mittel weniger ausgeprägt. Die Ergebnisse belegen, dass auch ambulante psychiatrische Patienten unter einer Dauertherapie mit Psychopharmaka - möglicherweise mitbedingt durch ihre Grunderkrankung - signifikante, verkehrsmedizinisch relevante Defizite aufweisen, die sich vor allem bei erhöhter Belastung auswirken können. Für die Beurteilung der Fahrtüchtigkeit sollte eine Einzelfallprüfung erfolgen.

\section{P-79}

ZUR SCHLÄFRIGKEIT BEI KRAFTFAHRERN -

ERGEBNISSE EINES ROAD-SIDE-TESTING AUF DER AUTOBAHN Grellner $\underline{1}$ W, Weeß ${ }^{2}$ HG., Binder ${ }^{2}$ R, Wilske ${ }^{1} \mathrm{~J}$

Institut für Rechtsmedizin der Universität des Saarlandes ${ }^{1}$, Gebäude 42, 66421 Homburg/Saar,

Interdisziplinäres Schlafzentrum der Pfalzklinik Landeck, Klingenmünster ${ }^{2}$

Eine erhöhte Schläfrigkeit am Steuer stellt ein erhebliches Gefährdungspotenzial dar. Im Rahmen der vorliegenden Untersuchung interessierte das Ausmaß der (Tages-)Schläfrigkeit von Kraftfahrern. Gemeinsam mit dem Gesundheitsmagazin Praxis des ZDF wurden PKW- und LKW-Fahrer auf einer Autobahnraststätte während eines 24-Stunden-Intervalls um ihre freiwillige Testteilnahme gebeten. Neben einem Fragebogen gelangte der pupillographische Schläfrigkeitstest (PST, AMTech, Weinheim) zum Einsatz. Als Leitparameter diente der Pupillenunruhe-Index (PUI) mit folgender Graduierung: unter $6,6 \mathrm{~mm} / \mathrm{min}$ : unauffällig, 6,6 bis unter $9,8 \mathrm{~mm} / \mathrm{min}$ : grenzwertig, ab 9,8 mm/min oder eingeschlafen: pathologisch. In die Auswertung kamen 157 Kraftfahrer (126 Männer,31 Frauen, Durchschnittsalter $41 \pm 11$ Jahre), von denen 38 einen LKW steuerten. In der Gesamtgruppe hatten 22 Personen grenzwertige Ergebnisse (erhöhte Einschlafneigung), 10 Kraftfahrer wiesen PUI-Werte über $9,8 \mathrm{~mm} / \mathrm{min}$ auf (sehr hohe Einschlafneigung) und weitere 6 Fahrer schliefen während des Testes ein. Es zeigten also insgesamt 38 Kraftfahrer $(24 \%)$ auffällige und darunter 16 Fahrer (10 \%) pathologische Testresultate. Während von den PKW-Fahrern $19 \%$ auffällige und $6 \%$ 
pathologische Ergebnisse aufwiesen, waren dies bei den LKW-Fahrern $39 \%$ und $24 \%$. Die über 40 -jährigen Kraftfahrer hatten fast doppelt so häufig pathologische Ergebnisse wie die jüngeren Testteilnehmer (13,5\% vs. $7,3 \%$ ), was sich bei Einbeziehung der grenzwertigen PUIResultate allerdings ausglich. Die Gesamtergebnisse der Studie belegen, dass ein erheblicher Anteil der Kraftfahrer auf Autobahnen eine erhöhte Einschlafneigung aufweist. Insbesondere gilt dies für LKWFahrer. Das davon ausgehende Gefährdungspotenzial für den Straßenverkehr ist zu diskutieren.

\section{P-80 \\ NACHWEIS PSYCHOTROPER SUBSTANZEN \\ BEI ÄLTEREN VERKEHRSTEILNEHMERN \\ Heinemann $A^{*}$, Grellner $W^{* *}$, Preuß $\mathrm{J}^{* * *}$, Cordes $\mathrm{O}^{\star}$, Stein $\mathrm{S}^{*}$, Kratochwil $M^{\star *}$, Schmoldt $A^{\star}$, Püschel $K^{\star}$, Wilske J**, Lignitz E*** Institut für Rechtsmedizin, Universität Hamburg, Butenfeld 34, 22529 Hamburg \\ Institut für Rechtsmedizin, Universität des Saarlandes, 66421 Homburg/Saar \\ Institut für Rechtsmedizin, Ernst-Moritz-Arndt-Universität, Kuhstr. 30, 17489 Greifswald}

Die Altersgruppe der Senioren über 6o Jahre wird zukünftig einen weiter steigenden Anteil unter den Fahrerlaubnisinhabern aufweisen. Gleichzeitig wird in einem Teil dieser Population ein nicht unerheblicher Medikamentenmißbrauch, insbesondere von Benzodiazepinen, vermutet. Es ist von Interesse, inwieweit ältere Verkehrsteilnehmer gegenüber Jüngeren in Routinekontrollen bzw. als Unfallverursacher im Zusammenhang mit dem Einfluß verschreibungsfähiger psychotroper Substanzen auffallen. In der vorliegenden Studie wird eine 10-Jahres- Analyse toxikologischer Untersuchungsergebnisse von Verkehrsteilnehmern aus 3 Regionen mit unterschiedlicher Bevölkerungsdichte vorgenommen und die Altersgruppe der Senioren mit Verkehrsteilnehmern aus dem 5. Lebensjahrzehnt u.a. hinsichtlich Nachweisfrequenz, Substanzspektrum und Deliktstruktur verglichen. Die Altersgruppe der Senioren wies im Gesamtkollektiv einen Anteil von $2 \%$ ( $n=109$ unter 5318 Analysen) auf, der auch im Zuge deutlich ansteigender Gesamtanalysezahlen in den vergangenen beiden Jahren relativ stabil blieb. Über 60\% der Serumanalysen bei älteren Fahrern zeigten ein negatives Resultat; in vielen dieser Fälle waren Vorerkrankungen dokumentiert, die zur auffälligen Fahrweise geführt hatten. Unter den nachgewiesenen Substanzen kam Benzodiazepinen die größte Bedeutung zu.

Schlußfolgerungen: Die Altersgruppe der Senioren ist, orientiert an ihrer Jahresfahrleistung, in straßenverkehrsbezogenen toxikologischen Analysen unterrepräsentiert. Die Polizei als Auftraggeber zeigt diesbezüglich in den untersuchten Regionen im Zeitverlauf keine Änderung ihres Ermittlungsverhaltens. Die häufig negativen toxikologischen Befunde zeigen aber auch, daß die bekannte, auf die Jahresfahrleistung bezogene relative Zunahme des Unfallrisikos ab 60 Jahren in vielen Fällen durch altersbedingte psychophysische bzw. somatische Leistungseinschränkungen erklärt werden kann.

\section{P-81}

ENTWICKLUNG EINES MODELLS

ZUR ABSCHÄTZUNG DES EINFLUSSES VON PHENOTHIAZINEN

AUF DEN KRAFTFAHRER UNTER VERWENDUNG

DER BILD-TRANSFORMATIONS-METHODE

Pufal E, Sykutera M, Rochholz G* ${ }^{*}$, Schütz $\mathrm{HW}^{*}$, Sliwka K

Institut für Rechtsmedizin Bydgoszczy, Polen

${ }^{*}$ Institut für Rechtsmedizin der Universität Kiel

Zur Objektivierung von durch zentralwirksame Substanzen hervorgerufene Ausfallserscheinungen werden verschiedene Tests sowie aufwendige Methoden eingesetzt, wie z.B. die Pupillometrie zur Messung der Latenzzeit und der Dauer der Pupillenreaktion oder die „Luzerner Festplatte“ zur Darstellung von Standunsicherheiten.

Aus forensischer Sicht kommt der Prüfung von Stand- und Gangunsicherheiten große Bedeutung $\mathrm{zu}$, die sich durch fotografische Methoden dokumentieren lassen. Der Einfluss von Alkohol und Phenothiazinen auf die Gangunsicherheit wurde schon 1977 von Raszeja und Mitarbeitern mit Hilfe eines Blinklichtes und eines Photoapparates gemessen. Der Einsatz der Videotechnik eröffnet neue Möglichkeiten zur Verbesserung dieser Untersuchungsmethode. Unter Verwendung eines Laufbands, einer Videokamera und eines speziell für diese Untersuchungsmethode entwickelten Computerprogramms lässt sich der Einfluss von Alkohol und Medikamenten auf den Gang dokumentieren.

Zu diesem Zweck wurden Aufnahmen von Probanden von der Seite und von hinten angefertigt, die sich auf dem Laufband mit einer Schrittfrequenz von 70 Schritten/Minute bewegten. Die Bewegungen des Kopfes, der Schulter, des Ellbogens, des Knies und des Fußknöchels wurden aufgezeichnet und zueinander ins Verhältnis gesetzt.

Unter Wahl der Schulter als Bezugspunkt fanden sich deutliche Abweichungen bei der Bewegung des Kopfes und des Fußknöchels nach Einnahme von Phenothiazinen im Vergleich mit unbeeinflussten Personen.

Die Methodik scheint geeignet, um den Einfluss von Medikamenten auf den Kraftfahrer objektiv darzustellen und mit den durch Alkohol hervorgerufenen Ausfallserscheinungen vergleichbar zu machen, was für die "Grenzwertdiskussion“ von Medikamenten und Drogen von Bedeutung sein könnte.

\section{P-82 \\ MIKROANALYTISCHE TOXIKOLOGISCHE UNTERSUCHUNG VON BLUTSPUREN IM TATFAHRZEUG ZUR FESTSTELLUNG DER DROGENBEDINGTEN FAHRUNTÜCHTIGKEIT.

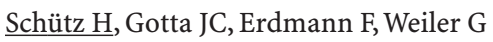 \\ Institut für Rechtsmedizin der Justus-Liebig-Universität Gießen}

Nach einem schweren Verkehrsunfall mit Getöteten konnte der nur leichtverletzte Verursacher flüchten und erst viele Stunden später sistiert werden. Eine forensisch-toxikologische Untersuchung der entnommenen Blutprobe führte zum Nachweis des Kokainderivates Benzoylecgonin $(147 \mathrm{ng} / \mathrm{mL})$. Kokain selbst war nicht feststellbar. Im Fahrzeug des Unfallverursachers wurden zahlreiche Blutspuren gefunden, die wir mit einer speziellen Mikromethode untersuchten: Eluierung mittels Tris-Phosphatpuffer, Extraktion mit Hilfe des Pipettierroboters ASPEC XL (Gilson) und SPE Säulen, 25 mg, HCX (IST), GC/MS. Die Analyse führte ebenfalls zum Nachweis von Benzoylecgonin. Somit konnten wichtige Rückschlüsse auf den Geschehensablauf gezogen werden.

\section{P-83 \\ ZUM BERSTUNGSDRUCK DES MAGENS - EIN BEITRAG ZUR FORENSISCHEN BIOMECHANIK \\ Kohl S, Neis P, Rittner C \\ Institut für Rechtsmedizin Mainz}

Stumpfe abdominelle Gewalteinwirkung führt in manchen Fällen zur Ruptur von Oberbauchorganen. In seltenen Fällen ist hiervon auch der Magen betroffen. Bei der gerichtlichen Klärung solcher Fälle wird immer auch nach der Stärke der Gewalteinwirkung gefragt, die solche Verletzungen hervorrufen können. In der überschaubaren Literatur finden sich dazu allerdings keine Hinweise.

In einem Modellversuch wurde versucht den Berstungsdruck des Magens zu ermitteln. Hierzu wurde eine Messapparatur entwickelt, die es 
ermöglicht den Druck innerhalb von Hohlorganen während einer Druckbelastung zu messen. Hierbei können auch Druckunterschiede im Bereich von Millisekunden registriert werden. Untersucht wurden zunächst Faktoren wie Füllungszustand, Luftanteil sowie Stärke der Druckänderung pro Zeiteinheit.

Die Ergebnisse der Untersuchungen werden vorgestellt und diskutiert.

\section{P-84}

WIRBELSÄULENVERLETZUNGEN

BEI TRAUMATISCHER AORTENRUPTUR

VON TÖDLICH VERUNFALLTEN VERKEHRSTEILNEHMERN

Niess C$=$, Albert $\mathrm{D}^{1}$, Lutz FU ${ }^{1}$, Petermann ${ }^{2}$

${ }^{1}$ Zentrum der Rechtsmedizin,

Johann Wolfgang Goethe-Universität Frankfurt am Main

${ }^{2}$ Klinik für Unfallchirurgie, Philipps-Universität Marburg

Durch ein Kompressionstrauma des Thorax kann die Aorta gegen die Wirbelsäule gedrückt werden. In Verbindung mit der Deceleration erleidet die Wirbelsäule oft ein Flexions - Distraktionstrauma. Eine Verletzung der Wirbelsäule könnte daher ein diagnostischer Hinweis auf eine traumatische Aortenruptur (TAR) darstellen. Die Letalität der Patienten am Unfallort ist hoch, von 10-30\%, die lebend ein Krankenhaus erreichen, sterben weitere ca. $30 \%$ noch vor einer chirurgischen Intervention. Daher ist eine schnellst mögliche Diagnostik wichtig. In der vorliegenden Analyse wird die Koinzidenz zwischen TAR und Verletzungen der Wirbelsäule untersucht.

Hierzu wurden alle Sektionsfälle mit TAR aus dem Obduktionsgut von 1993 - 2000 ausgewertet.

Von 268 Fällen ereigneten sich 145 im Straßenverkehr. 77 Personen waren PKW-Insassen, 45 verunfallten als Fußgänger, 14 als Motorradund 9 als Fahrradfahrer. Sowohl bei den Fußgängern als auch bei den Radfahrern fand sich in $67 \%$ eine Wirbelsäulenverletzung. Bei $36 \%$ der verunfallten Motorradfahrer und bei $29 \%$ der PKW-Insassen konnten gleichzeitig eine TAR und eine Wirbelsäulenverletzung festgestellt werden. Die Rupturlokalisation befand sich zu 60\% im Aortenisthmusbereich. Frakturen der BWS fanden sich bei 53 Fußgängern, 44\% Radfahrern, 29\% Motorradfahrern und 18\% PKW-Insassen. Insgesamt am häufigsten waren der 3. und der 4. BWK betroffen. Am dritthäufigsten war der 7. HWK und der 1. LWK geschädigt. Verletzungen der unteren HWS sowie der oberen BWS in Verbindung mit einem Rasanztrauma weisen mit einer hohen Inzidenz auf eine traumatische Aortenverletzung hin. Sollte bei dem Aufnahmethoraxbefund eine Wirbelsäulenverletzung radiologisch in Verbindung mit einer Mediastinalverbreiterung nachgewiesen werden, sollte möglichst umgehend eine TAR ausgeschlossen werden.

\section{P-85 \\ ZUR BIOMECHANIK UND HANDLUNGSFÄHIGKEIT BEI UNGEWÖHNLICH OFFENEN FRAKTUREN \\ Weinandi T, Reuhl J, Graenert G \\ Zentrum der Rechtsmedizin \\ der Johann-Wolfgang-Goethe-Universität Frankfurt a.M.}

In einem Zeitraum von einem Monat kamen zwei Fälle zur Untersuchung, bei denen offene Frakturen (einmal Unterschenkel, einmal Oberarm) vorlagen und sich die Frage nach der Herkunft der Verletzungen und der Handlungsfähigkeit stellten.

In dem einen Fall soll ein 70 Jahre alter Mann mit einem offenen Bruch noch eine Treppe bis in das erste Stockwerk gestiegen sein, im zweiten Fall lag bei einer 76 Jahre alten Frau eine offene Humerusfraktur vor, die offenbar durch einen Sturz aus Körperhöhe bedingt war.

Die morphologischen und pathologisch-anatomischen Befunde der Fälle werden dargestellt, ebenso die kriminalistischen Überlegungen.

\section{P-86}

DIE BEURTEILUNG

DES AUSSAGEWERTES VERSCHIEDENER METHODEN

IN DER RADIOLOGISCHEN DIAGNOSTIK

ANHAND VON RADIOLOGISCHEN FEHLDIAGNOSEN

${ }^{1}$ Maksymowicz K, ${ }^{2}$ Maksymowicz H

${ }^{1}$ Lehrstuhl und Institut für Gerichtliche Medizin

der Medizinischen Akademie Wroclaw, Polen

${ }^{2}$ Labor für Radiologie, T. Marciniak Krankenhaus, Wroclaw, Polen

Bei der Betrachtung von verschiedenen diagnostisch - klinischen Methoden im letzten Jahrzehnt wird deutlich, daß die radiologische Diagnostik eines der sich am schnellsten entwickelnden Fächer bei gleichzeitiger Abnahme seiner Invasität ist. Die Anwendung von ganz neuen Methoden in der alltäglichen klinischen Praxis und auch die Modifizierung der klassischen Verfahren erweitern die Möglichkeiten der Bilddiagnostik und erhöhen dadurch auch den Aussagewert der Untersuchungen im rechtsmedizinischen Gutachten.

Trotzdem stoßen wir in Begutachtungsverfahren aus unserem Institut auf einige radiologische Fehldiagnosen, die nicht selten von erheblicher Bedeutung für den Patienten sind.

Wir benutzen bei der Begutachtung strittiger Probleme gleichzeitig verschiedene Methoden der radiologischen Diagnostik mit unterschiedlicher Aussagekraft.

Beachtenswert ist, daß die Grenzen unterschiedlicher radiologischer Methoden durch Art, Lokalisation, Charakteristik und Zeit des Entstehens der von uns ermittelten traumatischen oder pathologischen Veränderungen gegeben sind.

\section{P-87}

\section{RADIOLOGICAL FINDINGS}

AFTER PERCUTANEOUS VERTEBROBLASTY

OR WHAT THE FORENSIC DOCTOR HAS TO KNOW

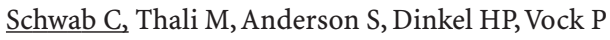

Institute of Diagnostic Radiology, University of Berne, Switzerland

\section{Background}

The procedure Percutaneous Vertebroblasty includes an injection of acrylic cement into the damaged vertebra for the purpose of partially stabilizing the bone in order to decrease associated pain and avoid neurological damage.In this study, the most frequent, radiologically provable, post-operative complications will be discussed and graphically presented.

Materials and Methods

In the examination of post-operative patients, the following ectopic acrylic cement deposits were discovered:

- Acrylic cement deposits in the spinal canal or neuro foramina,

- Paravertebral acrylic cement deposits,

- Acrylic cement deposits in the paravertebral circulatory system,

- In one case, acrylic cement was found in a pulmonary artery (embolism).

Discussion/Conclusion

Percutaneous Vertebroblasty was introduced in the 1980's. A lack of knowledge, on the part of the radiologist, of this procedure's radiologically detectable complications can lead to a misdiagnosis. Severe complications are rare and restricted to localized processes such as infection or cement leakage into the spinal canal or into the perivertebral venous system. In particular, neural and vascular complications can arise.From the radiological perspective, the possibility of detecting ectopic acrylic cement in and around the spinal canal, and the danger of an acryliccement pulmonary embolism occurring subsequent to a thoracic procedure are not to be overlooked. 


\section{Abstracts}

\section{P-88}

VIRTOPSY: FALLBERICHT SUIZID DURCH BRUSTSTICH HERAUSFORDERUNG FÜR DAS POSTMORTALE CT UND MRI. $\underline{\text { Schweitzer W}}^{*}(1)$, Yen K (1), Thali M (1,2), Scheurer E (1), Vock P (2), Bösch C (3), Ith M (3), Sonnenschein M (2), Brügger K $(2,3)$, Spielvogel E (2), Königsdorfer U (1), Dorn R (1), Dirnhofer R (1) (1) Institut für Rechtsmedizin, Universität Bern, Bühlstrasse 20, 3012 Bern, Schweiz

(2) Department für Diagnostische Radiologie, Universität Bern, Inselspital, 3010 Bern, Schweiz

(3) Department für Klinische Forschung, Universität Bern, Inselspital, 3010 Bern, Schweiz

Ein 83-jähriger wurde mit intaktem Schlafanzug bekleidet tot in Rückenlage in seinem Bett auf einer Blutlache gefunden. Auf seiner Brust lag ein langes Messer, am Einstich fehlten Probierschnitte. In den Wochen zuvor hatte man dem Mann eröffnet, er müsse wegen Renovationsarbeiten seine Wohnung temporär räumen.

Die Autopsie zeigte, dass der Mann mit einem tiefen Stich Haut, Perikard und linke Kammer durchstochen hatte. Als Einstichstelle hatte er eine alte Thorakotomienarbe gewählt. Als Todesursache fanden sich Befunde eines Verblutens.

Der Leichnam wurde mit MRI und CT untersucht, bevor die Autopsie durchgeführt wurde. Befunde des Bruststichs sind besonders deutlich in einer Serie von MR-Bildern dargestellt, welche auf einem 1.5 T MRIGerät der Firma GE u.a. mit einem Torso Coil in einer Auflösung von bis zu $0.46 \mathrm{~mm}$ x $0.46 \mathrm{~mm}$ x $2.1 \mathrm{~mm}$ Voxelgrösse erfasst wurde. Diese Zahlen verdeutlichen auch gleichzeitig die Grenzen der Methode: rekonstruktiv bedeutsame Details der Stichwunde, sowohl an Haut, wie auch Perikard oder Herzkammer, waren präparatorisch besser darzustellen. Insgesamt bietet die nichtinvasive Bildgebung in diesem Fall aber eine genügend gute Dokumentation von Befunden, die - mittels Vergleich zur Autopsie als richtig validiert - Rückschlüsse auf Stichverlauf, Blutverlust und somit die Todesursache zulassen.

(Teil eines Forschungsprojektes, das durch die Gebert-Rüf Stiftung (Schweiz) gefördert wird).

\section{P-89}

\section{MICRO-CT AND FORENSIC PATHOLOGY}

Thali ${ }^{1}$, Taubenreuther $\mathrm{U}^{2}$, Braun $\mathrm{M}^{3}$, Scholz N ${ }^{2}$, Brueschweiler $\mathrm{W}^{3}$, Kalender $\mathrm{W}^{2}$, Dirnhofer $\mathrm{R}^{1}$

1. Institute of Forensic Medicine, University of Berne, Switzerland

2. Institute of Medical Physics, University of Erlangen, Germany

3. Scientific Forensic Service, Zurich City Police, 8004 Zurich,

Switzerland

PURPOSE: Micro-CT may offer a worthwhile opportunity to analyse so called patterned injuries in bone. In the field of forensic science, it has not been possible until now to non-destructively document such damages to bone. MATERIALS AND METHODS: Based on a real murder case, porcine pelvic bones were experimentally stabbed with multiple knives. Afterwards these bone samples were examined with a micro-CT system developed at the IMP Erlangen. This cone beam scanner can achieve an isotropic resolution from 10 to $100 \mu \mathrm{m}$ for sample diameters from 1 to $40 \mathrm{~mm}$. Resolution in the specific bone samples is 30 to $75 \mu \mathrm{m}$ depending on the sample size. So far analysis has been performed by visual inspection of double oblique slices of the reconstructed volume to optimally display the plane cut by the knife using Impact View (VAMP GmbH, Erlangen,Germany). Additionally the stabbing wounds were quantitatively evaluated by measuring distances and angles.

RESULTS: The micro-CT datasets of the injured bone samples were used to obtain those $2 \mathrm{D}$ slices that optimally showed the stabbing wounds inside. Based on the measured distances and angles it was easily possible to uniquely identify the size and shape of the injury-causing knife in straight stabs.
CONCLUSIONS: In the field of forensic pathology Micro-CT provides a new and advantageous tool for the non-destructive examination and analysis of patterned tool marks in bones. By using the micro-CT technology new horizons are opened for matching a possible injury-causing instrument against the patterned lesion in the bone.

\section{P-90}

BISSSPUREN-ANALYSE

MIT FORENSISCHER 3D-CAD-PHOTOGRAMMETRIE

Thali M (1), Braun M (2), Brüschweiler W (2), Binda S (3), Yen K (1), Zollinger U (1), Markwalder T (1), Dirnhofer R (1)

1. Institut für Rechtsmedizin, Universität Bern, 3012 Bern, Schweiz

2. Wissenschaftlich-technischer Dienst, Stadtpolizei Zürich,

8000 Zürich, Schweiz

3. Rechtsmedizinische Abteilung, Pathologisches Institut Locarno, Schweiz

Hintergrund: Bei Opfern von Gewalttaten können geformte Verletzungen mit einer spezifischen Form und /oder Struktur an Haut und Knochen Rückschlüsse auf das Tatwerkzeug und dadurch allenfalls auch auf die Täterschaft geben. Die Methode wurde bisher erfolgreich bei Verletzungen durch Schuhsohlen, Reifenprofile sowie Schlagwerkzeuge (Hammer etc.) angewendet.

Methode: Wir entwickelten ein neues Dokumentations- und Auswertungsverfahren für die form-, winkel- und massgerechte Darstellung von Verletzungsbefunden, nämlich die forensische $3 \mathrm{D}$-CAD-Photogrammetrie. Die forensische $3 \mathrm{D}$-CAD-Photogrammetrie dokumentiert Verletzungsbefunde dreidimensional $(3 \mathrm{D})$ und ohne Veränderung/Zerstörung von Details des Wundbefundes. Das selbe Verfahren kann auch zur Erfassung des fraglichen Tatwerkzeuges angewendet werden.

Basierend auf bisherigen experimentellen Versuchen wurden erstmals reale Bissverletzungen dokumentiert, analysiert und mit mutmasslichen Tätergebissen verglichen.

Resultate / Diskussion: Dabei zeigte sich, dass die forensische 3DCAD-Photogrammetrie den bisherigen Overlay-Methoden und neuerdings angewandten (zweidimensionalen) Photoshop-Vergleichsmethoden, insbesondere durch die Dreidimensionalität der Befunddokumentation und -analyse überlegen ist. Ferner kann aus dem photogrammetrisch dokumentierten Datensatz jederzeit ein 3D-Modell der Bissverletzung, z.B. durch stereolithographische Methoden hergestellt werden.

\section{P-91}

\section{SPIRAL CT EVALUATION OF A KNIFE WOUND}

TO THE THORACIC AORTA

Thali M (1, 2), Schwab C (1), Tairi K (1), Dirnhofer R (2), Vock P (1)

1. Institute of Radiology, Berne, Switzerland

2. Institute of Forensic Medicine, Berne, Switzerland

Goal: The Spiral-CT evaluation of a stabbing knife injury to the thoracic aorta.

Methods: A man found with a knife imbedded in his back was brought into the emergency room. Since the patient was clinically in stable condition, a CT scan was performed to localize the knife exactly in order to direct the surgical approach.

Results: The knife blade penetrated the dorsal wall of the descending aorta, with the knife point in the lumen, touching the ventral wall. Intravenous contrast medium enhancement showed no extravasation, and there was only a minimal amount of hemorrhage around the aorta. With a subsequent 3-D reconstruction it was possible to clearly show the relative location of the knife, the aorta, and the bony structures. Surgery was successful and the follow-up uneventful.

Conclusion: With the use of the Spiral CT technique data of a complete volume can be studied. The $3-\mathrm{D}$ reconstruction offers the option of 
exactly localizing a foreign body in its relation to anatomical structures. So, without any displacement a knife imbedded in a wound can be documented in little time. Despite the appearance of metal artifacts in the CT scans, anatomical localization of the knife is accurate for treatment planning and, in this case, supported the decision to leave the knife in place until surgery which was probably life-saving. For vascular injuries, the Spiral CT technique presents a non-invasive alternative to the classic method of angiography. The CT's finely detailed three-dimensional depictions are especially helpful in the presentation of forensic cases in court. The 3-D reconstruction offers a method ideally suited for demonstrating medical findings because it greatly reduces the difficulty of clearly and understandably communicating the conclusions of medical forensic experts to a lay audience.

\section{P-92}

GESCHOSSE UND METALLARTEFAKTE - „STATE OF THE ART“

Thali M (1), Watzke O (2), Kachelriess M (2), Fuchs T (2),

Kneubuehl B (1), Dirnhofer R (1), von Allmen G, Schwab C,

Kalender W (2)

1. Institut für Rechtsmedizin, Universität Bern, Schweiz

2. Institut für Medizinische Physik, Universität Erlangen, Deutschland

Hintergrund: Die Einsatzmöglichkeit der CT wird durch Metallobjekte im Strahlengang stark eingeschränkt. Metallteile beeinträchtigen die Röntgenstrahlung auf dem Weg zum Detektor meist so stark, dass Strukturen um das Projektil oder in der Untersuchungsebene kaum zu beurteilen sind.

Material und Methode: Verschiedene Projektile wurden in Margarineblöcke eingebettet.

Nach der Multislice-CT-Untersuchung wurden die Daten durch folgende Software nachbearbeitet:

- Softwarepaket der Firma Vamp, Möhrendorf mit unbeschränkter Houndsfieldskala

- Mathematische Artefaktreduktionsmethoden wie lineare Interpolation im Metallschatten mit zusätzlicher Interpolation interessanter Strukturen (wie z.B. Knochen)

- Physikalische Artefaktreduktionsmethoden wie adaptive Filterung im Metallschatten mit

- Bildbasierte gewichtete Verschmelzung der beiden oben genannten Methoden

Resultate: Durch die Anhebung des Röhrenstroms konnten bereits Metallartefakte reduziert werden. Bei Erweiterung des Houndsfieldfensterung bis ca. 30'0oo konnte das Projektil hinsichtlich Form und Grösse erkannt werden. Die ergänzende Anwendung von Methoden zur physikalischen und mathematischen Metallartefaktreduktion zeigten sich erfolgversprechend. Während die physikalische Filtermethode das Bildpunktrauschen erheblich senkt, kann mit der mathematischen Korrektur die Nahumgebung des Metallobjektes sehr gut dargestellt werden. Eine Kombination der Methoden verspricht optimalen Bildeindruck bei minimaler Beeinträchtigung der Auflösung. Diskussion: Da auch aus klinischer Sicht die Metallartefaktreduktion gefordert wird, werden mit grosser Wahrscheinlichkeit in Zukunft auch entsprechende Metallartefaktreduktionsmöglichkeiten in die Ausrüstung der klinischen CT integriert werden.

\section{P-93}

BALLISTISCH-RADIOLOGISCHE CT-REKONSTRUKTION EINES UNERLAUBTEN LUCHSABSCHUSSES

Thali M (1), Kneubuehl B (1,2), Ozdoba C (3), Spielvogel E (3), Dirnhofer R (1)

1. Institut für Rechtsmedizin, Universität Bern, 3012 Bern, Schweiz

2. Gruppe Rüstung, Fachabteilung 26, Ballistik und Detonik Labor, 3602 Thun, Schweiz

3. Abteilung für Neuroradiologie, Universität Bern, Inselspital, 3010 Bern, Schweiz
Hintergrund: Seit einigen Jahren versucht man in der Schweiz den Luchs wieder in die heimische Fauna zu integrieren. Immer wieder kommen unerlaubte Abschüsse des geschützten Tieres vor.

Kasuistik: Im vorliegenden Fall wurden wir von der Tierpathologie der Universität Bern beigezogen, um an der Begutachtung und Rekonstruktion eines erschossenen Luchses mitzuwirken.

Methode / Resultat: Am überbrachten Tierfell und dem vorobduzierten Tierkadaver konnten insgesamt drei Durchschüsse und ein Steckschuss eines ricochierten Geschosses festgestellt werden. Bei der rekonstruktiven Fragestellungen erwies sich die Untersuchung des Tierkadavers mit Multislice-Computertomographie-Technik als hilfreich. In der feinauflösenden 3D-Rekonstruktion konnten neben Projektilresten auch Durchschüsse des Schulterblattes und der Wirbelsäule visualisiert werden.

Diskussion: Für rekonstruktive ballistische Fragestellungen - insbesondere des knöchernen Systems - ist die Multislice-CT-Untersuchung dem konventionellen Röntgenbild hinsichtlich Dokumentations- und Aussagekraft deutlich überlegen.

Das Post -Processing der CT-Datensätze eröffnet neue Visualisierungsmöglichkeiten für die Präsentation der Untersuchungsergebnisse.

\section{P-94}

VIRTOPSY: POSTMORTALE MS-CT UND MR-UNTERSUCHUNGEN NACH STUMPFER GEWALTEINWIRKUNG;

DARSTELLUNG ANHAND VON VERKEHRSUNFÄLLEN

Yen K (1), Thali MJ $(1,2,3)$, Schweitzer W (1), Scheurer E (1), Vock P (2), Ozdoba C (3), Schroth G (3), Sonnenschein M (2), Boesch C (4),

Ith M (4), Brügger K (4), Spielvogel E (3), Königsdorfer U (1),

Dorn R (1), Dirnhofer R (1)

Institut für Rechtsmedizin (1);

Institut für Diagnostische Radiologie, (2),

Abteilung für Neuroradiologie, (3);

Abteilung für klinische Forschung - Magnetresonanzspektroskopie (4) Universität Bern

$\underline{\text { Ziel: }}$ Es soll gezeigt werden, dass der Einsatz radiologischer Methoden zur Befunderhebung und forensischen Begutachtung von bei Verkehrsunfällen Verstorbenen geeignet ist.

Material und Methode: 10 Personen, die bei Verkehrsunfällen als Fahrer, Beifahrer, Radfahrer oder Fussgänger ums Leben gekommen waren, wurden postmortal einer Ganzkörper-MS-CT- sowie MR-Untersuchung unterzogen. In allen Fällen wurde eine Autopsie durchgeführt.

Resultate: Unter Verwendung von aus den computertomographischen Datensätzen angefertigten 2D/3D-Rekonstruktionen waren Anfahrstelle und -Richtung jeweils eindeutig diagnostizierbar, wobei insbesondere Verletzungen des Skelettsystems und der Weichteile eindrucksvoll gezeigt werden konnten. Vitalitätszeichen wie Luftembolie oder Blutaspiration fanden sich in allen Fällen. Schwierigkeiten ergaben sich noch im Bereich der Organdiagnostik, hingegen war die Todesursache jeweils feststellbar.

Diskussion: Postmortal angewandte MR- und MS-CT- Untersuchungen sind zur vollständigen Erfassung und Dokumentation forensisch bedeutsamer Befunde ausgezeichnet geeignet. Insbesondere erweist sich die Möglichkeit der 3D- Darstellung von Knochenbrüchen für die Rekonstruktion als wertvoll, da diesbezügliche Untersuchungsmöglichkeiten bei der Autopsie eingeschränkt sind (Gesicht, Becken). Die „Virtuelle Autopsie“ ist im Hinblick auf rechtsmedizinische Begutachtungsfragen der „klassischen Autopsie“ zum Teil deutlich überlegen, so dass eine breite Anwendung der Methode im Bereich der Verkehrsunfallbegutachtung absehbar ist. 
Autorenverzeichnis

\begin{tabular}{|c|c|c|c|c|c|}
\hline Abdel Salam HF & P-08 & Budjarek B & V-014 & Fries JW & P-67 \\
\hline Abdelaziz M & P-08 & Buhmann D & $\mathrm{P}-26$ & Fuchs T & P-92 \\
\hline Aebi B & V-048 & Bujdosó G & $\mathrm{P}-36$ & Fuhrer R & $V-111$ \\
\hline Ahrens B & P-56 & Bungardt N & P-39 & Füredi S & $\mathrm{P}-34$ \\
\hline Albert D & P-84 & Bürig KF & $V-105$ & & \\
\hline Allmen von G & P-92 & Buromskiy IW & $\mathrm{P}-02$ & Gabriel P & $\mathrm{P}-58$ \\
\hline Alt KW & P-28 & Busch K & V-050, V-051 & Gamerdinger U & V-o89 \\
\hline Amendt J & P-01 & Buske N & $\mathrm{P}-30$ & Gatternig R & $\mathrm{P}-72$ \\
\hline Anders S & P-05 & Büttner A & P-53 & Gehl HB & V-078 \\
\hline Anderson S & P-87 & & & Gehrke G & P-26 \\
\hline Anslinger K & $\mathrm{P}-14$ & Calistru P & P-70 & Georg T & P-77, P-78 \\
\hline Arnold H & V-095 & Carstens W & P-06 & Gerber HG & P-77, P-78 \\
\hline Arnold J & V-oo4 & Chadova L & P-09, P-60 & Gergis RS & P-08 \\
\hline Arnold R & V-015 & Chowaniec CZ & V-069 & Gerling I & V-078 \\
\hline Arnold T & V-095 & Claussen U & $\mathrm{P}-32$ & Geserick G & V-o11 \\
\hline \multirow[t]{2}{*}{ Augustin C } & $\mathrm{V}-108$ & Clauwaert K & P-16 & Giebe B & P-56 \\
\hline & & Cordes O & $\mathrm{P}-80$ & Giebe W & P-56 \\
\hline Baasner A & P-07, P-71, V-040 & Craeymeersch M & $\mathrm{P}-16$ & Giese A & $\mathrm{P}-25, \mathrm{P}-26$ \\
\hline Bajanowski T & V-019 & & & Gotta JC & $\mathrm{P}-82$ \\
\hline Balogh MK & $\mathrm{P}-28$ & Daldrup T & $V-105$ & Graebe M & $\mathrm{P}-71$ \\
\hline Baltz M & $\mathrm{P}-35$ & Darok M & $\mathrm{P}-72$ & Graenert G & $\mathrm{P}-85$ \\
\hline Banaschak S & $\mathrm{P}-64, \mathrm{~V}-040$ & Daum S & P-29 & Graß H & P-17, P-67, V-076, V-081 \\
\hline Bär W & $\mathrm{P}-55$ & De Letter EA & $\mathrm{P}-16$ & Grauss G & P-50 \\
\hline Bartsch Ch & $\mathrm{V}-023$ & Delling G & V-067 & Grellner W & $\mathrm{P}-24, \mathrm{P}-26, \mathrm{P}-44, \mathrm{P}-77$ \\
\hline Barz J & $\mathrm{P}-58$ & Demme U & $\mathrm{P}-56$ & & P-78, P-79, P-80 \\
\hline Bauer G & P-21, V-018, V-109 & Denk W & V-109 & & \\
\hline Bauer M & $\mathrm{P}-10, \mathrm{~V}-026, \mathrm{~V}-066$ & Dermengiu D & P-69, P-70 & Hampel A & $\mathrm{P}-28$ \\
\hline Baur MP & P-36 & Dermengiu S & P-69, P-70 & Härling M & $\mathrm{P}-30$ \\
\hline Beck N & $\mathrm{V}-042$ & Dettmeyer R & P-07, P-71 & Hartmann $\mathrm{R}$ & P-61 \\
\hline Becker J & $\mathrm{P}-15$ & Dilger M & P-06, V-007, V-110 & Häusler G & V-072 \\
\hline Bedeir SM & P-33 & Dinkel HP & P-87 & Hausmann R & V-oo8 \\
\hline Behnsen S & $\mathrm{P}-17$ & Dirnhofer R & P-88, P-89, P-90, P-91, & Hecker R & $\mathrm{P}-18$ \\
\hline Behrendt N & $\mathrm{P}-40$ & & P-92, P-93, P-94, V-001, & Heid O & V-062 \\
\hline Bellmann D & $\mathrm{P}-24$ & & V-058, V-065, V-079, & Heide S & P-73 \\
\hline Bender K & $\mathrm{P}-28$ & & V-082, V-083, V-084, & Heidorn F & $\mathrm{V}-041$ \\
\hline Benecke M & V-055 & & V-085, V-086, V-087, & Heinemann A & $\mathrm{P}-80, \mathrm{~V}-028$ \\
\hline Benthaus S & V-010, V-074, V-075 & & V-088, V-099 & Helmchen B & $\mathrm{V}-023$ \\
\hline Bernhard W & V-048 & Dorn R & P-88, P-94, V-079, & Henßge C & V-013 \\
\hline Berzinsch U & $\mathrm{P}-50$ & & V-o82, V-083, V-084 & Hermann KG & V-o68 \\
\hline Berzlanovich A & $\mathrm{P}-38, \mathrm{~V}-109$ & Draheim N & P-41 & Herzog C & V-077 \\
\hline Betz P & V-0o8, V-049 & Dreßler J & V-095 & Hideg Z & $\mathrm{P}-19$ \\
\hline Binda S & P-9o & Driever F & V-040 & Höche W & V-078 \\
\hline Binder $\mathrm{R}$ & P-79 & Du Chesne A & V-010, V-019, V-074 & Hönigschnabl S & $\mathrm{P}-21$ \\
\hline Bockholdt B & $\mathrm{P}-51, \mathrm{~V}-050, \mathrm{~V}-051$ & Duchstein HJ & $\mathrm{P}-23$ & Horisberger B & P-46, V-097 \\
\hline Boesch C & $\begin{array}{l}\text { V-063, V-079, V-083, } \\
\text { V-084, V-085, V-086 }\end{array}$ & Dumser $\mathrm{T}$ & $\mathrm{V}-052$ & Huckenbeck W & $\mathrm{P}-58$ \\
\hline Bohle RM & V-o89 & Ebenhöh L & P-75 & Inagaki S & $\mathrm{P}-42, \mathrm{~V}-105$ \\
\hline Böhme B & P-53 & Eberl N & V-096 & Ishida Y & $\mathrm{V}-102$ \\
\hline Bohnert M & V-100 & Egelund R & $\mathrm{P}-40$ & Ishikawa $\mathrm{T}$ & $\mathrm{P}-42, \mathrm{P}-63, \mathrm{~V}-105$ \\
\hline Bonte W $(\dagger)$ & $V-104$ & Egyed B & $\mathrm{P}-34$ & Ishizu $\mathrm{H}$ & $\mathrm{P}-42, \mathrm{P}-63, \mathrm{~V}-105$ \\
\hline Bösch C & P-88, P-94, V-082 & Ehrlich E & $\mathrm{P}-11, \mathrm{P}-52, \mathrm{~V}-050, \mathrm{~V}-051$ & Iten PX & $\mathrm{P}-75, \mathrm{~V}-044$ \\
\hline Bouška I & $\mathrm{P}-54$ & Eisenmenger W & $\mathrm{P}-03, \mathrm{P}-04, \mathrm{P}-14, \mathrm{~V}-02 \mathrm{O}$ & Ith M & P-88, P-94, V-079, \\
\hline Bouska I & P-09 & & $\mathrm{V}-032, \mathrm{~V}-056$ & & V-o82, V-o83, V-o84, \\
\hline \multirow[t]{2}{*}{ Bratzke $\mathrm{H}$} & $\mathrm{P}-20, \mathrm{P}-29, \mathrm{P}-37, \mathrm{P}-68$, & El Shennawy I & P-08 & & V-085, V-086 \\
\hline & V-025, V-037, V-077 & Elias S & $\mathrm{V}-108$ & & \\
\hline \multirow[t]{2}{*}{ Braun $\mathrm{M}$} & $\mathrm{P}-89, \mathrm{P}-90, \mathrm{~V}-043$ & Engelmann K & V-077 & Jachau K & V-072 \\
\hline & V-087, V-088 & Erdmann F & $\mathrm{P}-82$ & Jacob B & $\mathrm{V}-105$ \\
\hline \multirow[t]{2}{*}{ Brinkmann B } & V-010, V-019, V-074, & Espeel M & $\mathrm{P}-16$ & Jagemann KU & V-015 \\
\hline & V-075 & & & Jasková A & P-66 \\
\hline Broese $\mathrm{T}$ & V-047 & Fasching $\mathrm{P}$ & $\mathrm{P}-38$ & Jaster R & V-047 \\
\hline Brogdon G & V-064 & Fechner G & V-019 & Jeszenszky E & $\mathrm{P}-19$ \\
\hline Bruchhaus $\mathrm{H}$ & $\mathrm{P}-32$ & Fekete S & $\mathrm{P}-34$ & Junge A & $\mathrm{P}-11$ \\
\hline \multirow{2}{*}{ Brügger K } & P-88, P-94, V-079, & Fiedler R & V-o8o & Junge M & P-05 \\
\hline & V-082, V-083, V-084 & Fink $\mathrm{T}$ & P-06, P-76, V-007, V-110 & & \\
\hline & V-091 & Fischbacher C & $\mathrm{V}-015$ & Kachelriess M & P-92 \\
\hline \multirow[t]{2}{*}{ Brüschweiler W } & P-57, P-89, P-90, V-043, & Fitzenreiter M & $\mathrm{P}-15$ & Käferstein H & V-046 \\
\hline & V-087, V-088, V-098 & Foad $\mathrm{H}$ & $\mathrm{P}-33$ & Kaff A & $\mathrm{P}-21$ \\
\hline Buda O & P-69, P-70 & Friedrich-Koch A & P-55 & Kalender W & P-89, P-92, V-o61, V-o\& \\
\hline
\end{tabular}




\begin{tabular}{|c|c|c|c|c|c|}
\hline Karger B & V-075 & Maksymowicz H & P-86 & Pollak S & $\mathrm{V}-033, \mathrm{~V}-100$ \\
\hline Kauert G & $\mathrm{V}-045$ & Maksymowicz K & $\mathrm{P}-49, \mathrm{P}-59, \mathrm{P}-86$ & Popov V & $\mathrm{P}-27$ \\
\hline Kaufmann T & P-47, P-76 & Malik F & V-002 & Preuß J & P-30, P-80 \\
\hline Kehrer B & V-06o & Mall G & P-03, P-04, V-014, V-056 & Pufal E & $\mathrm{P}-81$ \\
\hline \multirow[t]{2}{*}{ Keil W } & V-014, V-022, V-056, & Mangin $\mathrm{P}$ & P-46, V-097 & Pülschen D & V-093 \\
\hline & V-096 & Mannweiler S & P-72 & Püschel K & $\mathrm{P}-05, \mathrm{P}-25, \mathrm{P}-26, \mathrm{P}-48$ \\
\hline Kerner Á & P-19 & Manthei A & V-035 & & $\mathrm{P}-63, \mathrm{P}-80, \mathrm{~V}-028$ \\
\hline Khokhlov VD & P-43 & Markwalder T & $\mathrm{P}-90, \mathrm{~V}-043$ & & V-067, V-070, V-071, \\
\hline Khoury C & $V-105$ & Matschke J & P-74 & & V-107 \\
\hline Kijewski H & $\mathrm{P}-23, \mathrm{P}-61$ & Mattern R & V-030, V-037, V-073 & & \\
\hline Kilchör T & P-75 & Maxeiner $\mathrm{H}$ & $\mathrm{P}-41, \mathrm{P}-45, \mathrm{P}-51, \mathrm{P}-52$, & Rabl W & V-094 \\
\hline Kildüschov EM & $\mathrm{P}-\mathrm{O} 2$ & & V-027, V-050, V-051, & Rauch E & $\mathrm{P}-14, \mathrm{P}-53$ \\
\hline Kildüschova EA & $\mathrm{P}-\mathrm{O} 2$ & & $\mathrm{~V}-101$ & Rauch P & $\mathrm{P}-57$ \\
\hline Kimont HG & $\mathrm{P}-17$ & Meissner C & V-078 & Reichelt U & $V-103$ \\
\hline Kitao T & P-63 & M.F. Elsawy S & P-o8 & Reisinger W & V-011, V-068 \\
\hline Kleiber M & $\mathrm{P}-73, \mathrm{~V}-021, \mathrm{~V}-029$ & Michael M & $\mathrm{P}-32$ & Reuhl J & $\mathrm{P}-85$ \\
\hline Klein A & P-32, P-56, V-015, V-017 & Michaud K & P-46, V-097 & Richter E & V-067 \\
\hline Klotzbach H & V-067, V-107, V-108 & Mielke U & V-092 & Riepert T & $\mathrm{P}-35, \mathrm{~V}-076, \mathrm{~V}-081$ \\
\hline \multirow{2}{*}{ Kneubuehl BP } & P-92, P-93, V-034, & Mitterauer B & V-090 & Riße M & V-012, V-089 \\
\hline & V-079, V-o88 & Miyaishi S & $\mathrm{P}-42, \mathrm{P}-63, \mathrm{~V}-105$ & Risser D & $\mathrm{P}-21$ \\
\hline Kobek M & V-069 & Molnár A & $\mathrm{P}-19$ & Rittner C & $\mathrm{P}-06, \mathrm{P}-18, \mathrm{P}-28, \mathrm{P}-35$, \\
\hline Koczan D & V-047 & Molz G & P-55 & & $\mathrm{P}-39, \mathrm{P}-47, \mathrm{P}-76, \mathrm{P}-83$, \\
\hline Kohl S & $\mathrm{P}-83$ & Mori R & $\mathrm{V}-102$ & & V-007, V-059 \\
\hline Kohlhase C & $\mathrm{V}-101$ & Mühler M & V-o68 & Ritz-Timme S & V-009 \\
\hline Kondo T & $\mathrm{V}-102$ & Muhm M & $\mathrm{P}-38, \mathrm{~V}-109$ & Rixen S & $\mathrm{P}-14$ \\
\hline König HG & V-078 & Müllerklein T & $\mathrm{P}-20$ & Rochholz G & P- 81 \\
\hline König M & V-o11 & Musshoff F & P-15, P-64, P-65, V-105 & Röhrich J & $\mathrm{P}-18$ \\
\hline \multirow[t]{2}{*}{ Königsdorfer U } & P-88, P-94, V-079, & & & Romain $\mathrm{N}$ & P-46, V-097 \\
\hline & V-082, V-083, V-084 & Nafe B & $\mathrm{P}-35$ & Romanowski U & P-73 \\
\hline Kontadakis $\mathrm{K}$ & $\mathrm{P}-34$ & Naka T & $P-42, P-63$ & Rommeiß S & V-015 \\
\hline Koops E & $\mathrm{P}-25, \mathrm{P}-26$ & Neis $P$ & $\mathrm{P}-18, \mathrm{P}-47, \mathrm{P}-83$ & Ropohl D & V-100 \\
\hline Krahforst R & V-077 & Niess C & P-01, P-20, P-29, P-37, & Roßbach JS & V-080 \\
\hline Krämer M & V-052 & & P-84 & Rossi A & V-097 \\
\hline Kratochwil M & P-80 & Noth J & V-006 & Rygol K & V-069 \\
\hline \multirow[t]{2}{*}{ Krause D } & $\mathrm{P}-13, \mathrm{~V}-042, \mathrm{~V}-072$, & Nour-El-Din M & $\mathrm{P}-33$ & & \\
\hline & V-o8o & & & Saleh SA & $\mathrm{P}-33$ \\
\hline Kreis $\mathrm{R}$ & V-085, V-086 & Oehmichen M & V-078 & Sanft J & $\mathrm{P}-32$ \\
\hline Krempien B & $\mathrm{V}-023$ & Oehmke S & $\mathrm{V}-041$ & Saternus KS & $\mathrm{P}-23$ \\
\hline Krettek R & P-01 & Ogbuihi S & $\mathrm{P}-39$ & Scheurer E & P-88, P-94, V-079, \\
\hline Krill A & $\mathrm{P}-44$ & Ohshima K & V-102 & & V-082, V-083, V-084, \\
\hline Kröner L & $\mathrm{P}-65$ & Ohshima T & V-102 & & V-085, V-086 \\
\hline Krug B & V-o81 & Olze A & V-011, V-o68 & Schläfke D & V-047 \\
\hline Kuchheuser W & V-o8o & Ondra P & P-66 & Schmeling A & V-011, V-068 \\
\hline Kühn-Becker H & P-77, P-78 & Orlopp K & V-106 & Schmid G & V-047 \\
\hline \multirow[t]{2}{*}{ Kulikowska J } & P-62 & Ortmann C & V-075 & Schmidt H & $\mathrm{P}-29$ \\
\hline & & Ozdoba C & P-93, P-94, V-079, & Schmidt P & P-15, V-036, V-105, \\
\hline Laas $\mathrm{R}$ & P-74 & & V-o83, V-o84 & & V-106 \\
\hline Lachenmeier D & P-65 & & & Schmidt S & $\mathrm{P}-32$ \\
\hline Lackner K & V-076, V-081 & Pádár Z & $\mathrm{P}-34$ & Schmidt U & $\mathrm{P}-31$ \\
\hline Lambert W & $\mathrm{P}-16$ & Paetzold V & V-096 & Schmitt T & $\mathrm{P}-31$ \\
\hline Lamszus K & $\mathrm{P}-74$ & Paperno S & V-o81 & Schmoldt A & $\mathrm{P}-80$ \\
\hline Lasczkowski G & V-o89 & Patscheider $\mathrm{H}$ & V-099 & Schnabel A & P-68 \\
\hline Lászik A & $\mathrm{P}-36$ & Patzelt D & $\mathrm{P}-10, \mathrm{~V}-066$ & Schnatterbeck P & V-073 \\
\hline Leinzinger EP & $\mathrm{P}-72$ & Penning R & $\mathrm{P}-53$ & Schneider H & V-053 \\
\hline Lemr K & P-66 & Peschel O & $\mathrm{V}-020, \mathrm{~V}-022, \mathrm{~V}-035$ & Schneider PM & $\mathrm{P}-28$ \\
\hline Lieske S & $\mathrm{P}-13, \mathrm{~V}-042$ & & V-056 & Schneider V & $\mathrm{P}-11$ \\
\hline Lignitz E & P-30, P-80, V-054 & Petermann J & P-84 & Scholz N & P-89, V-087 \\
\hline Liniger B & V-031 & Petersen D & V-078 & Scholz T & $\mathrm{P}-45$ \\
\hline Logemann E & V-o48 & Pfefferli P & V-005 & Schönpflug M & $\mathrm{V}-032$ \\
\hline Lohmann F & $\mathrm{P}-25$ & Pfeiffer $\mathrm{H}$ & V-010, V-075 & Schröder H & V-107, V-108 \\
\hline Lutz FU & $\mathrm{P}-84$ & Pfudl S & $\mathrm{P}-21$ & Schröer J & $\mathrm{V}-028$ \\
\hline \multirow{2}{*}{ Lutz S } & $\mathrm{P}-31$ & Piette M & P-16 & Schroth & V-079 \\
\hline & & Placidi P & $\mathrm{V}-038$ & Schroth G & $\mathrm{P}-94, \mathrm{~V}-083, \mathrm{~V}-084$ \\
\hline \multirow[t]{4}{*}{ Madea B } & P-07, P-11, P-15, P-64, & Plaksin WO & $\mathrm{P}-02$ & Schuff A & P-67,V-076, V-081 \\
\hline & P-65, P-71, V-016, V-036, & Plate I & $\mathrm{V}-042$ & Schuller E & $\mathrm{V}-032$ \\
\hline & V-038,V-040, V-105, & Plattner T & V-057 & Schultes A & V-076, V-o81 \\
\hline & $\mathrm{V}-106$ & Pluisch F & $V-046$ & Schulz F & P-05 \\
\hline M.A. Hassan M & P-o8 & Poetsch M & $\mathrm{P}-30$ & Schulz M & V-047 \\
\hline
\end{tabular}




\begin{tabular}{|c|c|c|c|c|c|}
\hline Schuricht J & P-75 & Takata T & P-63 & Wegener R & V-047 \\
\hline Schütz H & P-82 & Taubenreuther U & $\mathrm{P}-89, \mathrm{~V}-087$ & Wehner F & $\mathrm{P}-22$ \\
\hline Schütz HW & P-81 & Teige K & V-010, V-074 & Wehner HD & $\mathrm{P}-22$ \\
\hline Schwab C & P-87, P-91, P-92 & Thali MJ & P-87, P-88, P-89, P-90, & Weiler G & $\mathrm{P}-82, \mathrm{~V}-012, \mathrm{~V}-023$ \\
\hline Schweden F & $\mathrm{P}-35$ & & P-91, P-92, P-93, P-94, & & V-041, V-o89 \\
\hline \multirow[t]{3}{*}{ Schweitzer W } & P-88, P-94, V-079, & & V-043, V-079, V-082, & Weinandi $\mathrm{T}$ & P-29, P-37, P-85 \\
\hline & V-o82,V-083,V-084, & & V-083, V-084, V-085, & Weirich S & V-047 \\
\hline & V-085, V-086 & & V-086, V-087, V-088, & Weirich V & V-047 \\
\hline Schyma C & $\mathrm{V}-036, \mathrm{~V}-037, \mathrm{~V}-038$ & & V-099 & Werner R & $\mathrm{P}-56$ \\
\hline Sebald D & $\mathrm{P}-21$ & Thiesen & $\mathrm{V}-047$ & Wicht H & $\mathrm{P}-37$ \\
\hline Seidl S & V-oo8 & Thoben $\mathrm{M}$ & $\mathrm{P}-23$ & Wilske J & $\mathrm{P}-24, \mathrm{P}-26, \mathrm{P}-44, \mathrm{P}-77$, \\
\hline Seifert D & V-070, V-071 & Tholen P & V-070 & & P-78, P-79, P-80 \\
\hline $\operatorname{Sim} \mathrm{E}$ & $\mathrm{P}-38$ & Titz K & V-047 & Winkelmann S & P-71 \\
\hline Sliwka K & P-81 & Tjurin $\mathrm{M}$ & $\mathrm{P}-27$ & Wirasuta I & $\mathrm{P}-23$ \\
\hline \multirow[t]{2}{*}{ Sonnenschein } & P-88, P-94, V-079, & Tóth J & V-039 & Wittig H & $\mathrm{V}-072$ \\
\hline & V-082, V-083, V-084 & Toupalik P & P-09, P-54 & Wolf J & $\mathrm{V}-107$ \\
\hline Sótonyi P & $\mathrm{P}-36$ & Trnka J & P-49 & Woller J & $\mathrm{P}-34$ \\
\hline Sperhake JP & P-48, V-067 & Trübner K & $\mathrm{P}-69, \mathrm{~V}-021, \mathrm{~V}-029$ & Wörth J & V-o48 \\
\hline Spielvogel E & $\begin{array}{l}\text { P-88, P-93, P-94, V-079, } \\
\text { V-082, V-083, V-084 }\end{array}$ & Tsokos M & V-103 & Wrobel G & $\mathrm{P}-11$ \\
\hline Staak M & $\mathrm{P}-17, \mathrm{~V}-081$ & Varga $\mathrm{T}$ & P-19 & Yamamoto Y & $\mathrm{P}-42, \mathrm{~V}-105$ \\
\hline Steevens M & $\mathrm{P}-11$ & Verhoff MA & V-012, V-023, V-041 & Yen $\mathrm{K}$ & P-88, P-90, P-94, V-043, \\
\hline Stein KM & V-073 & Vock P & P-87, P-88, P-91, P-94, & & V-079, V-o82, V-083, \\
\hline Stein S & $\mathrm{P}-80$ & & V-079, V-082,V-083, & & V-084, V-085, V-086 \\
\hline Stengel P & P-68 & & V-o84 & Yoshitome K & $\mathrm{P}-42, \mathrm{~V}-105$ \\
\hline Stichenwirth M & $\mathrm{P}-21$ & $\operatorname{Vog} 1 \mathrm{~T}$ & V-077 & & \\
\hline Sticht G & V-046 & Vogler M & P-57 & Zarma L & $\mathrm{P}-70$ \\
\hline Stiller D & V-021, V-029 & Volksone V & $\mathrm{P}-50$ & Zedníková K & P-66 \\
\hline Subke J & $\mathrm{P}-22$ & & & Zehner R & P-01 \\
\hline Swiatek B & P-59 & Walz F & $\mathrm{V}-024$ & Zimmer AK & P-77, P-78 \\
\hline Sybirska H & P-62 & Warth C & $\mathrm{V}-\mathrm{0} 48$ & Zimmer G & V-073 \\
\hline Sykutera M & P-81 & Wasserburger L & V-035 & Zimmermann W & V-070 \\
\hline \multirow[t]{2}{*}{ Szibor R } & $\mathrm{P}-13, \mathrm{~V}-042$ & Watzke O & P-92 & Zintl F & V-017 \\
\hline & & Weber M & V-003, V-071 & Zöldág L & $\mathrm{P}-34$ \\
\hline Tachibana $\mathrm{T}$ & P-42 & Weeß HG & P-79 & Zollinger U & $\mathrm{P}-90, \mathrm{~V} 043, \mathrm{~V}-057$ \\
\hline Tairi K & P-91 & Wegener S & V-047 & & V-058,V-098 \\
\hline
\end{tabular}

